LUCAS D. H. SAMPAIO

EFICIÊNCIA ENERGÉTICA E CAPACIDADE:

ESTRATÉGIAS DE ALOCAÇÃO DE RECURSOS EM REDES SEM FIO DE MÚLTIPLO ACESSO 


\section{EFICIÊNCIA ENERGÉTICA E CAPACIDADE: ESTRATÉGIAS DE ALOCAÇÃO DE RECURSOS EM REDES SEM FIO DE MÚLTIPLO ACESSO}

Tese apresentada à Escola Politécnica da Universidade de São Paulo para obtenção do Título de Doutor em Engenharia Elétrica.

Área de Concentração:

Sistemas Eletrônicos

Orientador:

Paul Jean Etienne Jeszensky

Coorientador:

Taufik Abrão

São Paulo

2015 
LUCAS D. H. SAMPAIO

\section{EFICIÊNCIA ENERGÉTICA E CAPACIDADE: ESTRATÉGIAS DE ALOCAÇÃO DE RECURSOS EM REDES SEM FIO DE MÚLTIPLO ACESSO}

Tese apresentada à Escola Politécnica da Universidade de São Paulo para obtenção do Título de Doutor em Engenharia Elétrica. 
Este exemplar foi revisado e corrigido em relação à versão original, sob responsabilidade única do autor e com a anuência de seu orientador.

São Paulo, de de

Assinatura do autor:

Assinatura do orientador:

Catalogação-na-publicação

Sampaio, Lucas Dias Hiera

Eficiência energética e capacidade: estratégias de alocação de recursos em redes sem fio de múltiplo acesso / L. D. H. Sampaio -- versão corr. -- São Paulo, 2015.

$312 \mathrm{p}$.

Tese (Doutorado) - Escola Politécnica da Universidade de São Paulo. Departamento de Engenharia de Telecomunicações e Controle.

1.Telecomunicações 2. Wireless 3.Alocação e recursos 4 .Energia (Eficiência) I.Universidade de São Paulo. Escola Politécnica. Departamento de Engenharia de Telecomunicações e Controle II.t. 
Aos meus pais,

Aquiles Aparecido Sampaio e

Veralice Dias Hiera Sampaio. 


\section{AGRADECIMENTOS}

Gostaria de registrar os meus mais sinceros agradecimentos ao meu orientador, Prof. Dr. Paul Jean Etienne Jeszensky, por todo o apoio, confiança, disposição, orientações e por toda a formação técnica que me foi concedida.

Ao meu coorientador, Prof. Dr. Taufik Abrão, pela dedicação, orientação, companheirismo e apoio desde o mestrado na Universidade Estadual de Londrina.

À todos os membros da banca e suplentes, pela leitura cuidadosa deste manuscrito e por todas as suas considerações, sugestões e contribuições

Aos meus pais, Aquiles Aparecido Sampaio e Veralice Dias Hiera Sampaio, por todo esforço e apoio incondicional que foram de suma importância para chegar até aqui.

À minha noiva, Mariana, por todo o carinho, incentivo, companheirismo e paciência nos últimos quatro anos. Seu apoio foi fundamental para concluir essa etapa.

Ao meu irmão Gabriel por dividir as noites em claro quando os dias já não eram mais suficientes para os estudos e por sempre estar disposto a me ajudar.

Aos meus familiares, e de forma especial à minha avó Lourdes que sempre me incentivou.

Aos meus primos Rodolpho, Rosângela e Rodolfo por me acolherem em São Paulo e por me concederem um teto sempre que necessário. Jamais conseguirei retribuir à altura o que fizeram por mim.

Aos amigos e colegas de estudos: Álvaro, Mário Henrique, Moisés, Bruno Zarpelão, Bruno Angélico, Mateus, Nathália, Jaime e José Carlos.

Aos amigos e colegas que encontrei ao longo da vida.

À Universidade de São Paulo e a Universidade Estadual de Londrina.

Ao CNPq pelo apoio financeiro.

E àqueles que, de alguma forma, contribuiram para a evolução deste trabalho. 
"A tarefa não é tanto ver aquilo que ninguém viu, mas pensar o que ninguém ainda pensou sobre aquilo que todo mundo vê." 


\section{RESUMO}

Neste trabalho são investigados problemas de alocação de espectro e potência em redes sem fio de múltiplo acesso e propostas sete soluções distintas para diferentes cenários e topologias que serão enumeradas a seguir. Primeiramente o problema de maximização da eficiência energética em redes cooperativas do tipo multiportadora com múltiplo acesso por divisão de código de sequência direta é abordado e as seguintes soluções são apresentadas: duas abordagens na perspectiva de teoria de jogos, uma utilizando algoritmo de water-filling (1) e outra utilizando o algoritmo distribuído de controle de potência baseado no equilíbrio de Verhulst (2), uma terceira solução também inspirado no último algoritmo citado e na média dos coeficientes de canal das subportadoras do sistema (3); uma abordagem heurística utilizando o algoritmo dos vaga-lumes (4) e outra utilizando a otimização por enxame de partículas (5). Em segundo lugar, foram investigados problemas de otimização em sistemas de múltiplo acesso por divisão ortogonal de frequência com provisão de qualidade de serviço estatística. Nesta segunda topologia dois problemas distintos foram analisados: o primeiro problema de maximização da capacidade efetiva do sistema foi solucionado utilizando o método de decomposição dual de Lagrange (6), o segundo problema cujo objetivo é a maximização da eficiência energética efetiva foi investigado e um solução baseada na combinação do método de Dinkelbach e da decomposição dual de Lagrange foi proposta (7). Simulações computacionais foram conduzidas tendo em vista averiguar o desempenho das abordagens propostas e, quando possível, tais resultados numéricos foram comparados àqueles obtidos a partir de algoritmos alternativos existentes na literatura.

Palavras-chave: Sistemas de Comunicação de Múltiplo Acesso; Alocação de Recursos; Otimização; Eficiência Energética; Capacidade. 


\section{ABSTRACT}

This work investigates the spectrum and power allocation problems in wireless multiple access networks and seven different solutions to different scenarios and topologies, which are enumerated as follows. Three distinct solutions are presented to the energy efficiency maximization problem in multicarrier direct sequence code division multiple access cooperative: two game theoretic approaches, one using the iterative water-filling algorithm (1) and another one using the distributed power control algorithm based on Verhulst equilibrium concept (2), and a third solution also based on the last algorithm but considering the average channel power gain (3); an heuristic approach using the firefly algorithm (4) and the particle swarm optimization algorithm (5). In orthogonal frequency division multiple access networks, optimization problems considering a statistical quality of service metric were analyzed: the first one is the effective capacity maximization which was solved through Lagrange dual decomposition method (6). The second one, in which the objective is to maximize the effective energy efficiency was addressed and solution based on the Dinkelbach method and further application of Lagrange dual decomposition was developed (7). Simulations were conducted to verify the proposed approaches performance and, whenever possible, the numerical results were compared to previous solution proposed in the literature.

Keywords: Multiple Access Communication Systems; Resource Allocation; Optimization; Energy Efficiency; Capacity. 


\title{
SUMÁRIO
}

\section{Lista de Figuras}

\author{
Lista de Tabelas
}

Lista de Lemas e Teoremas

Lista de Abreviaturas e Siglas

Notações

\section{Lista de Símbolos}

1 Introdução $\quad 45$

1.1 Escopo e Motivação . . . . . . . . . . . . . . . . . . . 45

1.2 Conceitos Básicos e Sistemas . . . . . . . . . . . . . . . . . . . . . 48

1.2.1 Modelos de Canal . . . . . . . . . . . . . . . . . . . 50

1.3 Justificativa . . . . . . . . . . . . . . . . . 55

1.4 Revisão Bibliográfica . . . . . . . . . . . . . . . 57

1.5 Contribuições e Produção Científica . . . . . . . . . . . . 63

1.5.1 Contribuições . . . . . . . . . . . . . . 63

1.5.2 Produção Científica . . . . . . . . . . . . . . . . . 64

1.6 Descrição do Conteúdo . . . . . . . . . . . . . . . . . 66 
2.1 Sistemas de Múltiplo Acesso com Espalhamento Espectral . . . . 68

2.1.1 Sistemas DS/CDMA . . . . . . . . . . . 71

2.1.1.1 Modelo de Consumo de Potência . . . . . . . . . 84

2.1.1.2 Definições - Sistema DS/CDMA . . . . . . . 86

2.1.2 Sistemas MC-DS/CDMA . . . . . . . . . . . . . 92

2.1.2.1 Definições - Sistema MC-DS/CDMA . . . . . . . 94

2.1.3 Sistemas MC-DS/CDMA Cooperativos . . . . . . . . 97

2.2 Sistemas OFDMA . . . . . . . . . . . . 106

2.2.1 Capacidade Efetiva . . . . . . . . . . . . 111

3 Métodos de Otimização Determinísticos e Heurísticos 125

3.1 Problemas de Otimização . . . . . . . . . . . . . . . 126

3.1.1 Taxonomia dos Problemas de Otimização . . . . . . . . . . 130

3.2 Fundamentos de Otimização Convexa . . . . . . . . . . . . . . . 134

3.2.1 Problemas de Otimização Convexa . . . . . . . . . . . 135

3.3 Fundamentos de Programação Fracional Não Linear . . . . . . . . 150

3.4 Fundamentos de Teoria de Jogos . . . . . . . . . . . . . 158

3.4.1 Definição e Breve Histórico . . . . . . . . . . . . . . . 159

3.4 .2 Conceitos e Classificação . . . . . . . . . . . . . . 161

3.4.3 Classificação e Tipos de Jogos . . . . . . . . . . . . . . 162

3.4.4 Descrição Matemática . . . . . . . . . . . 165 
3.5 Heurísticas . . . . . . . . . . . . . . . . . . 167

3.5.1 Conceitos Básicos . . . . . . . . . . . . . . . . . . 169

3.5.2 Algoritmo dos Vaga-lumes . . . . . . . . . . . . . 170

3.5.3 Otimização por Enxame de Partículas . . . . . . . . . . . 174

4 Técnicas de Otimização Aplicadas à Alocação de Recursos em $\begin{array}{ll}\text { Redes Sem Fio } & 180\end{array}$

4.1 Alocação de Recursos em Sistemas com Espalhamento Espectral . 181

4.1.1 Controle de Potência em Sistemas DS/CDMA . . . . . . . 182

4.1.2 Controle de Potência em Sistemas MC-DS/CDMA . . . . 189

4.1.3 Eficiência Energética em Sistemas MC-DS/CDMA Cooperativos .......................... 195

4.1.3.1 Abordagem de Teoria de Jogos para Maximização da Eficiência Energética em Sistemas MCDS/CDMA Cooperativos . . . . . . . . 202

4.1.3.2 Abordagem pelo Método de Dinkelbach . . . . . 216

4.1.3.3 Abordagem por Métodos Heurísticos . . . . . . 218

4.2 Alocação de Recursos em Sistemas com Múltiplo Acesso por Divisão de Frequências Ortogonais . . . . . . . . . . . . . . . . . . . . 219

4.2.1 Maximização da Capacidade Efetiva em Sistemas OFDMA 223

4.2.2 Maximização da Eficiência Energética Efetiva em Sistemas

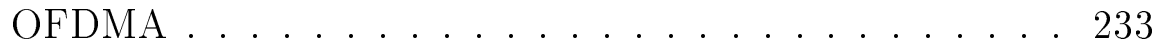

5 Resultados Numéricos de Simulação para os Problemas de Oti- 
5.1 Análise Numérica para o Problema de Maximização da Eficiência Energética em Sistemas MC-DS/CDMA Cooperativos . . . . . . . 242

5.1.1 Abordagens Distribuídas . . . . . . . . . . . . . . 244

5.1 .2 Síntese dos Resultados . . . . . . . . . . . . . . . . . 254

5.2 Resultados e Discussões para o Problema de Maximização da Capacidade Efetiva em Sistemas OFDMA . . . . . . . . . 255

5.3 Resultados e Discussões para o Problema de Maximização da Eficiência Energética Efetiva em Sistemas OFDMA . . . . . . . . . 269

6 Conclusões e Trabalhos Futuros $\quad 280$

$\begin{array}{ll}\text { Referências } & 285\end{array}$

Apêndice A - Fundamentos de Análise Convexa 298

A.1 Conjuntos Convexos . . . . . . . . . . . . . . . . . 298

A.2 Funções Convexas . . . . . . . . . . . . . . . . . . . 303

A.3 Funções Quase Convexas . . . . . . . . . . . . . . . . . . 312 


\section{LISTA DE FIGURAS}

1 Disposição dos diversos usuário da rede em sistemas com múltiplo acesso por divisão por tempo, frequência e código em sequência direta. ......................... 49

2 Ilustração da variação do ganho de canal em função da distância considerando os efeitos de perda de percurso, sombreamento e desvanecimento. Fonte: adaptado de (GOLDSMITH, 2005) . . . . 52

3 Ilustração em termos de densidade espectral de potência de um sinal do tipo DS/CDMA antes e após o espalhamento espectral. . 70

4 Desenho esquemático do espalhamento espectral por sequência direta. Fonte: adaptado de (GOLDSMITH, 2005) . . . . . . . . . 74

$5 \quad$ Elo de subida e elo de descida em sistemas de comunicação sem fio. 76

6 Desenho esquemático para o sistema de múltiplo acesso por divisão em código de sequência direta. . . . . . . . . . . . . . . 78

7 Diagrama de blocos do transmissor MC-DS/CDMA para o usuário

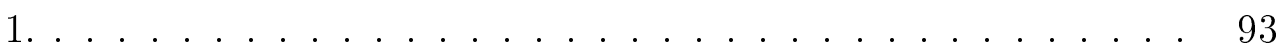

8 Ilustração da comunicação entre fonte e destino denominada caminho direto (em preto) e da comunicação através de um repetidor em sistemas cooperativos, denominado caminho indireto (em vermelho)

9 Exemplo de enlance de subida de um sistema cooperativo com 3 usuários e múltiplas subportadoras (representadas pelo indexador

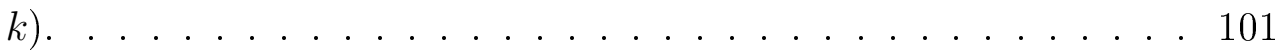


10 Disposição das subportadoras em sistemas com multiplexação por divisão de frequência sem sobreposição (acima) e com sobreposição (abaixo). Fonte: adaptado de (GOLDSMITH, 2005). . . . . . . 107

11 Diagrama de blocos do transmissor e receptor OFDM desconsiderando os efeitos nocivos do canal. . . . . . . . . . . . . . . 109

12 Diagrama de um transmissor com controle de enlance e fila estacionária para armazenamento temporário de informação não enviada.

13 Classificação dos problemas de otimização de um ponto de vista simples considerando tipo de domínio, restrições e número de objetivos.

14 Classificação dos problemas de otimização acerca do tipo de domínio.

15 Classificação dos problemas de otimização acerca do tipo de domínio, restrições e linearidade. . . . . . . . . . . . . . . . . 132

16 Classificação dos problemas de otimização acerca do tipo de domínio, restrições, linearidade e convexidade.

17 Exemplo de dualidade fraca. A reta representa os possíveis valores da função objetivo (tanto primal $f$ quanto dual $\ell$ ). O gap entre os pontos ilustra a definição de dualidade fraca.

18 Exemplo de dualidade forte. A reta representa os possíveis valores da função objetivo (tanto primal $f$ quanto dual $\ell$ ). O gap entre os pontos ótimos do problema primal e dual é nulo, o que ilustra a definição de dualidade forte. 
19 Interpretaçao geométrica da função $F$ para o método de Dinkel-

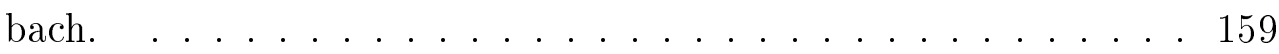

20 Representação geométrica em duas dimensões do movimento dos vaga-lumes descrito pela equação (3.80). Neste caso $j$ produz luz mais intensa que $i$ e, portanto, $i$ move-se em direção a $j . . .174$

21 Representação geométrica bidimensional para a atualização da posição de uma partícula (a) e para o cálculo da velocidade (b) no algoritmo de otimização por enxame de partículas. Fonte: do autor 178

22 Diagrama de blocos para a operação de um algoritmo de controle de potência distribuído. . . . . . . . . . . . . . . . . 189

23 Interpretação geométrica para a solução de water-filling considerando $N=8$ subportadoras e $U=1$ usuário no sistema. . . . . . 191

24 Interpretação gráfica para o usuário 1 do algoritmo iterativo de water-filling considerando $N=8$ subportadoras. . . . . . . . . 196

25 Interpretação gráfica para o usuário 1 da função $g(\mu)$ utilizada no algoritmo iterativo de water-filling considerando $N=8$ subporta-

26 Disposição geográfica dos terminais móveis (usuários), estação retransmissora (retransmissor) e estação rádio-base no sistema MCDS/CDMA cooperativo considerado nesta seção. . . . . . . . . . . 197

27 Numerador e sua segunda derivada em função da SINR para os parâmetros: $M=1024$ e $V=20$. . . . . . . . . . . . . 207

28 Região do espaço $\left\{A_{i} \times N_{0} \times p_{i, k}\right\}$ onde o menor principal (4.96) da matriz Hessiana da função C é não positivo. . . . . . . . . . . . 229 
29 Eficiência energética (a) e eficiência espectral (b) em função do número de bits por pacote para cada um dos três algoritmos distribuídos, com $U=5$ usuários no sistema. . . . . . . . . . . 247

30 Eficiência energética (a) e eficiência espectral (b) em função do número de bits por pacote para cada um dos três algoritmos distribuídos, com $U=20$ usuários no sistema. . . . . . . . . . . 248

31 Eficiência energética para diferentes valores de tamanho de população e número máximo de iterações. Média em 100 amostras de matriz de ganhos de canal distintas.

32 Relação entre os valores do expoente de qualidade de serviço estatística $\theta$, o atraso máximo tolerável em bits, $d_{\max }$, e a probabilidade de violação do atraso máximo para um atraso arbitrário $D$, $P_{\mathrm{R}}\left(D \geq d_{\max }\right) . \ldots \ldots \ldots \ldots \ldots \ldots \ldots$

33 Capacidade efetiva em função do expoente de qualidade de serviço estatística para um cenário arbitrário.

34 Capacidade efetiva em função da potência de transmissão do usuário 2, cenário 3 (valores de parâmetros definidos na tabela 13).

35 Evolução do algoritmo de maximização da capacidade efetiva baseado na decomposição dual de Lagrange: (a) em termos de potência total de transmissão por usuário; (b) em termos de capacidade efetiva total do sistema. Cenário 3 com $C_{\min }=67$. . . . . . . . 262

36 Evolução do algoritmo de maximização da capacidade efetiva baseado na decomposição dual de Lagrange: (a) em termos de potência total de transmissão por usuário; (b) em termos de capacidade efetiva total do sistema. Cenário 3 com $C_{\min }=70$. . . . . . . . 263 
37 Evolução do algoritmo de maximização da capacidade efetiva baseado na decomposição dual de Lagrange: (a) em termos de potência total de transmissão por usuário; (b) em termos de capacidade efetiva total do sistema. Cenário 3 com $C_{\min }=72$. . . . . . . . . 264

38 Capacidade efetiva em função da potência total de transmissão do usuário 2 para diferentes políticas de alocação de subportadoras descritas em (5.2).

39 (a) Ganho de potência para a subportadora do usuário 2 no cenário 3. (b) e (c) Taxa instantânea para a potência ótima do usuário 2 que maximiza a capacidade efetiva do sistema. Em (c) existe a ocorrência de uma violação de QoS. Note que as figuras (b) e (c) estão relacionadas à realizações de canal diferentes. . . . . . . . . 266

40 Evolução do algoritmo de maximização da capacidade efetiva baseado na decomposição dual de Lagrange: (a) em termos de potência total de transmissão por usuário; (b) em termos de capacidade efetiva total do sistema. Cenário 4 com $C_{\min }=1 . \quad \ldots \ldots$. . . . 268

41 Curvas de nível e superfície tridimensional para a eficiência energética efetiva. A linha tracejada apresenta a combinação de valores de potência de transmissão para o usuário 1 e 2 onde a capacidade efetiva é máxima.

42 (a) Eficiência energética efetiva e (b) potência total de transmissão em cada iteração do algoritmo 4.5 para o cenário 5 (tabela 16). 272

43 (a) Eficiência energética efetiva e (b) potência total de transmissão em cada iteração do algoritmo 4.5 para o cenário 6 (tabela 17). 273 
44 Potência de transmissão ótima em função dos valores de expoente de qualidade de serviço estatística $\theta$; para o usuário número 2, nos cenário 5 e 7, considerando que o mesmo transmite em apenas uma subportadora.

45 Potência de transmissão ótima em função da ineficiência do amplificador $\varrho$ para o usuário número 2 , nos cenários 5 e 7 , considerando que o mesmo transmite em apenas uma subportadora.

46 Potência de transmissão ótima em função da potência consumida pelos circuitos do transmissor $P_{\mathrm{C}}$ para o usuário número 2, nos cenários 5 e 7 , considerando que o mesmo transmite em apenas uma subportadora.

47 Exemplo de Conjunto convexo e não convexo: o conjunto (a) é convexo pois quaisquer que sejam os pontos $\mathbf{x}$ e $\mathbf{y}$, todo o segmento de reta entre eles pertence ao conjunto. O conjunto (b) não é convexo, conforme demonstra o ponto c que não pertence ao conjunto. Fonte: adaptado de (BOYD; VANDENBERGHE, 2004). . . . . . 299

48 Interpretação da função perspectiva utilizando o conceito de câmera escura. A linha em $z_{3}=0$ é opaca com exceção do orifício na origem. Os raios de luz emitidos ou refletidos por objetos fora da câmera, representados pelas flexas, atingem o plano $z_{3}=-1$ formando uma imagem bidimensional. O mapeamento da posição do objeto para sua posição na imagem está relacionada a função perspectiva. Fonte: adaptado de (BOYD; VANDENBERGHE, 2004). 
49 Exemplos de envoltórias convexas no $\mathbb{R}^{2}$ : em a) a envoltória convexa do conjunto composto pelos pontos em preto é o pentágono sombreado. Já em b) o conjunto delimitado pela linha contínua que lembra o formato de um rim tem sua envoltória convexa delimitada pela área sombreada. Fonte: (BOYD; VANDENBERGHE, 2004, Figura 2.3 na Página 24) . . . . . . . . . . . . . . . . . . 302

50 A função $f$ definida como $f: \mathbb{R} \rightarrow \mathbb{R}, f(x)=x^{2}$ é um exemplo de função convexa. Os pontos $(-0,4,0 ; 016)$ e $(0,6 ; 0,36)$ são destacados e o segmento de reta entre tais pontos (descrito pela equação $\lambda f(x)+(1-\lambda) f(y) \operatorname{com} \lambda \in[0,1])$ está acima da curva da função $f$ entre $x$ e $y$, indicada na figura pela equação $f(\lambda x+(1-\lambda) y)$ $\operatorname{com} \lambda \in[0,1] . \ldots \ldots \ldots 303$

51 A área sombreada é um exemplo de epigrafo da função $f$ : $[-1,1] \rightarrow[0,1], f(x)=x^{2} . \ldots \ldots 304$

52 Interpretação geométrica da diferença entre funções convexas (a) e (d) e côncavas $($ b) e $($ c) . . . . . . . . . . . . . . . . 305

53 Interpretação geométrica da desigualdade de Jensen para funções quase convexas.

54 Exemplo de função quase convexa que não é convexa (a) e função quase convexa que é convexa (b). . . . . . . . . . . . . . 315 


\section{LISTA DE TABELAS}

1 Valor do Ponto de Inflexão $\delta_{\text {in }}$ para Diferentes Parâmetros. . . . . 209

2 Parâmetros Para o Cenário 1. . . . . . . . . . . . . . . 244

3 Quantidade de Usuários Por Classe para o Cenário 1 . . . . . 246

4 Desempenho em Eficiência Energética entre os Três Algoritmos. . 249

5 Desempenho em Eficiência Espectral entre os Três Algoritmos. . . 249

6 Desempenho dos Algoritmos termos de Potência de Transmissão Média. ........................ 250

$7 \quad$ Parâmetros Para o Cenário 2 . . . . . . . . . . . . . . 252

8 Desempenho em Eficiência Energética Média para Diferentes pa-

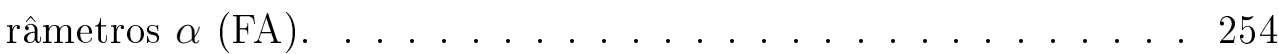

9 Desempenho em Eficiência Energética Média para Diferentes pa-

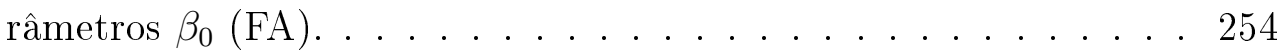

10 Desempenho em Eficiência Energética Média para Diferentes parâmetros $\alpha(\mathrm{FA}) . \ldots \ldots \ldots \ldots$

11 Desempenho em Eficiência Energética Média para Diferentes parâmetros $c_{1}$ e $c_{2}(\mathrm{PSO}) \ldots \ldots \ldots \ldots \ldots . \ldots \ldots 255$

12 Desempenho em Porcentagem da Eficiência Energética Ótima (Valores Aproximados). . . . . . . . . . . . . . . . . . . 255

13 Parâmetros de Simulação para o Cenário 3 . . . . . . . . . . 258 
14 Solução Ótima do Problema de Maximização da Capacidade Efetiva $(\mathrm{CE})$ Para o Cenário $3 \ldots$. . . . . . . . . . . . . 260

15 Parâmetros de Simulação do Cenário 4 . . . . . . . . . . 267

16 Parâmetros de Simulação para o Cenário 5 . . . . . . . . . . 269

17 Parâmetros de Simulação para o Cenário 6 . . . . . . . . . . . . . 274

18 Número de Iterações Necessárias à Convergência para o Algoritmo AIMEEE . . . . . . . . . . . . . . . . . 274

19 Parâmetros de Simulação para o Cenário 7 . . . . . . . . . . 275 


\section{LISTA DE LEMAS E TEOREMAS}

1 Teorema (Ótimo Global) . . . . . . . . . . . . . . 137

2 Teorema (Critério de Otimalidade) f. . . . . . . . . . 138

3 Teorema (Condição de Qualificação das Restrições) . . . . . . . . 145

4 Teorema (Condições Necessárias de Primeira Ordem - Condições de KKT) . . . . . . . . . . . . . . . . . . . . 148

5 Teorema (Convergência do Método de Dinkelbach) . . . . . . . 157

6 Teorema (Existência e Unicidade do Problema de Controle de Po-

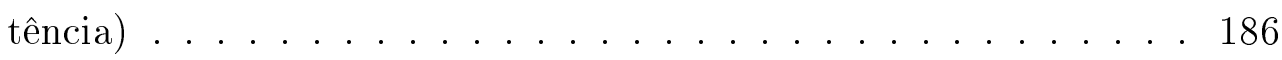

7 Lema (Numerador da Função Utilidade é uma Curva Sigmóide) 207

8 Lema (Quase Concavidade da Função Utilidade) . . . . . . . . . . 211

9 Teorema (Existência de um Equilíbrio de Nash) . . . . . . . . . . 212

10 Lema (Concavidade da Capacidade Efetiva) . . . . . . . . . . . 227

11 Lema (Quase Concavidade da Eficiência Energética Efetiva) . . . 235

12 Teorema (Desigualdade de Jensen) . . . . . . . . . . . . . . 305

13 Teorema (Condição de Primeira Ordem) . . . . . . . . . . . 306

14 Teorema (Condição de Segunda Ordem) . . . . . . . . . . . . . . 308

15 Teorema (Otimalidade Global) . . . . . . . . . . . . . . . . 312 


\section{LISTA DE ABREVIATURAS E SIGLAS}

$3 \mathrm{GPP}$

$3 \mathrm{GPP} 2$

$\mathrm{ABR}$

$\mathrm{ACO}$

ADSL

ADSL2+

$\mathrm{AF}$

AFI

AIMCE

AIMEE

AIMEEE

AWGN

BER

CAD

CDA
Third Generation Partnership Project - Projeto de parceria para terceira geração de comunicações móveis Third Generation Partnership Project 2 - Segundo projeto de parceria para terceira geração de comunicações móveis

Amplificador de baixo ruído

Ant Colony Optimization - Otimização por Colônia de Formigas Asymmetric Digital Subscriber Line - Padrão de comunicação Asymmetric Digital Subscriber Line 2+ - Evolução do padrão de comunicação ADSL

Amplify and Forward - Amplifica e Encaminha

Amplificador de frequência intermediária

Algoritmo Iterativo para Maximização da Capacidade Efetiva

Algoritmo Iterativo para Maximização da Eficiência Energética Algoritmo Iterativo para Maximização da Eficiência Energética Efetiva

Additive White Gaussian Noise - Ruído Aditivo Gaussiano Branco

Bit Error Rate - Taxa de Erro de Bit

Conversor analógico-digital

Conversor digital-analógico 
CDMA Code Division Multiple Access - Múltiplo Acesso por Divisão de Código

CE

Capacidade Efetiva

CEET

Centre for Energy-Efficient Telecommunications

$\mathrm{CF}$

Compress and Forward - Comprime e Encaminha

CTO

Chief Technology Officer - Diretor Chefe de Tecnologia

CSS

Chirp Spread Spectrum - Espalhamento espectral por chirps

DF

Decode and Forward - Decodifica e Encaminha

DinkOpt Solução centralizada baseada no algoritmo de Dinkelbach utilizando programação convexa disciplinada

DPCA Distributed Power Control Algorithm - Algoritmo Distribuído de Controle de Potência

DS/CDMA Direct Sequence Code Division Multiple Access - Múltiplo Acesso por Divisão de Códio de Sequência Direta

EE

Eficiência Energética

EE-IWFA Solução distribuída baseada em teoria de jogos com o controle de potência realizado pelo algoritmo iterativo de water-filling;

EE-MDPCA Solução distribuída baseada em teoria de jogos com o controle de potência realizado pelo algoritmo distribuído de controle de potência utilizando o equilíbrio de Verhulst considerando apenas o ganho de canal médio.

EE-VDPCA Solução distribuída baseada em teoria de jogos com o controle de potência realizado pelo algoritmo distribuído de controle de potência utilizando o equilíbrio de Verhulst; 
EEE

EEE-DINK Método de Dinkelbach para maximização da eficiência energética efetiva no enlace direto de sistemas OFDMA

EE-MCDINK Método de Dinkelbach para maximização da eficiência energética no enlace reverso de Sistemas MC-DS/CDMA

ERB

FDMA

FA

FFT

FiR

FiT

FH/CDMA Frequency Hopping Code Division Multiple Access - Múltiplo

GSM

IEEE

i.i.d.

IFFT

IWFA Acesso por Divisão de Código com Saltos de Frequência

Global System for Mobile Communications - Sistema Global para Comunicação Móvel

Estação Rádio Base

Frequency Division Multiple Access - Múltiplo Acesso por Divisão de Frequências Ortogonais

Firefly Algorithm - Algoritmo dos Vaga-lumes

Fast Fourier Transform - Transformada Rápida de Fourier

Filtro de Recepção

Filtro de Transmissão

Institute of Electrical and Electronic Engineers - Instituto dos Engenheiros Eletricistas e Eletrônicos

Independente e identicamente distribuídas

Inverse Fast Fourier Transform - Transformada Rápida Inversa de Fourier

Iterative Water-Filling Algorithm - Algoritmo Iterativo de Water-Filling 
LTE

LTE-A

MC-CDMA

MC-DS/CDMA Multicarrier DS/CDMA - DS/CDMA Multiportadora

Método de Dinkelbach

MIX

MMSE

NMSE

Np-Hard

OFDM

Orthogonal Frequency Division Multiplexing - Multiplexação por

Divisão de Frequências Ortogonais

OFDMA Orthogonal Frequency Division Multiple Access - Múltiplo Acesso por Divisão de Frequências Ortogonais

PAPR Peak to Average Power Ratio - Razão da Potência de Pico pela Potência Média

PSO

Particle Swarm Optimization - Otimização por Enxame de Partículas

QoS

Quality of Service - Qualidade de Serviço

SINR

Signal to Interference plus Noise Ratio - Relação sinalinterferência mais ruído 
SYN

TDMA

TH/CDMA

UMTS

URSS

WiMAX
Synthesizer - Sintetizador

Time Division Multiple Access - Múltiplo Acesso por Divisão de Tempo

Time Hopping Code Division Multiple Access - Múltiplo Acesso por Divisão de Código por Saltos de Tempo

Terminal móvel

Universal Mobile Telecommunications Systems

União das Repúblicas Socialistas Soviéticas

Worldwide Interoperability for Microwave Access - padrão de quarta geração de comunicações móveis 


\section{NOTAÇÕES}

$a, \alpha, A \quad$ Letra em itálico representa um escalar

a Letra minúscula em negrito representa um vetor

A Letra maiúscula em negrito representa uma matriz

$\{\cdot\}^{T} \quad$ Operador matriz transposta

$\{\cdot\}^{H} \quad$ Operador hermitiano transposto

$\{\cdot\}^{-1} \quad$ Operador matriz inversa

$\operatorname{tr}(\cdot) \quad$ Operador traço da matriz

$|\cdot| \quad$ Operador valor absoluto (módulo)

$\|\cdot\| \quad$ Operador norma Euclidiana

$\|\cdot\|_{p} \quad$ Operador norma $p$

$\mathbb{E}(\cdot) \quad$ Operador esperança estatística

$\operatorname{Pr}(\cdot) \quad$ Operador probabilidade

* $\quad$ Operador de convolução

$\mathbf{v} \geq 0 \quad$ Indica que todos os elementos do vetor $\mathbf{v}$ são não negativos

$\mathbf{v} \leq 0 \quad$ Indica que todos os elementos do vetor $\mathbf{v}$ são não positivos

$\mathbf{A} \preceq 0 \quad$ Indica que a matriz A é semidefinida negativa

$\mathbf{A} \succeq 0 \quad$ Indica que a matriz $\mathbf{A}$ é semidefinida positiva

$C_{1} \subset C_{2} \quad$ Indica que $C_{1}$ é um subconjunto de $C_{2}$

$C_{1} \subseteq C_{2} \quad$ Indica que $C_{1}$ é um subconjunto de $C_{2}$ ou o próprio $C_{2}$ 


$\begin{array}{ll}\max [\cdot] & \text { Valor máximo assumido pelo argumento } \\ \min [\cdot] & \text { Valor mínimo assumido pelo argumento } \\ \mathcal{U}(x, y) & \text { Processo aleatório de distribuição uniforme entre as variáveis } x \text { e } y \\ \log & \text { Quando a base for omitida log }=\ln \\ \inf \{\cdot\} & \text { Infimo do argumento } \\ \sup \{\cdot\} & \text { Supremo do argumento } \\ \forall & \text { Qualquer que seja } \\ \in & \text { Pertence } \\ \triangleq & \text { Por definição }\end{array}$




\section{LISTA DE SÍMBOLOS}

A Cap. 2 - Amplitude do sinal

$A_{i} \quad$ Parâmetro utilizado no computo da capacidade efetiva relacionado ao expoente de qualidade de serviço estatística do $i$-ésimo usuário

$A_{g} \quad$ Ganho combinado das antenas de recepção e transmissão

A Cap. 2 - Matriz de amplificação do sinal no retransmissor

$\alpha \quad$ Cap. 2 - Parâmetro da função densidade de probabilidade de uma variável aleatória que assume distribuição exponencial

Cap. 3 - Tamanho do passo aleatório no algoritmo dos vaga-lumes

$\alpha_{i} \quad$ Ganho de amplitude introduzido pelo canal do $i$-ésimo usuário

$\alpha_{l} \quad$ Cap. 2 - Componente de amplitude da resposta impulsiva do canal no l-ésimo percurso

$\alpha_{L} \quad$ Perda de percurso no modelo completo

$\alpha_{\mathrm{s}} \quad$ Perda de percurso no modelo simplificado

$\alpha_{v} \quad$ Coeficiente de aceleração do algoritmo distribuído de controle de potência baseado no equilíbrio de Verhulst

$b_{i} \quad$ Cap. 2 - Símbolo modulado do $i$-ésimo usuário (CDMA) ou da $i$ ésima subportadora (OFDMA)

Cap. 3 - Limite da $i$-ésima restrição de desigualdade

$b_{j} \quad j$-ésimo símbolo modulado transmitido 
$\tilde{r}_{i} \quad$ Sinal do $i$-ésimo usuário na entrada do detector após o banco de filtros casados

$b_{i, j, l} \quad$ Símbolo do $j$-ésimo usuário no $l$-ésimo período de símbolo relacionado com o atraso do sinal do usuário $i$

bi,l Símbolo do $i$-ésimo usuário no $l$-ésimo período de símbolo

b Vetor de símbolos transmitidos pelos usuários do sistema

$\tilde{\mathbf{r}} \quad$ Sinal espalhado e modulado recebido pela estação rádio-base em banda base

b Sinal estimado na estação rádio-base

$B \quad$ Largura de banda do canal

$B_{e}(\theta) \quad$ Largura de banda efetiva relacionada ao expoente de qualidade de serviço $\theta$

$\mathrm{BER}_{M-\mathrm{QAM}}^{\mathrm{AWGN}}$ Taxa de erro de bit média em canais AWGN com modulação M-QAM de constelação quadrada

$\mathrm{BER}_{M-\mathrm{QAM}}^{\text {Rayleigh }}$ Taxa de erro de bit média em canais com desvanecimento do tipo Rayleigh e modulação M-QAM de constelação quadradas

$\overline{\mathrm{BER}}_{M \text {-QAM }}^{\text {RAYLigh }}$ Aproximação da taxa de erro de bit média em canais com desvanecimento do tipo Rayleigh e modulação M-QAM de constelação quadrada

$\beta \quad$ Cap. 1 - Valor da atenuação do sombreamento

$\beta_{0} \quad$ Atratividade entre os vaga-lumes quando a distãncia é nula

$\beta_{i j} \quad$ Atratividade entre o vaga-lume $i$ e o $j$

$\beta_{i, k} \quad$ Interferência mais ruído normalizados para o usuário $i$ na subportadora $k$ 
$\beta^{d B} \quad$ Valor da atenuação do sombreamento em dB

$c_{1} \quad$ Parâmetro do algoritmo de otimização por enxame de partículas que pondera soluções locais

$c_{2} \quad$ Parâmetro do algoritmo de otimização por enxame de partículas que pondera soluções globais

$c_{i}(j) \quad$ Cap. 2 - $j$-ésimo chip da sequência de espalhamento do usuário $i$

$\mathcal{C}_{\mathrm{e}}(\theta) \quad$ Capacidade efetiva relacionada ao expoente de qualidade de serviço estatística $\theta$

$\mathcal{C}_{\mathrm{e}}^{\text {on-off }} \quad$ Capacidade efetiva de um canal on-off relacionada ao expoente de qualidade de serviço estatística $\theta$ e a relação sinal-ruído $\delta$

$\mathcal{C}_{\mathrm{e}, \mathrm{RFC}} \quad$ Capacidade efetiva do sistema OFDMA em canais com desvanecimento Rayleigh

$\mathcal{C}_{\mathrm{e}, \mathrm{RFC}}^{i} \quad$ Capacidade efetiva do $i$-ésimo usuário do sistema OFDMA em canais com desvanecimento Rayleigh

C Matriz de sequências de espalhamento ponderadas pelos ganhos de amplitude do canal dos usuários

d Cap. 1 - Distância entre transmissor e receptor

Cap. 2 - Símbolo transmitido

Cap. 3 - Distância entre os vaga-lumes

$d_{0} \quad$ Distância de referência

$d_{j} \quad j$-ésimo bit na saída do demodulador em um banco de filtros casados

$d_{\max } \quad$ Atraso máximo tolerável no controle de enlace 
$D \quad$ Atraso estável observado no controlador de enlace

$\mathbf{d}_{i} \quad$ Filtro linear do $i$-ésimo usuário

D $_{\text {DESC }} \quad$ Matriz de filtros lineares utilizando o detector descorrelacionador

$\delta(\cdot) \quad$ Função delta de Dirac

$\delta \quad$ Relação sinal-interferência mais ruído

$\delta_{i} \quad$ Relação sinal-interferência mais ruído do $i$-ésimo usuário

$\bar{\delta}_{i} \quad$ Relação sinal-interferência mais ruído média do $i$-ésimo usuário

$\delta_{\text {in }} \quad$ Ponto de inflexão

$\delta_{i}[t] \quad$ Relação sinal-interferência mais ruído do $i$-ésimo usuário na iteração $t$

$\delta_{i}^{*} \quad$ Relação sinal-interferência mais ruído mínima para o $i$-ésimo usuário

$\delta_{i, k} \quad$ Relação sinal-interferência mais ruído do $i$-ésimo usuário no subcanal $k$

$\delta_{i}^{\text {PRE }} \quad$ Relação sinal-interferência mais ruído do $i$-ésimo usuário antes do processo de detecção

$\delta_{i, k}^{\mathrm{PRE}} \quad$ Relação sinal-interferência mais ruído do $i$-ésimo usuário na $k$-ésima subportadora antes do processo de detecção

$\delta_{i}^{\text {pos }} \quad$ Relação sinal-interferência mais ruído do $i$-ésimo usuário após o processo de detecção

$\delta_{i, k}^{\text {Pos }} \quad$ Relação sinal-interferência mais ruído do $i$-ésimo usuário na $k$-ésima subportadora após o processo de detecção

$\delta_{i, k}^{M C C} \quad$ Relação sinal-interferência mais ruído do $i$-ésimo usuário na $k$-ésima subportadora após o processo de detecção na estação rádio-base em sistemas MC-DS/CDMA cooperativo 
$\delta_{i, k}^{O F D M A}$ Relação sinal-ruído do $i$-ésimo usuário na $k$-ésima subportadora em sistemas OFDMA

$\Delta \varphi_{i, j} \quad$ Diferença do deslocamento de fase introduzido pelo canal entre o usuário $i$ e o usuário $j$

$\mathrm{e}_{i} \quad$ Estratégia do $i$-ésimo jogador

$\mathrm{e}_{i}^{*} \quad$ Estratégia de melhor resposta do $i$-ésimo jogador

e

Perfil de estratégias dos jogadores

$\mathbf{e}_{-i} \quad$ Perfil de estratégias dos jogadores com exceção do jogador $i$

$e^{*} \quad$ Equilíbrio de Nash

$\mathcal{E} \quad$ Conjunto de estratégias disponíveis para todos os jogadores

$\mathcal{E}_{i} \quad$ Conjunto de estratégias do $i$-ésimo jogador

$\mathcal{E}_{i}^{k} \quad$ Conjunto de estratégias do $i$-ésimo jogador na $k$-ésima subportadora

$\mathfrak{E}_{i, k} \quad$ Argumento da capacidade efetiva relacionada à canais sem linha de visada cujos ganhos de amplitude assumem uma distribuição estatística de Rayleigh

$\boldsymbol{\eta} \quad$ Vetor de ruído térmico

$\boldsymbol{\eta}_{k} \quad$ Vetor de ruído térmico na $k$-ésima subportadora

$\boldsymbol{\eta}_{1, k} \quad$ Vetor de ruído térmico na $k$-ésima subportadora no percurso fonteretransmissor

$\boldsymbol{\eta}_{2, k} \quad$ Vetor de ruído térmico na $k$-ésima subportadora no percurso retransmissor-destino

$\boldsymbol{\eta}(t) \quad$ Vetor de ruído térmico no tempo contínuo 
$\eta(t) \quad$ Parcela devida ao ruído térmico de tempo contínuo
$\eta_{j} \quad$ Parcela de ruído térmico relacionada ao $j$-ésimo bit transmitido
$\eta_{l} \quad$ Parcela de ruído térmico relacionada ao $l$-ésimo período de símbolo

$f_{c} \quad$ Frequência da portadora

$f_{k} \quad$ Frequência da $k$-ésima subportadora

$f\left(\delta_{i}\right) \quad$ Função de penalização (Taxa média de acerto de bit)

$f(\mathbf{x}) \quad$ Função objetivo

f(·) Função de densidade de probabilidade

F Cap. 2 - Comprimento da sequência

$F(q) \quad$ Função relacionada ao parâmetro $q$ método de Dinkelbach

$F_{i} \quad$ Comprimento da sequência de espalhamento do usuário $i$

$F_{i, k} \quad$ Comprimento da sequência de espalhamento do usuário $i$ na $k$-ésima subportadora

F Matriz diagonal com o comprimento das sequências de espalhamento dos $U$ usuários

$\phi_{i, k} \quad$ Variável binária responsável por indicar se o usuário $i$ transmite na subportadora $k$

$\phi \quad$ Matriz de alocação de subportadora

$\varphi_{i} \quad$ Deslocamento de fase para o usuário $i$

$\varphi_{i}^{\prime} \quad$ Deslocamento de fase introduzido pelo canal no sinal do usuário $i$ 
$\mathrm{g}_{k} \quad$ Ganho complexo de canal entre retransmissor e estação rádio-base na $k$-ésima subportadora

g Ganho de potência médio entre retransmissor e estação rádio-base

$g(\mathbf{x}) \quad$ Função de restrição de desigualdade

$\mathcal{G} \quad$ Gap de dualidade

$\mathfrak{G}\left(\delta_{i, k}\right) \quad$ Potência total consumida pelo sistema em função da relação sinalinterferência mais ruído

$\gamma \quad$ Coeficiente de absorção de luz

$\gamma_{p} \quad$ Expoente da perda de percurso

$\Gamma \quad$ Jogo arbitrário

$\mathrm{h}(t) \quad$ Resposta impulsiva do canal no tempo contínuo

$\mathrm{h}_{i} \quad$ Ganho complexo do canal do $i$-ésimo usuário

$\mathrm{h}_{i, k} \quad$ Ganho complexo do $k$-ésimo canal do $i$-ésimo usuário

$\overline{\mathrm{h}}_{i} \quad$ Ganho de potência médio de canal para o usuário $i$

$\underline{\mathrm{h}}_{i, k} \quad$ Ganho de potência do $k$-ésimo subcanal do usuário $i$

$\mathrm{h}_{i}(t) \quad$ Resposta impulsiva do canal do $i$-ésimo usuário no tempo contínuo

$\mathrm{h}_{i}^{L P}(t) \quad$ Resposta impulsiva do canal do $i$-ésimo usuário no tempo contínuo na saída de um filtro passa-baixa

$h(\mathbf{x}) \quad$ Função de restrição de igualdade

$\overline{\mathbf{h}} \quad$ Vetor de ganhos de potência médios

H Matriz de ganhos complexos de canal

$\theta \quad$ Expoente de qualidade de serviço estatística 
$\theta_{i} \quad$ Expoente de qualidade de serviço estatística para o $i$-ésimo usuário

$\theta_{D} \quad$ Expoente de qualidade de serviço estatística relacionada ao atraso

$\boldsymbol{\theta} \quad$ Vetor de expoentes de qualidade de serviço estatística

$\vartheta \quad$ Taxa de crescimento linear do consumo de potência extra de transmissão para a estação rádio-base

$\vartheta_{i} \quad$ Taxa de crescimento linear do consumo de potência extra de transmissão para o $i$-ésimo usuário

I Número máximo de iterações

$\mathcal{I}_{i} \quad$ Intensidade de luz produzida pelo $i$-ésimo vaga-lume

$\mathfrak{I}_{i, l} \quad$ Interferência de múltiplo acesso sobre o usuário $i$ no $l$-ésimo período de símbolo

$\mathcal{J} \quad$ Conjunto de jogadores

$k \quad$ Número de restrições de igualdade

$K \quad$ Cap. 1 - Constante adimensional relacionada a perda de percurso

$\mathcal{K} \quad$ Total de símbolos transmitidos

$J^{M L}(\cdot) \quad$ Função custo do detector de máxima verossimilhança

l Cap 2. - Indexador de percurso

$\mathcal{L}(\cdot) \quad$ Lagrangiano

$\ell(\cdot) \quad$ Função dual de Lagrange 
$\ell_{i, k} \quad$ Taxa de codificação do usuário $i$ na subportadora $k$

$\bar{\ell}_{i} \quad$ Taxa média de codificação do usuário $i$

$\lambda \quad$ Cap. 1 - Comprimendo de onda

Cap. 3 - Valor real no intervalo $[0,1]$

$\lambda_{i} \quad i$-ésimo multiplicador de Lagrange

$\boldsymbol{\lambda} \quad$ Vetor de multiplicadores de Lagrange

$\Lambda(\cdot) \quad$ Função geradora do momento logarítmico assintótico

$m \quad$ Número de restrições de desigualdade

$M \quad$ Cap. 2 - Ordem de modulação QAM

Cap. 3 - Tamanho da população de um método heurístico

$\mathcal{M}(q) \quad$ Conjunto de possíveis soluções para o problema paramétrico no método de Dinkelbach dado o parâmetro $q$

M Matriz arbitrária

$\mu \quad$ Nível d'água no algoritmo iterativo de water-filling

$\mu_{i} \quad$ Nível d'água no algoritmo iterativo de water-filling para o usuário $i$

$\mu_{\beta}^{d B} \quad$ Média do sombreamento em dB

n Vetor de ruído normalizado

$N \quad$ Número de subportadoras

$N_{i} \quad$ Número de portadoras alocadas para o usuário $i$ em um sistema OFDMA

$\tilde{N} \quad$ Número de subportadoras ligadas no algoritmo iterativo de waterfilling 
$N_{0} \quad$ Densidade espectral de potência do ruído em [Watts/Hertz]

$\nu$

$\boldsymbol{\nu}$

$p$

$p_{i}$

$p_{i}[t]$

$p_{i, k}$

$p_{\mathrm{R}}$

$P(\cdot) \quad$ Função perspectiva

$P_{N} \quad$ Potência média do sinal recebido no retransmissor de um sistema MC-DS/CDMA cooperativo

$P_{\mathrm{SYN}} \quad$ Potência consumida pelo sintetizador

$P_{\mathrm{MIX}} \quad$ Potência consumida pelo mixer

$P_{\mathrm{ABR}} \quad$ Potência consumida pelo amplificador de baixo ruído

$P_{\text {FIT }} \quad$ Potência consumida pelo filtro de transmissão

$P_{\mathrm{FIR}} \quad$ Potência consumida pelo filtro de recepção

$P_{\mathrm{AFI}} \quad$ Potência consumida pelo amplificador de frequências intermediárias

$P_{\mathrm{CAD}} \quad$ Potência consumida pelo conversor analógico-digital

$P_{\mathrm{CDA}} \quad$ Potência consumida pelo conversor digital-analógico

$P_{\mathrm{C}} \quad$ Potência constante consumida pelos circuitos

$P_{\mathrm{C}_{\mathrm{R}}} \quad$ Potência constante consumida pelos circuitos do retransmissor em sistemas cooperativos 
$P_{\mathrm{C}}^{D S} \quad$ Potência consumida pelos circuitos de transmissão e recepção de um sistema DS/CDMA

$P_{\mathrm{T}}(\cdot) \quad$ Energia total consumida no intervalo $T$ pelo sistema OFDMA em função das matrizes de alocação de subportadora, potência e taxa de transmissão

$P_{\mathrm{T}}^{i}(\cdot) \quad$ Energia total consumida no intervalo $T$ pelo $i$-ésimo usuário do sistema OFDMA em função dos vetores de alocação de subportadora, potência e taxa de transmissão

$P_{\mathrm{T}}^{D S} \quad$ Potência total consumida pelo sistema DS/CDMA

$P_{\mathrm{T}}^{M C} \quad$ Potência total consumida pelo sistema MC-DS/CDMA

$P_{\mathrm{T}}^{M C C} \quad$ Potência total consumida pelo sistema MC-DS/CDMA cooperativo

$P_{\mathrm{T}}^{O F D M A} \quad$ Potência total consumida pelo sistema OFDMA

$P_{\mathrm{TR}}^{D S}(\cdot) \quad$ Potência consumida na transmissão da informação em sistemas DS/CDMA

p Vetor de potências de transmissão

$\mathbf{p}_{-i} \quad$ Vetor de potências de transmissão de todos os usuários com exceção do usuário $i$

$\mathbf{p}_{-i, k} \quad$ Vetor de potências de transmissão de todos os usuários na subportadora $k$ com exceção do usuário $i$

$\mathbf{P} \quad$ Matriz de potências de transmissão

$q \quad$ Cap. 2 - Tamanho da fila do controlador de enlace

Cap. 3 - Parâmetro do método de Dinkelbach

$q_{t} \quad$ Parâmetro do método de Dinkelbach na iteração $t$ 
$q^{*} \quad$ Parâmetro ótimo do método de Dinkelbach (Valor máximo da função do problema original)

$q_{\max } \quad$ Tamanho máximo da fila do controlador de enlace

q Vetor arbitrário

Q Tamanho instantâneo da fila do controlador de enlace

Q Matriz diagonal com os ganhos de amplitude introduzidos pelos canais dos usuários

$\xi^{D S} \quad$ Eficiência energética do sistema DS/CDMA

$\xi^{M C} \quad$ Eficiência energética do sistema MC-DS/CDMA

$\xi^{M C C} \quad$ Eficiência energética do sistema MC-DS/CDMA cooperativo

$\xi_{\mathrm{e}, \mathrm{RFC}} \quad$ Eficiência energética efetiva de um sistema OFDMA com canais cuja amplitude do desvanecimento assume distribuição estatística de Rayleigh

$\xi_{\mathrm{e}, \mathrm{RFC}}^{i} \quad$ Eficiência energética efetiva do $i$-ésimo usuário de um sistema OFDMA com canais cuja amplitude do desvanecimento assume distribuição estatística de Rayleigh

$\xi_{i}^{D S} \quad$ Eficiência energética do $i$-ésimo usuário de um sistema DS/CDMA

$\xi_{i}^{M C} \quad$ Eficiência energética do $i$-ésimo usuário de um sistema MCDS/CDMA

$\xi_{\mathrm{e}} \quad$ Eficiência energética efetiva em sistemas OFDMA

$\xi_{\mathrm{e}} \quad$ Versão relaxada da eficiência energética efetiva em sistemas OFDMA

$\tilde{r} \quad$ Taxa de entrega de informação da fonte de tráfego no controlador de enlace 
Taxa de transmissão do canal on-off

$r_{i}$

Taxa de transmissão de informação do $i$-ésimo usuário

$r_{i}^{*}$

Taxa de transmissão de informação mínima para o usuário $i$

$r_{i, k} \quad$ Taxa de transmissão de informação do $i$-ésimo usuário no subcanal $k$

$\mathbf{r}$

Vetor de taxas de transmissão da informação

$R \quad$ Taxa de transmissão de informação total do sistema

$R_{i} \quad$ Taxa de transmissão de informação total do usuário $i$

$R_{\mathrm{e}} \quad$ Taxa de informação efetivamente transmitida

$R[j] \quad j$-ésimo elemento da sequência $\{R[j], j=1,2, \ldots\}$ que denota um serviço de transmissão

$\mathcal{R}(t) \quad$ Soma parcial dos $t$ primeiros elementos da sequência $\{R[j], j=$ $1,2, \ldots\}$

$\mathcal{R}_{i} \quad$ Taxa de transmissão de informação em bits por quadro para o $i$-ésimo usuário de um sistema OFDMA

R Matriz de correlação cruzada das sequências de espalhamento

$\mathbf{R}_{\mathrm{T}} \quad$ Matriz de taxas de transmissão de cada usuário em cada subportadora

$\mathfrak{R} \quad$ Estimativa da taxa de transmissão de informação efetiva do sistema

$\mathfrak{R}\left(\delta_{i, k}\right) \quad$ Estimativa da taxa de transmissão de informação efetiva do sistema em função da relação sinal-interferência mais ruído

$\rho_{i, j} \quad$ Correlação cruzada das sequências de espalhamento dos usuários $i$ e $j$ com atrasos $\tau_{i}$ e $\tau_{j}$, respectivamente 

$\rho(\mathbf{X}) \quad$ Raio espectral da matriz $\mathbf{X}$
$\varrho \quad$ Ineficiência do amplificador de potência da estação rádio-base
$\varrho_{i} \quad$ Ineficiência do amplificador de potência do $i$-ésimo usuário
$\varrho_{\mathrm{R}} \quad$ Ineficiência do amplificador de potência do retransmissor em siste- mas cooperativos

Sequência de espalhamento

$\mathbf{s}_{i} \quad$ Sequência de espalhamento do usuário $i$

$\mathbf{s}(t) \quad$ Sequência de espalhamento no tempo contínuo

$\mathbf{s}_{i}(t) \quad$ Sequência de espalhamento do usuário $i$ no tempo contínuo

$\mathbf{s}(t-\tau) \quad$ Sequência de espalhamento no tempo contínuo com atraso $\tau$

$\mathbf{s}_{i}\left(t-\tau_{i}\right) \quad$ Sequência de espalhamento do $i$-ésimo usuário no tempo contínuo com atraso $\tau_{i}$

$\mathcal{S}^{D S} \quad$ Eficiência espectral do sistema DS/CDMA

$\mathcal{S}^{M C} \quad$ Eficiência espectral do sistema MC-DS/CDMA

$\mathcal{S}^{M C C} \quad$ Eficiência espectral do sistema MC-DS/CDMA cooperativo

$\mathcal{S}_{i}^{D S} \quad$ Eficiência espectral do $i$-ésimo usuário de um sistema DS/CDMA

$\mathcal{S}_{i}^{M C} \quad$ Eficiência espectral do $i$-ésimo usuário de um sistema MCDS/CDMA

S Matriz de sequências de espalhamento

$\sigma^{2} \quad$ Potência do ruído térmico

$\sigma_{k}^{2} \quad$ Potência do ruído térmico na subportadora $k$ 
$\sigma_{1, k}^{2} \quad$ Potência do ruído térmico na subportadora $k$ no primeiro salto (fonte-retransmissor)

$\sigma_{2, k}^{2} \quad$ Potência do ruído térmico na subportadora $k$ no segundo salto (retransmissor-destino)

$\sigma_{\beta}^{d B} \quad$ Desvio padrão do sombreamento em dB

$\sigma_{\varsigma} \quad$ Desvio padrão do desvanecimento

$\varsigma \quad$ Valor da atenuação em amplitude do desvanecimento

$t \quad$ Cap. 2 - Relativo ao tempo

T Período de transmissão

$T_{s} \quad$ Período de símbolo

$T_{c} \quad$ Período de chip

$T_{N} \quad$ Período de símbolo OFDM

$\tau \quad$ Cap. 2 - Atraso relativo

$\tau_{i} \quad$ Atraso relativo ao sinal do usuário $i$

$\tau_{l} \quad$ Atraso relativo ao $l$-ésimo percurso

$u_{i} \quad$ Função utilidade relacionada ao jogador $i$

$u_{i}^{k} \quad$ Função utilidade relacionada ao usuário $i$ na $k$-ésima subportadora

U Número de usuários no sistema

$\mathbf{U}_{i, 1}[t] \quad$ Matriz diagonal cujos elementos são variáveis aleatórias uniformemente distribuídas no intervalo $[0,1]$ 
$\mathbf{U}_{i, 2}[t] \quad$ Matriz diagonal cujos elementos são variáveis aleatórias uniformemente distribuídas no intervalo $[0,1]$

$v \quad$ Taxa de crescimento linear da potência extra dos circuitos de acordo com o aumento da taxa de transmissão de informação da estação rádio-base

$v_{i} \quad$ Taxa de crescimento linear da potência extra dos circuitos de acordo com o aumento da taxa de transmissão de informação do $i$-ésimo usuário

$\mathbf{v}_{i}[t] \quad$ Velocidade da partícula $i$ na iteração $t$

$\mathbf{v}_{k} \quad$ Vetor cujos elementos estão relacionados a cada um dos usuários da subportadora $k$, e são equivalentes ao produto da potência de transmissão pelo símbolo e pela atenuação de canal de cada usuário

$V \quad$ Número de bits enviados no pacote

$V_{\max } \quad$ Velocidade máxima das partículas

$\psi(\cdot) \quad$ Função de pulso modulador

$\psi^{*}(-t) \quad$ Função do demodulador do sinal

$W F(\cdot) \quad$ Operador de water-filling

w Vetor arbitrário

W Filtro linear MMSE

$\omega \quad$ Inércia da velocidade no método de otimização por enxame de partículas 
$\Omega \quad$ Conjunto de matrizes de alocação de subportadora factíveis

$x_{1} \quad$ Probabilidade de um canal on-off estar desligado

$x_{2} \quad$ Probabilidade de um canal on-off estar ligado

$x_{k} \quad$ Amostra temporal do sinal OFDM relacionada à $k$-ésima subportadora

$x_{i, k} \quad$ Símbolo enviado pelo $i$-ésimo usuário na subportadora $k$

$x(t) \quad$ Sinal modulado em banda base no tempo contínuo

$x_{i}(t) \quad$ Sinal modulado do $i$-ésimo usuário no tempo contínuo

$X_{k} \quad$ Amostra no domínio da frequência do sinal OFDM relacionada à $k$-ésima subportadora

x Variável de decisão no $\mathbb{R}^{n}$

$\mathbf{x}^{*} \quad$ Solução do problema de otimização

$\mathbf{x}_{i}^{\text {best }}[t] \quad$ Melhor posição assumida pela partícula $i$ até a iteração $t$

$\mathbf{x}_{g}^{\text {best }}[t] \quad$ Melhor posição assumida pelo enxame até a iteração $t$

$\mathbf{x}_{i}[t] \quad$ Posição do vaga-lume/partícula $i$ na iteração $t$

$\tilde{\mathbf{x}}(t) \quad$ Sinal recebido e concentrado

$\tilde{x}_{M F} \quad$ Sinal recebido e concentrado em um bando de filtros casados

$\mathcal{X} \quad$ Variável aleatória de distribuição Gaussiana de média zero e variância unitária

$\mathbf{y}(t) \quad$ Cap 2. - Sinal modulado e espalhado em banda passante no tempo contínuo 
$\mathbf{y}_{i}(t) \quad$ Sinal modulado e espalhado do usuário $i$ em banda passante no tempo contínuo

$\tilde{\mathbf{y}}(t) \quad$ Sinal recebido na entrada do receptor em tempo contínuo

$\tilde{\mathbf{y}}_{i}(t) \quad$ Sinal recebido na entrada do receptor (enlace de subida)

$\tilde{\mathbf{y}}_{k} \quad$ Sinal recebido no retransmissor de um rede cooperativa MCDS/CDMA na $k$-ésima subportadora

$\epsilon \quad$ Cap. 2 - Probabilidade de violação do atraso máximo tolerável no controlador de enlace

Cap. 4 - Precisão ou margem de erro tolerada

$\epsilon_{D} \quad$ Precisão do método de Dinkelbach

$\mathbf{Z}$

Cap. 2 - Sinal em banda base na entrada da estação rádio-base de um sistema MC-DS/CDMA cooperativo

Cap. 3 - Vetor arbitrário

Z Matriz de interferência normalizada 


\section{INTRODUÇÃO}

Este capítulo introdutório tem por objetivo apresentar o escopo deste trabalho de doutorado e sua motivação na seção 1.1. Os conceitos básicos e modelos de sistemas são introduzidos na seção 1.2 e discutidos com maior profundidade posteriormente. A seção 1.3 apresenta a justificativa da pesquisa e sistemas considerados no trabalho de doutorado. Uma revisão bibliográfica é oferecida na seção 1.4 enquanto a seção 1.5 apresenta a proposta de pesquisa, seguida da indentificação das principais contribuições e produção científica associada. Finalmente, a organização deste texto é descrita na seção 1.6.

\subsection{Escopo e Motivação}

O advento dos sistemas de telecomunicações de quarta geração é acompanhado de um crescimento vertiginoso no mercado de serviços de comunicação multimídia: em 2013, o número de dispositivos móveis ${ }^{1}$ conectados chegou a 7 bilhões de unidades, dos quais 1 bilhão e 750 milhões são smartphones e 4 bilhões e meio são dispositivos móveis convencionais ${ }^{2}$. Ainda que em menor número, os smartphones foram responsáveis por $88 \%$ do tráfego de informações nas redes sem fio, dos quais 30\% foram gerados por dispositivos de quarta geração (CISCO, 2014).

As perspectivas de crescimento para as telecomunicações são, ao mesmo

\footnotetext{
${ }^{1}$ Celulares convencionais, smartphones, tablets, computadores portáteis e handhelds

${ }^{2}$ Celulares convencionais são aparelhos que não suportam a utilização de serviços multimídia.
} 
tempo, alarmantes e animadoras. Animadoras pois implicam no crescimento do mercado e a necessidade de desenvolvimento de novas tecnologias capazes de atender a demanda de forma eficiente, garantindo a satisfação dos consumidores e os objetivos financeiros das companhias. Por exemplo, de acordo com o relatório técnico da (CISCO, 2014), o número de dispositivos móveis conectados atingirá valores próximos a 10 bilhões de unidades em 2018, cujo tráfego mensal será da ordem de 16 hexabytes ${ }^{3}$.

Por outro lado, estas perspectivas são alarmantes se considerarmos o desenvolvimento de tecnologias sem responsabilidade ambiental: segundo o relatório anual de 2013 do Centro para Telecomunicações Energeticamente Eficientes (do inglês, Centre for Energy-Efficient Telecommunications, CEET), a previsão de consumo anual de energia de toda a infra estrutura das telecomunicações do globo para 2015 é de aproximadamente 32,4 terawatts hora ${ }^{4}$ o que representa um crescimento de $350 \%$ em relação ao consumo do ano de 2012, 9, 2 terawatts hora. Para entender o impacto desta previsão basta verificar que o consumo do ano de 2012 é equivalente ao fornecimento anual de energia para 800 milhões de domicílios do porte de uma residência norte-americana média (CEET, 2013; EIA, 2015).

De forma mais específica, o relatório técnico da (ELTEK, 2012) afirma que a empresa de telecomunicações Verizon apresentou gastos anuais de energia equivalentes a 8, 9 bilhões de quilowatts hora responsáveis pela emissão de aproximadamente 7,1 milhões de toneladas de gás carbônico na atmosfera.

Diante deste cenário, o projeto de redes sem fio, convencionalmente focado no aumento da vazão ${ }^{5}$ ou da eficiência espectral ${ }^{6}$, passa a dar atenção ao conceito

\footnotetext{
${ }^{3}$ Equivalente a $16 \times 2^{60}$ bytes ou aproximadamente $16 \times 10^{18}$ bytes

${ }^{4} \mathrm{Um}$ terawatt hora é equivalente a $10^{12}$ quilowatts hora

${ }^{5}$ Neste texto vazão do sistema é a soma das taxas de transmissão de todos os usuários

${ }^{6} \mathrm{~A}$ eficiência espectral é a taxa de informação digital transmitida por unidade de espectro ocupado.
} 
de eficiência energética (EE). De forma geral, o projeto focado na maximização da eficiência energética é definido como o uso da menor quantidade possível de energia para prover o mesmo serviço, ou ainda, prover a maior quantidade possível de serviços com a mesma quantidade de energia (IEA, 2015).

Em telecomunicações, a eficiência energética é, portanto, definida como a quantidade de informação efetivamente transmitida por unidade de energia utilizada no processo de comunicação: uma vez que o primeiro é mensurado em bits e o segundo em Joules, a eficiência energética é uma medida de dimensão bits por Joule, ou ainda, em bits por Watts por unidade de tempo.

Um exemplo prático do impacto de projetos de comunicação sem-fio eficientes do ponto de vista energético pode ser concebido em relação à empresa de telecomunicações Verizon. Se a mesma fosse capaz de melhorar sua eficiência energética na prestação dos serviços de tal sorte a reduzir em $6 \%$ seu consumo anual de energia, a economia corresponderia a 534 milhões de quilowatts hora, além de uma redução no impacto ambiental $^{7}$ por não emitir 426 mil toneladas de gás carbônico na atmosfera.

Uma sub-área das telecomunicações, importante para o projeto de sistemas eficientes do ponto de vista energético, trata do gerenciamento de recursos como energia e espectro. O primeiro é de fundamental importância e está diretamente relacionado ao conceito de eficiência energética. O segundo, está indiretamente relacionado e é fundamental para explorar a diversidade em frequência dos sistemas. Gerenciá-los de forma ótima é um desafio em redes de múltiplo acesso e objeto de estudo deste texto.

\footnotetext{
${ }^{7}$ A matriz de energia mundial tem $67 \%$ de sua produção baseada em termelétricas, portanto uma redução no consumo de energia tem, necessariamente, uma redução nas emissões de gás carbônico na atmosfera (TSP, 2015).
} 


\subsection{Conceitos Básicos e Sistemas}

Existem basicamente cinco formas não-híbridas distintas que permitem o acesso de múltiplos transmissores e receptores a um canal comum em sitemas de comunicação sem fio, denominadas técnicas de múltiplo acesso. A primeira é através da divisão temporal conhecida como múltiplo acesso por divisão de tempo (do inglês, time division multiple access, TDMA). Neste tipo de sistema um intervalo de tempo é reservado para que cada transmissor utilize o canal de comunicação sem fio a fim de transmitir informações a um receptor. De forma equivalente, quando a divisão ocorre em frequência, i.e. diferentes faixas de frequência são reservadas para que diferentes ativos de rede utilizem o canal, o sistema é denominado múltiplo acesso por divisão de frequência (do inglês, frequency division multiple access, FDMA). Este esquema de múltiplo acesso é realizado através de frequências portadoras distintas que podem ser ortogonais, permitindo uma sobreposição entre as mesmas de tal forma a obter uma maior eficiência espectral.

O terceiro tipo de múltiplo acesso ocorre através da técnica de espalhamento espectral: nestes sistemas o sinal original é combinado a um outro sinal de largura de banda maior, denominado sequência de espalhamento. Esta combinação pode ser feita de três formas distintas: por sequência direta, conhecido como múltiplo acesso por divisão em código por sequência direta (do inglês, direct sequence code division multiple access, DS/CDMA), por saltos em frequência, denominado múltiplo acesso por divisão de código com saltos em frequência (do inglês, frequency hopping code division multiple access, FH/CDMA) ou por saltos no tempo, denominado múltiplo acesso por divisão de código com saltos no tempo (do inglês, time hopping code division multiple access, TH/CDMA).

A quarta forma de múltiplo acesso é conhecida como múltiplo acesso por divisão espacial: neste caso um conjunto de antenas é utilizado para criar o sinal 
destinado a um receptor cuja localização geográfica é conhecida de tal forma que o sinal ao invés de omnidirecional é, na realidade, um feixe. Desta forma, a diferença na localização geográfica é responsável por permitir o múltiplo acesso a um canal de comunicação comum. Finalmente, o múltiplo acesso por divisão de polarização é a quinta técnica de múltiplo acesso apresentada. Nesta técnica o múltiplo acesso ocorre através da transmissão por antenas com polarizações diferentes. Os receptores, por sua vez, possuem antenas com a mesma polarização das antenas transmissoras.

Note que os cinco sistemas de múltiplo acesso referem-se a cinco dimensões distintas: tempo, frequência, código, espaço e polarização. Uma vez que é inviável a representação em cinco dimensões dos sistemas de múltiplo acesso para ilustrar suas diferenças, apresenta-se a figura 1 com os três principais sistemas de múltiplo acesso: TDMA, FDMA e DS/CDMA. Considerando as dimensões tempo, frequência e potência de transmissão do sinal, é possivel observar que no sistema de múltiplo acesso por divisão em código de sequência direta todos os transmissores enviam a informação na mesma faixa de frequência e de forma simultânea causando o que é conhecido como interferência de múltiplo acesso.

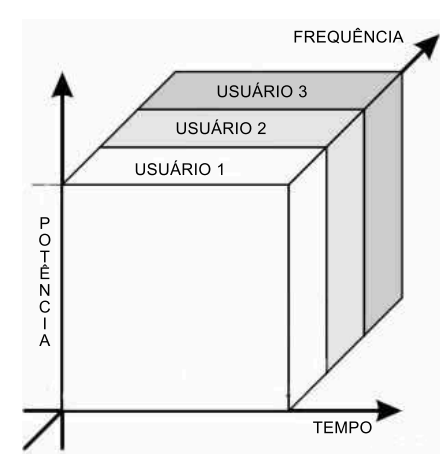

FDMA

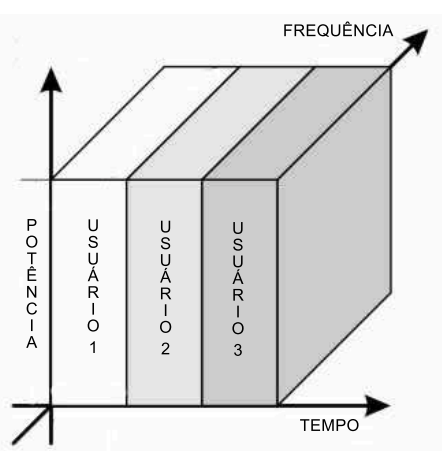

TDMA

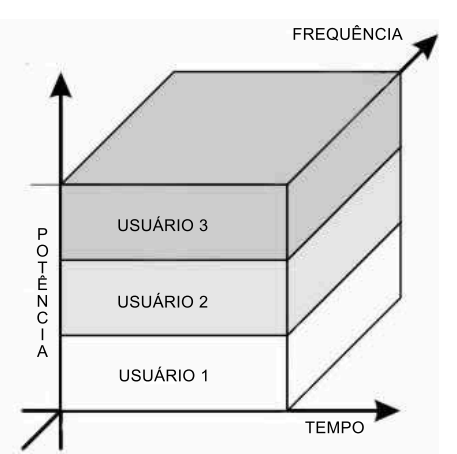

CDMA

Figura 1: Disposição dos diversos usuário da rede em sistemas com múltiplo acesso por divisão por tempo, frequência e código em sequência direta.

Neste trabalho, dois sistemas de múltiplo acesso serão considerados: o sistema de múltiplo acesso por divisão ortogonal de frequência (do inglês, ortho- 
gonal frequency division multiple access, OFDMA) e o sistema híbrido resultado da combinação de sistemas de múltiplo acesso por divisão em código de sequência direta e sistemas de multiplexação por divisão ortogonal de frequência, conhecido como DS/CDMA multiportadora (do inglês, multicarrier DS/CDMA, MC-DS/CDMA).

Independente da forma como o múltiplo acesso é feito, em sistemas de comunicação sem fio, o canal de comunicação é responsável por introduzir efeitos que degradam o sinal e, muitas vezes, impedem a correta recuperação da informação no receptor. Na subseção a seguir serão apresentados as principais características dos canais sem fio, os principais efeitos nocivos que estes introduzem e como são modelados matematicamente.

\subsubsection{Modelos de Canal}

Em sistemas de comunicação sem fio a propagação das ondas de rádio, geralmente, não ocorre em cenários com linha de visada e/ou ambientes bucólicos onde existem poucos ou nenhum objeto no ambiente que seja capaz de obstruir completamente o sinal que percorre a linha de visada, ou contribuir para a geração de múltiplas reflexões do sinal até o receptor. De maneira geral, os canais de comunicações sem fio são considerados meios inóspitos quando comparados a canais de comunicação guiados, tais como cabeados ou fibra óptica, tornando a comunicação com altas taxas de transmissão neste meio um desafio (GOLDSMITH, 2005).

O canal de comunicação sem fio introduz atenuações no sinal cujas características são geralmente determinadas pela frequência da portadora, superfícies que absorvem parte da energia do sinal, superfícies que refletem ou difratam o sinal, obstáculos e pela distância entre transmissor e receptor. É comum distinguir três efeitos distintos, em termos de escala espacial, que compõe a atenuação do canal: 
o primeiro é o efeito de larga escala denominado perda de percurso; o segundo, o efeito de média escala denominado sombreamento ${ }^{8}$; e o terceiro efeito denominado desvanecimento ${ }^{9}$ ou termo de pequena escala, podendo ser classificado como desvanecimento rápido ou lento (dependendo da relação entre o período de decisão no receptor e o tempo de coerência do canal)

As variações na perda de percurso ocorrem ao longo de grande distâncias, enquanto as variações do efeito de sombreamento ocorrem em distâncias proporcionais ao tamanho do objeto obstrutor do sinal e, finalmente, as variações de pequena escala acontecem em distâncias muito curtas, da ordem do comprimento de onda do sinal. Para ilustrar estas diferenças entre os três efeitos de propagação do canal, a figura 2 apresenta os ganhos do canal $^{10}$ relativo a cada efeito (ou combinação de efeitos) de acordo com a distância $d$ percorrida pelo sinal (GOLDSMITH, 2005).

A perda de percurso está diretamente associada efeitos de reflexão, difração e a atenuaçao da amplitude do sinal com a distância percorrida pelo mesmo, portanto, alterações significativas na perda de percurso ocorrem quando se percorre centenas de metros. A frequência da portadora, o ganho das antenas de transmissão e recepção, e a distância entre transmissor e receptor, influênciam diretamente nas características da perda de percurso, de tal forma que esta é diretamente proporcional ao ganho das antenas e ao comprimento de onda do sinal e inversamente proporcional à distância. De acordo com (GOLDSMITH, 2005) a perda de percurso é dada por,

$$
\alpha_{L}=\frac{A_{g} \lambda^{2}}{(4 \pi)^{2} d^{2}}
$$

\footnotetext{
${ }^{8}$ Do inglês, shadowing.

${ }^{9}$ Do inglês, fading.

${ }^{10} \mathrm{O}$ conceito de ganho de canal é o inverso da atenuação, i.e. a atenuação elevada indica um efeito mais nocivo sobre o sinal ao percorrer o canal enquanto o ganho maior indica um efeito menos nocivo sobre o sinal ao percorrer o canal.
} 


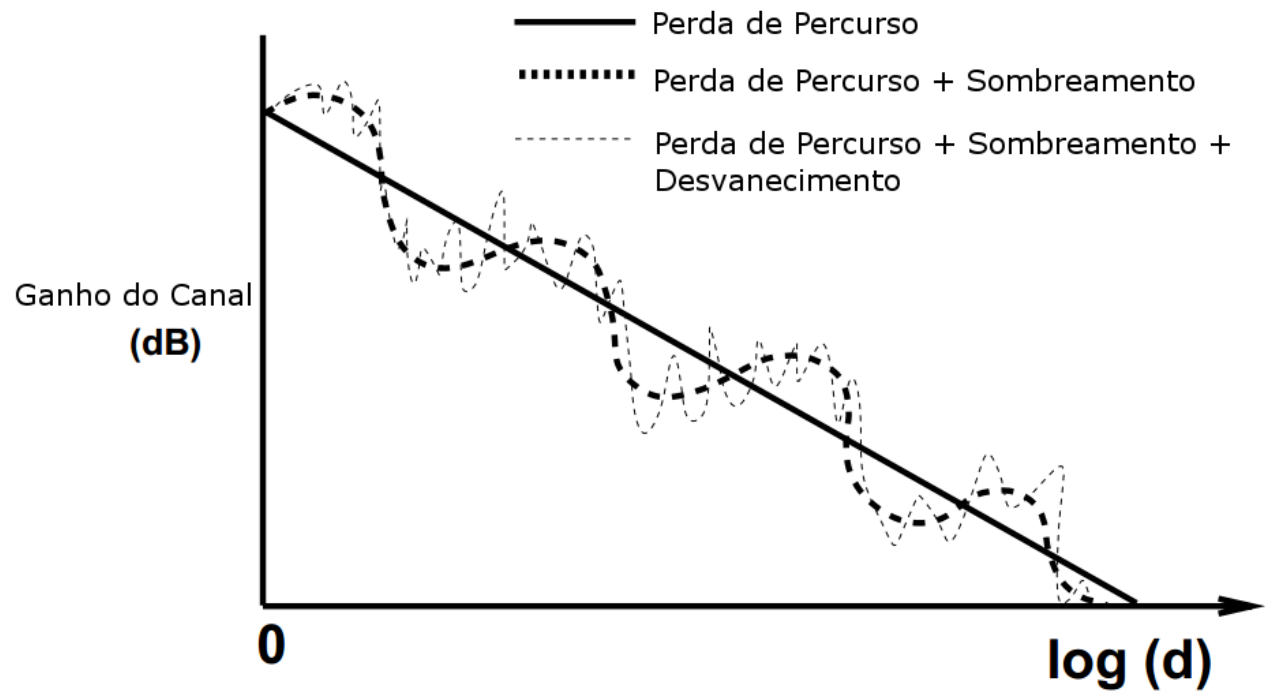

Figura 2: Ilustração da variação do ganho de canal em função da distância considerando os efeitos de perda de percurso, sombreamento e desvanecimento. Fonte: adaptado de (GOLDSMITH, 2005)

onde $\alpha_{L}$ é a perda de percurso, $A_{g}$ é o ganho combinado das antenas de transmissão e recepção considerando o percurso com linha de visada, $\lambda$ é o comprimento de onda e $d$ a distância entre transmissor e receptor. Este modelo, todavia, requer o conhecimento do tipo de antenas utilizado bem como seus padrões de radiação. É conveniente utilizar modelos mais simples que podem ser adaptados a diferentes cenários. Um modelo simples e amplamente utilizado na literatura para modelar a perda de percurso é (HATA, 1980),

$$
\alpha_{\mathrm{s}}=K\left[\frac{d_{0}}{d}\right]^{\gamma_{p}}
$$

sendo $K$ uma constante adimensional, $d_{0}$ é uma distância de referência ${ }^{11}, d$ é a distância entre transmissor - receptor, e $\gamma_{p}$ é o expoente de perda de percurso relacionado ao ambiente de propagação, cujos valores estão usualmente no intervalo $[1,6 ; 6,5]$ tal que valores maiores são usados de acordo com a densidade de construções e objetos no ambiente. Desta forma, $K$ é usualmente determinado

\footnotetext{
${ }^{11}$ Uma distância para a qual, normalmente, já se conhece a perda de percurso
} 
por medidas da perda de percurso em $d_{0}$ (ERCEG et al., 1999; GOLDSMITH, 2005).

O efeito de sombreamento por sua vez é inerente à presença de objetos entre transmissor e receptor como árvores, prédios e folhagens. Mudanças no sombreamento podem ser notadas quando se percorre dezenas de metros, o que justifica o termo efeito de média escala. A maneira mais comum de modelar o sombreamento $\beta$ é através de uma variável aleatória log-normal cuja função densidade de probabilidade é (GOLDSMITH, 2005):

$$
f(\beta)=\frac{10}{\sqrt{2 \pi} \sigma_{\beta}^{d B} \beta} \exp \left[-\frac{\left(10 \log _{10}(\beta)-\mu_{\beta}^{d B}\right)^{2}}{2\left(\sigma_{\beta}^{d B}\right)^{2}}\right], \beta>0
$$

onde $\sigma_{\beta}^{d B}$ e $\mu_{\beta}^{d B}$ são o desvio padrão e a média da variável $\beta^{d B}=10 \log _{10}(\beta)$. A média $\mu_{\beta}$ (a atenuação linear média) é dada por (GOLDSMITH, 2005),

$$
\mathbb{E}[\beta]=\exp \left[\frac{\log (10) \mu_{\beta}^{d B}}{10}+\frac{1}{2}\left(\frac{\log (10) \sigma_{\beta}^{d B}}{10}\right)^{2}\right]
$$

onde $\mathbb{E}[\cdot]$ é o operador de esperança matemática. Desta forma, o valor da atenuação causada pelo sombreamento pode ser estabelecido por,

$$
\beta=10\left(\frac{\sigma_{\beta}^{d B}}{10} \mathcal{X}\right)
$$

onde $\mathcal{X}$ é uma variável aleatória de distribuição de probabilidade normal com média zero e variância unitária.

O último efeito associado ao canal sem fio, o desvanecimento, é responsável por alterar a amplitude do sinal através de flutuações rápidas e de grande magnitude na atenuação introduzida ao canal. O efeito de pequena escala ocorre uma vez que objetos que espalham o sinal e reflexões geram cópias do sinal com 
atrasos observados de forma distinta no receptor, fenômeno este conhecido como desvanecimento multi-percurso.

O desvanecimento ou termo de pequena escala apresenta uma subclassificação no domínio do tempo e da frequência:

\section{- Tempo}

- Desvanecimento Rápido: um canal é classificado como rápido no tempo quando a resposta impulsiva do canal muda a uma taxa maior que a taxa de símbolo, ou ainda, quando o tempo de coerência do canal $\left((\Delta t)_{c}\right)$ é maior que o período de símbolo $\left(T_{s}\right)$. O tempo de coerência do canal está diretamente ligado ao desvio Doppler (ou efeito Doppler), i.e. ao desvio de frequência quando transmissor e/ou receptor estão em movimento. Ou seja, em canais com desvanecimento rápido $(\Delta t)_{c}<$ $T_{s}$.

- Desvanecimento Lento: um canal é classificado como lento no tempo quando sua resposta impulsiva muda a uma taxa mais lenta que a taxa de símbolo, ou ainda, quando o tempo de coerência do canal é maior que o período de símbolo, i.e. $(\Delta t)_{c}>T_{s}$.

\section{- Frequência}

- Desvanecimento Seletivo em Frequência: um canal é classificado como seletivo em frequência quando a largura de banda do sistema de comunicação $(B)$ for muito maior que a banda de coerência do canal $\left((\Delta B)_{c}\right)$. De forma equivalente, o canal é seletivo em frequência quando o período de símbolo é muito menor que o espalhamento de atraso. Este último está relacionado ao atraso dos múltiplos percursos percorridos pelo sinal. Ou seja, em canais com desvanecimento seletivo em frequência $(\Delta B)_{c}<<B$. 
- Desvanecimento Plano: um canal é plano se o período de símbolo for muito maior que o espalhamento de atraso do canal. De forma análoga, um canal é classificado como plano quando a largura de banda do sistema é muito menor que a banda de coerência do canal, i.e. $(\Delta B)_{c}>>B$

Em cenários sem linha de visada, comuns nos grandes centros urbanos, é comum admitir que os ganhos de amplitude do canal assumem uma distribuição de Rayleigh (SIMON; ALOUINI, 2000). Desta forma, a amplitude do desvanecimento de pequena escala $\varsigma$ é distribuída de acordo com a função densidade de probabilidade,

$$
f(\varsigma)=\frac{2 \varsigma}{\sigma_{\varsigma}^{2}} \exp \left[-\frac{\varsigma^{2}}{\sigma_{\varsigma}^{2}}\right]
$$

onde $\sigma_{\varsigma}^{2}$ é o segundo momento estatístico de $\varsigma$. Do ponto de vista operacional, os ganhos de amplitude do desvanecimento de pequena escala com distribuição estatística de Rayleigh podem ser obtidos a partir do módulo da soma complexa de duas variáveis aleatórias Gaussianas independentes e identicamente distribuídas (i.i.d.) com médias zero.

\subsection{Justificativa}

Neste trabalho são considerados dois sistemas de comunicação de múltiplo acesso: os sistemas de múltiplo acesso por divisão de frequências ortogonais, OFDMA, e os sistemas com múltiplas portadoras e múltiplo acesso por divisão em código de sequência direta, MC-DS/CDMA. O primeiro é o sistema de transmissão do elo de descida ${ }^{12}$ dos principais sistemas de comunicação de quarta

\footnotetext{
${ }^{12} \mathrm{O}$ elo de descida é o enlace onde a informação é transmitida de um único transmissor para múltiplos receptores. Já o elo de subida é caracterizado pela transmissão a partir de vários ativos de rede distintos para um receptor comum.
} 
geração: o Long Term Evolution (LTE), o LTE-Advanced, ambos propostos pelo Third Generation Partnership Project (3GPP); e o sistema Worldwide Interoperability for Microwave Access (WiMAX) definidos pelo Institute of Electrical and Electronic Engineers (IEEE) na família de padrões IEEE 802.16.

O uso crescente das redes de quarta geração tornam importante a otimização do ponto de operação de transmissores e receptores para garantir a satisfação dos usuários da rede e torná-la mais eficiente do ponto de vista energético. No trabalho de (HUANG et al., 2012) uma análise do consumo de energia de redes LTE revelou que estas são muito menos eficientes, energeticamente, do que redes também baseadas no múltiplo acesso por divisão ortogonal de frequência como as redes Wi-Fi descritas no padrão IEEE 802.11. Fica evidente, desta forma, a importância de propor sistemas de gerenciamento de recursos que melhorem de forma significativa a eficiência energética do sistema de comunicação sem fio associado a estes padrões.

O outro sistema abordado neste trabalho é baseado em tecnologias de espalhamento espectral. Atualmente, estas são utilizadas em sistemas de comunicação de terceira geração como o padrão WCDMA ${ }^{13}$ e o padrão CDMA2000. O primeiro foi desenvolvido pelo 3GPP e faz parte do Universal Mobile Telecommunications Systems (UMTS) enquanto o segundo foi desenvolvido pelo 3GPP2 como uma evolução do padrão cdmaOne.

Um dos grandes desafios dos padrões de quarta geração está na funcionalidade básica dos terminais móveis: a ligação telefônica. Sistemas como o LTE e WiMAX não prevêem a comunicação através da comutação de circuitos como as redes Global System for Mobile Communications (GSM). Desta forma, para utilizar um smartphone que possua um transceptor LTE, por exemplo, é necessário que o aparelho também possua um transceptor GSM para que ligações telefônicas,

\footnotetext{
${ }^{13}$ CDMA de banda larga
} 
atualmente, sejam possíveis. ${ }^{14}$

Desta forma, estabelecer um padrão único capaz de atingir altas taxas de dados e, simultaneamente, atender a necessidade de ligações telefônicas requer uma elevada granularidade. Esta granularidade pode, de fato, ser atingida através da combinação dos sistemas DS/CDMA de terceira geração aos sistemas de multiplexação por divisão ortogonal de frequência nos quais os sistemas de quarta geração são inspirados. Neste sentido, os sistemas MC-DS/CDMA apresentam-se como uma alternativa para futuros padrões de telefonia que pretendam unificar os diferentes serviços disponíveis em telecomunicações em uma rede e/ou padrão de comunicação único.

\subsection{Revisão Bibliográfica}

O primeiro trabalho relacionado a alocação de recursos em redes sem fio de múltiplo acesso foi publicado em (BOCK; EBSTEIN, 1964), onde o controle de potência de transmissão para combater a interferência co-canal foi modelado como um problema de programação linear. O controle de potência em um cenário onde o canal introduz ruído e existe interferência de múltiplo acesso tem por objetivo garantir que uma determinada relação entre a potência do sinal transmitido e a potência dos sinais interferentes mais a potência do ruído tenham valores de interesse no receptor, i.e. o controle de potência visa balancear essa relação de tal forma que no receptor todos os enlaces tenham a mesma qualidade (GOLDSMITH, 2005).

Mais tarde, no trabalho de (AEIN, 1973), com objetivo semelhante, discutiuse o controle de potência em sistemas de satélite considerando tanto canais que

\footnotetext{
${ }^{14}$ Em seu discurso no PIRMC 2013, Stephen Pusey, então Chief Technology Officer (CTO) da companhia de telecomunicações Vodafone afirmou que ao desenvolver os padrões de quarta geração os engenheiros esqueceram-se do principal motivo pelo qual os indivíduos possuem, em primeiro lugar, um celular: para realizar ligações telefônicas (serviço de voz).
} 
introduzem ruído como os livre de ruído. A existência e unicidade de uma solução factível para estes problemas de controle de potência está associado à matriz de ganho de enlace e é consequência do teorema de Perron-Frobenius.

A primeira adaptação do conceito de controle de potência para sistemas com espalhamento espectral foi publicada no trabalho de (NETTLETON, 1980 apud NETTLETON; ALAVI, 1983). Nestes trabalhos, bem como em (NETTLETON; ALAVI, 1982), o objetivo principal do controle de potência, principalmente no elo de subida, era a mitigação do efeito perto-longe. A idéia do efeito perto-longe remete, de forma oposta, ao objetivo de controle de potência: os sinais, oriundos de diferentes posições geográficas, são atenuados em proporções diferentes o que indica que na recepção estes sinais possuem diferentes amplitudes. Uma vez que em sistemas de espalhamento espectral os usuários transmitem na mesma faixa de frequências e ao mesmo tempo, os sinais menos atenuados dos transmissores que estão próximos do receptor causam um nível de interferência elevado no sinal dos transmissores mais distantes, os quais proporcionam amplitudes menores no receptor.

O controle de potência pode ser dividido em duas classes diferentes: controle distribuído e controle centralizado. O trabalho de (NETTLETON; ALAVI, 1983) é um exemplo de sistema de controle de potência centralizado, embora o termo tenha sido empregado de fato no trabalho de (GRANDHI et al., 1993). Em 1993, Foschini e Miljanic propuseram um algoritmo de controle de potência distribuído que tornou-se clássico na literatura pela simplicidade e eficiência (FOSCHINI; MILJANIC, 1993). Trabalhos posteriores analisaram a estabilidade do algoritmo em diferentes cenários considerando atrasos temporais (CHARALAMBOUS; LESTAS; VINNICOMBE, 2008) e (CAMPOS-DELGADO; LUNA-RIVERA, 2011).

No controle de potência distribuído do elo reverso a gestão de recursos é re- 
alizada de forma individual pelos terminais móveis (TM), portanto, não há a necessidade de transmissão de informação de controle de potência de transmissão da estação rádio-base (ERB) para os usuários do sistema. Esta característica implica em uma redução da sobrecarga de informação que trafega na rede em canais de serviço. Adicionalmente, quando o controle distribuído é feito de forma eficiente e com baixa complexidade computacional, pode-se aumentar a longevidade das baterias dos terminais móveis.

A necessidade de algoritmos de baixa complexidade levou à criação de algoritmos subótimos e, posteriormente, ao uso de algoritmos heurísticos, desta forma vários algoritmos heurísticos bem estabelecidos na literatura têm sido utilizados para realizar o controle de potência em redes do tipo DS/CDMA, particularmente, destacam-se três: no trabalho de (MOUSTAFA; NAGHSHINEH, 2000) o tradicional algoritmo genético baseado nos conceitos de evolução das espécies de Charles Darwin foi empregado. O trabalho de (ELKAMCHOUCHI; ELRAGAL; MAKAR, 2007), por sua vez, apresenta a otimização por enxame de partículas (do inglês, particle swarm optimization, PSO) como alternativa para o controle de potência em redes de múltiplo acesso por espalhamento espectral. Finalmente, o algoritmo de de otimização por colônia de formigas (do inglês, ant colony optimization, ACO) foi utilizado em (SAMPAIO et al., 2013a) também para o controle de potência em redes DS/CDMA.

Embora muitas vezes apresentem complexidade computacional menor que outros métodos numéricos, as heurísticas são métodos não determinísticos e, portanto, não há garantia de convergência explícita para a solução ótima em um determinado problema de otimização. Sendo assim, pesquisadores buscaram algoritmos determinísticos de baixa complexidade que solucionassem o problema do controle de potência em redes sem fio de múltiplo acesso. Muitas soluções foram propostas com base na teoria de jogos desenvolvida por (VON NEUMANN; 
MORGENSTERN, 1944) e posteriores contribuições de (NASH, 1950b).

A aplicação destes conceitos em redes sem fio de múltiplo acesso iniciou-se na década de 90 com o trabalho de (SHAH; MANDAYAM; GOODMAN, 1998) onde uma estrutura para o controle de potência para o serviço de transferência de dados em redes fio é apresentada. O uso de teoria de jogos para solucionar problemas de otimização em redes sem fio apenas aumentou na década seguinte e inúmeros trabalhos nos mais diversos cenários foram publicados. Algumas referências a respeito do uso de teoria de jogos no controle de potência podem ser citados: (MACKENZIE; WICKER, 2001), (SARAYDAR; MANDAYAM; GOODMAN, 2002), (AKKARAJITSAKUL et al., 2011) e (SCUTARI et al., 2010).

Com o crescimento vertiginoso das telecomunicações na última década e da quantidade de informação que trafega nas redes ao redor do globo, o consumo de energia também aumentou drasticamente. Este aumento é acompanhado por um impacto ambiental devido às emissões de carbono, e também de um impacto financeiro dado os custos da energia consumida. Isto levou a uma mudança na visão de como é feita a alocação de recursos em redes de telecomunicações: o objetivo que antes estava relacionado ao controle de potência clássico passou a ser a melhoria da eficiência energética global do sistema de comunicação.

Em abril do ano 2000, Goodman e Mandayam publicaram um artigo intitulado "Power control for wireless data" onde definiam a eficiência energética de um sistema de comunicação como a quantidade de informação efetivamente transmistida por unidade de energia ${ }^{15}$. Tem-se formado consenso a adoção de bits por Joule para unidade de eficiência energética; alternativamente, alguns autores adotam a unidade Joule por bit, ou ainda, watts por bit por Hertz para quantificar o mesmo conceito (GOODMAN; MANDAYAM, 2000).

Para os sistemas de múltiplo acesso por espalhamento espectral, algoritmos

\footnotetext{
${ }^{15}$ A definição está na equação (2) em (GOODMAN; MANDAYAM, 2000).
} 
determinísticos e heurísticos foram desenvolvidos nos últimos quinze anos buscando encontrar soluções de compromisso que aumentassem a eficiência energética dos sistemas e, simultaneamente, apresentassem baixa complexidade computacional. Entre os trabalhos desenvolvidos, alguns merecem destaque: o trabalho inicial de (GOODMAN; MANDAYAM, 2000) apresentou o conceito de eficiência energética e propôs uma solução baseada em teoria de jogos. No trabalho de (MESHKATI; POOR; SCHWARTZ, 2007), a eficiência energética em redes DS/CDMA com múltiplas antenas de recepção é analisada sob a perspectiva de teoria de jogos; uma solução baseada em teoria de jogos para sistemas DS/CDMA cooperativos é apresentado em (ZAPPONE; BUZZI; JORSWIECK, 2011), estendendo-se ao cenário DS/CDMA com múltiplas portadoras, MCDS/CDMA; um esquema de controle de potência baseado em teoria de jogos é apresentado em (FANG; FIGUEIREDO, 2007).

Uma busca recente na base de dados do IEEE associada com a alocação de recursos em sistemas DS/CDMA e/ou MC-DS/CDMA relacionou 31 artigos. Nenhum destes artigos considera um cenário cooperativo em redes MC-DS/CDMA focado no projeto do receptor linear e controle de potência buscando maior eficiência energética.

Os sistemas com múltiplo acesso por divisão ortogonal de frequência por sua vez são comumente utilizados para atingir altas taxas de informação. Sendo assim, um dos problemas mais conhecidos em sistemas OFDMA é a maximização da vazão dos sistemas no enlace direto (JANG; LEE, 2003). O problema consiste basicamente em alocar diferentes níveis de potência de transmissão para cada usuário de tal forma a maximizar a soma das taxas de todos os usuários do sistema. Note que nesta abordagem toda a potência de transmissão disponível é normalmente alocada.

Do ponto de vista do múltiplo acesso, a solução ótima para o problema de 
maximização é obtida quando o transmissor em cada subportadora é associado ao usuário com o melhor canal naquela subportadora. Do ponto de vista da potência, a solução ótima é obtida através de uma solução do tipo water-filling uma vez que as subportadoras foram devidamente alocadas (GALLAGER, 1968).

Desta forma, pode-se inferir que nas últimas décadas, o problema de maximização da vazão do sistema nos mais diversos cenários de redes OFDMA foi exaustivamente investigado, dado a enorme quantidade de trabalhos disponíveis, entre os quais podem ser citados: em (WONG et al., 1999) um método para alocação de potência, subportadora e bit adaptativo é proposto em sistemas onde se tem conhecimento das condições de canal de cada usuário; por outro lado, em (BOHGE et al., 2007) uma análise relacionada à otimização entre camadas ${ }^{16}$ para sistemas OFDMA é apresentada. O modelo matemático para otimização entre camadas é descrito e métodos heurísticos são oferecidos para realizar a alocação dinâmica de recursos; em (WONG; EVANS, 2009) um método para alocação ótima de potência e espectro no enlace de subida de sistemas OFDMA sujeitos a erros/imperfeições na informação da condição do canal foi investigado.

Em termos de otimização entre camadas, no trabalho de (WU; NEGI, 2003) foi proposto um modelo matemático para sistemas sem fio com medidas de qualidade de serviço (do inglês, quality of service, QoS). Os autores denominaram a medida de desempenho capacidade efetiva, caracterizada como a taxa de informação que pode ser transmitida dado um atraso máximo tolerável e uma probabilidade de violação deste atraso. O modelo considera, ainda, filas de tamanho grande que funcionam como buffers, i.e. quando a taxa de transmissão em um quadro é inferior a quantidade de informação a ser transmitida no mesmo, a parte da informação que não é transmitida é colocada na fila para que possa ser enviada

\footnotetext{
${ }^{16}$ Otimização entre camadas de forma geral leva em consideração o projeto de filas de armazenamento de pacotes, alocação de subportadoras, sistemas tolerantes ou não ao atraso, além do controle de potência de transmissão.
} 
no quadro seguinte e nunca ocorre a condição em que a fila está vazia.

$\mathrm{Na}$ busca de redes energeticamente eficientes, o conceito de capacidade efetiva foi utilizado em alguns trabalhos para propor esquemas de alocação de recursos que maximizam a chamada eficiência energética efetiva ${ }^{17}$. O trabalho de (XIONG et al., 2013) apresenta um limite para a eficiência energética considerando uma qualidade de serviço estatística dada por um expoente e um algoritmo para a alocação de subportadoras e potência visando a maximização da eficiência energética. De forma similar, o trabalho de (LOODARICHEH; MALLICK; BHARGAVA, 2014) apresenta uma técnica de maximização da eficiência energética considerando o limite de taxa de transmissão de Shannon e qualidade de serviço na forma de taxa mínima. Os autores propõe a utilização do método de Dinkelbach (DINKELBACH, 1967) associado ao método de decomposição dual de Lagrange para atingir a eficiência energética máxima.

\subsection{Contribuições e Produção Científica}

Esta seção apresenta as principais contribuições desta Tese de doutorado e a produção científica deccorente do trabalho de investigação: artigos publicados em periódicos e anais de congresso, e capítulos de livros.

\subsubsection{Contribuições}

As contribuições desta Tese de doutorado são:

1. Proposta de algoritmo distribuído para maximização da eficiência energética no enlance reverso de sistemas cooperativos MC-DS/CDMA utilizando teoria de jogos e o algoritmo iterativo de water-filling;

\footnotetext{
${ }^{17}$ A eficiência energética efetiva é o conceito de eficiência energética obtido a partir da capacidade efetiva, i.e. eficiência energética efetiva é a razão da capacidade efetiva do sistema pela potência total consumida. A capacidade efetiva, por sua vez, é a taxa de informação que pode ser transmitida dado um atraso máximo tolerável e uma probabilidade de violação deste atraso.
} 
2. Proposta de algoritmo distribuído para maximização da eficiência energética no enlance reverso de sistemas cooperativos MC-DS/CDMA utilizando teoria de jogos e o algoritmo distribuído de controle de potência baseado no equilíbrio de Verhulst;

3. Proposta de algoritmo distribuído para maximização da eficiência energética no enlance reverso de sistemas cooperativos MC-DS/CDMA considerando o sistema como um DS/CDMA convencional e realizando alocação de potência uniforme em todas as subportadoras;

4. Proposta de algoritmo centralizado para maximização da eficiência energética no enlance reverso de sistemas cooperativos MC-DS/CDMA utilizando o algoritmo dos vaga-lumes;

5. Proposta de algoritmo centralizado para maximização da eficiência energética no enlance reverso de sistemas cooperativos MC-DS/CDMA utilizando a otimização por enxame de partículas;

6. Proposta de algoritmo centralizado para a maximização da capacidade efetiva do enlace direto de sistemas OFDMA sem a necessidade de conhecimento da condição instantânea do canal;

7. Proposta de algoritmo centralizado para a maximização da eficiência energética efetiva do enlace direto de sistemas OFDMA sem a necessidade de conhecimento da condição instantânea do canal;

\subsubsection{Produção Científica}

O conteúdo e contribuições dos capítulos 4 e 5 foram publicados e/ou submetidos na forma de artigos científicos em periódicos, conferências e capítulo de livros: 
1 Sampaio, L. D. H.; Souza, A. R. C.; Abrão, T.; Jeszensky, P. J. E.; Game Theoretic Energy Efficiency Design in MC-CDMA Cooperative Networks, IEEE Sensors Journal, vol.14, no.9, pp.3065,3075, Set. 2014.

2 Sampaio, L. D. H.; Souza, A. R. C.; Abrão, T.; Jeszensky, P. J. E.; Energy Efficiency Design in MC-CDMA Cooperative Networks. In: IEEE International Symposium on Personal, Indoor and Mobile Radio Communications, 2013, Londres. 24th IEEE International Symposium on Personal, Indoor and Mobile Radio Communications - PIMRC'13, 2013. v. 1. p. 1-6.

3 Adanyia, M. H.; Carvalho, L. F.; Zarpelão, B. B.; Sampaio, L. D. H.; Abrão, T.; Jeszensky, P. J. E.; Proença Jr, M. L.; Firefly Algorithm in Telecommunications. Capítulo de livro em: Xin-She Yang; Su Fong Chien; Tiew on Ting. (Org.). Bio-Inspired Computation in Telecommunications. $1^{\text {a }}$ ed. Whaltam: Elsevier, 2015, p. 44-70.

4 Abrão, T; Sampaio, L. D. H.; Cheung, K; Shaoshi, Y; Jeszensky, P. J. E; Hanzo, L. "Spectral Efficiency and Effective Capacity in OFDMA Networks Under Statistical QoS Provisioning". p. 1-16. (Em processo de submissão)

5 Abrão, T; Sampaio, L. D. H.; Cheung, K; Shaoshi, Y; Jeszensky, P. J. E; Hanzo, L. "Energy Efficiency in OFDMA Networks Under Statistical QoS Provisioning". p. 1-17. (Em processo de submissão)

Outro trabalhos foram objetos de estudo durante o curso de doutorado e, embora não sejam projetos apresentados neste trabalho, foram desenvolvidos no contexto de alocação de recursos em redes sem fio de múltiplo acesso:

6 Souza, A. R.C.; Abrão, T.; Sampaio, L. D. H.; Jeszensky, P. J. E.; PérezRomero, J.; Casadevall, F.; Energy and spectral efficiencies trade-off with 
filter optimization in multiple access interference-aware networks. Transactions on Emerging Telecommunications Technologies (Online), 2013.

7 Sampaio, L. D. H.; Marques, M. P.; Adanyia, M. H.; Abrão, T.; Jeszensky, P. J. E.; Ant Colony Optimization for Resource Allocation and Anomaly Detection in Communication Networks. In: Taufik Abrão. (Org.). Search Algorithms for Engeneering Optmization. 1 ed. Rijeka: InTech, 2013, v. 1, p. 1-34.

8 Souza, A. R. C.; Abrão, T.; Sampaio, L. D. H.; Jeszensky, P. J. E.; Durand, F. R.; Energy and Spectral Efficiencies Trade-off in Multiple Access Interference-Aware Networks. In: Simpósio Brasileiro de Telecomunicações, 2012, Brasilia. XXX Simpósio Brasileiro de Telecomunicações (SBrT'12), 2012. v. 1. p. $1-5$.

9 Souza, A. R. C.; Sampaio, L. D. H.; Abrão, T.; Jeszensky, P. J. E.; Energy and Spectral Efficiencies Trade-off with Filter Optimization in Multiple Access Interference-Aware Networks. In: Simpósio Brasileiro de Redes de Computadores e Sistemas Distribuídos (SBRC), 2012, Ouro Preto. SBRC 2012 - XXX Simpósio Brasileiro de Redes de Computadores e Sistemas Distribuídos, 2012. v. 1. p. 1-14.

\subsection{Descrição do Conteúdo}

Esta Tese de doutorado contém, além do capítulo introdutório, cinco capítulos cujo conteúdo é sintetizado nos itens a seguir:

- Capítulo 2 - Neste capítulo são descritos os modelos matemáticos para transmissão e recepção dos sistemas MC-DS/CDMA e OFDMA. Para os sistemas MC-DS/CDMA, o modelo matemático de redes cooperativas também é apresentado. Finalmente, o modelo de canal sem linha de visada 
adotado, bem como o modelo de controle de potência e alocação de subportadoras são descritos.

- Capítulo 3 - Neste capítulo são apresentados os métodos determinísticos e heurísticos utilizados na solução de problemas de otimização em sistemas de telecomunicações abordados neste trabalho. A primeira seção trata da otimização convexa e apresenta o método da decomposição dual de Lagrange, bem como os conceitos necessários à sua compreensão. Na segunda seção são expostos conceitos sobre programação fracional não linear e, de forma mais específica, o método de Dinkelbach. Na terceira seção são apresentados os conceitos de teoria de jogos e a definição de equilíbrio de Nash. Finalmente, na última seção são apresentados os métodos heurísticos utilizados: o algoritmo dos vaga-lumes e a otimização por enxame de partículas.

- Capítulo 4 - Neste capítulo são apresentados os problemas de alocação de recursos organizados de acordo com o sistema de telecomunicações, i.e. redes cooperativas MC-DS/CDMA e redes OFDMA. Os métodos apresentados no capítulo 3 são empregados de forma específica aos problemas de otimização descritos. Os algoritmos propostos são apresentados e comentados.

- Capítulo 5 - Neste capítulo são apresentados os cenários e parâmetros de simulação considerados, bem como os resultados numéricos e uma análise sistemática considerando o compromisso desempenho $\times$ complexidade dos algoritmos propostos.

- Capítulo 6 - Por fim, neste capítulo são apresentadas as principais conclusões e hipóteses de trabalho para a continuidade dos estudos. 


\section{MODELOS DO SISTEMA}

Este capítulo encontra-se dividido em duas seções nas quais serão caracterizados os sistemas de comunicação sem fio abordados neste trabalho: na primeira seção serão apresentados os sistemas de múltiplo acesso com espalhamento espectral. Já na segunda seção, o sistema de múltiplo acesso por divisão ortogonal em frequência, OFDMA, será descrito.

\subsection{Sistemas de Múltiplo Acesso com Espalha- mento Espectral}

Sistemas de comunicação que utilizam múltiplo acesso por espalhamento espectral existem há mais de 70 anos em aplicações militares por duas razões principais: por serem capazes de superar situações de alta interferência intencional, conhecido como jamming, e por conseguirem manter certo sigilo de mensagens de eventuais tentativas de interceptação e quebra da confidencialidade, conhecido como eavesdropping. Estes objetivos são assegurados através do espalhamento do sinal de tal forma a torná-lo indistinguível do ruído de fundo (VITERBI, 1995).

Redes de comunicação comerciais que utilizam a técnica de múltiplo acesso por espalhamento espectral são conhecidas como múltiplo acesso por divisão de código (do inglês, code division multiple access, CDMA). A primeira publicação relacionada à tecnologia CDMA data de 1935, um artigo publicado pelo Professor Dmitriy V. Ageev (AGEEV, 1935 apud ALI, 2014), no qual foi demons- 
trado através de métodos lineares a existência de três tipos de separação do sinal: frequência, tempo e através de um sinal compensatório (assinatura).

Em 1957 o engenheiro e militar da então União das Repúblicas Socialistas Soviéticas (URSS), Leonid Kupriyanovich, criou o primeiro telefone móvel com tecnologia CDMA o qual denominou LK-1. Kupriyanovich foi capaz de comunicar-se com uma estação rádio-base utilizando o LK-1 que tinha massa equivalente a 3 quilogramas, entre 20 e 30 horas de autonomia de bateria e alcance de 20 a 30 quilometros (KUPRIYANOVICH, 1957).

Quase trinta anos após os primeiros experimentos de Kupriyanovich, em 7 de novembro de 1989, a primeira demonstração comercial de um sistema de comunicação utilizando tecnologia de espalhamento espectral foi realizada nas dependências da Qualcomm (QUALCOMM, 2015).

Nos sistemas de telecomunicações modernos, o espalhamento espectral pode ser feito de quatro formas distintas ${ }^{1}$ : por salto de frequência (frequency hopping CDMA, FH/CDMA) (ZENNECK, 1908), por salto em tempo (time hopping CDMA, TH/CDMA) (MOLISCH; ZHANG; MIYAKE, 2003), por chirps (chirp spread spectrum, CSS) (IEEE COMPUTER SOCIETY, 2007) e por sequência direta (direct sequence CDMA, DS/CDMA) (VITERBI, 1995).

No primeiro caso, espalhamento por salto em frequência, o sinal é transmitidos com rápidas trocas de canal (sub-canal ou bandas espectrais) de transmissão. No segundo caso, os saltos no tempo indicam que o sinal é transmitido em intervalos de tempo distintos. Em ambos os casos, uma sequência pseudoaleatória conhecida pelo transmissor e o receptor é responsável por determinar quais saltos serão feitos ou quais intervalos de tempo devem ser ocupados pelo dono da sequência. No espalhamento espectral por chirps, terceiro caso, um onda senoidal cuja frequência varia no tempo é utilizada para espalhar o sinal.

\footnotetext{
${ }^{1}$ Excetuando-se possíveis combinações
} 
Uma vez que o foco deste trabalho são redes com espalhamento espectral por sequência direta, esta técnica será apresentada com maior profundidade. Sendo assim, sistemas de comunicação que utilizam a técnica DS/CDMA não buscam alocar frequências diferentes ou intervalos no tempo distintos para cada usuário do sistema; pelo contrário, esta abordagem aloca todos os recursos de frequência para todos os usuários, simultaneamente, ao passo que controla a potência de transmissão para que um nível mínimo de desempenho seja garantido (VITERBI, 1995).

Para tornar este feito possível cada terminal móvel emprega um sinal pseudoaleatório de banda maior que o sinal original a ser transmitido, espalhando o sinal original de tal forma que o sinal resultante seja semelhante a um ruído branco de fundo. Uma interpretação em termos de densidade espectral de potência para o processo de espalhamento espectral é apresetando na figura 3.

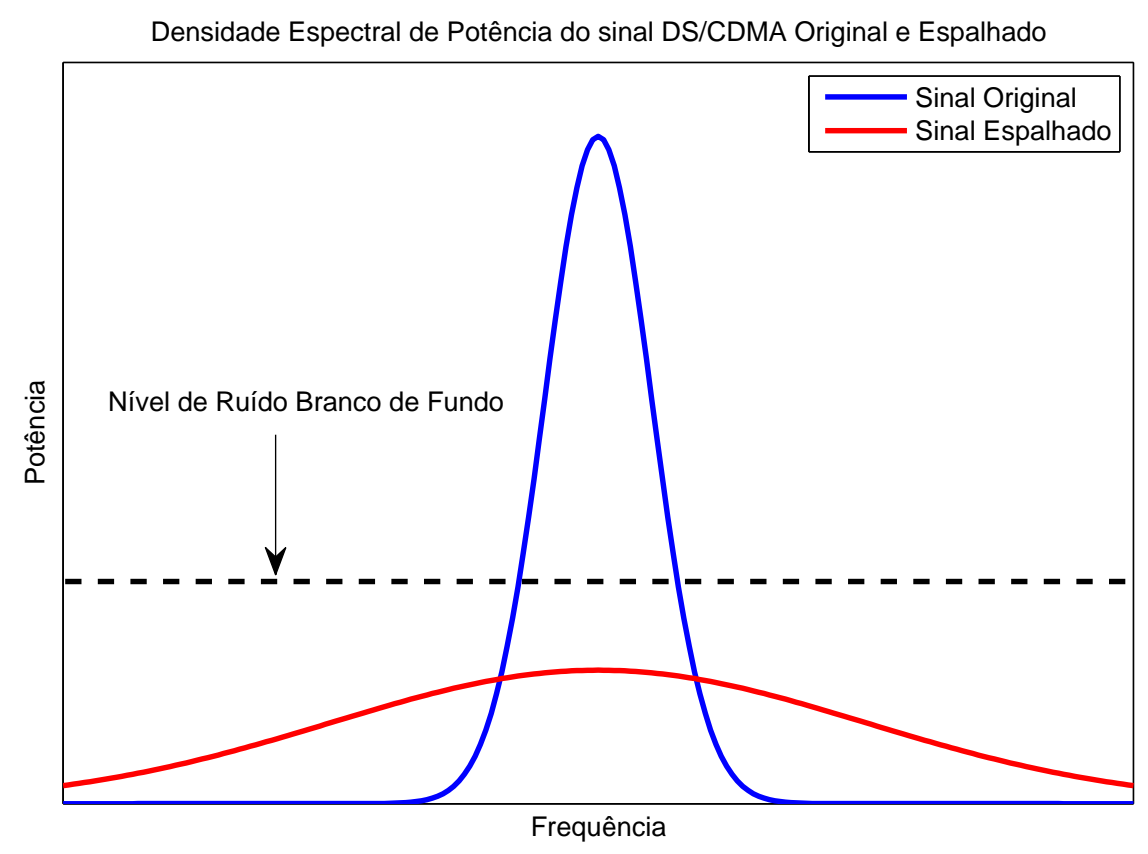

Figura 3: Ilustração em termos de densidade espectral de potência de um sinal do tipo DS/CDMA antes e após o espalhamento espectral.

O sinal pseudoaleatório utilizado para espalhar o sinal original na figura 3 é denominado sequência de espalhamento; trata-se de um vetor de valores pseudo- 
aleatórios 1 e -1 denominados chips. A sequência de espalhamento é matematicamante definida como (VITERBI, 1995):

$$
\mathbf{s}_{i} \triangleq \frac{1}{\sqrt{F_{i}}}\left[c_{i}(1), c_{i}(2), \ldots, c_{i}\left(F_{i}\right)\right]^{T}, \quad c_{i}(j) \in\{ \pm 1\}, j=1, \ldots, F_{i}
$$

onde $\mathbf{s}_{i}$ é a sequência de espalhamento do usuário $i, c_{i}(j)$ são os chips da sequência do $i$-ésimo usuário e $F_{i}$ é o tamanho da sequência para o usuário $i$.

Para facilitar a análise e apresentação dos modelos matemáticos as três subseções a seguir apresentam os modelo de sistema de redes DS/CDMA, MCDS/CDMA e MC-DS/CDMA cooperativo.

\subsubsection{Sistemas DS/CDMA}

Em sistemas DS/CDMA, uma característica importante do sistema é o ganho de processamento: uma vez que nestes sistemas um sinal de banda estreita é espalhado espectralmente em um sinal de banda maior, o ganho de processamento pode ser determinado pela razão entre estas diferentes bandas. Formalmente, o ganho de processamento é a razão entre a taxa de chip do sistema e a taxa de símbolo. A primeira é o número de chips (definidos a seguir) por segundo que são utilizados para espalhar o sinal original. A segunda taxa é o número de símbolos de informação por segundo que são transmitidos. Neste trabalho, por simplicidade, considerar-se-á que o ganho de processamento é o tamanho da sequência de espalhamento do sinal, i.e. a razão do período de símbolo pelo período de chip é o tamanho da sequência de espalhamento.

Antes de apresentar os sistemas de múltiplo acesso por divisão de código por sequência direta, apresentar-se-á o sistema de espalhamento espectral por sequência direta para o caso uni-usuário. Neste sistema mais simples, a sequência 
de espalhamento de tamanho $F$ é definida como $\mathbf{s}(t)=\left[c_{1}(t), \ldots, c_{F}(t)\right]^{T}$.

Os símbolos $d_{j}$ a serem transmitidos, $j=1, \ldots, \mathcal{K}$ são inicialmente modulados de tal forma que o seguinte sinal em banda base é gerado:

$$
x(t)=\sum_{j=1}^{\mathcal{K}} b_{j} \psi\left(t-j T_{s}\right)
$$

onde $\psi(\cdot)$ é a formatação de pulso do modulador, $T_{s}$ é o período de símbolo e $b_{j}$ é o símbolo modulado transmitido no $j$-ésimo período de símbolo. Em seguida, este sinal é amplificado e posteriormente multiplicado pela sequência de espalhamento $\mathbf{s}(t)$ com período de chip $T_{c}$. Finalmente, o sinal é convertido para banda passante através da portadora $f_{c}$. Logo, na saída do transmissor o sinal em banda passante é equivalente a:

$$
\mathbf{y}(t)=\sqrt{2 p} x(t) \mathbf{s}(t) \cos \left(2 \pi f_{c} t\right)
$$

onde $p=A^{2} / 2, p$ é a potência de transmissão normalizada e $A$ é a amplitude do sinal na saída do amplificador de rádio-frequência.

O sinal amplificado e espalhado passa por um canal cuja resposta impulsiva é $\mathrm{h}(t)$ o qual também introduz ruído branco Gaussiano de fundo $\boldsymbol{\eta}(t)=$ $\left[\eta_{1}(t), \eta_{2}(t), \ldots, \eta_{F}\right]^{T}$. Desta forma o sinal recebido no receptor é equivalente a:

$$
\tilde{\mathbf{y}}(t)=\sqrt{2 p} x(t) \mathbf{s}(t) \cos \left(2 \pi f_{c} t\right) * \mathrm{~h}(t)+\boldsymbol{\eta}(t)
$$

onde $*$ é o operador de convolução, i.e.

$$
x(t) \mathbf{s}(t) \cos \left(2 \pi f_{c} t\right) * \mathrm{~h}(t)=\int_{-\infty}^{\infty} x(t) \mathbf{s}(t) \cos \left(2 \pi f_{c} t\right) \mathrm{h}(t-\tau) d \tau
$$


Supondo que o canal $\mathrm{h}$ introduz componentes multi-percurso, i.e. $\mathrm{h}(t)=$ $\sum_{l} \alpha_{l} \delta\left(t-\tau_{l}\right)$, onde $\delta$ é a função Delta de Dirac, $\alpha_{l}$ é a componente de amplitude do $l$-ésimo percurso e $\tau_{l}$ o seu atraso. O sincronizador utiliza o sinal recebido em banda base para alinhar o atraso das sequências de espalhamento do receptor com os atrasos dos múltiplos percursos. Em um cenário ideal o sincronizador utilizaria o percurso cuja componente tem a maior amplitude $\alpha_{l}$, todavia, como isto envolve um procedimento de busca complexo, o sincronizador usualmente utiliza a primeira componente encontrada que satisfaz uma amplitude mínima (GOLDSMITH, 2005).

No passo seguinte, com o atraso $\tau$ já estabelecido pelo sincronizador, o sinal em banda base é concentrado multiplicando-o pelo Hermitiano ${ }^{2}$ da sequência de espalhamento com atraso $\tau$ denominada $\mathbf{s}(t-\tau)^{H}$. Logo o sinal concentrado é dado por:

$\tilde{x}(t)=\mathbf{s}(t-\tau)^{H} \cos \left(2 \pi f_{c} t\right)\left[\sqrt{2 p} x(t) \mathbf{s}(t) \cos \left(2 \pi f_{c} t\right) * \mathrm{~h}(t)\right]+\mathbf{s}(t-\tau)^{H} \boldsymbol{\eta}(t) \cos \left(2 \pi f_{c} t\right)$

Esse sinal passa então por um demodulador $\psi^{*}(-t)$ e posteriormente por um decisor para detectar qual o símbolo enviado. O sistema de transmissão e recepção do espalhamento espectral por sequência direta é ilustrado na figura 4.

Para ilustrar o funcionamento de um receptor para sistemas com espalhamento espectral por sequência direta apresenta-se o exemplo abaixo (GOLDSMITH, 2005).

Exemplo 1 (Recepção por Filtros Casados). Por simplicidade, assuma que pulsos retangulares são utilizados na modulação, i.e. $\psi(t)=\sqrt{2 / T_{s}}, 0 \leq t \leq T_{s}$. $O$ filtro casado $\psi^{*}(-t)$ simplesmente multiplica o sinal recebido e concentrado em

\footnotetext{
${ }^{2}$ Transposto conjugado
} 


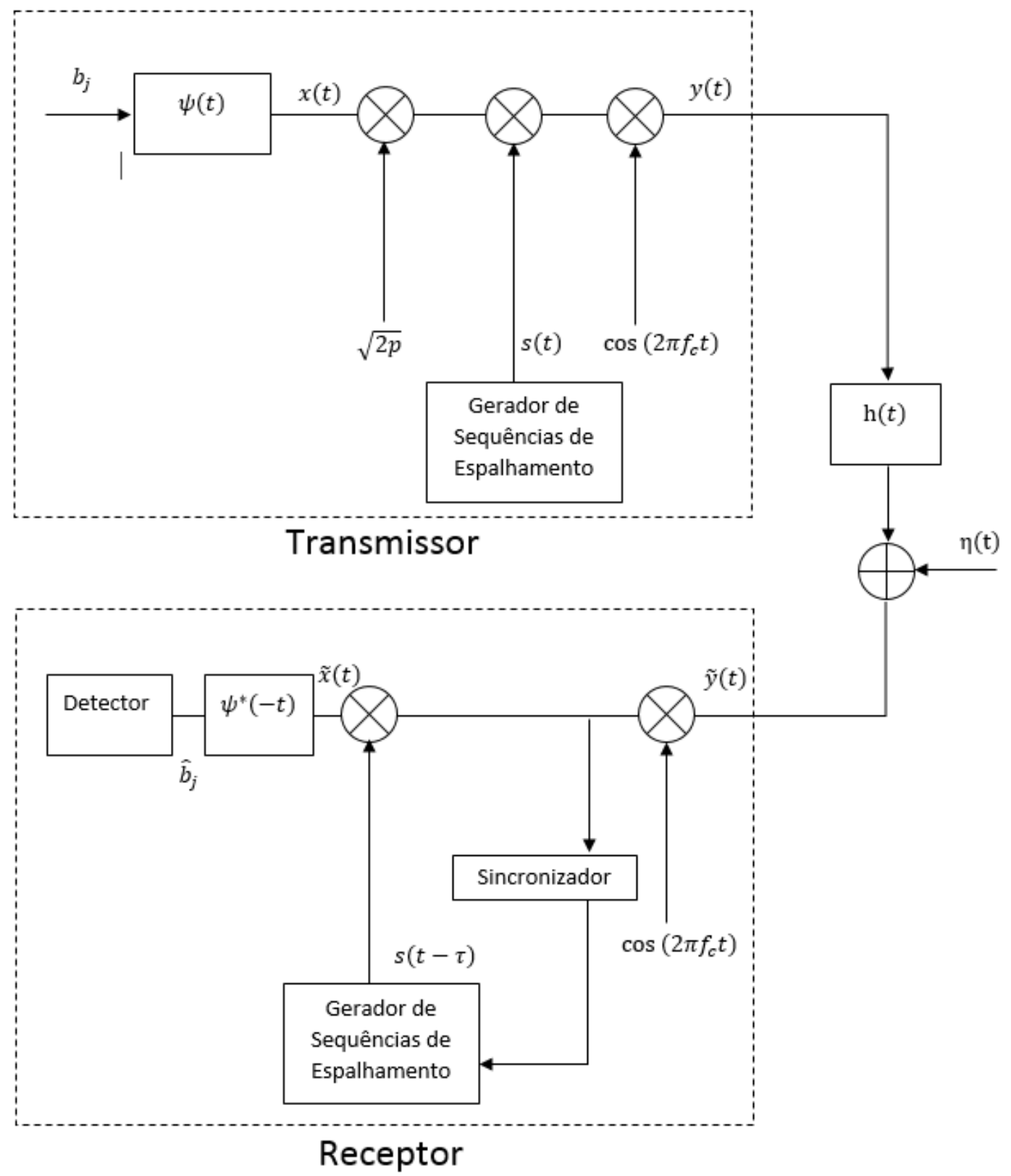

Figura 4: Desenho esquemático do espalhamento espectral por sequência direta. Fonte: adaptado de (GOLDSMITH, 2005) 
banda base $\tilde{x}(t)$ por $\sqrt{2 / T_{s}}$ e integra de 0 a $T_{\text {s }}$ para obter o simbolo estimado. Se um sistema sem múltiplos percursos for considerado então $h(t)=\delta(t)$, e o receptor irá sincronizar em $\tau=0$. Portanto o espalhamento/desespalhamento não tem impacto no sinal em banda base $\tilde{x}$ uma vez que $\mathbf{s}(t)^{H} \mathbf{s}(t)=1, \forall t$. Com essas características $\tilde{x}$ pode ser simplificado de acordo com:

$$
\tilde{x}_{M F}=x(t) \cos ^{2}\left(2 \pi f_{c} t\right)+\mathbf{s}(t)^{H} \boldsymbol{\eta}(t) \cos \left(2 \pi f_{c} t\right)
$$

Desta forma, assumindo que $\mathbf{s}(t)$ é uma sequência suficientemente grande então $\mathbf{s}(t)^{H} \boldsymbol{\eta}(t)$ tem as mesmas propriedades estatísticas que $\boldsymbol{\eta}(t)$, ou seja, é um processo aleatório Gaussiano de média zero e densidade espectral de potência $N_{0} / 2$. Logo, a saída do filtro casado resulta no seguinte símbolo estimado, assumindo $f_{c}>>1 / T_{s}$

$$
\begin{aligned}
\tilde{r}_{i} & =\int_{0}^{T_{s}} \tilde{x}_{M F} * \psi^{*}(-t) d t \\
& =\frac{2}{T_{s}} \int_{0}^{T_{s}} x(t) \cos ^{2}\left(2 \pi f_{c} t\right) d t+\sqrt{\frac{2}{T_{s}}} \mathbf{s}(t)^{H} \boldsymbol{\eta}(t) \cos \left(2 \pi f_{c} t\right) \\
& =\frac{2}{T_{s}} \int_{0}^{T_{s}} x(t) \cos ^{2}\left(2 \pi f_{c} t\right) d t+\sqrt{\frac{2}{T_{s}}} \int_{0}^{T_{s}} \mathbf{s}(t)^{H} \boldsymbol{\eta}(t) \cos \left(2 \pi f_{c} t\right) \\
& \approx d_{j}+\eta_{j}
\end{aligned}
$$

onde $d_{j}$ e $\eta_{j}$ correspondem aos bits e ao ruído da saída de um demodulador convencional sem espalhamento espectral no j-ésimo perído de símbolo.

Para o caso multiusuário, é importante diferenciar o elo de descida (direto) e o elo de subida (reverso). No primeiro, a comunicação é feita de tal forma que há um transmissor e vários receptores. No segundo acontece o oposto, a comunicação é feita a partir de vários transmissores para um receptor comum. Existem diferenças substanciais entre as duas situações: por exemplo, no elo de descida a transmissão tem maior sincronismo uma vez que todos os sinais partem de um 
transmissor comum. Por outro lado, tanto o sinal de interesse quanto a interferência de múltiplo acesso percorrem o mesmo percurso até atingir o terminal móvel de interesse. Já no elo reverso, os usuários transmitem de forma tipicamente assíncrona para um receptor comum, a estação rádio base. Adcionalmente, o sinal de interesse percorre um percurso distinto dos sinais interferentes. A figura 5 ilustra o funcionamento dos elos direto e reverso.
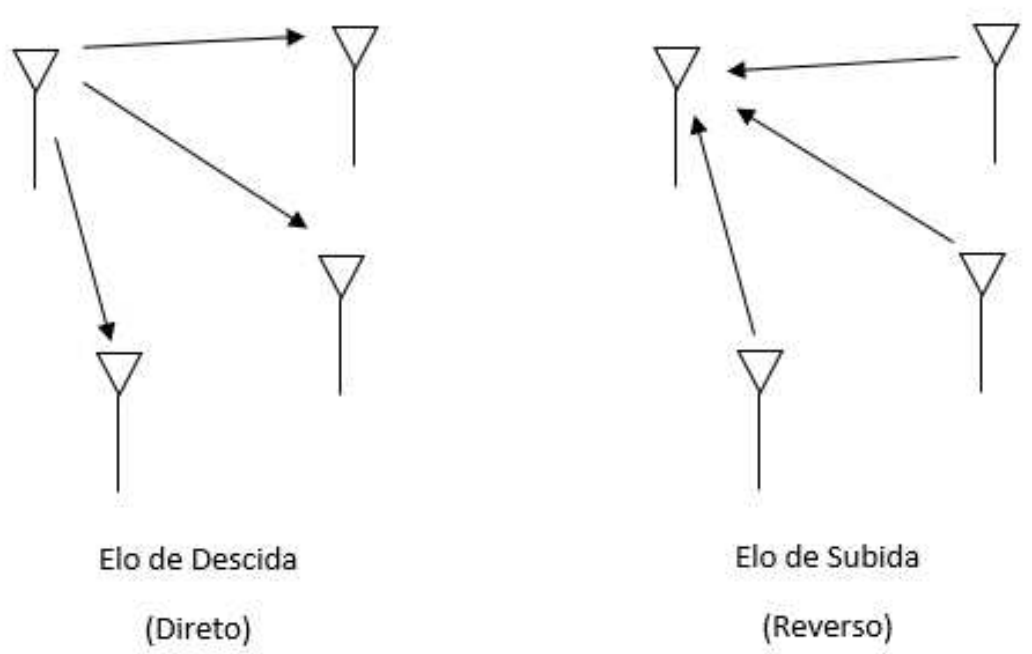

Figura 5: Elo de subida e elo de descida em sistemas de comunicação sem fio.

O foco deste trabalho está no elo de subida de redes sem fio, portanto apenas este cenário será abordado para o caso multiusuário.

Considere um sistema DS/CDMA com $U$ usuários, cuja sequência de espalhamento do $i$-ésimo usuário é $\mathbf{s}_{i}(t)=\left[c_{i}(1), c_{i}(2), \ldots, c_{i}\left(F_{i}\right)\right]$. O sinal modulado em banda base $x_{i}(t)$ (assumindo pulsos retangulares) é amplificado pela potência de transmissão $\sqrt{2 p_{i}}$, multiplicado pelo código de espalhamento $\mathbf{s}_{i}(t)$ e convertido para banda passante na portadora $f_{c}$. O sinal na saída do $i$-ésimo transmissor, $\mathbf{y}_{i}(t)$ é dado por:

$$
\mathbf{y}_{i}(t)=\sqrt{2 p_{i}} x_{i}(t) \mathbf{s}_{i}(t) \cos \left(2 \pi f_{c} t+\varphi_{i}\right)
$$

Note que o sinal da portadora para cada usuário tem fases diferentes $\varphi_{i}$. Este 
sinal então é enviado através do canal do $i$-ésimo usuário para a estação receptora que tem resposta impulsiva $\mathrm{h}_{i}(t)$. Uma vez que os $U$ usuários transmitem na mesma portadora $f_{c}$ os sinais são somados e influenciados pelo ruído Gaussiano branco de fundo $\boldsymbol{\eta}(t)$. Portanto, o sinal recebido na estação rádio-base é descrito como:

$$
\tilde{\mathbf{y}}(t)=\left[\sum_{i=1}^{U}\left(\sqrt{2 p_{i}} x_{i}(t) \mathbf{s}_{i}(t) \cos \left(2 \pi f_{c} t+\varphi_{i}\right)\right) * \mathrm{~h}_{i}(t)\right]+\boldsymbol{\eta}(t)
$$

O sinal $\tilde{\mathbf{y}}(t)$ na entrada do receptor é direcionado paralelamente para $U$ blocos de recepção correspondente aos $U$ usuários do sistema. Assume-se que o canal $\mathrm{h}_{i}(t)$ introduz um atraso $\tau_{i}$ e que este atraso causa uma mudança de fase na portadora $\varphi_{i}^{\prime}$. Quando o usuário está sincronizado têm-se que $\tau_{i}=0$.

Sendo assim, cada bloco de recepção retorna o sinal para banda base levando em conta o deslocamento de fase $\varphi_{i}^{\prime}$, em seguida, desespalha o sinal utilizando a sequência de espalhamento sincronizada com o atraso $\tau_{i}$ do usuário. Finalmente o sinal passa por um filtro casado e é amostrado de tal forma a obter uma estimativa do símbolo transmitido. A figura 6 apresenta o diagrama de funcionamento de um sistema DS/CDMA multiusuário.

Note na figura 6 que a informação de cada transmissor passa por $U$ canais distintos o que contribui para a ocorrência do efeito perto-longe (do inglês, nearfar). Para simplificar a análise, considere que todos os usuários transmitam com potência equivalente. Neste caso, os usuários mais próximos do receptor do elo de subida podem causar altos níveis de interferência no sinal dos usuários que se encontram distantes. Adicionalmente, é possível associar cada bloco no receptor ao método de recepção do sistema uni-usuário. Desta forma, a recepção pode ser feita através de um banco de filtros casados. A saída do demodulador $\psi_{i}^{*}(-t)$ para o $i$-ésimo bloco e l-ésimo período de símbolo, considerando pulsos retângulares 


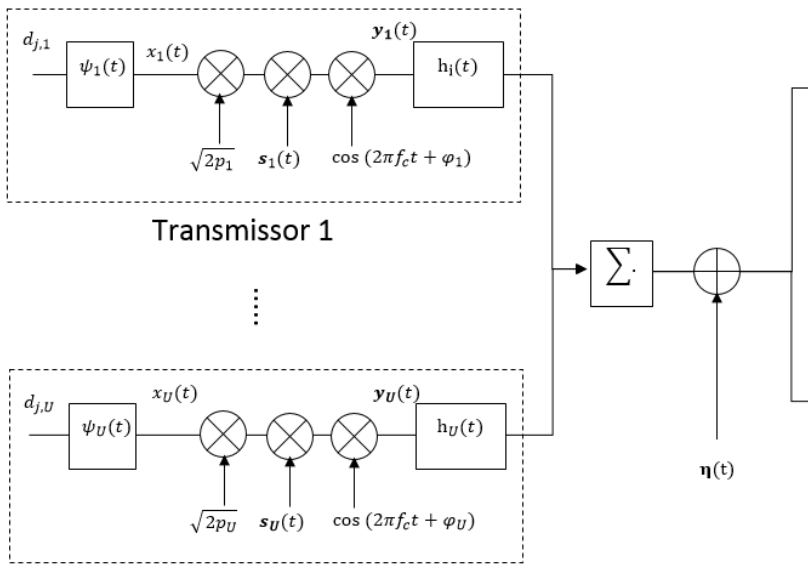

Transmissor $U$

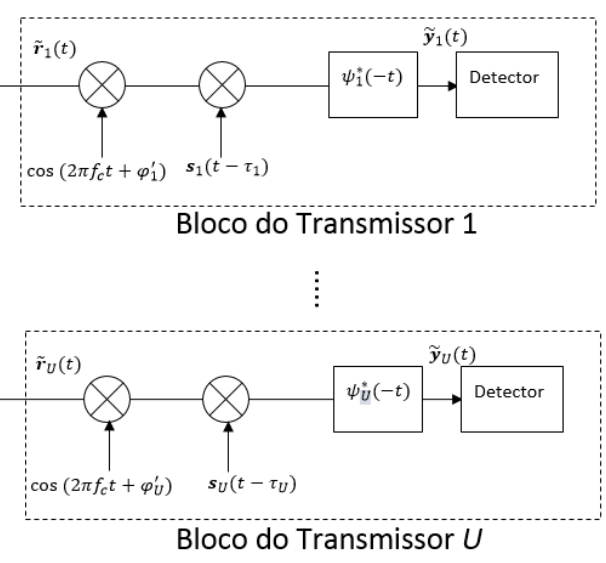

Receptor

Figura 6: Desenho esquemático para o sistema de múltiplo acesso por divisão em código de sequência direta.

no modulador $\psi(t)$, é dada por:

$$
\begin{aligned}
& \tilde{r}_{i}= \sqrt{\frac{2}{T_{s}}} \int_{0}^{T_{s}} \mathbf{s}_{i}\left(t-\tau_{i}\right)^{H}\left[\sum_{j=1}^{U} \sqrt{2 p_{j}} x_{j}(t) \mathbf{s}_{j}(t) * \mathrm{~h}_{j}^{L P}(t)\right] \\
&= \frac{2}{T_{s}} \int_{0}^{T_{s}} \mathbf{s}_{i}\left(t-\tau_{i}\right)^{H}\left[\sqrt{2 p_{i}} b_{i, i, l} \mathbf{s}_{i}(t) * \mathrm{~h}_{i}^{L P}(t)\right] \cos ^{2}\left(2 \pi f_{c} t+\varphi_{i}^{\prime}\right) d t+ \\
& \frac{2}{T_{s}} \int_{0}^{T_{s}}\left[\sum_{\substack{j=1 \\
j \neq i}}^{U} \sqrt{2 p_{j}} b_{i, j, l} \mathbf{s}_{j}(t) * \mathrm{~h}_{j}^{L P}(t)\right] \mathbf{s}_{i}\left(t-\tau_{i}\right)^{H} \\
& \cos \left(2 \pi f_{c} t+\varphi_{i}^{\prime}\right) \cos \left(2 \pi f_{c} t+\varphi_{j}^{\prime}\right) d t+
\end{aligned}
$$

onde $\mathrm{h}_{i}^{L P}(t)$ é o equivalente em banda base do filtro passa-baixa para $\mathrm{h}_{i}(t)$ e $b_{i, j, l}$ é o símbolo do $j$-ésimo usuário transmitido no $j$-ésimo canal no intervalo de tempo $\left[l T_{s}-\tau_{j}+\tau_{i},(l+1) T_{s}-\tau_{j}+\tau_{i}\right]$. Assume-se que o símbolo é constante no intervalo mencionado e, portanto, não há interferência intersimbólica.

Note que em (2.11) o símbolo estimado é resultado da soma de três expres- 
sões: a primeira é o símbolo de interesse, a segunda é a interferência de múltiplo acesso, finalmente, a última, é o ruído Gaussiano branco de fundo. Sendo assim, assumindo que o canal introduz um ganho $\alpha_{j}$ e um atraso $\tau_{j}$ de tal forma que $\mathrm{h}_{j}^{L P}=\alpha_{j} \delta\left(t-\tau_{j}\right)$. Então a saída do demodulador para o $i$-ésimo bloco no receptor no $l$-ésimo período de símbolo torna-se:

$$
\tilde{r}_{i}=\alpha_{i} b_{i, l}+\mathfrak{I}_{i, l}+\eta_{l}
$$

Sendo a interferência $\mathfrak{I}_{i, l}$ :

$$
\begin{aligned}
\mathfrak{I}_{i, l} & =\frac{2}{T_{s}} \int_{0}^{T_{s}} \mathbf{s}_{i}\left(t-\tau_{i}\right)^{H}\left[\sum_{\substack{j=1 \\
j \neq i}}^{U} \sqrt{2 p_{j}} b_{i, j, l} \mathbf{s}_{j}(t) * \alpha_{j} \delta\left(t-\tau_{j}\right)\right] \\
& =\frac{2}{T_{s}} \int_{0}^{T_{s}} \mathbf{s}_{i}\left(t-\tau_{i}\right)^{H}\left[\sum_{\substack{j=1 \\
j \neq i}}^{U} \alpha_{j} \sqrt{2 p_{j}} b_{i, j, l} \mathbf{s}_{j}\left(t-\tau_{j}\right)\right] \\
& \approx \sum_{\substack{j=1 \\
j \neq i}}^{U} \alpha_{j} \sqrt{2 p_{j}} \cos \left(2 \pi f_{c} t+\varphi_{i}^{\prime}\right) \cos \left(2 \pi f_{c} t+\varphi_{j}^{\prime}\right) d t \\
& =\sum_{\substack{j=1 \\
j \neq i}}^{U} \alpha_{j} \sqrt{2 p_{j}} \cos \left(\Delta \varphi_{i, j}\right) b_{i, j, l} \\
b_{i, j, l} & \underbrace{\frac{1}{T_{s}} \mathbf{s}_{j}\left(t-\tau_{j}\right)^{H} \mathbf{s}_{i}\left(t-\tau_{i}\right) d t}_{\rho_{i, j}\left(\tau_{j}-\tau_{i}\right)}
\end{aligned}
$$

onde $\Delta \varphi_{i, j}=\varphi_{i}^{\prime}-\varphi_{j}^{\prime}$ e $\rho_{i, j}\left(\tau_{j}-\tau_{i}\right)$ é a correlação cruzada das sequências de espalhamento $i$ e $j$ com atrasos $\tau_{i}$ e $\tau_{j}$, respectivamente. A aproximação acima é baseada no fato da taxa de chip ser muito menor que a frequência da portadora, i.e. $f_{c}>>1 / T_{c}($ GOLDSMITH, 2005).

O problema do efeito perto-longe, previamente citado, surge das diferenças 
entre os $\alpha_{j}$. Quando $\alpha_{j}>\alpha_{i}$ a interferência no sinal de $i$ causada pelo usuário $j$ pode impedir a detecção do símbolo. Desta forma, o controle de potência de transmissão, i.e. dos valores de $p_{i}$, é fundamental para o bom funcionamento dos sistemas DS/CDMA (VITERBI, 1995).

É importante salientar que os sinais interferentes não necessariamente devem ser tratados como ruído de fundo para possibilitar a detecção. De fato, se as sequências de espalhamento forem conhecidas por todos os usuários então esta informação pode ser utilizada para mitigar os efeitos da interferência de múltiplo acesso. Um receptor DS/CDMA com estas características é denominado detector multiusuário (GOLDSMITH, 2005)

O conceito de detecção multiusuário foi proposto inicialmente por (VERDú, 1983) no qual o detector ótimo para o elo reverso de sistemas de espalhamento espectral assíncronos foi apresentado. Em sua proposta Verdú assume um canal com ruído aditivo Gaussiano de fundo e diferentes ganhos de canal para cada usuário. Desta forma, o detector ótimo escolhe os símbolos associados aos $U$ usuários que minimiza o erro quadrático médio entre o sinal recebido e o sinal que seria gerado pelos símbolos escolhidos.

Para tornar a análise mais simples considere um canal reverso síncrono com $U$ usuários, ganhos de canal $\alpha_{i}, i=1, \ldots, U$, sequências de espalhamento $\mathbf{s}_{i}$ de tamanho $F_{i}$, e assuma que o sistema é sincronizado. Considerando pulsos retangulares, o sinal complexo $\tilde{\mathbf{r}}$ recebido pela estação rádio-base em um período de símbolo em banda base é:

$$
\tilde{\mathbf{r}}=\boldsymbol{\eta}+\sum_{i=1}^{U} \alpha_{i} b_{i} \mathbf{s}_{i}
$$

onde $b_{i}$ são os símbolos dos $U$ usuários. A equação acima pode ser escrita na forma matricial: considere a matriz $F_{i} \times U$ definida como (LIU; YIN, 2001): 


$$
\mathbf{C}=\left[\begin{array}{cccc}
\alpha_{1} c_{1}(1) & \alpha_{2} c_{2}(1) & \ldots & \alpha_{U} c_{U}(1) \\
\alpha_{1} c_{1}(2) & \alpha_{2} c_{2}(2) & \ldots & \alpha_{U} c_{U}(2) \\
\vdots & \vdots & \ddots & \vdots \\
\alpha_{1} c_{1}\left(F_{1}\right) & \alpha_{2} c_{2}\left(F_{2}\right) & \ldots & \alpha_{U} c_{U}\left(F_{U}\right)
\end{array}\right]
$$

onde $c_{i}(j)$ é o $j$-ésimo chip da sequência de espalhamento do usuário $i$. Seja $\mathbf{b}=\left[b_{1}, b_{2}, \ldots, b_{U}\right]^{T}$, então a equação (2.14) na forma matricial é (LIU; YIN, 2001):

$$
\tilde{\mathbf{r}}=\mathbf{C b}+\boldsymbol{\eta}
$$

É possível, ainda, escrever a equação (2.14) em termos das correlações cruzadas das sequências de espalhamento. Considere sequências de espalhamento de tamanho equivalente para todos os usuários, i.e. $F_{1}=F_{2}=\ldots=F_{U}=F$. A matriz de sequências de espalhamento $F \times U$ é definida como:

$$
\mathbf{S}=\left[\begin{array}{cccc}
c_{1}(1) & c_{2}(1) & \ldots & c_{U}(1) \\
c_{1}(2) & c_{2}(2) & \ldots & c_{U}(2) \\
\vdots & \vdots & \ddots & \vdots \\
c_{1}(F) & c_{2}(F) & \ldots & c_{U}(F)
\end{array}\right]
$$

e portanto a matriz de correlação cruzada das sequências de espalhamento $U \times U$ é definida como:

$$
\mathbf{R}=\mathbf{S}^{T} \mathbf{S}
$$

Desta forma o sinal equivalente em banda base após a etapa de desespalha- 
mento espectral pode ser definido, também, como (GOLDSMITH, 2005):

$$
\tilde{\mathbf{y}}=\mathbf{R Q b}+\boldsymbol{\eta}
$$

onde $\mathbf{Q}$ é uma matriz $U \times U$ diagonal cujos elementos são os ganhos de amplitude dos canais $\alpha_{i}, i=1, \ldots, U$.

O detector ótimo, denominado detector de máxima verossimilhança, tem como entrada o sinal $\tilde{\mathbf{y}}$ e como saída o vetor de símbolos detectados $\left[b_{1}^{*}, \ldots, b_{U}^{*}\right]$ de tal forma que o erro quadrático é minimizado, isto é:

$$
\underset{\mathbf{b}}{\arg \min } \int_{0}^{T_{s}}\left(\tilde{\mathbf{y}}(t)-\sum_{i=1}^{U} \alpha_{i} b_{i} \mathbf{s}_{i}(t)\right)^{2} d t
$$

o que é equivalente, no caso de usuários síncronos, a encontrar o vetor b que maximiza a função custo (GOLDSMITH, 2005):

$$
\begin{aligned}
J^{M L}(\mathbf{b}) & =2 \int_{0}^{T_{s}}\left[\sum_{i=1}^{U} \alpha_{i} b_{i} \mathbf{s}_{i}(t)\right] \tilde{\mathbf{y}} d t-\int_{0}^{T_{s}}\left[\sum_{i=1}^{U} \alpha_{i} b_{i} \mathbf{s}_{i}(t)\right]^{2} d t \\
& =2 \mathbf{b}^{T} \mathbf{Q} \tilde{\mathbf{y}}-\mathbf{b}^{T} \mathbf{Q R Q b}
\end{aligned}
$$

O detector de máxima verossimilhança, embora ótimo, apresenta características que tornam difícil sua implementação em sistemas de comunicação: primeiramente, a sua complexidade cresce exponencialmente de acordo com o número de usuários. Uma busca em árvore binária para maximizar a função custo (2.21), apresenta complexidade $M^{U}$, onde $M$ é a ordem de modulação. Adicionalmente, o detector ótimo requer o conhecimento de todas as amplitudes de canal $\alpha_{i}$ (GOLDSMITH, 2005).

Sabe-se que a complexidade dos detectores pode ser reduzida às custas da perda da otimalidade. Desta forma, muitos detectores multiusuário subótimos foram desenvolvidos com diferentes níveis de desempenho, complexidade e de re- 
quisitos quanto a informações do estado do canal. De maneira geral, os detectores subótimos podem ser divididos em lineares e não lineares.

Os detectores subótimos lineares aplicam uma transformação linear à saída do banco de filtros casados para recuperar a informação enviada. Os detectores mais comuns dessa classe são o detector descorrelacionador e o detector por mínimo erro quadrático médio (do inglês, minimum mean squared error, MMSE) (LUPAS; VERDú, 1989).

O descorrelacionador multiplica a matriz inversa das correlações cruzadas $\mathbf{R}^{-1}$ pelo sinal recebido em banda base, i.e.

$$
\hat{\mathbf{b}}=\mathbf{R}^{-1} \tilde{\mathbf{y}}=\mathbf{R}^{-1}[\mathbf{R Q b}+\boldsymbol{\eta}]=\mathbf{Q b}+\mathbf{R}^{-1} \boldsymbol{\eta}
$$

Na maioria dos casos a matriz $\mathbf{R}$ é não singular e, portanto, existe uma inversa. Note que, na ausência de ruído, i.e. $\boldsymbol{\eta}=\mathbf{0}$, a saída do descorrelacionador é a informação enviada pelos usuários ponderada pelos ganhos de canais. Em outras palavras, neste cenário o descorrelacionador remove completamente a interferência de múltiplo acesso além de não requerer o conhecimento do estado do canal. O lado negativo deste detector está no fato do mesmo amplificar o ruído de fundo uma vez que $\boldsymbol{\eta}$ é multiplicado pela matriz inversa da matriz de correlações cruzadas (GOLDSMITH, 2005).

Desta forma, é possivel definir o filtro linear descorrelacionador utilizado para detectar o sinal de cada usuário $i$ como (SOUZA et al., 2013):

$$
\mathbf{D}_{\mathrm{DESC}}=\left[\mathbf{d}_{1}, \mathbf{d}_{2}, \ldots, \mathbf{d}_{U}\right]=\mathbf{S}\left(\mathbf{S}^{T} \mathbf{S}\right)^{-1}=\mathbf{S R}^{-1}
$$

sendo $\mathbf{d}_{i}$ um vetor $F \times 1$ o filtro linear utilizado para desespalhar e descorrelacionar o sinal do $i$-ésimo usuário de interesse dos demais usuários interferentes. 
Outro filtro linear de grande importância na literatura é o detector de mínimo erro quadrático médio. O MMSE aplica uma matriz $\mathbf{W}$ tal que a multiplicação da saída do banco de filtros casados multiplicada pela matriz $\mathbf{W}$ minimiza o erro quadrático médio esperado entre o vetor de informações transmitidas b e a multiplicação da matriz $\mathbf{W}$ pelo vetor de informações recebidas, i.e.

$$
\underset{\mathbf{W}}{\arg \min } \mathbb{E}\left\{\|\mathbf{b}-\mathbf{W} \mathbf{s} \tilde{\mathbf{r}}\|^{2}\right\}
$$

sendo $\tilde{\mathbf{r}}$ dado por (2.16).

De acordo com o trabalho de (MOSHAVI, 1996), a matriz W que minimiza o erro quadrático médio esperado é,

$$
\mathbf{W}=\left[\mathbf{R}+\sigma^{2} \mathbf{Q}^{-2}\right]^{-1}
$$

sendo $\sigma^{2}$ a potência do ruído térmico introduzido no sinal original e $\mathbf{Q}$ a matriz diagonal dos ganhos de amplitude dos canais. Uma vez que neste trabalho será abordado apenas o descorrelacionador ${ }^{3}$ para uma literatura mais completa sobre detecores subótimos lineares e não lineares recomenda-se a leitura dos trabalhos de (VERDú, 1983; VERDú, 1995) e (NETO, 2012).

Nas duas seções a seguir serão apresentados o modelo de consumo de potência de um sistema DS/CDMA e os conceitos e definições relacionadas ao sistema que serão utilizados no capítulo 4.

\subsubsection{Modelo de Consumo de Potência}

O consumo de potência de sistemas de comunicação é de fundamental importância para o projeto de sistemas energeticamente eficientes. Desta forma, observe

\footnotetext{
${ }^{3} \mathrm{O}$ motivo de considerar apenas o descorrelacionador será indicado posteriormente.
} 
que em sistemas de comunicação sem fio é possível distinguir duas utilizações diferentes de potência: a primeira é a potência necessária para a transmissão da informação e a segunda é a potência consumida pelos circuitos responsáveis pela transmissão e recepção.

A potência necessária para transmissão da informação no enlace de subida de redes DS/CDMA é denominada $P_{\mathrm{TR}}^{D S}$ e é definida como:

$$
P_{\mathrm{TR}}^{D S}(\mathbf{p}, \mathbf{r})=\sum_{i=1}^{U} \varrho_{i} p_{i}+\sum_{i=1}^{U} \vartheta_{i} r_{i}
$$

onde o primeiro termo da soma é referente ao amplificador de potência e o segundo termo é uma dependência linear da taxa de transmissão do $i$-ésimo usuário. Sendo assim, para o usuário $i, \varrho$ é a ineficiência do amplificador de potência de rádiofrequência, $r$ é a taxa de transmissão e $\vartheta \geq 0$ é um fator linear de ponderação do incremento de potência relacionado com o crescimento da taxa de transmissão. Dependendo de seu valor, $\vartheta$ representa a potência de processamento de sinal final em banda base do transmissor, receptor ou ambos (NG; LO; SCHOBER, 2012).

A potência consumida pelos circuitos, por sua vez, é determinada pelos blocos ativos tais como conversor analógico-digital (CAD), conversor digital-analógico (CDA), sintetizador (SYN), mixer (MIX), amplificador de baixo ruído (ABR), amplificador de frequência intermediária (AFI), filtro de recepção (FIR) e filtro de transmissão (FIT). Logo, o consumo de potência pelos circuitos pode ser decomposto nos seguintes termos:

$$
P_{\mathrm{C}}^{D S}=2 P_{\mathrm{SYN}}+P_{\mathrm{MIX}}+P_{\mathrm{ABR}}+P_{\mathrm{FIT}}+P_{\mathrm{FIR}}+P_{\mathrm{AFI}}+P_{\mathrm{CAD}}+P_{\mathrm{CDA}}
$$

Uma vez que na transmissão a potência consumida é dominada pelo mixer, sintetizador, filtro de recepção e pelo amplificador de baixo ruído, seria razoável 
que a potência consumida pelos circuitos fosse independente da taxa de transmissão. Na recepção o consumo de potência é dominado pelo amplificador de frequências intermediárias. Desta forma, a potência de circuito pode ser modelada como dois termos sendo o primeiro uma constante e o segundo linearmente dependente da taxa de transmissão (CUI; GOLDSMITH; BAHAI, 2005):

$$
P_{\mathrm{C}}^{D S}(\mathbf{r})=P_{\mathrm{C}}+\sum_{i=1}^{U} v_{i} r_{i}
$$

onde $r$ é a taxa do $i$-ésimo usuário e $P_{\mathrm{C}}$ é a potência, admitida fixa, gasta pelos circuitos.

Portanto para sistemas DS/CDMA o consumo total de potência é:

$$
P_{\mathrm{T}}^{D S}(\mathbf{p}, \mathbf{r})=P_{\mathrm{C}}+\sum_{i=1}^{U} \varrho_{i} p_{i}+\sum_{i=1}^{U}\left(\vartheta_{i}+v_{i}\right) r_{i}
$$

\subsubsection{Definições - Sistema DS/CDMA}

Nos parágrafos a seguir serão apresentados conceitos relacionados a sistemas DS/CDMA que serão utilizados posteriormente nos problemas de otimização em sistemas de comunicação sem fio apresentados no capítulo 4. Estas definições estão associadas aos conceitos de relação sinal-interferência mais ruído pré e pós detecção ${ }^{4}$; eficiência energética; eficiência espectral e taxa de erro de bit. Para estas definições é considerado o enlace reverso de um sistema DS/CDMA com sincronismo perfeito.

Definição 1 (Relação Sinal Interferência Mais Ruído - Pré Detecção). A relação sinal-interferência mais ruído (do inglês, Signal to Interference plus Noise Ratio, SINR) antes do processo de detecção é a relação entre a potência do sinal de interesse à entrada do receptor dividida pela potência da interferência de múltiplo

\footnotetext{
${ }^{4}$ Para detectores lineares.
} 
acesso mais o ruído aditivo Gaussiano branco de fundo (do inglês, additive white Gaussian noise, AWGN). A SINR pré detecção para o i-ésimo usuário DS/CDMA é definida como (GOLDSMITH, 2005):

$$
\delta_{i}^{\mathrm{PRE}}=\frac{F_{i} p_{i}\left|h_{i}\right|^{2}}{F_{i} \sigma^{2}+\sum_{\substack{j=1 \\ j \neq i}}^{U} p_{j}\left|h_{j}\right|^{2}}
$$

onde $p_{i}$ e $p_{j}$ são as potências do i-ésimo e j-ésimo usuário, $h_{i}$ e $h_{j}$ são os ganhos em amplitude e fase do canal do usuário $i$ e $j$, respectivamente, e $F_{i}$ é o ganho de processamento ${ }^{5}$ do usuário $i$. Finalmente, $\sigma^{2}$ é a potência do ruído de fundo $A W G N$, sendo equivalente a $N_{0} B$, onde $B$ é a banda do sistema DS/CDMA e $N_{0}$ a densidade espectral de potência do ruído.

Definição 2 (Relação Sinal Interferência Mais Ruído - Pós Detecção). A relação sinal-interferência mais ruído após o processo de detecção através de detectores lineares é a relação entre a potência do sinal de interesse pós-detecção (considera o filtro de detecção) dividida pela potência da interferência de múltiplo acesso mais o ruído aditivo Gaussiano branco de fundo. Considerando que no receptor o sinal recebido é processado por um filtro/receptor linear $\mathbf{d}_{i}$ e que cada usuário possuí uma sequência de espalhamento $\mathbf{s}_{i}$ de tamanho $F_{i}$, a SINR pós detecção para o i-ésimo usuário é definida como (ZAPPONE; BUZZI; JORSWIECK, 2011):

$$
\delta_{i}^{\text {POS }}=\frac{F_{i} p_{i}\left|h_{i}\right|^{2}\left|\mathbf{d}_{i}^{H} \mathbf{s}_{i}\right|^{2}}{F_{i} \sigma^{2}\left\|\mathbf{d}_{i}\right\|^{2}+\sum_{\substack{j=1 \\ j \neq i}}^{U} p_{j}\left|h_{j}\right|^{2}\left|\mathbf{d}_{i}^{H} \mathbf{s}_{j}\right|^{2}}
$$

onde $p_{i}$ e $p_{j}$ são as potências do $i$-ésimo e j-ésimo usuário, $h_{i}$ e $h_{j}$ são os ganhos em amplitude e fase do canal do usuário $i$ e $j$, respectivamente, $\left\|\mathbf{d}_{i}\right\|$ é a norma Euclidiana do filtro linear do usuário $i$. Finalmente, $\sigma^{2}$ é a potência do ruído de fundo $A W G N$ e é equivalente a $N_{0} B$, onde $B$ é a banda do sistema DS/CDMA e

\footnotetext{
${ }^{5}$ Em sistemas onde o espalhamento é por sequência direta, o ganho de processamento é equivalente ao tamanho da sequência.
} 
$N_{0}$ a densidade espectral de potência do ruído.

Definição 3 (Taxa de Transmissão de Informação). Admite-se que a taxa de transmissão de informação é equivalente à capacidade de canal de (SHANNON, 1948). Assim, para o i-ésimo usuário, a taxa $r_{i}$ é definida por (GOLDSMITH, 2005):

$$
r_{i}=B \log _{2}\left(1+\delta_{i}\right) \quad\left[\frac{b i t s}{s}\right]
$$

onde $B$ é a largura de banda do sistema e $\delta_{i}$ a relação sinal-interferência mais ruído do usuário $i$. A taxa, portanto, é uma função não linear da SINR e pode ser utilizada em sua versão pré detecção ou pós detecção. Uma vez que nenhuma destas é utilizada de forma exclusiva neste texto, quando se fizer uso da definição de SINR indicar-se-á pós ou pré detecção.

Definição 4 (Eficiência Espectral). A eficiência espectral é a razão entre taxa de transmissão de bits por segundo por Hertz de banda do sistema DS/CDMA. Sendo assim, a eficiência espectral do sistema DS/CDMA é definida como (GOLDSMITH, 2005):

$$
\mathcal{S}^{D S}=\frac{R}{B}=\frac{1}{B} \sum_{i=1}^{U} B \log _{2}\left(1+\delta_{i}\right)=\sum_{i=1}^{U} \log _{2}\left(1+\delta_{i}\right) \quad\left[\frac{\text { bits }}{s \cdot H z}\right]
$$

onde $R=\sum_{i=1}^{U} r_{i}$ é a taxa de transmissão de informação total do sistema $D S / C D M A, B$ é a largura de banda do sistema, $\delta_{i}$ é a relação sinal-interferência mais ruído do i-ésimo usuário. É possivel definir ainda a eficiência espectral do usuário i como:

$$
\mathcal{S}_{i}^{D S}=\frac{r_{i}}{B}=\log _{2}\left(1+\delta_{i}\right) \quad\left[\frac{b i t s}{s \cdot H z}\right]
$$

O último conceito a ser apresentado é o conceito de taxa de erro de bit (do inglês, bit error rate, BER). Bits errados são bits recebidos através de um canal de comunicação, os quais foram alterados devido a fatores como ruído, interferência, atenuação do canal, erros de sincronização e desvanecimento multi- 
percurso. A taxa de erro de bit, portanto, é a razão entre a quantidade de bits que foram alterados durante a comunicação pelo número total de bits transmitidos no intervalo de tempo no qual ocorreu a comunicação.

A taxa de erro de bit é diretamente influenciada pela relação sinalinterferência mais ruído, pela modulação, pelo esquema de codificação utilizado na transmissão e pela estatística do canal de transmissão. A BER pode ser computada através de simulações de Monte Carlo ou de forma analítica.

Conforme apresentado e discutido no trabalho de (LU et al., 1999) a taxa de erro de bit média considerando um canal com ruído de fundo do tipo Gaussiano branco e assumindo modulações $M$-QAM com constelações quadradas pode ser assintoticamente aproximada pela expressão,

$$
\mathrm{BER}_{M-\mathrm{QAM}}^{\mathrm{AWGN}} \simeq 4\left(\frac{\sqrt{M}-1}{\sqrt{M} \log _{2}(M)}\right) \sum_{i=1}^{\sqrt{M} / 2} Q\left(\sqrt{\frac{3 \delta(2 i-1)^{2} \log _{2}(M)}{(M-1)}}\right)
$$

onde $M$ é a ordem de modulação QAM, $\delta$ é a relação sinal-interferência mais ruído e a função $Q(x)=\operatorname{Pr}(\mathcal{X}>x)=\int_{x}^{\infty} f_{\mathcal{X}}(y) d y$ sendo $f_{\mathcal{X}}$ a função densidade de probabilidade da variável aleatória Gaussiana $\mathcal{X}, x=\left(x_{0}-\mu_{\mathcal{X}}\right) / \sigma_{\mathcal{X}}, \mu_{\mathcal{X}}$ a média do processo estocástico $\mathcal{X}$ e $\sigma$ o seu desvio padrão.

Desta forma, a função $Q(x)$ pode ser interpretada como a probabilidade associada à area da cauda (à direita) de uma distribuição estatística normal, ou ainda, em outras palavras, a função $Q(x)$ é a probabilidade de uma variável aleatória de distribuição Gaussiana atingir um valor maior ou igual ao desvio padrão multiplicado por $x$ distante da média da distribuição. Logo, a função $Q$ é definida 
como

$$
Q(x)=\frac{1}{\sqrt{2 \pi}} \int_{x}^{\infty} e^{\left(-\frac{y^{2}}{2}\right)} d y
$$

Considerando o tipo de canal abordado neste trabalho, i.e. canais sem linha de visada, planos e lentos, e assumindo que os canais introduzem uma variação na envoltória do sinal representado através de uma variável aleatória com distribuição estatística de Rayleigh, é possível estabelecer uma relação entre a SINR média e a taxa de erro de bit média para diferentes tipos de modulação. Utilizando a expressão para taxa de erro de bit média em canais AWGN contido no trabalho de (LU et al., 1999) é possível estabelecer uma expressão para a BER média em canais com desvanecimento Rayleigh (SIMON; ALOUINI, 2000, Página 223),

$\mathrm{BER}_{M-\mathrm{QAM}}^{\mathrm{RAYLEGH}} \simeq\left(\frac{2(\sqrt{M}-1)}{\sqrt{M} \log _{2}(M)}\right) \sum_{i=1}^{\sqrt{M} / 2}\left(1-\sqrt{\frac{1,5(2 i-1)^{2} \delta \log _{2}(M)}{(M-1)+1,5(2 i-1)^{2} \delta \log _{2}(M)}}\right)$

onde $M$ é a ordem de modulação $M$-QAM e $\delta$ é a relação sinal-interferência mais ruído média. Note que a expressão em (2.37) apresenta uma certa complexidade matemática e de cômputo, quando $M$ cresce, o que poderia comprometer o tratamento matemático se a mesma fosse aplicada a um problema de otimização. Sendo assim, nas páginas 232 a 234 da obra de (DU; SWAMY, 2010) é apresentada uma análise sobre a probabilidade de erro de bit de modulações $M$-QAM em canais com desvanecimento do tipo Rayleigh e os autores oferecem uma boa aproximação para a expressão em (2.37) em regimes de baixa, média e alta SINR, resultando em:

$$
\overline{\operatorname{BER}}_{M-\mathrm{QAM}}^{\mathrm{RAYleigh}} \approx \frac{2(\sqrt{M}-1)}{\sqrt{M} \log _{2}(M)}\left(1-\sqrt{\frac{3 \delta \log _{2}(M)}{2(M-1)+3 \delta \log _{2}(M)}}\right)
$$


Nesta Tese o modelo de taxa de erro de bit média adotado é a expressão simplificada proposta por (DU; SWAMY, 2010) e reproduzida na equação (2.38). Esta abordagem foi adotada primeiramente pelo modelo de canal escolhido para o desenvolvimento do trabalho e, em segundo lugar, pela simplicidade ${ }^{6}$ e maior facilidade de manipulação matemática da expressão.

Definição 5 (Eficiência Energética do Sistema). A eficiência energética do elo de subida de um sistema DS/CDMA é definida como a razão da quantidade de bits efetivamente transmitidos por unidade de energia, mensurada em Joules. Matematicamente, a eficiência energética é definida como (GOODMAN; MANDAYAM, 2000):

$$
\xi^{D S}=\frac{R_{\mathrm{e}}}{P_{\mathrm{T}}^{D S}}=\frac{\sum_{i=1}^{U} \ell_{i} B \log _{2}\left(1+\delta_{i}\right) f\left(\delta_{i}\right)^{V}}{P_{\mathrm{C}}+\sum_{i=1}^{U} \varrho_{i} p_{i}+\sum_{i=1}^{U}\left(\vartheta_{i}+v_{i}\right) r_{i}} \quad\left[\frac{\text { bits }}{\text { Joule }}\right]
$$

onde $B$ é a banda do sistema DS/CDMA, $\ell_{i}$ é a taxa de codificação $o^{7}$ do usuário $i, \delta_{i}$ é a relação sinal-interferência mais ruído ${ }^{8}$ do i-ésimo usuário, $f\left(\delta_{i}\right)$ é uma função de penalizaçã $o^{9}$ da taxa de transmissão cujo argumento é a SINR do usuário $i, V$ é o número de símbolos enviados por pacote/quadro; o denominador da função descreve o consumo total de potência de todo o sistema DS/CDMA, conforme descrito na seção 2.1.1.1.

Observação 1. As equações de capacidade definidas ao longo deste trabalho tratam da capacidade instantânea do canal Rayleigh (dentro do intervalo onde o desvanecimento é estático) uma vez que a SINR é definida utilizando o ganho de potência do canal que em canais com desvanecimento Rayleigh assume uma

\footnotetext{
${ }^{6}$ Menor complexidade da expressão quando comparada a expressões exatas de taxa de erro de bit médias em canais Rayleigh

${ }^{7}$ A razão entre bits de informação transmitidos e número total de bits transmitidos (informação mais redundância).

${ }^{8}$ Pré ou pós detecção. No Capítulo 4 será discriminado qual a SINR utilizada na equação conforme a necessidade.

${ }^{9}$ É comum assumir que a função de penalidade seja a taxa de acerto de bits. As características desta função e o seu papel no cálculo da eficiência energética serão discutidos de forma mais completa no Capítulo 4
} 
distribuição estatística exponencial. De fato, a capacidade, conforme definida no texto, não representa a capacidade média para um canal Rayleigh (normalmente calculada em termos de probabilidade de interrupção do serviço), mas sim a sua capacidade instantânea. Logo, o modelo descrito é válido uma vez que ambas capacidade instantânea de canal e taxa de acerto de bit média são definidas em canais cujas atenuações de amplitude assumem uma distribuição estatística de Rayleigh.

Definição 6 (Eficiência Energética do Usuário $\boldsymbol{i}$ ). A eficiência energética do i-ésimo usuário do elo de subida de um sistema DS/CDMA é definida como a quantidade de bits efetivamente transmitidos pelo usuário por unidade de energia gasta pelo mesmo. Matematicamente, a eficiência energética do usuário i é imediatamente definida a partir de (2.47) (GOODMAN; MANDAYAM, 2000):

$$
\xi_{i}^{D S}=\frac{\ell_{i} B \log _{2}\left(1+\delta_{i}\right) f\left(\delta_{i}\right)^{V}}{P_{\mathrm{C}}+\varrho_{i} p_{i}+\vartheta_{i} r_{i}} \quad\left[\frac{\text { bits }}{\text { Joule }}\right]
$$

onde $B$ é a banda do sistema DS/CDMA, $\ell_{i}$ é a taxa de codificação do usuário, $\delta_{i}$ é a relação sinal-interferência mais ruído do i-ésimo usuário, $f\left(\delta_{i}\right)$ é a função de penalização da taxa de transmissão, $V$ é o número de símbolos enviados no pacote/quadro , $\varrho_{i}$ é a ineficiência do amplificador de potência do $i$-ésimo usuário e $\vartheta_{i}$ é o coeficiente de crescimento de consumo de potência do usuário $i$ conforme aumenta sua taxa de transmissão de informação, finalmente $P_{\mathrm{C}}$ é a potência constante gasta pelos circuitos do transmissor.

\subsubsection{Sistemas MC-DS/CDMA}

O primeiro trabalho combinando as técnicas de multiplexação por múltiplas portadoras ortogonais e o múltiplo acesso por divisão de código foi publicado em 1993 o qual descrevia a combinação dessas técnicas considerando o espalhamento no domínio da frequência (YEE; LINNARTZ; FETTWEIS, 1993). Esta técnica 
ficou conhecida como CDMA multiportadora (do inglês, multicarrier CDMA, MC-CDMA), e difere dos sistemas MC-DS/CDMA pelo domínio no qual o espalhamento espectral é feito.

Em redes com múltiplas portadoras e múltiplo acesso por divisão em código de sequência direta o espectro disponível é dividido em subcanais/subportadoras ortogonais nos quais operam transmissores e receptores DS/CDMA convencionais como os estudados na seção 2.1.1. Desta forma, em um sistema MC-DS/CDMA com $N$ subportadoras, considerando o $j$-ésimo período de símbolo e admitindo que cada um dos $U$ usuários do sistema possui uma sequência de espalhamento única para transmitir que o identifica. O diagrama de blocos de um dos $U$ transmissores é apresentado na figura 7 .

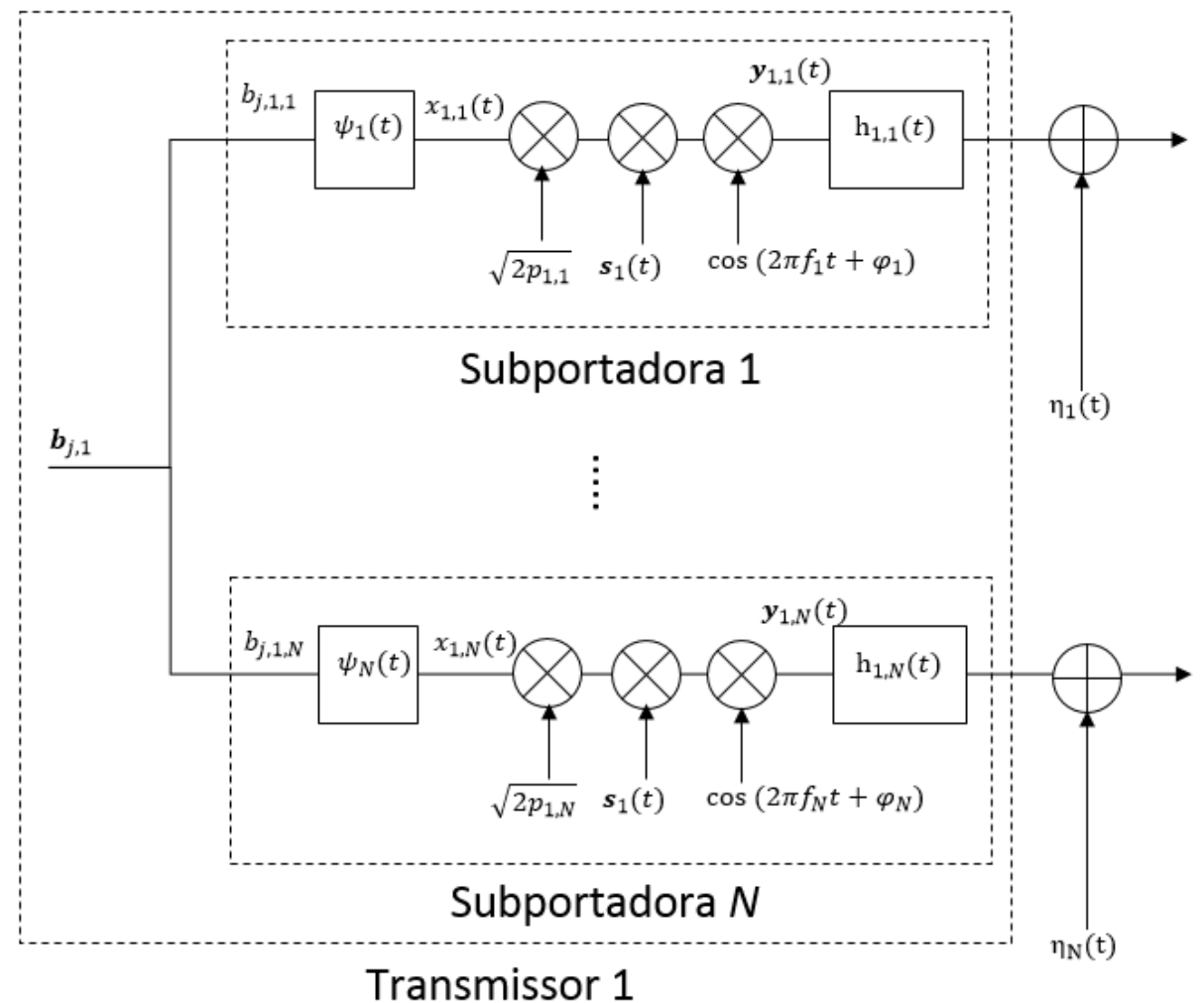

Figura 7: Diagrama de blocos do transmissor MC-DS/CDMA para o usuário 1.

Note que o espalhamento espectral na figura 7 é feito no domínio do tempo. Quando $N=1$ obtêm-se o clássico sistema DS/CDMA apresentado anteriormente. 
Desta forma, é posssível redefinir os conceitos de relação sinal-interferência mais ruído (pré e pós detecção), eficiência espectral e eficiência energética para estes sistemas tomando como base as definições para redes DS/CDMA apresentadas na seção 2.1.1.

\subsubsection{Definições - Sistema MC-DS/CDMA}

Nas definições e conceitos apresentados nesta seção é considerado um sistema MC-DS/CDMA com $N$ subportadoras com canais descorrelacionados e $U$ usuários ativos na rede.

Definição 7 (Relação Sinal Interferência Mais Ruído - Pré Detecção). A definição de relação sinal-interferência mais ruído antes do processo de detecção é equivalente à definição do sistema DS/CDMA, com a diferença de que em um sistema com $N$ subportadoras, há a inclusão de um indice que identifica de qual subcanal refere-se a SINR. Desta forma para o i-ésimo usuário e k-ésima subportadora, a SINR é definida como (GOLDSMITH, 2005):

$$
\delta_{i, k}^{\mathrm{PRE}}=\frac{F_{i, k} p_{i, k}\left|h_{i, k}\right|^{2}}{F_{i, k} \sigma_{k}^{2}+\sum_{\substack{j=1 \\ j \neq i}}^{U} p_{j, k}\left|h_{j, k}\right|^{2}}
$$

onde $p_{i, k}$ e $p_{j, k}$ são as potências de transmissão do usuário $i$ e $j$, respectivamente, na k-ésima subportadora; $h_{i, k}$ e $h_{j, k}$ são os ganhos em amplitude e fase do canal e $F_{i, k}$ é o ganho de processamento do usuário $i$ na subportadora $k$. Finalmente, $\sigma_{k}^{2}$ é a potência do ruído de fundo AWGN na k-ésima subportadora.

Definição 8 (Relação Sinal Interferência Mais Ruído - Pós Detecção). A relação sinal-interferência mais ruído após o processo de deteç̧ão para sistemas $M C$ DS/CDMA é definida como (ZAPPONE; BUZZI; JORSWIECK, 2011):

$$
\delta_{i, k}^{\text {Pos }}=\frac{F_{i, k} p_{i, k}\left|h_{i, k}\right|^{2}\left|\mathbf{d}_{i}^{H} \mathbf{s}_{i}\right|^{2}}{F_{i, k} \sigma_{k}^{2}\left\|\mathbf{d}_{i}\right\|^{2}+\sum_{\substack{j=1 \\ j \neq i}}^{U} p_{j, k}\left|h_{j, k}\right|^{2}\left|\mathbf{d}_{i}^{H} \mathbf{s}_{j, k}\right|^{2}}
$$


onde $i$ e $k$ são os indexadores de usuário e subportadora, respectivamente. A potência de transmissão é representada por $p, F$ é o ganho de processamento, $\mathbf{d}$ é o filtro linear na recepção, $\mathbf{s}$ é a sequência de espalhamento, h é o ganho complexo de canal e $\sigma^{2}$ a potência do ruído branco Gaussiano de fundo.

Definição 9 (Taxa de Transmissão de Informação). A expressão da taxa de transmissão de informação em redes $M C$-DS/CDMA é similar à dos sistemas $D S / C D M A$. Considera-se a capacidade de canal de Shanon e a diferenciação se dá através do indexador de subcanal $k$ presente nos sistemas com múltiplas portadoras. Desta forma, a taxa de transmissão do i-ésimo usuário na k-ésima subportadora é:

$$
r_{i, k}=B \log _{2}\left(1+\delta_{i, k}\right)
$$

onde $B$ é a largura de banda da subportadora e $\delta_{i, k}$ a relação sinal-interferência mais ruído do usuário $i$ no subcanal $k$.

Definição 10 (Eficiência Espectral). A eficiência espectral de sistemas $M C$ DS/CDMA apresenta a mesma definição dos sistemas DS/CDMA: é a taxa de transmissão de bits alcançável por segundo por Hertz de banda do sistema MC$D S / C D M A$. Considerando um sistema com $N$ subportadoras ortogonais de banda B, a eficiência espectral do sistema é definida como (GOLDSMITH, 2005):

$$
\mathcal{S}^{M C}=\frac{R}{B}=\frac{1}{B} \sum_{i=1}^{U} \sum_{k=1}^{N} B \log _{2}\left(1+\delta_{i, k}\right)=\sum_{i=1}^{U} \sum_{k=1}^{N} \log _{2}\left(1+\delta_{i, k}\right) \quad\left[\frac{\text { bits }}{s \cdot \text { Hertz }}\right]
$$

onde $R=\sum_{i=1}^{U} \sum_{k=1}^{N} r_{i, k}$ é a vazão do sistema e $\delta_{i, k}$ é a relação sinal-interferência mais ruído do i-ésimo usuário na k-ésima subportadora. É possível definir ainda a eficiência espectral do usuário i como:

$$
\mathcal{S}_{i}^{M C}=\frac{R_{i}}{B}=\sum_{k=1}^{N} \log _{2}\left(1+\delta_{i, k}\right) \quad\left[\frac{\text { bits }}{s \cdot \text { Hertz }}\right]
$$

onde $R_{i}=\sum_{k=1}^{N} r_{i, k}$ 
Definição 11 (Eficiência Energética do Sistema). A definição teórica de eficiência energética em sistemas $M C$-DS/CDMA é equivalente à dos sistemas $D S / C D M A$, i.e. a quantidade de bits transmitidos efetivamente por unidade de energia. Matematicamente, a eficiência energética é definida como (GOODMAN; MANDAYAM, 2000):

$$
\xi^{M C}=\frac{R_{\mathrm{e}}}{P_{\mathrm{T}}^{M C}}=\frac{\sum_{i=1}^{U} \sum_{k, 1}^{N} \ell_{i, k} B \log _{2}\left(1+\delta_{i, k}\right) f\left(\delta_{i, k}\right)^{V}}{P_{\mathrm{C}}+\sum_{i=1}^{U} \sum_{k=1}^{N} \varrho_{i} p_{i, k}+\sum_{i=1}^{U} \sum_{k, 1}^{N}\left(\vartheta_{i}+v_{i}\right) r_{i, k}} \quad\left[\frac{\text { bits }}{\text { Joule }}\right]
$$

onde $B$ é a banda da subportadora, $\delta_{i, k}$ é a relação sinal-interferência mais ruido do i-ésimo usuário na k-ésima subportadora, $f\left(\delta_{i, k}\right)$ é uma função de penalização da taxa de transmissão cujo argumento é a SINR do usuário $i$ no subcanal $k, V$ é o número de símbolos enviados no pacote/quadro. O denominador da função é o consumo total de potência do sistema, tal que $P_{\mathrm{C}}$ é a potência consumida pelos circuitos de forma constante, $\varrho_{i}$ é a ineficiência do amplificador de potência do usuário $i$ e $p_{i, k}$ a sua potência de transmissão na k-ésima subportadora, $\vartheta_{i} e$ $v_{i}$ são os coeficientes de crescimento no consumo de potência do transmissor e receptor conforme o aumento na taxa de transmissão do usuário.

Definição 12 (Eficiência Energética do Usuário). A eficiência energética do $i$ ésimo usuário do elo de subida de um sistema $M C$-DS/CDMA é definida matematicamente como:

$$
\xi_{i}^{M C}=\frac{\sum_{k, 1}^{N} \ell_{i, k} B \log _{2}\left(1+\delta_{i, k}\right) f\left(\delta_{i, k}\right)^{V}}{P_{\mathrm{C}}+\sum_{k, 1}^{N} \varrho_{i} p_{i, k}+\sum_{k, 1}^{N} \vartheta_{i} r_{i, k}} \quad\left[\frac{\text { bits }}{\text { Joule }}\right]
$$

onde $B$ é a banda do subcanal, $\ell_{i, k}$ a taxa de codificação do usuário na subportadora $k, \delta_{i, k}$ é a relação sinal-interferência mais ruído, $f\left(\delta_{i, k}\right)$ é a função de penalização da taxa de transmissão, $V$ é o número de símbolos enviados no pacote/quadro, $\varrho_{i}$ é a ineficiência do amplificador de potência do i-ésimo usuário e 
$\vartheta_{i}$ é o coeficiente de crescimento de consumo de potência do usuário i conforme aumenta sua taxa de transmissão de informação $r_{i, k}$. Finalmente, $P_{\mathrm{C}}$ é a potência constante gasta pelos circuitos do transmissor.

\subsubsection{Sistemas MC-DS/CDMA Cooperativos}

As três principais formas de diversidade em sistemas de telecomunicações são a diversidade temporal, a diversidade em frequência e a diversidade espacial (GOLDSMITH, 2005). Técnicas onde o mesmo sinal é transmitido em diferentes instantes de tempo exploram a diversidade temporal, e.g. códigos corretores de erro. No domínio da frequência, técnicas que enviam sinais em diferentes portadoras bem como sistemas que empregam espalhamento espectral são exemplos de exploração da diversidade em frequência. Finalmente, a diversidade espacial é aquela que se beneficia das diferentes posições geográficas entre transmissores e receptores de um sistema. Uma técnica amplamente conhecida de diversidade espacial é a utilização de múltiplas antenas para recepção e/ou para transmissão (TSE; VISWANATH, 2005).

Note que estas técnicas podem ser utilizadas para melhorar o desempenho/confiabilidade do sistema em termos de probabilidade erro, bem como também podem ser utilizadas para aumentar a capacidade/vazão da rede sem fio sem, necessariamente, aumentar a banda de transmissão ${ }^{10}$.

Outra forma de se utilizar a diversidade espacial é através da cooperação entre os transmissores e receptores do sistema, o que é conhecido como comunicação cooperativa. Note que a comunicação cooperativa não é uma técnica que exclui a possibilidade do emprego de outra técnica que explore diversidade espacial, como o uso de múltiplas antenas de transmissão e/ou recepção.

\footnotetext{
${ }^{10} \mathrm{~A}$ utilização das técnicas para estes fins não é mutuamente exclusiva, i.e. é possivel utilizar técnicas que exploram as diferentes diversidades buscando melhorar o desempenho em termos de probabilidade de erro e, simultaneamente, aumentar a vazão e ou a capacidade do sistema (TSE; VISWANATH, 2005).
} 
A proposta de comunicação de forma cooperativa foi apresentada inicialmente no trabalho de (MEULEN, 1971) onde o seu modelo de transmissão cooperativa era formado por três ativos da rede: uma fonte, um repetidor e um destinatário. Neste sistema a fonte produz informações que devem ser enviadas ao destinatário. O repetidor encontra-se no percurso entre fonte e destinatário e é responsável por reencaminhar a informação da fonte para o destino. Formam-se assim dois canais de comunicação distintos: o primeiro é denominado caminho direto entre a fonte e o destinatário, o segundo é o caminho indireto, sendo formado pelos canais fonte-repetidor e repetidor-destino. A figura 8 apresenta uma rede cooperativa com fonte, repetidor e destino ilustrando em preto o canal direto e em vermelho o canal indireto.

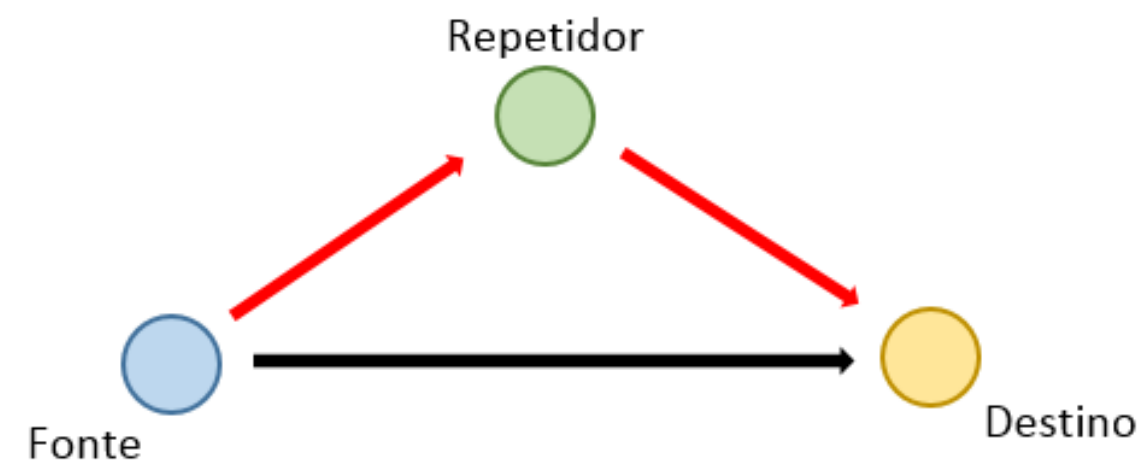

Figura 8: Ilustração da comunicação entre fonte e destino denominada caminho direto (em preto) e da comunicação através de um repetidor em sistemas cooperativos, denominado caminho indireto (em vermelho).

Em sistemas de comunicação cooperativos os repetidores são usualmente ativos de redes que não possuem informação própria, i.e. são ativos utilizados única e exclusivamente para a retransmissão de informações. Um exemplo oposto a esta topologia são as redes de malha (do inglês, mesh networks), onde todos os nós da rede atuam como retransmissores de informação.

A atuação dos repetidores em redes cooperativas pode utilizar diferentes protocolos de retransmissão. De acordo com (LANEMAN; TSE; WORNELL, 2004) dois protocolos distintos podem ser utilizados nos retransmissores: o amplifica 
e encaminha (do inglês, amplify and forward, AF), e o protocolo decodifica e encaminha (do inglês, decode and forward, DF).

No primeiro, o retransmissor recebe o sinal da fonte, amplifica com o objetivo de compensar a atenuação na amplitude do sinal imposta pelo percurso fonteretransmissor, na sequência o sinal é transmitido para o destino. No protocolo decodifica e encaminha, o retransmissor é responsável por recuperar a informação transmitida pela fonte, i.e. transformar o sinal recebido em bits de informações que são modulados novamente e enviados ao destino (LANEMAN; TSE; WORNELL, 2004).

Embora a proposta do protocolo amplifica e encaminha e do protocolo decodifica e encaminha date do trabalho de (MEULEN, 1971) e do trabalho de (COVER; GAMAL, 1979), possivelmente a primeira aparição destas denominações na literatura ocorreu na Tese de doutorado de (LANEMAN, 2002).

Outro protocolo de retransmissão proposto por (COVER; GAMAL, 1979) é conhecido hoje como comprime e enchaminha (do inglês, compress and forward, $\mathrm{CF}$ ); neste protocolo o retransmissor é responsável por quantizar e realizar a compressão da informação enviada pela fonte e, posteriormente, retransmití-la ao destino (KRAMER; GASTPAR; GUPTA, 2005).

É evidente que o protocolo amplifica e encaminha é o mais simples do ponto de vista de funcionamento e de projeto. Sob a perspectiva de consumo de potência, por ser o mais simples dos três protocolos é natural que apresente um consumo de potência de seus circuitos inferior àqueles de implementações utilizando protocolos DF ou CF. Por outro lado, sua simplicidade implica ganhos de desempenho inferiores aos demais protocolos, tanto em termos de aumento da capacidade quanto de redução na taxa de erro de bit (KRAMER; GASTPAR; GUPTA, 2005; LANEMAN; TSE; WORNELL, 2004). 
Logo, a fim de manter a complexidade do projeto da rede simples e, simultaneamente, explorar os benefícios da diversidade espacial utilizando retransmissores $^{11}$, adotou-se neste trabalho a utilização do protocolo amplifica e encaminha.

A comunicação fonte-retransmissor e retransmissor-destino pode ocorrer de maneiras diferentes: quando estas duas transmissões ocorrem em tempos distintos temos o que se conhece por duplexação por divisão de tempo. Isto acarreta na redução da taxa de transmissão da fonte uma vez que esta não transmitirá de forma constante mas em intervalos de tempo regulares. Por outro lado, a comunicação fonte-retransmissor pode ocorrer em faixas de frequência distintas do segundo salto. Neste caso, uma vez que a mesma informação é transmitida em duas bandas diferentes a eficiência espectral é reduzida pela metade. No trabalho de doutorado assumiu-se uma duplexação por divisão em frequência para as transmissões fonte-retransmissor e fonte-destino de tal forma que não há interferência entre elas.

Antes de apresentar o modelo matemático do enlace de subida de um sistema MC-DS/CDMA cooperativo é importante estabelecer algumas premissas em relação às características da rede. Sendo assim, sem perda da generalidade, considere o elo reverso de um sistema macro celular com $U$ usuários, $N$ subportadoras, uma estação retransmissora fixa ${ }^{12}$, e uma estação rádio-base.

Um exemplo de cenário com estas características é apresentado na figura 9. Os canais em vermelho estão relacionados ao primeiro salto (terminal móvel estação retransmissora) e tem coeficientes de canal complexos $\mathrm{h}_{i, k}$, onde $i$ é o indexador de usuário e $k$ o de subcanal. O canal em preto é relacionado ao segundo salto da comunicação (estação retransmissora - estação rádio-base) e, no exemplo considerado, é representado pelo coeficiente de canal complexo $g_{k}$ onde

\footnotetext{
${ }^{11}$ É comum referir-se à diversidade espacial de retransmissores como diversidade cooperativa ou macro-diversidade, reservando o termo diversidade espacial para sistemas com múltiplas antenas.

${ }^{12}$ Cuja posição geográfica não é alterada ao longo do tempo.
} 


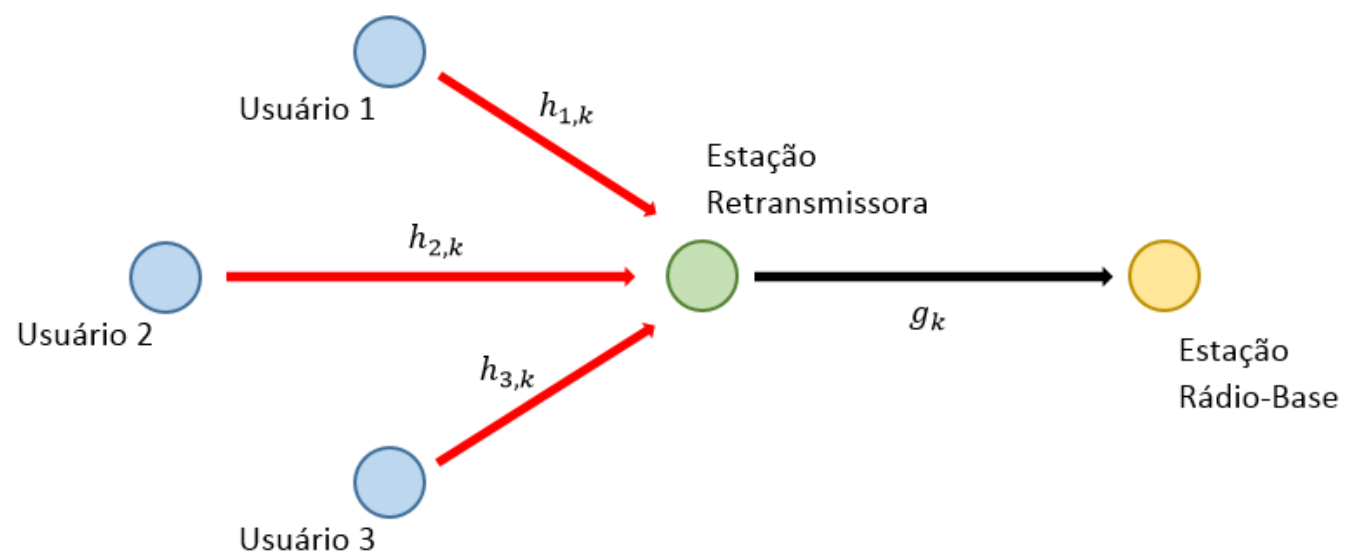

Figura 9: Exemplo de enlance de subida de um sistema cooperativo com 3 usuários e múltiplas subportadoras (representadas pelo indexador $k$ ).

$k$ é o indexador de subportadora. Note que no primeiro salto existem $U \times N$ canais de comunicação enquanto no segundo existem apenas $N$.

Note que na análise apresentada aqui e no modelo de sistema adotado o caminho direto entre o terminal móvel e a estação rádio-base é desconsiderado. Esta premissa é verdadeira em muitos cenários práticos de interesse onde os usuários estão muito distantes da estação rádio-base e faz-se necessário a instalação de um repetidor. Adicionalmente, a atenuação do canal não é linear em relação à distância, como visto ateriormente; logo, em cenários onde a célula tem diâmetro da ordem de unidades de quilômetros, a atenuação do canal devido à perda de percurso é grande o suficiente para a detecção do sinal proveniente do terminal móvel tornar-se impossivel no destino, de tal forma que muitas vezes o mesmo é tratado como ruído de fundo.

De acordo com o que foi apresentado na seção 2.1.1 e as complementações desenvolvidas na seção 2.1.2, o sinal que chega à estação retransmissora em banda base na $k$-ésima subportadora é:

$$
\tilde{\mathbf{y}}_{k}=\left[\sum_{i=1}^{U} \sqrt{2 p_{i, k}} x_{i, k} \mathbf{s}_{i} \mathrm{~h}_{i, k}\right]+\boldsymbol{\eta}_{k}
$$


onde $i$ é o indexador de usuário, $p_{i, k}$ é a potência de transmissão, $x_{i, k}$ é o símbolo enviado na subportadora $k$ pelo usuário $i, \mathbf{s}_{i}$ é a sequência de espalhamento do $i$-ésimo usuário ${ }^{13}$ de comprimento $F_{i}, \mathrm{~h}_{i, k}$ é o coeficiente complexo do canal entre o $i$-ésimo usuário e a estação retransmissora no subcanal $k$. Finalmente, $\boldsymbol{\eta}$ é o vetor de ruído aditivo Gaussiano branco. Por simplicidade da análise, mas sem perda da generalidade, considere que as sequências de espalhamento dos usuários tenham o mesmo comprimento, i.e. $F_{1}=F_{2}=\ldots=F$. Os vetores $\tilde{\mathbf{y}}_{k}$, s $\mathbf{s}_{i}$ e $\boldsymbol{\eta}_{k}$ são vetores $F \times 1$.

No retransmissor o sinal $\tilde{\mathbf{y}}$ é, primeiramente, normalizado pela raíz quadrada da potência média do sinal recebido, i.e. $\sqrt{\mathbb{E}\left[\left\|\tilde{\mathbf{y}}_{k}\right\|^{2}\right]}$. Reescrevendo a equação (2.48) na forma matricial obtêm-se:

$$
\tilde{\mathbf{y}}_{k}=\mathbf{S v}_{k}+\boldsymbol{\eta}_{k}
$$

onde

$$
\mathbf{S}=\left[\begin{array}{cccc}
c_{1,1} & c_{1,2} & \cdots & c_{1, U} \\
c_{2,1} & c_{2,2} & \cdots & c_{2, U} \\
\vdots & \vdots & \ddots & \vdots \\
c_{F, 1} & c_{F, 1} & \cdots & c_{F, U}
\end{array}\right], \quad \text { e } \quad \mathbf{v}_{k}=\left[\begin{array}{c}
\sqrt{2 p_{1, k}} x_{1, k} \mathrm{~h}_{1, k} \\
\sqrt{2 p_{2, k}} x_{2, k} \mathrm{~h}_{2, k} \\
\vdots \\
\sqrt{2 p_{U, k}} x_{U, k} \mathrm{~h}_{U, k}
\end{array}\right]
$$

Considerando que o ruído $\boldsymbol{\eta}_{k}$ e os símbolos de informação $x_{i, k}$ sejam descorrelacionados, temos que:

$$
\sqrt{\mathbb{E}\left[\|\tilde{\mathbf{y}}\|^{2}\right]}=\sqrt{\|\tilde{\mathbf{y}}\|^{2}}=\sqrt{\left\|\mathbf{S v}_{k}+\boldsymbol{\eta}_{k}\right\|^{2}}
$$

\footnotetext{
${ }^{13} \mathrm{O}$ transmissor utiliza a mesma sequência em todos os sub-canais para realizar o espalhamento espectral do sinal no domínio do tempo de forma independente em cada subportadora.
} 
ou ainda, aplicando a seguinte definição $P_{N}=\mathbb{E}\left[\|\tilde{\mathbf{y}}\|^{2}\right]$, na forma de somatório $P_{N}$ é definido como:

$$
P_{N}=\sigma^{2}+\sum_{i=1}^{U} 2 p_{i, k}\left|x_{i, k}\right|^{2}\left|\mathrm{~h}_{i, k}\right|^{2} \mathbf{s}_{i}^{H} \mathbf{s}_{i}
$$

Por simplicidade de análise, considere que a potência do símbolo normalizado é unitária, $\left|x_{i, k}\right|^{2}=1$ e a autocorrelação normalizada da sequência de espalhamento também é unitária, $\mathbf{s}_{i}^{H} \mathbf{s}_{i}=1$, a expressão acima pode ser simplificada:

$$
P_{N}=\sigma^{2}+\sum_{i=1}^{U} 2 p_{i, k}\left|\mathrm{~h}_{i, k}\right|^{2}
$$

Após a normalização do sinal na entrada do retransmissor, $\tilde{\mathbf{y}}$, o mesmo é amplificado pela matriz $\mathbf{A}$ de dimensões $F \times F$. A matriz de amplificação $\mathbf{A}$ é restrita a potência disponível $P_{\mathrm{R}}$ no retransmissor, i.e. $\operatorname{tr}\left(\mathbf{A} \mathbf{A}^{H}\right) \leq P_{\mathrm{R}}$, onde $\operatorname{tr}(\cdot)$ é o traço da matriz do argumento (ZAPPONE; BUZZI; JORSWIECK, 2011).

O sinal amplificado pela matriz A percorre o canal entre retransmissor e estação rádio base $g_{k}$ onde $k$ é o indexador de subportadora. Logo, o sinal na entrada da estação rádio-base $\mathbf{z}$ em banda base é:

$$
\mathbf{z}=\frac{\mathbf{g}_{k}}{\sqrt{P_{N}}}\left(\mathbf{A} \boldsymbol{\eta}_{1, k}+\sum_{i=1}^{U} \sqrt{2 p_{i, k}} x_{i, k} \mathrm{~h}_{i, k} \mathbf{A} \mathbf{s}_{i}\right)+\boldsymbol{\eta}_{2, k}
$$

onde $\boldsymbol{\eta}_{1, k}$ e $\boldsymbol{\eta}_{2, k}$ são os ruídos aditivos brancos Gaussianos de fundo introduzidos pelo canal fonte-retransmissor e retransmissor-destino, respectivamente, cujas matrizes de covariância são $\sigma_{1, k}^{2} \mathbf{I}_{F}$ e $\sigma_{2, k}^{2} \mathbf{I}_{F}$, onde $\mathbf{I}_{F}$ é a matriz identidade de ordem $F$. O sinal z na estação rádio-base passa por um detector MC-DS/CDMA composto por um banco de filtros casados e um filtro linear $\mathbf{d}$. Desta forma, a relação sinal-interferência mais ruído após a detecção é definida como (ZAPPONE; 
BUZZI; JORSWIECK, 2011):

$$
\delta_{i, k}^{\mathrm{MCC}}=\frac{F p_{i, k}\left|\mathrm{~h}_{i, k}\right|^{2}\left|\mathrm{~g}_{k}\right|^{2}\left|\mathbf{d}_{i}^{H} \mathbf{A} \mathbf{s}_{i}\right|^{2}}{P_{N} \sigma_{2, k}^{2}|| \mathbf{d}_{i}\left\|^{2}+F \sigma_{1, k}^{2}\left|\mathrm{~g}_{k}\right|^{2}\right\| \mathbf{A}^{H} \mathbf{d}_{i} \|^{2}+\left|\mathrm{g}_{k}\right|^{2} \sum_{\substack{j=1 \\ j \neq i}}^{U} p_{j, k}\left|\mathrm{~h}_{j, k}\right|^{2}\left|\mathbf{d}_{i}^{H} \mathbf{A} \mathbf{s}_{j}\right|^{2}}
$$

onde $\sigma_{1, k}^{2}$ é a potência do ruído de fundo da $k$-ésima subportadora no primeiro salto, $\sigma_{2, k}^{2}$ é a potência do ruído de fundo na subportadora $k$ no segundo salto.

Como consequência de optar pela duplexação por divisão em frequência, a eficiência espectral de sistemas MC-DS/CDMA cooperativos é equivalente à metade dos sistemas não cooperativos, i.e.

$$
\mathcal{S}^{\mathrm{MCC}}=\frac{R}{2 B}=\frac{1}{2 B} \sum_{i=1}^{U} \sum_{k=1}^{N} B \log _{2}\left(1+\delta_{i, k}\right)=\frac{1}{2} \sum_{i=1}^{U} \sum_{k=1}^{N} \log _{2}\left(1+\delta_{i, k}\right)\left[\frac{\mathrm{bits}}{\mathrm{s} \cdot \mathrm{Hz}}\right]
$$

onde $B$ é a largura de banda de uma subportadora e $\delta_{i, k}$ é a relação sinalinterferência mais ruído do $i$-ésimo usuário na $k$-ésima subportadora e é obtida através da equação (2.55).

A eficiência energética em sistemas cooperativos é semelhante a dos sistemas não cooperativos. A principal diferença está na potência total consumida, que incorpora os gastos de potência do retransmissor, e na definição da relação sinal-interferência mais ruído. Considerando um sistema onde os circuitos do retransmissor consomem uma potência fixa $P_{\mathrm{C}_{\mathrm{R}}}$ e a potência utilizada para a amplificação do sinal é denominada $p_{\mathrm{R}}$, a eficiência energética pode ser definida 
como (ZAPPONE; BUZZI; JORSWIECK, 2011):

$$
\xi^{M C C}=\frac{R_{\mathrm{e}}}{P_{\mathrm{T}}^{M C}}=\frac{\sum_{i=1}^{U} \sum_{k, 1}^{N} \ell_{i, k} B \log _{2}\left(1+\delta_{i, k}\right) f\left(\delta_{i, k}\right)^{V}}{P_{\mathrm{C}}+P_{\mathrm{C}_{\mathrm{R}}}+\varrho_{\mathrm{R}} p_{\mathrm{R}}+\sum_{i=1}^{U} \sum_{k=1}^{N} \varrho_{i} p_{i, k}+\sum_{i=1}^{U} \sum_{k, 1}^{N}\left(\vartheta_{i}+v_{i}\right) r_{i, k}} \quad\left[\frac{\text { bits }}{\text { Joule }}\right]
$$

onde $i$ é o indexador do usuário e $k$ o de subportadora, e os demais símbolos utilizados apresentam os seguintes significados:

- $\ell$ é a taxa de codificação (número de bits de informação por número de bits enviados),

- $B$ é a largura de banda de cada subportadora ortogonal,

- $\delta$ é a relação sinal-interferência mais ruído,

- $f(\delta)$ é a função de penalização que impõe a taxa de bits efetivamente recebidos,

- $V$ é o número de bits enviados dentro de um quadro de transmissão,

- $P_{\mathrm{C}}$ é a potência fixa consumida pelos circuitos dos usuários transmissores,

- $P_{\mathrm{C}_{\mathrm{R}}}$ é a potência fixa consumida pelos circuitos no retransmissor,

- $\varrho_{\mathrm{R}}$ é a ineficiência do amplificador de potência do retransmissor,

- $p_{\mathrm{R}}$ é a potência de transmissão do retransmissor,

- $\varrho_{i}$ é a ineficiência do amplificador de potência usuário $i$,

- $p_{i, k}$ é a potência de transmissão do $i$-ésimo usuário na $k$-ésima subportadora,

- $r_{i, k}$ é a taxa de transmissão do usuário $i$ na subportadora $k$, 
- $\vartheta_{i}$ é a taxa de crescimento da potência de transmissão em relação ao aumento da taxa de transmissão de informação,

- $v_{i}$ é a taxa de crescimento da potência consumida pelo circuito transmissor para um dado aumento na taxa de transmissão de informação,

\subsection{Sistemas OFDMA}

Os sistemas de múltiplo acesso por divisão ortogonal de frequência são sistemas de múltiplo acesso baseados na técnica de multiplexação por divisão ortogonal de frequência (do inglês, orthogonal frequency division multiplexing, OFDM) nos quais a multiplexação é feita com múltiplos usuários (DAHLMAN et al., 2007). Neste tipo de múltiplo acesso a banda disponível para transmissão é dividida em subportadoras ou subcanais de banda mais estreita que a banda de coerência do canal. O canal antes seletivo em frequência torna-se plano, característica que propicia aos sistemas baseados em multiplexação por divisão ortogonal de frequências maior robustez contra a interferência intersimbólica. Adicionalmente, a ortogonalidade das subportadoras permite uma superposição que implica em uma maior eficiência espectral quando comparado aos sistemas de multiplexação por divisão de frequência sem sobreposição (GOLDSMITH, 2005).

Para ilustrar de forma mais clara, considere um sistema com $N$ subportadoras de largura de banda $B$. A figural 10 apresenta a disposição de cada subportadora $f_{c}, f_{1}, f_{2}, \ldots$ no espectro com e sem superposição de bandas.

Utilizada na maioria dos sistemas modernos de comunicação móvel, os sistemas de modulação multiportadora foram utilizados inicialmente para aplicações militares em rádios de alta frequência no fim das décadas de 50 e início dos anos 60. Sua utilização em sistemas comerciais, todavia, era impossível na época devido à alta complexidade das implementações que necessitavam de moduladores 

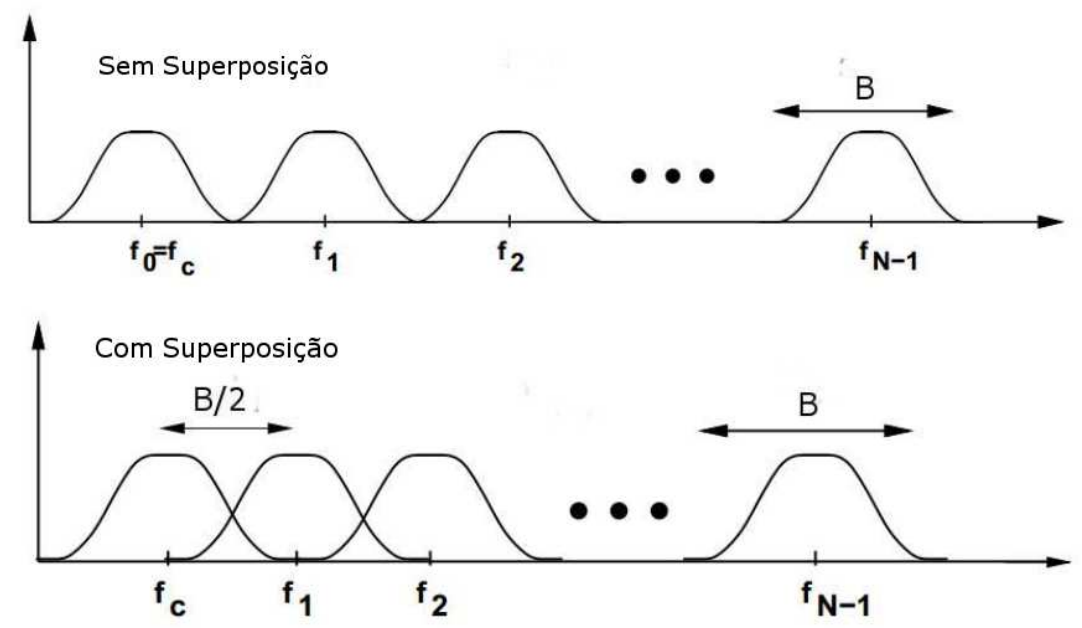

Figura 10: Disposição das subportadoras em sistemas com multiplexação por divisão de frequência sem sobreposição (acima) e com sobreposição (abaixo). Fonte: adaptado de (GOLDSMITH, 2005).

e demoduladores individuais para cada subcanal. Somente vinte anos depois com o desenvolvimento de algoritmos para a implementação da transformada de Fourier, a transformada rápida de Fourier (do inglês, fast Fourier transform, FFT) e a transformada inversa rápida de Fourier (do inglês, inverse fast Fourier transform, IFFT), bem como a constatação de que os sistemas OFDM poderiam ser implementados utilizando estas ferramentas é que se deu início ao processo de popularização da técnica (GOLDSMITH, 2005).

Atualmente, o OFDM está presente em padrões comerciais de comunicação com fio e sem fio tais como WiMax, LTE, LTE-A, IEEE 802.11 a/g, ADSL e ADSL2+ (GOLDSMITH, 2005). Nos sitemas modernos de comunicação que empregam a técnica de múltiplas subportadoras ortogonais, a informação é primeiramente modulada resultando em um símbolo complexo $b_{i}$. A sequência de símbolos $b_{0}, b_{1}, \ldots, b_{N-1}$ alimenta então um conversor serial-paralelo cuja saída é um conjunto de $N$ símbolos modulados que correspondem aos símbolos a serem transmitidos em cada subportadora. Para gerar o sinal de saída do modulador OFDM no tempo $x(t)$ a saída do conversor serial-paralelo alimenta uma transformada inversa discreta de Fourier de $N$ símbolos. A saída da IFFT é o símbolo 
OFDM que consiste de uma sequência $x_{k}=x_{0}, x_{1}, \ldots, x_{N-1}$ de amostras temporais de comprimento $N$ tal que:

$$
x_{k}=\frac{1}{\sqrt{N}} \sum_{i=0}^{N-1} b_{i} e^{æ 2 \pi k i / N}, \quad k=0,1, \ldots, N-1
$$

Desconsiderando a adição de prefixo cíclico, a saída da IFFT alimenta um conversor paralelo-serial e em seguida um conversor digital-analógico, resultando no sinal OFDM em banda base,

$$
x(t)=\frac{1}{\sqrt{N}} \sum_{i=0}^{N-1} b_{i} e^{æ 2 \pi t i / T_{N}}, 0 \leq t \leq T_{N}
$$

onde $T_{N}$ é o período de símbolo OFDM. As frequências de cada subportadora são definidas por $f_{k}=k / T_{N}$ e as amostras da equação (2.58) representam amostras discretas a cada $T_{N} / N$ segundos. Para finalizar a propagação em canais não guiados sem fio, o sinal é convertido para banda passante e transmitido. No receptor, as operações inversas são realizadas de tal forma a recuperar a informação transmitida.

A figura 11 apresenta o diagrama de blocos do transmissor e do receptor OFDM desconsiderando os efeitos nocivos do canal, i.e. ruído de fundo e desvanecimento. Note que é possível que os dados da entrada do modulador sejam oriundos/destinados a diferentes usuários, logo estes usuários utilizam diferentes subportadoras ou blocos de subportadoras para receber/enviar informação. Este tipo de sistema é denominado múltiplo acesso por divisão de frequência ortogonais.

É comum em sistemas OFDMA utilizar a dimensão temporal para que mais usuários utilizem o sistema, porém este não é o foco do trabalho e não será discutido no texto. Note que, ao contrário dos sistemas com espalhamento espectral, 


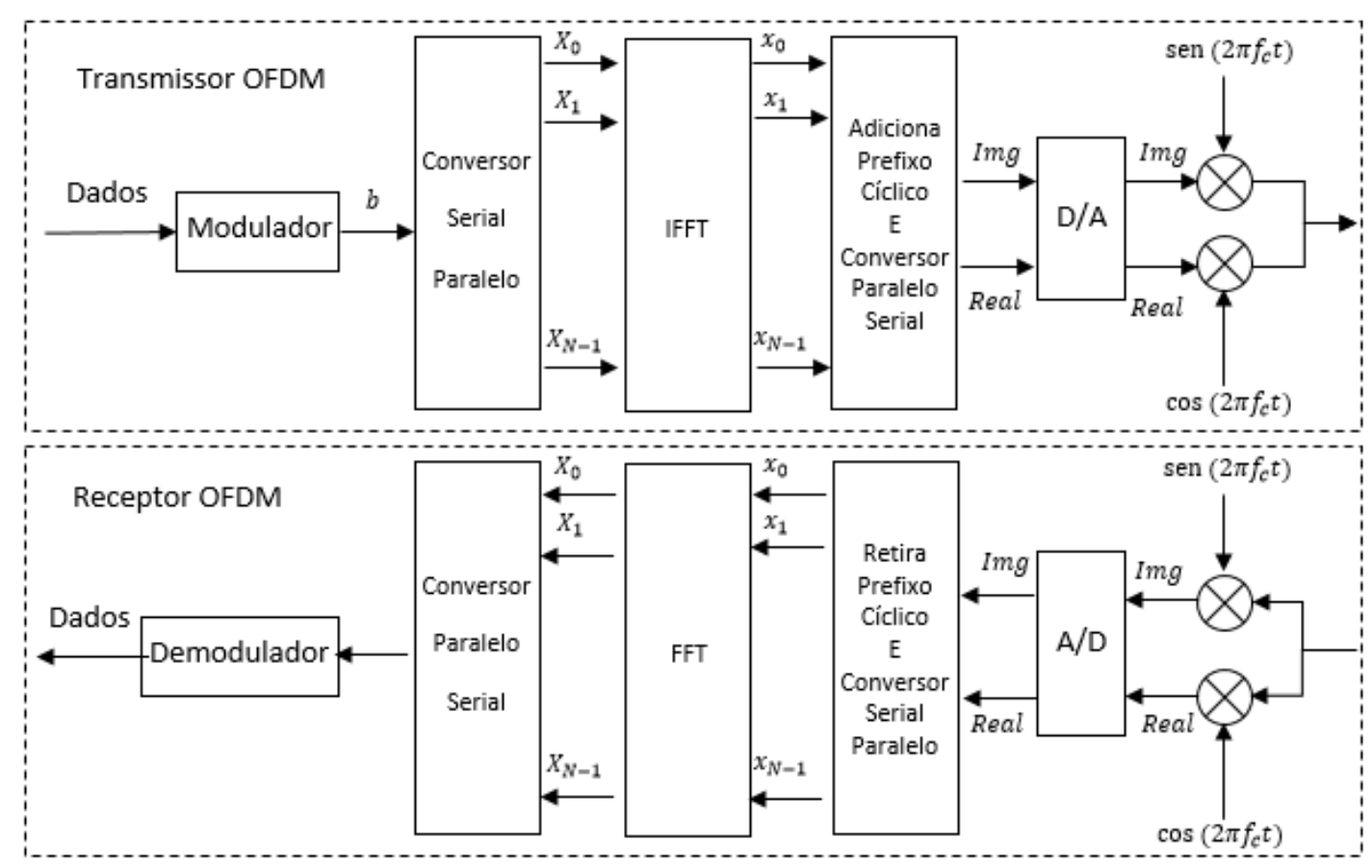

Figura 11: Diagrama de blocos do transmissor e receptor OFDM desconsiderando os efeitos nocivos do canal.

os sistemas com múltiplo acesso por divisão de frequências ortogonais não sofrem limitações com a interferência de múltiplo acesso já que cada subportadora pode estar alocada apenas para um único usuário.

Um dos grandes problemas com a técnica OFDM e, de forma geral, com qualquer sistema de transmissão multiportadora está associado às grandes variações na potência instantânea do sinal transmitido. Isto implica em uma redução da eficiência do amplificador de potência para lidar adequadamente com as grandes excursões do sinal e também na necessidade de se utilizar amplificadores lineares (classe A, B ou AB). O fato de apresentar valores elevados para a razão entre a potência de pico e potência média de transmissão ${ }^{14}$ faz com que as técnicas baseadas em OFDM sejam de difícil implementação no elo de subida (DAHLMAN et al., 2007). Por outro lado, a técnica OFDMA consolidou-se nos principais padrões da quarta geração, e é amplamente utilizado no elo de descida destes padrões, tais como o LTE (EKSTRöM et al., 2006). Desta forma, neste trabalho

\footnotetext{
${ }^{14}$ Denominada PAPR, do inglês, peak to average power ratio.
} 
de doutorado será analisado somente o elo de descida de redes de múltiplo acesso por divisão ortogonal de frequência.

Sendo assim, em sistemas OFDMA, uma importante métrica de qualidade de sinal é a relação sinal-ruído. Considere que na subportadora $k$ esteja alocado o $i$-ésimo usuário. A estação rádio-base transmite o sinal com uma potência $p_{i, k}$ que atravessa um canal com ganhos de potência identificado por, $\left|\mathrm{h}_{i, k}\right|^{2}$. Este canal introduz ainda ruído aditivo branco Gaussiano. Logo, a relação sinal-ruído é definida como a potência do sinal transmitido pela potência do ruído de fundo AWGN, i.e.

$$
\delta_{i, k}^{\text {OFDMA }}=\frac{p_{i, k}\left|\mathrm{~h}_{i, k}\right|^{2}}{\sigma_{k}^{2}}
$$

onde $\delta_{i, k}$ é a relação sinal-ruído do $i$-ésimo usuário na $k$-ésima subportadora e $\sigma_{k}^{2}$ é a potência do ruído na subportadora $k$, assumida, sem perda da generalidade, idêntica para todos os usuários.

A taxa de transmissão do usuário $i$ na subportadora $k$ pode ser obtida a partir da capacidade de canal de Shannon (SHANNON, 1948):

$$
r_{i, k}=B \log _{2}\left(1+\delta_{i, k}\right)
$$

onde $B$ é a banda da subportadora. Note que as métricas de qualidade e desempenho em camada física para redes OFDMA são parecidas com as métricas de desempenho das redes baseadas em espalhamento espectral apresentadas na seção anterior deste capítulo tais como eficiência espectral, eficiência energética e taxa de erro de bit.

Estabelecer métricas de desempenho que envolvam não somente a qualidade do sinal transmitido mas também o gerenciamento feito pelo controle de enlace 
como, por exemplo, tolerância a atraso, provimento estatístico de qualidade de serviço e capacidade de garantir uma taxa mínima de transmissão considerando um método de armazenamento temporário na forma de filas são um grande desafio em redes sem fio, o qual é facilmente tratado em redes cujo meio de transmissão seja guiado (WU; NEGI, 2003).

Com o intuito de estabelecer métricas de desempenho para redes de comunicação sem fio sujeitas a atraso e manutenção de QoS mínimo aceitável a partir de modelos bem estabelecidos de camada física, (WU; NEGI, 2003) propuseram o conceito de capacidade efetiva. Uma breve descrição deste conceito é apresentado na subseção a seguir.

\subsubsection{Capacidade Efetiva}

A capacidade efetiva é uma métrica muito útil de desempenho da rede quando na presença de limitações estatísticas de qualidade de serviço. Considere, desta forma, um sistema contendo um processo que gera tráfego para um controlador de enlace. Este controlador possuí à sua disposição um fila estacionária, logo, os pacotes que não são transmitidos devido a limitações físicas do transmissor ${ }^{15}$, são enviados para esta fila enquanto aguardam sua transmissão. Esta situação é esboçada na figura 12.

O conceito de capacidade efetiva é o dual da largura de banda efetiva, $B_{e}(\theta)$, que foi proposta de forma independente nos trabalhos de (GUéRIN; AHMADI; NAGHSHINEH, 1991), (KELLY, 1991) e (GIBBENS; HUNT, 1991) e descreve a largura de banda mínima necessária para a transmissão de um determinado serviço sujeito a condição de que a cauda da distribuição estatística relacionada ao comprimento da fila tenha taxa de decaimento $\theta$. Em outras palavras, a

\footnotetext{
${ }^{15} \mathrm{Um}$ exemplo prático desta situação acontece quando a quantidade de informação gerada em um intervalo de tempo e que deve ser transmitida é superior à taxa de transmissão de informação do dispositivo, geralmente ocasionada por uma baixa relação sinal-ruído.
} 


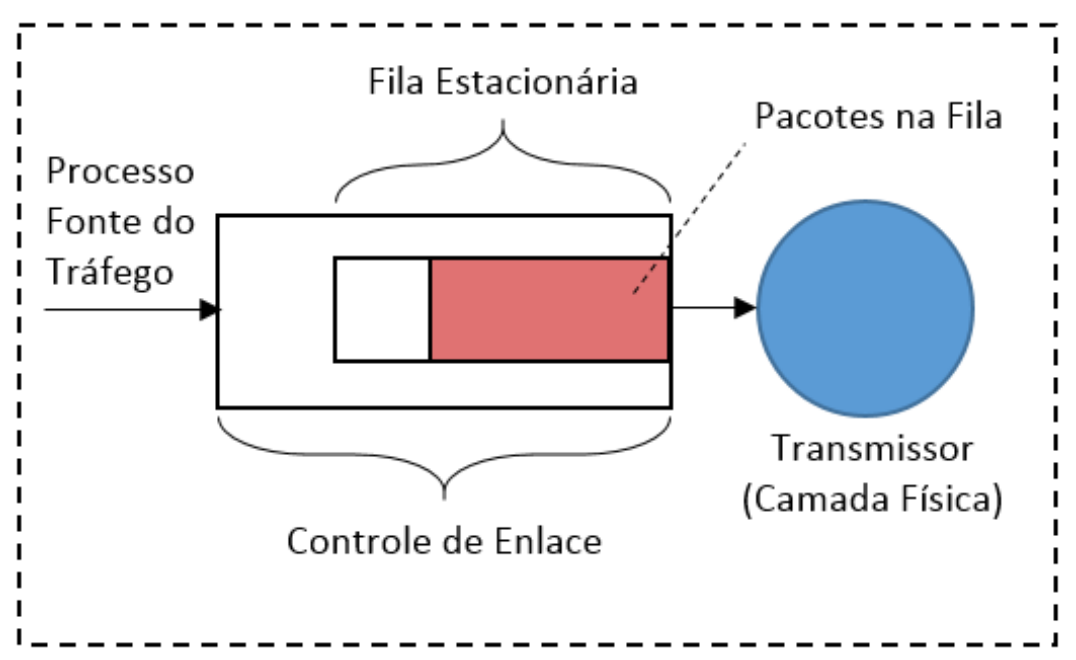

Figura 12: Diagrama de um transmissor com controle de enlance e fila estacionária para armazenamento temporário de informação não enviada.

largura de banda efetiva é a largura de banda mínima necessária para transmissão efetiva de um serviço dado um expoente de qualidade de serviço associado $\theta \geq 0$ (CHANG; THOMAS, 1995).

$\mathrm{Na}$ formulação do conceito de capacidade efetiva os autores (WU; NEGI, 2003) empregam a teoria dos grandes $\operatorname{desvios}^{16}$ e incorporam a idéia de limitações estatísticas de qualidade de serviço através da taxa de decaimento da probabilidade de saturação de um buffer considerando filas de comprimento elevado. Sendo assim, a capacidade efetiva pode ser interpretada como a máxima vazão de um sistema que opera com limitações na probabilidade de violação do tamanho da fila ${ }^{17}$.

A função da capacidade efetiva, denotada por $\mathcal{C}_{\mathrm{e}}(\theta)$, caracteriza a taxa de serviço praticável como função do expoente de qualidade de serviço, assumindo que $\theta \geq 0$. De forma especifica, no trabalho de (WU; NEGI, 2003) a capacidade efetiva é definida como a taxa de recepção máxima e constante na entrada do

\footnotetext{
${ }^{16} \mathrm{~A}$ teoria dos grandes desvios trata do comportamento assintótico de caudas remotas de distribuições de probabilidade. Foi formalmente apresentada no trabalho de (VARADHAN, 1966).

${ }^{17}$ Pacotes de informações são colocados na fila para transmissão quando a quantidade de dados a ser enviada em determinado intervalo de tempo é maior que a quantidade de informação efetivamente transmitida.
} 
controlador de enlace que é suportada garantindo um requisito estatístico de qualidade de serviço, especificado pelo expoente de QoS $\theta$. De forma análoga, a capacidade efetiva pode ser interpretada como a máxima taxa de transmissão sujeita a um atraso máximo tolerável na entrega de informações.

Sendo assim, é preciso revisitar alguns conceitos para introduzir matematicamente o conceito de capacidade efetiva. O primeiro conceito a ser revisto é relacionado a modelos de filas: seja $Q$ o comprimento de uma fila estacionária, e seja $\theta$ a taxa de decaimento da cauda da distribuição de probabilidade do comprimento instantâneo da fila expressa por (CHANG, 1994)

$$
\lim _{q \rightarrow \infty} \frac{\log [\operatorname{Pr}(Q \geq q)]}{q}=-\theta
$$

ou seja, a probabilidade do comprimento da fila $Q$ ultrapassar um limite $q$ decai exponencialmente conforme o limite $q$ aumenta. O parâmetro $\theta>0$ é de fundamental importância para a garantia da qualidade de serviço estatística, expressando a taxa de decaimento exponencial das probabilidades de violação do QoS. Como consequência, para um comprimento tolerável alto de fila estacionária, denotado por $q_{\max }$, a seguinte aproximação é válida para a probabilidade de violação do tamanho máximo da fila (CHANG, 1994)

$$
\operatorname{Pr}\left(Q \geq q_{\max }\right) \approx e^{-\theta q_{\max }}
$$

Desta forma, um valor pequeno de $\theta>0$ implica em uma taxa de dacaimento mais lenta, o que indica que o sistema pode prover somente uma garantia suave ${ }^{18}$ de QoS. Por outro lado, se o valor de $\theta$ é elevado, então a taxa de decaimento é rápida o que implica que condições mais restritivas de qualidade de serviço podem ser suportadas. Particularmente, quando $\theta \rightarrow 0$, o sistema deve tolerar um atraso

\footnotetext{
${ }^{18}$ Suave é empregado no sentido de condições menos restritivas de qualidade de serviço.
} 
de tamanho arbitrário, enquanto que $\theta \rightarrow \infty$, o sistema não pode tolerar nenhum atraso, correspondendo, portanto, a um limite de atraso extremamente rigoroso. Dado a sua proximidade com o provimento de qualidade de serviço estatística, o termo $\theta$ é denominado expoente de qualidade de serviço (WU; NEGI, 2003).

De forma similar, a idéia de fila para transmissão, quando a comunicação experimenta algum atraso, com $D$ denotando o atraso estável observado no controlador de enlace ${ }^{19}$ de comunicação, e admitindo-se um atraso máximo tolerável $d_{\max }$, a seguinte aproximação é verdadeira

$$
\operatorname{Pr}\left(D \geq d_{\max }\right) \approx e^{-\theta \tilde{r} d_{\max }} \leq \epsilon
$$

sendo $\tilde{r}$ a taxa com que a fonte de tráfego entrega informação ao controlador de enlace mensurada em [bits/seg]; $d_{\max }$ é o limite de atraso especificado e requer que a probabilidade de violação deste limite não seja superior a um determinado valor $\epsilon$. Sendo assim, um usuário do sistema pode ser especificado pelo ternário de QoS estatístico $\left(\tilde{r}, d_{\max }, \epsilon\right)$. Logo, em termos de restrições de QoS estatística, o atraso deve ser menor que o limite $d_{\max }$ dentro de uma probabilidade $\epsilon$, o que pode ser interpretado como um requisito de taxa máxima de perda de pacotes (AHN et al., 2010). A partir da equação (2.64) o expoente de QoS para um determinado usuário do sistema pode ser limitado por:

$$
\theta \geq \frac{-\log (\epsilon)}{\tilde{r} d_{\max }} \quad\left[\frac{1}{\text { bits }}\right]
$$

Quando o limite de atraso é a principal métrica de qualidade de serviço do ternário $\left(\tilde{r}, d_{\max }, \epsilon\right)$, é possivel derivar o expoente de qualidade de serviço $\theta_{D}$

\footnotetext{
${ }^{19} \mathrm{O}$ atraso está relacionado ao intervalo de tempo entre o instante em que a informação entra na fila e o instante em que a mesma é transmitida.
} 
referente ao atraso $d_{\max }$, definido como:

$$
\theta_{D}=\theta \tilde{r}=\frac{-\log (\epsilon)}{d_{\max }}
$$

Com esta nova definição é possivel dar outra interpretação à capacidade efetiva: é a taxa máxima e constante de recepção à entrada do controlador de enlace que um determinado serviço suporta, garantindo uma probabilidade limitada de violação do atraso máximo tolerável. Em outras palavras, a capacidade efetiva pode ser definida como a máxima vazão que satisfaz a restrição de comprimento da fila, com probabilidade de violação $\operatorname{Pr}\left(Q \geq q_{\max }\right)$ ou de forma similar, a restrição de atraso máximo, com probabilidade de violação $\operatorname{Pr}\left(D \geq d_{\max }\right)$, para valores de $q_{\max }$ e $d_{\max }$ elevados.

É importante frisar que a capacidade efetiva caracteriza o desempenho em sistemas com filas de grande comprimento. Se o tamanho da fila é finito e pequeno, as taxas de recepção $\tilde{r}$ suportadas serão menores que aquelas previstas através do modelo apresentado. Nestas situações ocorrem perdas de pacote e de dados quando a fila está cheia. Pode-se concluir, portanto, que sistemas com filas menores, de maneira geral, requerem mais energia para garantir a qualidade de serviço enquanto filas de grande extensão podem ser consideradas como um limite e utilizadas como referência (QIAO; GURSOY; VELIPASALAR, 2009).

A expressão analítica para o cálculo da capacidade efetiva de um processo estocástico arbitrário é, via de regra, complicada e de difícil análise. Todavia, quando o serviço puder ser caracterizado como um processo estocástico independente e identicamente distribuído, a expressão analítica da capacidade efetiva é simplificada (AHN et al., 2010).

O comportamento estocástico da fonte de tráfego na entrada do controlador de enlace pode ser modelado assintoticamente pela sua largura de banda 
efetiva $B_{e}(\theta)$. Considere que a sequência $\{R[j], j=1,2, \ldots\}$ denote um serviço de transmissão representado por um processo ergódico e estacionário nos instantes de tempo discretos $j$ e mensurado em bits. Adicionalmente, considere que $\mathcal{R}(t) \triangleq \sum_{j}^{t} R[j]$ é a soma parcial deste processo, em bits, no intervalo $j=1,2, \ldots, t$.

Assuma que a função geradora do momento logarítmico assintótico de $\mathcal{R}(t)$ definida como (WU; NEGI, 2003),

$$
\Lambda(-\theta)=\lim _{t \rightarrow \infty} \frac{1}{t} \log \left(\mathbb{E}\left[e^{-\theta \mathcal{R}(t)}\right]\right)
$$

existe para todo $\theta \geq 0$ e é convexa e diferenciável para todo $\theta \in \mathbb{R}$ (CHANG, 1994). Note que o operador de esperança matemática, $\mathbb{E}$, é empregado em relação ao tráfego $\mathcal{R}(t)$ uma vez que assume-se que este é estocástico e modelado assintoticamente por sua largura de banda efetiva $B_{\mathrm{e}}(\theta)=-\frac{\Lambda(-\theta)}{\theta}, \forall \theta \geq 0$ (WU; NEGI, 2003; CHANG; THOMAS, 1995).

Logo, a capacidade efetiva de um serviço de transmissão para um requisito estatístico de qualidade de serviço especificado pelo expoente $\theta>0$ pode ser definida como (WU; NEGI, 2003):

$$
\begin{aligned}
\mathcal{C}_{\mathrm{e}}(\theta) \triangleq \frac{\Lambda(-\theta)}{\theta} & =-\lim _{t \rightarrow \infty} \frac{1}{t \theta} \log \left(\mathbb{E}\left[e^{-\theta \sum_{j}^{t} R[j]}\right]\right) \\
& =-\lim _{t \rightarrow \infty} \frac{1}{t \theta} \log \left(\mathbb{E}\left[e^{-\theta \mathcal{R}(t)}\right]\right), \quad\left[\frac{\text { bits }}{\text { quadro }}\right]
\end{aligned}
$$

É importante observar que quando a sequência $\{R[j], j=1,2, \ldots\}$ associada ao serviço de transmissão $\mathcal{R}(t)$ é um processo estocástico descorrelacionado ${ }^{20}$ a

\footnotetext{
${ }^{20}$ Por exemplo, comunicação em canais com desvanecimento descorrelacionado em diferentes intervalos de tempo.
} 
capacidade efetiva pode ser simplificada para,

$$
\mathcal{C}_{\mathrm{e}}(\theta)=-\frac{1}{\theta} \log \left(\mathbb{E}\left[e^{-\theta R[j]}\right]\right), \quad \forall j=1,2, \ldots
$$

isto é, a capacidade efetiva é função da taxa de transmissão do serviço no intervalo discreto $j$.

O conceito de capacidade efetiva, definido de forma genérica ${ }^{21}$ até este ponto, e os resultados obtidos por (CHANG, 1994) foram utilizados no trabalho de (QIAO; GURSOY; VELIPASALAR, 2009) para a análise de comunicações em canais do tipo on-off. Como resultado, a capacidade efetiva para este tipo de canal dado uma relação sinal-ruído, denominada $\delta$, característica do mesmo, pode ser normalizada pela duração da transmissão $T$ e pela largura de banda do canal $B$; assim para um dado expoente de QoS estatístico $\theta$, a capacidade efetiva para canais on-off normalizada pela duração de quadro $T$ e largura de banda $B$ pode ser computada como:

$$
\begin{aligned}
\mathcal{C}_{\mathrm{e}}^{\text {on-off }}(\delta, \theta) & =\frac{1}{T B} \max _{r \geq 0}-\frac{\Lambda(-\theta)}{\theta} \quad\left[\frac{\text { bits }}{\mathrm{s} \cdot \text { Hertz }}\right] \\
& =\max _{r \geq 0}-\frac{1}{\theta T B} \log \left(x_{1}+x_{2} e^{-\theta T r}\right)
\end{aligned}
$$

onde $x_{1}$ e $x_{2}$ são as probabilidades do estado desligado e ligado, respectivamente, de tal forma que $x_{1}+x_{2}=1$. Adicionalmente, $r$ é a taxa de transmissão em bits por segundo, sendo uma função não linear da relação sinal-ruído do canal. Portanto, uma vez que a capacidade de canal de Shannon é um limite superior para a taxa de transmissão $r$, o valor máximo assumido pela capacidade efetiva ocorre quando a taxa de transmissão $r$ é equivalente a este limite, i.e. $r=$ $B \log (1+\delta)$.

\footnotetext{
${ }^{21}$ Sem a consideração de algum sistema de comunicação específico, e.g. OFDMA.
} 
Sendo assim, é imediato estender os resultados de capacidade efetiva em canais de comunicação on-off para sistemas OFDMA. Considere que a sequência $\{R[j], j=1,2, \ldots\}$ seja um processo estocástico descorrelacionado. Desta forma, $\mathcal{R}(t)$ pode ser visto como a ocupação do usuário $i$ em uma subportadora arbitrária em cada quadro de duração $T$ de tal forma que a taxa de transmissão total do usuário $i$ possa ser calculada como:

$$
\mathcal{R}_{i}=T \sum_{k=1}^{N} \phi_{i, k} r_{i, k} \quad\left[\frac{\text { bits }}{\text { quadro }}\right]
$$

onde $\phi_{i, k} \in\{0,1\}$ é uma variável binária responsável por indicar se o $i$-ésimo usuário está transmitindo na $k$-ésima subportadora, $r_{i, k}$ é a capacidade de canal de Shannon do usuário $i$ na subportadora $k$, mensurado em bits por segundo.

Note que é possível definir o conceito de matriz de alocação de subportadoras a partir do conjunto de variáveis $\phi_{i, k}$. Desta forma, uma matriz factível $^{22}$ de alocação de subportadoras é uma matriz de dimensão $U$ por $N$ que satisfaz:

$$
\phi \in \Omega \triangleq\left\{\phi \in\{0,1\}^{U \times N} \mid \sum_{i=1}^{U} \phi_{i, k} \leq 1, \forall \phi_{i, k} \in \phi \text { e } k=1, \ldots, N\right\}
$$

onde $U$ é o número de usuários, $N$ o número de subportadoras. A condição na definição acima indica que apenas um usuário do sistema pode estar ativo, i.e. transmitindo, na $k$-ésima subportadora.

Sendo assim, a partir da definição em (2.70) e (2.71) é possível definir a capacidade efetiva do sistema OFDMA cujo expoente de qualidade de serviço estatística do usuário $i$ é $\theta_{i}>0$ como,

\footnotetext{
${ }^{22}$ Que pode ser utilizada de forma prática dada as limitações do sistema OFDMA.
} 


$$
\begin{aligned}
\mathcal{C}_{\mathrm{e}}(\mathbf{P}, \boldsymbol{\phi}, \boldsymbol{\theta}) & =-\sum_{i=1}^{U} \frac{1}{\theta_{i}} \log \left(\mathbb{E}\left[e^{-\theta_{i} \mathcal{R}_{i}}\right]\right) \\
& =-\sum_{i=1}^{U} \frac{1}{\theta_{i}} \log \left(\mathbb{E}\left[e^{-\theta_{i} T \sum_{k=1}^{N} \phi_{i, k} r_{i, k}}\right]\right) \\
& =-\sum_{i=1}^{U} \sum_{k=1}^{N} \frac{1}{\theta_{i}} \log \left(\mathbb{E}\left[e^{-\theta_{i} T \phi_{i, k} r_{i, k}}\right]\right) \\
& =-\sum_{i=1}^{U} \sum_{k=1}^{N} \frac{\phi_{i, k}}{\theta_{i}} \log \left(\mathbb{E}\left[e^{-\theta_{i} T r_{i, k}}\right]\right) \\
& =-\sum_{i=1}^{U} \sum_{k=1}^{N} \frac{\phi_{i, k}}{\theta_{i}} \log \left(\mathbb{E}\left[e^{-\theta_{i} T B \log _{2}\left(1+\frac{p_{i, k}\left|h_{i, k}\right|^{2}}{N_{0} B}\right)}\right]\right)\left[\frac{\text { bits }}{\text { quadro }}\right]
\end{aligned}
$$

onde $p_{i, k}$ é a potência de transmissão e $\mathrm{h}_{i, k}$ é o ganho complexo de canal do usuário $i$ na $k$-ésima subportadora, ambos admitidos constante durante o intervalo de transmissão T. P é a matriz de alocação de potências cujos elementos são $p_{i, k}$. Adicionalmente, $N_{0}$ é a densidade espectral de potência do ruído branco Gaussiano de fundo, em [Watts/Hertz] e $B$ é a largura de banda da subportadora.

No desenvolvimento da definição de capacidade efetiva para sistemas OFDMA, duas passagens são importantes e merecem atenção: a primeira da equação (2.73) para (2.74), uma vez que a variável $\phi_{i, k}$ é binária, a múltiplicação na função exponencial ou fora do logarítmo é equivalente, i.e.:

$$
-\sum_{i=1}^{U} \sum_{k=1}^{N} \frac{1}{\theta_{i}} \log \left(\mathbb{E}\left[e^{-\theta_{i} T \phi_{i, k} r_{i, k}}\right]\right)=\sum_{i=1}^{U} \sum_{k=1}^{N} \frac{\phi_{i, k}}{\theta_{i}} \log \left(\mathbb{E}\left[e^{-\theta_{i} T r_{i, k}}\right]\right)
$$

pois para $\phi_{i, k}=1$, 


$$
\underbrace{\frac{1}{\theta_{i}} \log \left(\mathbb{E}\left[e^{-\theta_{i} T r_{i, k}}\right]\right)}_{\text {Substituindo } \phi_{i, k}=1 \text { em }(2.74)}=\underbrace{\frac{1}{\theta_{i}} \log \left(\mathbb{E}\left[e^{-\theta_{i} T r_{i, k}}\right]\right)}_{\text {Substituindo } \phi_{i, k}=1 \text { em }(2.73)}
$$

e para $\phi_{i, k}=0$

$$
\begin{aligned}
\frac{1}{\theta_{i}} \log \left(\mathbb{E}\left[e^{-\theta_{i} T \phi_{i, k} r_{i, k}}\right]\right) & =\frac{1}{\theta_{i}} \log \left(\mathbb{E}\left[e^{0}\right]\right)=0 \\
\frac{\phi_{i, k}}{\theta_{i}} \log \left(\mathbb{E}\left[e^{-\theta_{i} T r_{i, k}}\right]\right) & =\frac{0}{\theta_{i}} \log \left(\mathbb{E}\left[e^{-\theta_{i} T r_{i, k}}\right]\right)=0
\end{aligned}
$$

A segunda passagem importante é da equação (2.74) para (2.75). Neste caso, a taxa de transmissão de informação $r_{i, k}$ é considerada a capacidade máxima do canal para uma da relação sinal-ruído obtida através da equação de capacidade de canal de Shannon (SHANNON, 1948).

Assumindo-se um canal sem linha de visada, é comum modelar o ganho complexo de canal como a soma de duas varáveis aleatórias Gaussianas de média zero e variância unitária, de tal forma que os ganhos de amplitude do canal $\left|\mathrm{h}_{i, k}\right|$ assumem uma distribuição estatística de Rayleigh e por conseguinte os ganhos de potência do canal, $\underline{\mathrm{h}}_{i, k}=\left|\mathrm{h}_{i, k}\right|^{2}$, assumem uma distribuição estatística exponencial cuja função densidade de probabilidade é $\mathrm{f}\left(\underline{\underline{h}}_{i, k}\right)=\alpha e^{-\alpha \underline{\underline{h}}_{i, k}}$ onde o parâmetro $\alpha$ é o inverso do valor médio esperado da distribuição (GOLDSMITH, 2005).

Uma vez que $\mathrm{f}\left(\underline{\underline{h}}_{i, k}\right)$ é contínua e diferenciável em relação ao ganho de potência do canal, o termo $\mathbb{E}\left[e^{-\theta_{i} T r_{i, k}}\right]$ pode ser computado como:

$$
\mathfrak{E}_{i, k}=\mathbb{E}\left[e^{-\theta_{i} T r_{i, k}}\right]=\int_{0}^{\infty} e^{-\theta_{i} T B \log _{2}\left(1+\frac{p_{i, k} \underline{h_{i, k}}}{N_{0} B}\right)} \mathrm{f}\left(\underline{\underline{h}}_{i, k}\right) d \underline{\mathrm{h}}_{i, k}
$$

Por simplicidade de análise e sem perda da generalidade, pode-se assumir que a média dos ganhos de potência é unitária, i.e. $\alpha=1$. Reescrevendo a equação 
(2.80) obtêm-se:

$$
\mathfrak{E}_{i, k}=\int_{0}^{\infty} e^{-\theta_{i} T B \log _{2}\left(1+\frac{p_{i, k} \underline{\mathbf{h}}_{i, k}}{N_{0} B}\right)} e^{-\underline{\mathbf{h}}_{i, k}} d \underline{\mathbf{h}}_{i, k}
$$

Empregando-se as seguintes substituições:

$$
x=1+\underline{\mathrm{h}}_{i, k} y, \quad y=\frac{p_{i, k}}{N_{0} B}, \quad A_{i}=\frac{\theta_{i} T B}{\log (2)}
$$

e assumindo $^{23}$ que $y>0$ e $x>0$, a integral pode ser computada como,

$$
\begin{aligned}
\mathfrak{E}_{i, k} & =\int_{0}^{\infty} e^{-\theta_{i} T B \log _{2}\left(1+\frac{p_{i, k} \underline{\underline{h}}_{i, k}}{N_{0} B}\right)} e^{-\underline{\underline{h}}_{i, k}} d \underline{\underline{h}}_{i, k} \\
& =\int_{0}^{\infty} e^{-\underline{\underline{h}}_{i, k}}\left(1+\underline{\underline{h}}_{i, k} y\right)^{-A_{i}} d \underline{\underline{h}}_{i, k} \\
& =\frac{e^{\frac{1}{y}}}{y} \int_{1}^{\infty} e^{-\frac{x}{y}} x^{-A_{i}} d x \\
& =\frac{N_{0} B}{p_{i, k}} e^{\frac{N_{0} B}{p_{i, k}}} E_{A_{i}}\left[\frac{N_{0} B}{p_{i, k}}\right]
\end{aligned}
$$

onde $E_{A}[z] \triangleq \int_{1}^{\infty} e^{-z t} t^{-A} d t$ é a função integral exponencial. Com a equação (2.83) é possivel definir a capacidade efetiva de um sistema OFDMA com $U$ usuários e $N$ subcanais suscetíveis a desvanecimento de pequena escala do tipo Rayleigh descorrelacionados incorporando estes resultados à equação (2.75). Assim, a capacidade efetiva será uma função dos expoentes de qualidade de serviço estatística, da matriz de alocação de subportadoras e da potência de transmissão

\footnotetext{
${ }^{23}$ Uma vez que todos os valores envolvidos nas relações de $y$ e $x$ são posivitos, é natural assumir que ambos sejam variáveis de valores positivos
} 
de cada usuário,

$$
\mathcal{C}_{\mathrm{e}, \mathrm{RFC}}(\boldsymbol{\theta}, \boldsymbol{\phi}, \mathbf{P})=\sum_{i=1}^{U} \sum_{k=1}^{N}-\frac{\phi_{i, k}}{\theta_{i}} \log \left(\frac{N_{0} B}{p_{i, k}} e^{\frac{N_{0} B}{p_{i, k}}} E_{A_{i}}\left[\frac{N_{0} B}{p_{i, k}}\right]\right)
$$

onde $i$ e $k$ são os indexadores de usuário e subportadora, respectivamente, $\phi$ é a váriavel binária que representa a atividade do usuário $i$ na subportadora $k, p$ é a potência de transmissão, $N_{0}$ é a densidade espectral de potência do ruído, $B$ é a banda de cada uma das subportadoras ortogonais, $\theta_{i}$ o exponente de qualidade de serviço do usuário $i$ assumido idêntico para todas as subportadoras e, finalmente, $A_{i}=\frac{\theta_{i} T B}{\log (2)}$. A matriz $\mathbf{P}$ de alocação de potências de transmissão, possui dimensão $U \times N$. O vetor $\boldsymbol{\theta}=\left[\theta_{1}, \theta_{2}, \ldots, \theta_{U}\right]^{T}$ é o vetor de exponentes de QoS, e $\boldsymbol{\phi}$ é a matriz de alocação de subportadora definida em (2.72).

A partir de (2.84) é possivel derivar a expressão para a capacidade efetiva de cada usuário $i=1, \ldots, U$, denotada por $\mathcal{C}_{\mathrm{e}, \mathrm{RFC}}^{i}$,

$$
\mathcal{C}_{\mathrm{e}, \mathrm{RFC}}^{i}=-\frac{1}{\theta_{i}} \sum_{k=1}^{N} \phi_{i, k} \log \left(\frac{N_{0} B}{p_{i, k}} e^{\frac{N_{0} B}{p_{i, k}}} E_{A_{i}}\left[\frac{N_{0} B}{p_{i, k}}\right]\right)
$$

Antes de apresentar a definição de eficiência energética efetiva, derivada a partir do conceito de capacidade efetiva, faz-se necessário adaptar o modelo de consumo de potência apresentado na seção 2.1.1.1, introduzindo o conceito de alocação de subportadora e adaptando o modelo para o elo de descida de redes de múltiplo acesso por divisão de frequências ortogonais ${ }^{24}$. Desta forma, o consumo de potência no elo de descida de sistemas OFDMA sem fio é computado a partir

\footnotetext{
${ }^{24} \mathrm{O}$ modelo de potência estabelecido para o elo de subida de sistemas com espalhamento espectral pode ser utilizado para o elo de descida de sistemas OFDMA e as diferenças de gastos de potência dos circuitos destes sistemas pode ser incoporada na potência gasta pelos filtro lineares de transmissão e recepção $\left(P_{\mathrm{FiR}}\right.$ e $P_{\mathrm{FiT}}$ na equação $(2.27)$
} 
do cálculo do consumo de potência de cada usuário em cada subportadora, por:

$$
P_{\mathrm{T}}^{O F D M A}\left(\boldsymbol{\phi}, \mathbf{R}_{\mathrm{T}}, \mathbf{P}\right)=P_{\mathrm{C}}+\sum_{i=1}^{U} \sum_{k=1}^{N} \varrho \phi_{i, k} p_{i, k}+\sum_{i=1}^{U} \sum_{k=1}^{N}(\vartheta+v) \phi_{i, k} r_{i, k}
$$

onde $\mathbf{R}_{\mathrm{T}}$ é a matriz $U \times N$ de taxas de transmissão instantâneas equivalentes a capacidade de Shannon do canal, tal que cada elemento de $\mathbf{R}_{\mathrm{T}}$ na $i$-ésima linha e $k$-ésima coluna é equivalente a $r_{i, k}=B \log \left(1+\delta_{i, k}\right), i=1, \ldots, U$ e $k=1, \ldots, N$, sendo $r_{i, k}$ a taxa de transmissão instantânea do usuário $i$ na $k$-ésima subportadora; $\varrho$ é a ineficiência do amplificador de potência da estação rádio-base, $\vartheta$ e $v$ são taxas de crescimento da potência de acordo com a taxa de transmissão atingida; a primeira em termos de potência de transmissão e a segunda em termos de potência consumida pelos circuitos.

Estabelecido o modelo de consumo de potência e utilizando o conceito de capacidade efetiva, é possivel definir a eficiência energética efetiva do sistema OFDMA como sendo a quantidade de informação por unidade de energia consumida pelo sistema de transmissão de forma contínua, de acordo com um atraso máximo tolerável na entrega da informação e uma probabilidade de violação do tamanho da fila do controlador de enlace.

Matematicamente, a eficiência energética efetiva do sistema OFDMA, em bits por Joule, $\mathrm{e}^{25}$ :

$$
\xi_{\mathrm{e}, \mathrm{RFC}}=\frac{\mathcal{C}_{\mathrm{e}, \mathrm{RFC}}(\boldsymbol{\theta}, \boldsymbol{\phi}, \mathbf{P})}{P_{\mathrm{T}}\left(\boldsymbol{\phi}, \mathbf{R}_{\mathrm{T}}, \mathbf{P}\right)}=\frac{\sum_{i=1}^{U} \sum_{k=1}^{N}-\frac{\phi_{i, k}}{\theta_{i}} \log \left(\frac{N_{0} B}{p_{i, k}} e^{\frac{N_{0} B}{p_{i, k}}} E_{A_{i}}\left[\frac{N_{0} B}{p_{i, k}}\right]\right)}{T\left(P_{\mathrm{C}}+\sum_{i=1}^{U} \sum_{k=1}^{N} \varrho \phi_{i, k} p_{i, k}+\sum_{i=1}^{U} \sum_{k=1}^{N}(\vartheta+v) \phi_{i, k} r_{i, k}\right)}
$$

\footnotetext{
${ }^{25}$ Por conveniência, o termo $O F D M A$ presente em $P_{\mathrm{T}}^{O F D M A}$ na equação (2.86) é reduzido a $P_{\mathrm{T}}$.
} 
onde $T$ é o período de transmissão. Considerando, de forma análoga, a eficiência energética efetiva do usuário $i$ pode ser definida como:

$$
\xi_{\mathrm{e}, \mathrm{RFC}}^{i}=\frac{\mathcal{C}_{\mathrm{e}, \mathrm{RFC}}^{i}\left(\theta_{i}, \boldsymbol{\phi}_{i}, \mathbf{p}_{i}\right)}{P_{\mathrm{T}}^{i}\left(\boldsymbol{\phi}_{i}, \mathbf{r}_{i}, \mathbf{p}_{i}\right)}=\frac{\sum_{k=1}^{N}-\frac{\phi_{i, k}}{\theta_{i}} \log \left(\frac{N_{0} B}{p_{i, k}} e^{\frac{N_{0} B}{p_{i, k}}} E_{A_{i}}\left[\frac{N_{0} B}{p_{i, k}}\right]\right)}{T\left(P_{\mathrm{C}}+\sum_{k=1}^{N} \varrho \phi_{i, k} p_{i, k}+\sum_{k=1}^{N}(\vartheta+v) \phi_{i, k} r_{i, k}\right)}
$$




\section{MÉTODOS DE OTIMIZAÇÃO DETERMINÍSTICOS E HEURÍSTICOS}

Neste capítulo serão discutidos e apresentados os conceitos relacionados ao conceito de otimização, problemas de otimização, bem como as ferramentas matemáticas determinísticas e aos métodos heurísticos que foram utilizados para solucionar os problemas de otimização discutidos no capítulo 4.

O capítulo está subdividido em cinco seções: a primeira seção é introdutória e apresenta a formalização (enunciado formal) de um problema de otimização e uma classificação básica dos problemas de otimização quanto a natureza de suas equações e inequações, variáveis e funções. A segunda seção apresenta os conceitos relacionados à otimização convexa, desde a definição básica de convexidade para conjuntos e funções, até o método de decomposição dual de Lagrange (LAGRANGE, 1811). A terceira seção tem como foco os fundamentos de programação fracional não linear e, de forma mais específica, o método de Dinkelbach (DINKELBACH, 1967). Na quarta seção são apresentados os conceitos de teoria de jogos (VON NEUMANN; MORGENSTERN, 1944), equilíbrio de Nash (NASH, 1950b) e jogos não cooperativos (NASH, 1951). Finalmente, na última seção do capítulo são apresentados os métodos heurísticos utilizados neste trabalho: a otimização por enxame de partículas (do inglês, particle swarm optimization, PSO) (KENNEDY; EBERHART, 1995) e o algoritmo dos vaga-lumes (do inglês, firefly algorithm, FA) (YANG, 2008). 


\subsection{Problemas de Otimização}

A otimização é um aspecto muito importante em todo problema que envolve tomadas de decisão, seja este um problema de engenharia, economia, logística, biologia ou qualquer outra área do conhecimento. Escolher a melhor alternativa dentre todas as possibilidades existentes ou possíveis sem necessariamente observar os resultados provenientes de cada alternativa em particular é o objeto de estudo de uma área da matemática conhecida como pesquisa operacional (BRADLEY; HAX; MAGNANTI, 1977; CHONG; ZAK, 2001).

Note que o conceito de melhor escolha ou melhor decisão está sempre atrelado a alguma função objetivo ou indicador de desempenho que avalia numericamente o quão boa uma alternativa é. Adicionalmente, a tomada de decisão pode ser submetida a restrições que devem ser satisfeitas alterando então o conjunto de possíveis alternativas (candidatas a solução) também conhecido como domínio do problema de otimização (NOCEDAL; WRIGHT, 2006; CHONG; ZAK, 2001). Um problema de otimização apresenta o seguinte formalismo (BOYD; VANDENBERGHE, 2004):

$$
\begin{array}{ll}
\text { minimizar } & f(\mathbf{x}) \\
\text { sujeito à } & g_{i}(\mathbf{x}) \leq b_{i}, \quad i=1, \ldots, m \\
& h_{i}(\mathbf{x})=0, \quad i=1, \ldots, k
\end{array}
$$

No problema de otimização em (3.1) a função $f: \mathbb{R}^{n} \rightarrow \mathbb{R}$ é denominada função objetivo, o vetor $\mathbf{x}=\left[x_{1}, x_{2}, \ldots, x_{n}\right]$ é a variável de decisão, as funções $g_{i}: \mathbb{R}^{n} \rightarrow \mathbb{R}$ com $i=1, \ldots, m$ são denominadas restrições de desigualdade do problema, as constantes $b_{i}$ são os limites para cada restrição, e $h_{i}: \mathbb{R}^{n} \rightarrow \mathbb{R}$ com $i=1, \ldots, k$ são as restrições de igualdade. Um vetor $\mathbf{x}^{*}$ é denominado ótimo 
ou solução do problema (3.1) se ele possui o menor valor de função objetivo entre todos os vetores que satisfazem as restrições, i.e. para qualquer $\mathbf{z}$ que satisfaça $g_{1}(\mathbf{z}) \leq b_{1}, \ldots, g_{m}(\mathbf{z}) \leq b_{m}$ e $h_{1}(\mathbf{z})=\ldots=h_{k}(\mathbf{z})=0$ temos que $f\left(\mathbf{x}^{*}\right) \leq f(\mathbf{z})$. É importante observar também que embora a forma tradicional defina um problema de minimização como o em (3.1) o problema de maximização pode ser definido utilizando o negativo da função objetivo (CHONG; ZAK, 2001; BOYD; VANDENBERGHE, 2004).

Dentro do conjunto de todos os problemas de otimização existem diversas categorias que são identificadas por características específicas. De uma forma mais simples, os problemas de otimização podem, primeiramente, ser divididos em problemas de otimização contínuos e discretos: o primeiro quando as variáveis de decisão puderem assumir quaisquer valores no conjunto dos números reais, o segundo por sua vez quando as variáveis de decisão assumirem valores em um conjunto discreto, normalmente um subconjunto dos números inteiros (BRADLEY; HAX; MAGNANTI, 1977). Os problemas em (3.2) apresentam uma versão contínua e uma discreta do problema de otimização em (3.1).

$$
\begin{aligned}
& \text { minimizar } f(\mathbf{x}) \quad \text { minimizar } f(\mathbf{x}) \\
& \text { sujeito à } \quad g_{i}(\mathbf{x}) \leq 0, \quad i=1, \ldots, m \quad \text { sujeito à } \quad g_{i}(\mathbf{x}) \leq 0, \quad i=1, \ldots, m \\
& h_{i}(\mathbf{x})=0, \quad i=1, \ldots, k \quad h_{i}(\mathbf{x})=0, \quad i=1, \ldots, k \\
& \mathbf{x} \in \mathbb{R}^{n} \quad \mathbf{x} \in \mathbb{Z}^{n} \\
& \text { Problema de Otimização Contínuo } \\
& \text { Problema de Otimização Discreto }
\end{aligned}
$$

Em segundo lugar, os problemas de otimização podem ser classificados em com ou sem restrições. Problemas com restrição possuem $m$ funções do tipo $g_{i}(\mathbf{x})$ de restrição de desigualdade e $k$ funções do tipo $h_{i}(\mathbf{x})$ de restrição de igualdade, como é possível observar em (3.1), e podem abranger desde simples restrições 
até complexos sistemas de (in)equações que moldam a relação entre as variáveis de decisão. Problemas sem restrições por sua vez são muito comuns visto que problemas com restrição podem, muitas vezes, ser transformados em problemas sem restrição através do uso de um termo penalizador na função objetivo (ANTONIOU; LU, 2007).

O terceiro ponto a partir do qual emergem classes de problemas é quanto ao número de objetivos existentes no problema: nenhum, um ou vários objetivos. Os problemas de otimização sem objetivos normalmente envolvem a solução de sistemas de (in)equações e muitas vezes são tratados como casos especiais de problemas de otimização uni/multi-objetivo. Um exemplo deste caso é o problema linear complementar (MURTY, 1988) cujo primeiro algoritmo para solução foi desenvolvido em 1968 por Richard W. Cottle e George B. Dantzig (COTTLE; DANTZIG, 1968). Dado uma matriz $\mathbf{M} \in \mathbb{R}^{n \times n}$ e um vetor coluna $\mathbf{q} \in \mathbb{R}^{n}$, o problema linear complementar é encontrar $\mathbf{w}=\left[w_{1}, \ldots, w_{n}\right]^{T}$ e $\mathbf{z}=\left[z_{1}, \ldots, z_{n}\right]^{T}$ que satisfaçam:

$$
\left\{\begin{array}{l}
\mathbf{w}-\mathbf{M} \mathbf{z}=\mathbf{q} \\
\mathbf{w} \geq 0 \\
\mathbf{z} \geq 0 \\
w_{i} z_{i}=0, \quad \forall i=1, \ldots, n
\end{array}\right.
$$

Note que no problema apresentado em (3.3) não há função objetivo. Adicionalmente, observa-se que as duas inequações e as duas equações representam restrições do problema. Não obstante, as definições enunciadas anteriormente da matrix $\mathbf{M}$ e do vetor $\mathbf{q}$ determinam que o problema em questão deve ser classificado como problema de otimização contínuo com restrições sem objetivo (MURTY, 1988; University of Wisconsin - Madison, 2013). 
De forma análoga e com o intuito de diferenciar os casos uni-objetivo e multiobjetivo os seguintes problemas são apresentados (BRANKE et al., 2008):

$$
\begin{array}{ll}
\operatorname{minimizar} & f(\mathbf{x}) \\
\text { sujeito à } & g_{i}(\mathbf{x}) \leq 0, \quad i=1, \ldots, m \\
& h_{i}(\mathbf{x})=0, \quad i=1, \ldots, k \\
& \mathbf{x} \in \mathbb{R}^{n}
\end{array}
$$$$
\text { Problema de Otimização Uni-objetivo }
$$

$$
\begin{aligned}
& \operatorname{minimizar}\left\{f_{1}(\mathbf{x}), \ldots, f_{n}(\mathbf{x})\right\} \\
& \text { sujeito à } \quad g_{i}(\mathbf{x}) \leq 0, \quad i=1, \ldots, m \\
& h_{i}(\mathbf{x})=0, \quad i=1, \ldots, k \\
& \mathbf{x} \in \mathbb{R}^{n} \\
& \text { Problema de Otimização Multi-objetivo }
\end{aligned}
$$

Note que no caso uni-objetivo apenas uma função deve ser minimizada enquanto no problema multi-objetivo existem $n$ funções a serem minimizadas simultaneamente. É importante frisar que os objetivos podem ser conflitantes, o que implica que o vetor $\mathbf{x}$ que minimiza uma determinada função não é necessariamente o mesmo que minimiza outra função. De fato, em muitos problemas práticos, o vetor que minimiza uma determinada função do conjunto de objetivos pode ser exatamente o mesmo que maximiza outra função do mesmo conjunto.

A figura 13 sintetiza esta classificação simplificada para problemas de otimização. 


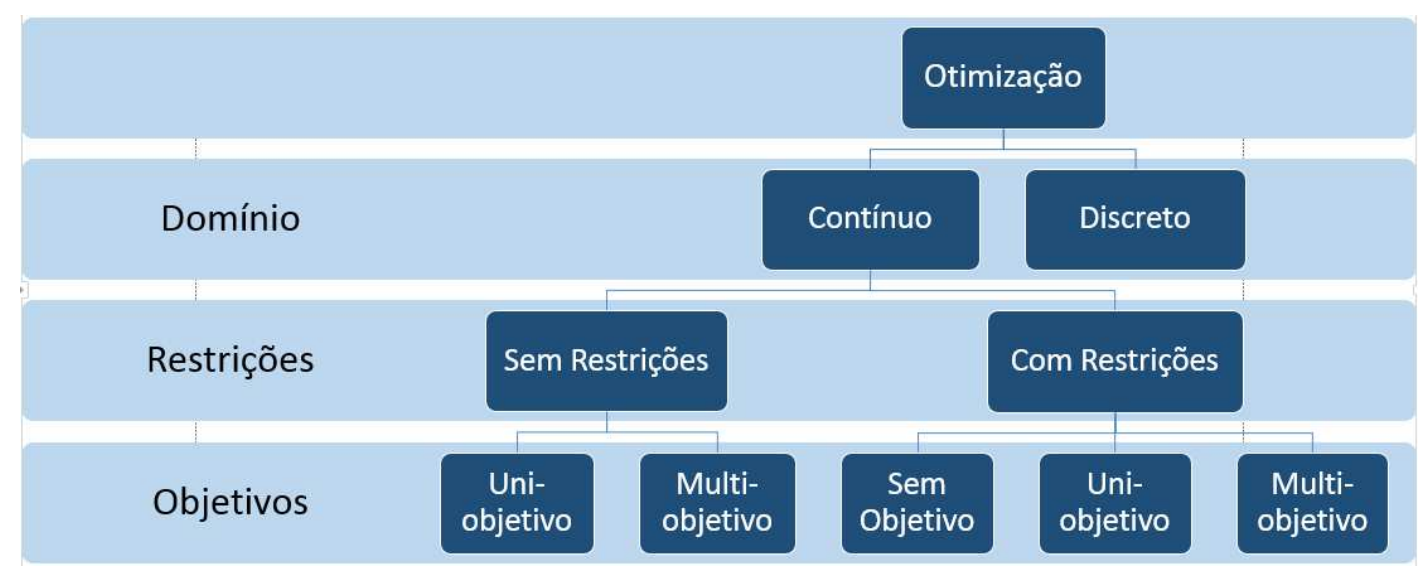

Figura 13: Classificação dos problemas de otimização de um ponto de vista simples considerando tipo de domínio, restrições e número de objetivos.

Este esboço a respeito da classificação dos problemas de otimização é simples e não considera outras características como a linearidade e convexidade, ou ainda, a não-linearidade e a não-convexidade. Adicionalmente, esta classificação não oferece a opção de classificação para um problema híbrido com variáveis de decisão contínuas e discretas de forma simultanea. Sendo assim, a subseção a seguir apresenta uma análise taxonômica dos diferentes tipos de problemas de otimização de forma mais completa que a apresentada anteriormente.

\subsubsection{Taxonomia dos Problemas de Otimização}

Para analisar de forma mais completa as diferentes classes de problemas de otimização, define-se primeiramente que apenas os problemas com objetivo único serão analisados. Em seguida, é possível separá-los em problemas discretos e contínuos, de tal forma que problemas discretos são compostos exclusivamente por variáveis de decisão discretas e nos problemas contínuos podemos considerar ambos os tipos de variável. Esta divisão inicial é apresentada na figura 14 . 


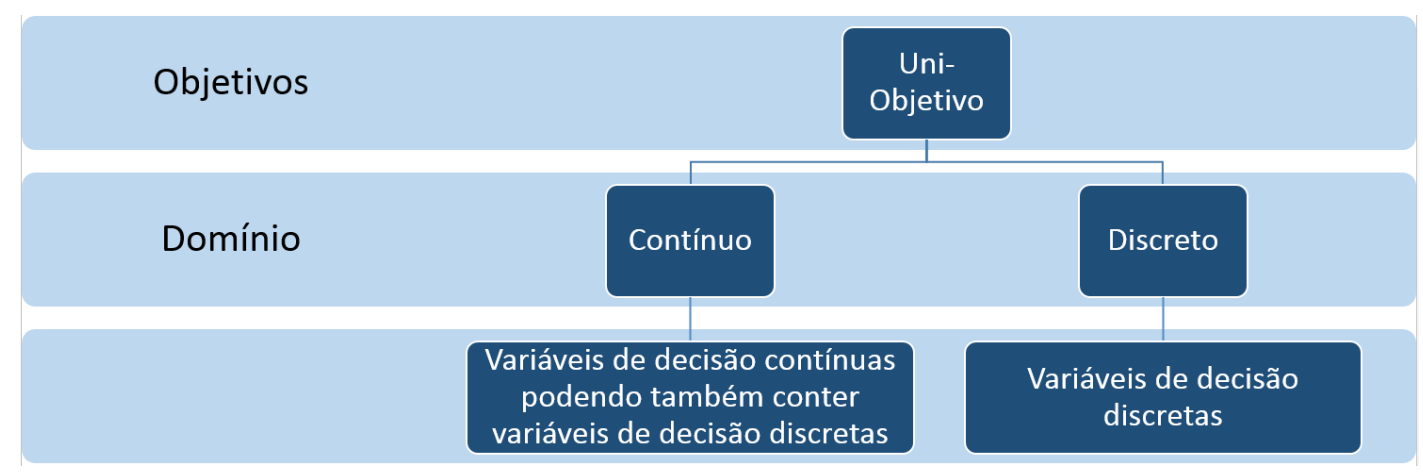

Figura 14: Classificação dos problemas de otimização acerca do tipo de domínio.

Os problemas de otimização discretos podem ser subdivididos em problemas de otimização combinatória e programação inteira. A diferença entre estes está na natureza do problema: enquanto as ferramentas que encontram a solução para problemas de otimização combinatória são utilizadas para qualquer conjunto discreto, as técnicas de programação inteira resolvem problemas cujo domínio são os números inteiros. É importante lembrar que, salvo exceções, os problemas de otimização combinatória podem ser reformulados como problemas de programação inteira e vice-versa (HAMMER; KORTE, 1979).

Uma vez que os problemas tratados nesta Tese não tem natureza puramente discreta, a classificação prosseguirá com ênfase no ramo dos problemas de otimização contínuos. Estes podem ser subdividos em problemas de otimização contínuos com restrição ou sem restrição da mesma forma como fora feito na seção anterior. Posteriormente, é possível classificar os problemas quanto a natureza de suas equações e inequações: para problemas sem restrição basta que a função objetivo seja linear para que o problema seja considerado linear, já quando o problema tem restrições este só será considerado linear se tanto a função objetivo quanto as restrições forem lineares, i.e. se as restrições e a função objetivo forem (in)equações lineares (VANDERBEI, 2000). A figura 15 sumariza estas informações do texto a partir da figura 14 até este ponto. 


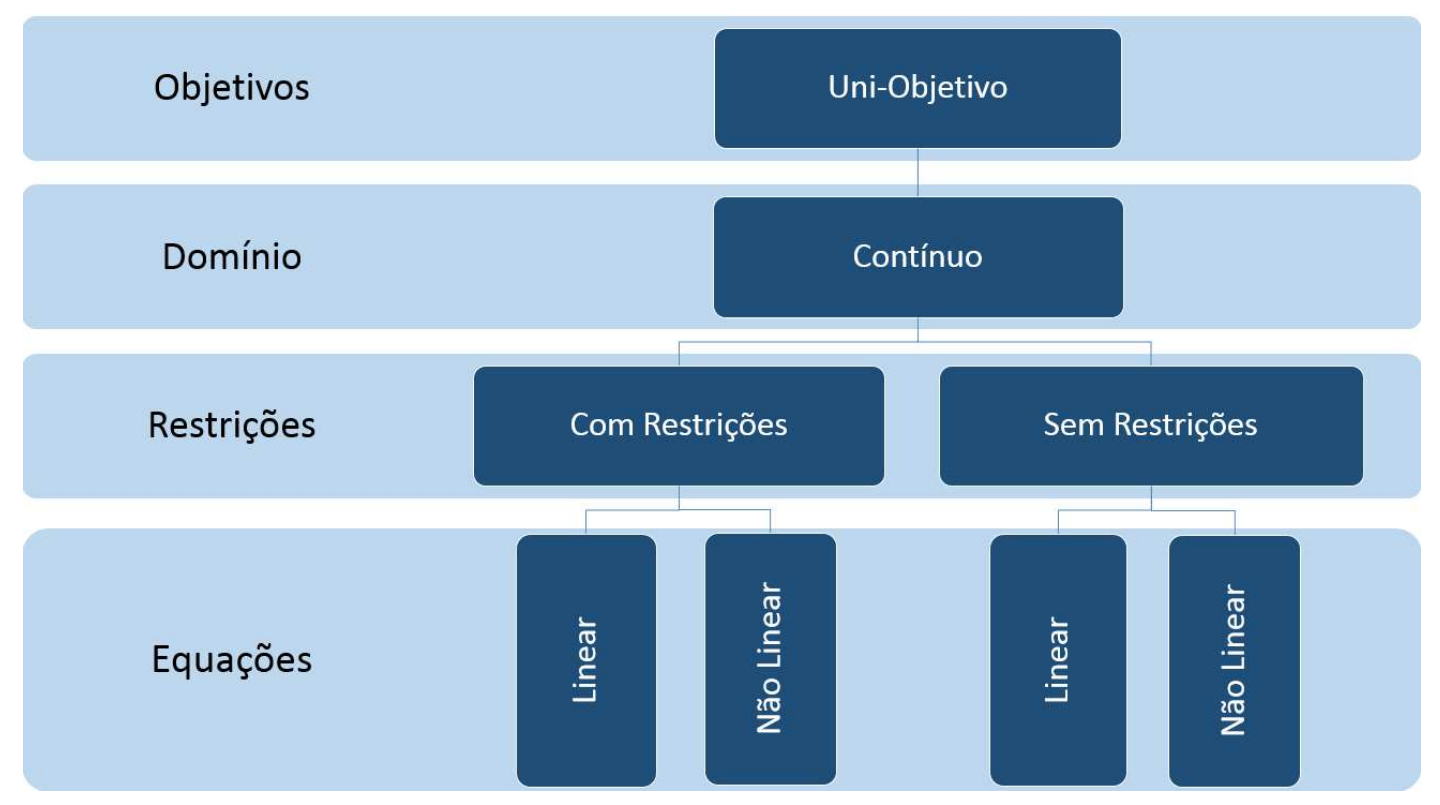

Figura 15: Classificação dos problemas de otimização acerca do tipo de domínio, restrições e linearidade.

Ainda quanto à natureza das equações e inequações os problemas de otimização com restrição ou sem restrição podem ser divididos quanto a sua convexidade. O conceito de convexidade pode ser conferido consultando os tópicos 2.1.4 na página 23 e 3.1 .1 na página 67 em (BOYD; VANDENBERGHE, 2004) e são reproduzidos na seção "3.2 - Fundamentos de Otimização Convexa".

Note que os problemas de otimização são denominados convexos quando a função objetivo é convexa e o domínio do problema é um conjunto convexo, i.e. as equações de restrição definem um conjunto convexo. Sendo assim, considerando o problema de otimização genérico:

$$
\begin{array}{ll}
\text { minimizar } & f(\mathbf{x}) \\
\text { sujeito à } & g_{i}(\mathbf{x}) \leq b_{i}, \quad i=1, \ldots, m \\
& h_{i}(\mathbf{x})=0, \quad i=1, \ldots, k
\end{array}
$$


o mesmo será classificado como convexo se todas as funções $f, g_{1}, \ldots, f_{m}$ e $h_{1}, \ldots, h_{k}$ forem convexas (BOYD; VANDENBERGHE, 2004, 1.3, página 7). Portanto se adicionarmos esta classificação à taxonomia dos problemas de otimização presente na figura 15 com foco nos problemas contínuos, observar-se-á a classes de problemas apresentadas na figura 16:

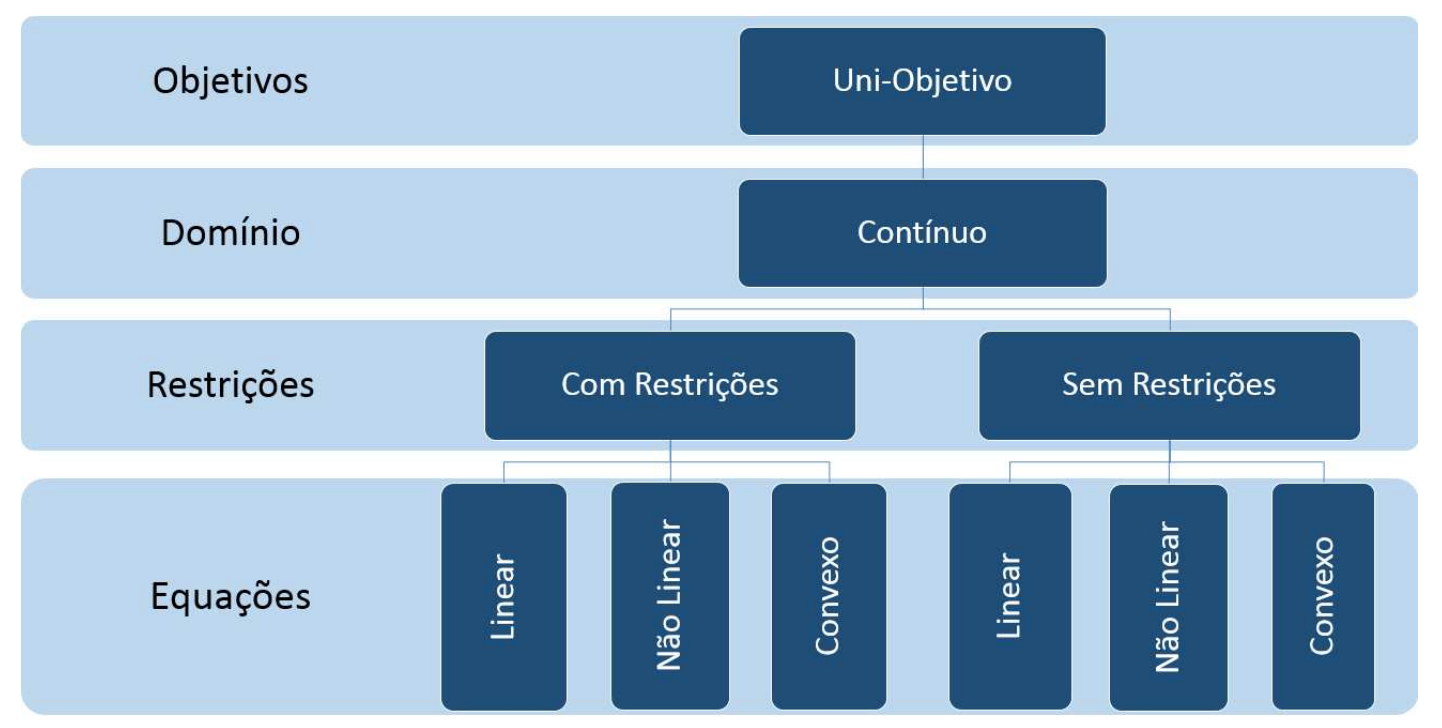

Figura 16: Classificação dos problemas de otimização acerca do tipo de domínio, restrições, linearidade e convexidade.

É importante frisar que a denominação do problema de otimização não linear é utilizada quando no problema de otimização a função objetivo e as restrições não forem lineares e não for possível determinar sua convexidade. Tal distinção é feita uma vez que não existem métodos eficientes para solucionar o problema de otimização não linear arbitrário, i.e. se as funções $f, g_{1}, \ldots, f_{m}$ e $h_{1}, \ldots, h_{k}$ em (3.5) forem não lineares e for impossível determinar sua convexidade, não existem métodos eficientes para solucionar o problema (BOYD; VANDENBERGHE, 2004, página 9).

Por fim, ainda é possível separar cada nó da árvore taxonômica da figura 16 quanto à presença ou ausência de variáveis discretas. Desta forma, problemas 
contínuos com ou sem restrições, lineares, não-lineares ou convexos, se possuirem pelo menos uma variável contínua, são denominados problemas de otimização inteiro misto (LEE; LEYFFER, 2011). Adicionalmente, deve-se notar que para cada tipo específico de problema existe uma sub-área da otimização matemática cujo foco do estudo são problemas com características específicas, e.g. os problemas do tipo uni-objetivo contínuos com restrições e linear foram profundamente estudados e podem ser solucionados eficientemente utilizando-se ferramentas de programação linear (VANDERBEI, 2000). Da mesma forma, problemas de otimização uni-objetivo contínuos e convexos (com ou sem restrição) foram exaustivamente estudados por pesquisadores da área de otimização convexa e uma gama de ferramentas eficientes estão disponíveis para solucioná-los (BOYD; VANDENBERGHE, 2004).

Note que esta classificação é importante para compreender as ferramentas apresentadas nesta Tese, uma vez que as mesmas podem ser utilizadas para solucionar apenas tipos específicos de problemas de otimização, i.e. as ferramentas podem ser aplicadas ao problema se o mesmo satisfizer todas as condições necessárias ao funcionamento da técnica. Desta forma, nas seções subsequentes serão apresentadas as ferramentas matemáticas e computacionais utilizadas para solucionar os problemas de otimização em sistemas de telecomunicações apresentados no capítulo 4.

\subsection{Fundamentos de Otimização Convexa}

Nesta seção serão abordados os conceitos relacionados à otimização convexa. O objetivo desta seção é discutir os problemas de otimização convexa e o método de decomposição dual de Lagrange (LAGRANGE, 1811) que será utilizado para solucionar problemas de otimização em telecomunicações no capítulo 4. Os fundamentos de análise convexa necessários à compreensão do conteúdo deste 
capítulo são discutidos de forma detalhada no apêndice A.

Adicionalmente, esta seção pretende delinear o raciocínio lógico e matemático que culmina no método supracitado de tal forma que os teoremas, proposições e definições apresentadas são autosuficientes para a compreensão do método de otimização utilizado neste trabalho. Sendo assim, a primeira seção discorre sobre conjuntos convexos e propriedades relacionadas aos mesmos, já a segunda e terceira seções tratam de funções convexas e quase convexas, respectivamente. Por fim, a última seção trata do conceito de otimização convexa e apresenta o método de decomposição dual de Lagrange.

\subsubsection{Problemas de Otimização Convexa}

O objetivo desta subseção é discursar sobre os principais conceitos associados a problemas de otimização convexos em que uma única função objetivo deve ser minimizada condicionada a restrições que limitam o conjunto de decisões factíveis. Desta forma, considere o problema de otimização genérico:

$$
\begin{array}{ll}
\text { minimizar } & f(\mathbf{x}) \\
\text { sujeito à } & g_{i}(\mathbf{x}) \leq 0, \quad i=1, \ldots, m \\
& h_{i}(\mathbf{x})=0, \quad i=1, \ldots, k
\end{array}
$$

O problema consiste em encontrar $\mathbf{x}$ que minimize a função $f$ enquanto satisfaz, simultaneamente, às condições $g_{i}(\mathbf{x}) \leq 0, i=1, \ldots, m$, e $h_{i}(\mathbf{x})=0$, $i=1, \ldots, k$. A variável $\mathbf{x}$ é denominada variável de otimização ou variável de decisão, a função $f: \mathbb{R}^{n} \rightarrow \mathbb{R}$ é chamada de função objetivo ou função custo, $g_{i}, i=1, \ldots, m$ são as funções de restrição de desigualdade, ao passo que $h_{i}$, $i=1, \ldots, k$ são as funções de restrição de igualdade. Quando $m=k=0 \mathrm{o}$ 
problema é chamado de problema de otimização sem restrições (BOYD; VANDENBERGHE, 2004).

O conjunto de pontos para os quais a função objetivo e as funções de restrição são definidas é chamado de domínio do problema de otimização, $\mathcal{D}$, i.e.:

$$
\mathcal{D}=\operatorname{dom} f \cap\left(\bigcap_{i=1}^{m} \operatorname{dom} g_{i}\right) \cap\left(\bigcap_{i=1}^{k} \operatorname{dom} h_{i}\right)
$$

Note que minimizar uma função convexa é equivalente a maximizar uma função côncava, i.e. o problema de otimização em (3.6) é equivalente a:

$$
\begin{array}{ll}
\text { maximizar } & -f(\mathbf{x}) \\
\text { sujeito à } & g_{i}(\mathbf{x}) \leq 0, \quad i=1, \ldots, m \\
& h_{i}(\mathbf{x})=0, \quad i=1, \ldots, k
\end{array}
$$

O valor ótimo relacionado ao problema de otimização convexa é definido como (BOYD; VANDENBERGHE, 2004, Página 127):

$$
f^{*}=\inf \left\{f(\mathbf{x}) \mid g_{i}(\mathbf{x}) \leq 0, i=1, \ldots, m, h_{i}(\mathbf{x})=0, i=1, \ldots, k\right\}
$$

onde inf é o ínfimo do conjunto, i.e. é o maior valor real que é menor ou igual à todos os elementos do conjunto. Considerando a definição de $f^{*}$, se $f(\mathbf{x}) \in f^{*}$ então $f(\mathbf{x}) \leq f(\mathbf{y})$ para todo $\mathbf{y}$ tal que $g_{i}(\mathbf{y}) \leq 0, i=1, \ldots, m, h_{i}(\mathbf{y})=0, i=$ $1, \ldots, k$.

Um ponto ótimo ou solução do problema, por sua vez, é um ponto $\mathrm{x}^{*}$ factível tal que $f\left(\mathbf{x}^{*}\right) \in f^{*}$. Todavia, métodos numéricos, em sua grande maioria, funcionam de forma eficaz satisfazendo um critério de erro máximo permitido. Esta 
característica de métodos numéricos fica evidente ao introduzir-se o conceito de ponto (solução) subótimo: seja $\mathbf{x}$ um ponto factível e $f(\mathbf{x}) \leq f\left(\mathbf{x}^{*}\right)+\epsilon$ e $\epsilon$ um valor tão pequeno quanto se deseja, então x é uma solução subótima (BOYD; VANDENBERGHE, 2004).

Para que o problema de otimização em (3.6) seja um problema de otimização convexo, três características devem ser observadas (BOYD; VANDENBERGHE, 2004, Página 137):

1. a função objetivo deve ser convexa, i.e. $f$ deve ser convexa;

2. as funções das restrições por desigualdade devem ser convexas, i.e. $g_{i}$ com $i=1, \ldots, m$ devem ser funções convexas;

3. as funções das restrições por igualdade devem ser funções afim do tipo $h_{i}(\mathbf{x})=\mathbf{a}_{i}^{T} \mathbf{x}-b_{i} \operatorname{com} i=1, \ldots, k$

Note que o domínio do problema é a intersecção de $m+1$ conjuntos convexos com $k$ hiperplanos do tipo $\left\{\mathbf{x} \mid \mathbf{a}_{i}^{T} \mathbf{x}=b_{i}\right\}$, logo, é possível redefinir $\mathcal{D}$ como (BOYD; VANDENBERGHE, 2004):

$$
\mathcal{D}=\operatorname{dom} f \cap\left(\bigcap_{i=1}^{m} \operatorname{dom} g_{i}\right)
$$

Uma das mais importantes características de problemas de otimização convexo é apresentada no teorema a seguir (BOYD; VANDENBERGHE, 2004, Seção 4.2.2 na Página 138).

Teorema 1 (Ótimo Global). Considere o problema de otimização abaixo:

$$
\begin{array}{ll}
\text { minimizar } & f(\mathbf{x}) \\
\text { sujeito } \grave{a} & g_{i}(\mathbf{x}) \leq 0, \quad i=1, \ldots, m \\
& \mathbf{a}_{i}^{T} \mathbf{x}-b_{i}=0, \quad i=1, \ldots, k
\end{array}
$$


Qualquer ótimo local do problema acima é também um ótimo global.

Demonstração. Suponha que $\mathbf{x}$ seja um ótimo local, i.e. $\mathbf{x}$ seja factível, isto é, $\mathbf{x}$ seja um ponto que satisfaz todas as restrições de igualdade e desigualdade, e que

$$
f(\mathbf{x})=\inf \{f(\mathbf{z}) \mid \mathbf{z} \text { factível, }\|\mathbf{z}-\mathbf{x}\|<R\}
$$

para um $R>0$. Agora suponha que $\mathbf{x}$ não seja um ótimo global, i.e. existe um y para o qual $f(\mathbf{y})<f(\mathbf{x})$. Desta forma, $\|\mathbf{y}-\mathbf{x}\|>R$, pois caso contrário $f(\mathbf{x})<f(\mathbf{y})$. Seja o ponto $\mathbf{z}$ dado por

$$
\mathbf{z}=(1-\lambda) \mathbf{x}+\lambda \mathbf{y}, \quad \lambda=\frac{R}{2\|\mathbf{y}-\mathbf{x}\|}
$$

Logo, conclui-se que $\|\mathbf{z}-\mathbf{x}\|=R / 2<R$ e, da convexidade do domínio do problema segue que $\mathbf{z}$ é factível. Da convexidade de $f$ segue:

$$
f(\mathbf{z}) \leq(1-\lambda) f(\mathbf{x})+\lambda f(\mathbf{y})<f(\mathbf{x})
$$

o que contradiz (3.12). Portanto não existe $\mathbf{y}$ factível com $f(\mathbf{y}) \leq f(\mathbf{x})$, logo $\mathbf{x}$ é um ótimo global.

Em otimização é importante definir de forma clara quais são as condições necessárias e suficientes para que um ponto $\mathbf{x}$ seja a solução do problema. O teorema abaixo confere condições necessárias e suficientes para a otimalidade de funções diferenciáveis (BOYD; VANDENBERGHE, 2004, 4.3.2 na Página 139)

Teorema 2 (Critério de Otimalidade). Suponha que a função $f$ em um problema de otimização como em (3.6) seja diferenciável. Seja $S=\left\{\mathbf{z} \in \operatorname{dom} f \mid g_{i}(\mathbf{z}) \leq\right.$ $\left.0, i=1, \ldots, m ; h_{i}(\mathbf{z})=0, i=1, \ldots, k\right\}$ o conjunto de todos os pontos factíveis. Então para todo $\mathbf{x} \in \operatorname{dom} f$ e $\mathbf{y} \in S, \mathbf{x}$ é um ponto de ótimo se, e somente se $\mathbf{x} \in S e$

$$
\nabla f(\mathbf{x})^{T}(\mathbf{y}-\mathbf{x}) \geq 0
$$


Demonstração. Primeiramente, suponha que $\mathbf{x} \in S$ e satisfaz (3.15). Das condições de primeira ordem para convexidade tem-se:

$$
f(\mathbf{y}) \geq f(\mathbf{x})+\nabla f(\mathbf{x})^{T}(\mathbf{y}-\mathbf{x})
$$

Logo, se $\mathbf{y} \in S$ então $f(\mathbf{y}) \geq f(\mathbf{x})$, e portanto $\mathbf{x}$ é um ponto ótimo que soluciona o problema de otimização convexa em (3.6). Isso conclui a prova da suficiência da condição. A demonstração da necessidade da condição pode ser feita por contradição. Sendo assim, suponha agora que $\mathbf{x} \in S$ é um ponto de ótimo mas a condição (3.15) não é verdadeira, ou seja:

$$
\exists \mathbf{y} \in S \mid \nabla f(\mathbf{x})^{T}(\mathbf{y}-\mathbf{x})<0
$$

Adicionalmente, considere $\lambda \in[0,1]$ e o ponto $z(\lambda)=\lambda \mathbf{y}+(1-\lambda) \mathbf{x}$. Uma vez que $\mathbf{x}$ e $\mathbf{y}$ são pontos factíveis e o conjunto $S$ é convexo, então $z(\lambda)$ que é um ponto do segmento de reta entre $\mathbf{x}$ e $\mathbf{y}$ também é factível. Note que:

$$
\left.\frac{\partial}{\partial \lambda} f(z(\lambda))\right|_{\lambda=0}=\nabla f(\mathbf{x})^{T}(\mathbf{y}-\mathbf{x})
$$

de tal forma que para um $\lambda$ pequeno $f(z(\lambda))<f(\mathbf{x})$. Isso demonstra que $\mathbf{x}$ não é ótimo se $\nabla f(\mathbf{x})^{T}(\mathbf{y}-\mathbf{x})<0$.

A condição de otimalidade pode ser interpretada da seguinte forma: se $\nabla f(\mathbf{x})=0, \mathbf{x}$ é um ótimo local de $f$ e, de acordo com o teorema 1, é também um ótimo global. Por outro lado, se $\nabla f(\mathbf{x}) \neq 0$ então $-\nabla f(\mathbf{x})$ define um hiperplano de suporte do conjunto $S$ (BOYD; VANDENBERGHE, 2004).

Note que encontrar a solução para o problema de otimização convexo em (3.6) é uma tarefa árdua, uma vez que é necessário delimitar o conjunto de pontos factíveis do problema, i.e. o conjunto de pontos que satisfazem as restrições de igualdade e desigualdade. Uma forma de resolver o problema de tal forma a manter-se o domínio $\mathcal{D}$ do problema é através da dualidade de Lagrange, assim 
denominado em homenagem a Joseph-Louis Lagrange, matemático e astrônomo Italiano (LAGRANGE, 1811).

Para compreender a dualidade de Lagrange, primeiramente apresenta-se o conceito de Lagrangiano (BOYD; VANDENBERGHE, 2004, Página 214):

Definição 13 (Lagrangiano). Considere o problema de otimização em (3.6). O Lagrangiano $\mathcal{L}: \mathbb{R}^{n} \times \mathbb{R}^{m} \times \mathbb{R}^{k} \rightarrow \mathbb{R}$, associado com tal problema de otimização é definido como:

$$
\mathcal{L}(\mathbf{x}, \boldsymbol{\lambda}, \boldsymbol{\nu})=f(\mathbf{x})+\sum_{i=1}^{m} \lambda_{i} g_{i}(\mathbf{x})+\sum_{i=1}^{k} \nu_{i} h_{i}(\mathbf{x})
$$

Dá-se o nome de multiplicador de Lagrange relacionado a $i$-ésima restrição de desigualdade para cada variável $\lambda_{i}$ e, da mesma forma, de multiplicador de Lagrange relacionado a $i$-ésima restrição de igualdade para cada variável $\nu_{i}$. Adicionalmente, os vetores $\boldsymbol{\lambda}$ e $\boldsymbol{\nu}$ são denominados variáveis duais do problema (3.6).

Outro conceito importante para a compreensão da dualidade de Lagrange é o de função dual de Lagrange (BOYD; VANDENBERGHE, 2004).

Definição 14 (Função Dual de Lagrange). A função dual de Lagrange $\ell: \mathbb{R}^{m} \times$ $\mathbb{R}^{k} \rightarrow \mathbb{R}$ é definida como o menor valor assumido pelo Lagrangiano para um dado $\mathbf{x}$ fixo. Para $\boldsymbol{\lambda} \in \mathbb{R}^{m}$ e $\boldsymbol{\nu} \in \mathbb{R}^{k}$ :

$$
\ell(\boldsymbol{\lambda}, \boldsymbol{\nu})=\inf _{\mathbf{x} \in \mathcal{D}} \mathcal{L}(\mathbf{x}, \boldsymbol{\lambda}, \boldsymbol{\nu})=\inf _{\mathbf{x} \in \mathcal{D}}\left(f(\mathbf{x})+\sum_{i=1}^{m} \lambda_{i} g_{i}(\mathbf{x})+\sum_{i=1}^{k} \nu_{i} h_{i}(\mathbf{x})\right)
$$

Note que se para um determinado $\mathbf{x}$, o Lagrangiano não é limitado inferiormente, a função dual assume então o valor $-\infty$.

Note que a função dual é um limite inferior do valor ótimo $f\left(\mathbf{x}^{*}\right)$ do problema de otimização convexo em (3.6), isto é, $\forall \boldsymbol{\lambda} \geq 00^{1}$ e qualquer $\boldsymbol{\nu}$ (BOYD;

\footnotetext{
${ }^{1} \mathrm{O}$ operador $\mathrm{x} \geq 0$ indica a operaçao de maior ou igual elemento a elemento.
} 
VANDENBERGHE, 2004, 5.1.3 na Página 216):

$$
\ell(\boldsymbol{\lambda}, \boldsymbol{\nu}) \leq f\left(\mathbf{x}^{*}\right)
$$

Esta propriedade é facilmente observada: seja y um ponto factível do domínio do problema. Então $g_{i}(\mathbf{y}) \leq 0, i=1, \ldots, m$ e $h_{i}(\mathbf{y})=0, i=1, \ldots, k$. Se $\boldsymbol{\lambda} \geq 0$ então:

$$
\sum_{i=1}^{m} \lambda_{i} g_{i}(\mathbf{y})+\sum_{i=1}^{k} \nu_{i} h_{i}(\mathbf{y}) \leq 0
$$

Uma vez que o primeiro termo da soma é não positivo e o segundo termo é nulo, conclui-se que:

$$
\mathcal{L}(\mathbf{y}, \boldsymbol{\lambda}, \boldsymbol{\nu})=f(\mathbf{y})+\sum_{i=1}^{m} \lambda_{i} g_{i}(\mathbf{y})+\sum_{i=1}^{k} \nu_{i} h_{i}(\mathbf{y}) \leq f(\mathbf{y})
$$

Logo:

$$
\ell(\boldsymbol{\lambda}, \boldsymbol{\nu})=\inf _{\mathbf{x} \in \mathcal{D}} \mathcal{L}(\mathbf{x}, \boldsymbol{\lambda}, \boldsymbol{\nu}) \leq \mathcal{L}(\mathbf{y}, \boldsymbol{\lambda}, \boldsymbol{\nu}) \leq f(\mathbf{y})
$$

Ou seja, $\ell(\boldsymbol{\lambda}, \boldsymbol{\nu}) \leq f(\mathbf{y})$ para todo ponto factível $\mathbf{y}$. Note que mesmo quando $\ell(\boldsymbol{\lambda}, \boldsymbol{\nu})=-\infty$ a desigualdade é verdadeira e o limite inferior torna-se trivial. Logo, define-se que um limite inferior é não trivial quando $(\boldsymbol{\lambda}, \boldsymbol{\nu}) \in \operatorname{dom} \ell=$ $\{(\boldsymbol{\lambda}, \boldsymbol{\nu}) \mid \ell(\boldsymbol{\lambda}, \boldsymbol{\nu})>-\infty, \boldsymbol{\lambda} \geq 0\}$ (BOYD; VANDENBERGHE, 2004, 5.1.2 na Página 216).

Uma vez que a função dual de Lagrange é um limite inferior para o valor ótimo $f\left(\mathbf{x}^{*}\right)$ este limite é dependente dos valores de $\boldsymbol{\lambda}$ e $\boldsymbol{\nu}$. Desta forma, dado o objetivo de encontrar o ponto de ótimo do problema de otimização convexa em (3.6), é desejável que o melhor limite inferior (ou limite inferior ótimo) seja aquele 
que mais se aproxima de $f\left(\mathbf{x}^{*}\right)$, e, se possível, seja equivalente ao ponto de ótimo $f\left(\mathbf{x}^{*}\right)$.

Sendo assim, é possível definir o seguinte problema dual de otimização, associado à função dual de Lagrange em (3.20):

$$
\begin{aligned}
\text { maximizar } & \ell(\boldsymbol{\lambda}, \boldsymbol{\nu}) \\
\text { sujeito à } & \lambda_{i} \geq 0, i=1, \ldots, m
\end{aligned}
$$

O problema de otimização acima é denominado problema dual de Lagrange do problema de otimização original em (3.6). Por conseguinte, este último é denominado problema primal (BOYD; VANDENBERGHE, 2004).

A mesma notação usada para caracterizar a variável ótima do problema primal, i.e. $\mathbf{x}^{*}$, é utilizada no problema dual. Em outras palavras, $\left(\boldsymbol{\lambda}^{*}, \boldsymbol{\nu}^{*}\right)$ é denominado ótimo dual ou multiplicadores de Lagrange ótimos, uma vez que maximizam o problema em $(3.25)$ e $\left(\boldsymbol{\lambda}^{*}, \boldsymbol{\nu}^{*}\right) \in \operatorname{dom} \ell$.

Conforme descrito anteriormente, o problema dual é um limite inferior da solução para o problema primal (definido pelo operador ínfimo, inf $\{\cdot\}$ ). Dessa forma, denomina-se gap de dualidade, $\mathcal{G}$, a diferença entre o valor ótimo do problema primal e o melhor/maior limite inferior que pode ser encontrado através da função dual, i.e. $\mathcal{G}=f\left(\mathbf{x}^{*}\right)-\ell\left(\boldsymbol{\lambda}^{*}, \boldsymbol{\nu}^{*}\right)$. De acordo com o gap de dualidade é possível observar duas características intrínsecas ao problema de otimização: a dualidade fraca e a dualidade forte (BOYD; VANDENBERGHE, 2004, 5.2.2 e 5.2.3 nas Páginas 225-226) e (BORWEIN; LEWIS, 2006, 4.3 nas Páginas 88-91).

Definição 15 (Dualidade Fraca). Seja $f\left(\mathbf{x}^{*}\right)$ o ponto de ótimo para um determinado problema de otimização. O valor ótimo do problema dual de Lagrange $\ell\left(\boldsymbol{\lambda}^{*}, \boldsymbol{\nu}^{*}\right)$ é o melhor limite inferior do problema primal que pode ser obtido pela 
função dual de Lagrange. Portanto a seguinte desigualdade é verdadeira:

$$
\ell\left(\boldsymbol{\lambda}^{*}, \boldsymbol{\nu}^{*}\right) \leq f\left(\mathbf{x}^{*}\right)
$$

A esta propriedade dá-se o nome de dualidade fraca. A desigualdade acima é válida também quando $\ell\left(\boldsymbol{\lambda}^{*}, \boldsymbol{\nu}^{*}\right)$ e $f\left(\mathbf{x}^{*}\right)$ são infinitos. No caso da solução do problema primal ser infinita, i.e. $f\left(\mathbf{x}^{*}\right)=-\infty$ então $\ell\left(\boldsymbol{\lambda}^{*}, \boldsymbol{\nu}^{*}\right)=-\infty$ e, portanto, o problema dual não é factivel. Da mesma forma, se $\ell\left(\boldsymbol{\lambda}^{*}, \boldsymbol{\nu}^{*}\right)=\infty$, então $f\left(\mathbf{x}^{*}\right)=\infty$, assim o problema primal não é factível.

Observação 2. A dualidade fraca, i.e. $\ell\left(\boldsymbol{\lambda}^{*}, \boldsymbol{\nu}^{*}\right) \leq f\left(\mathbf{x}^{*}\right)$ é satisfeita mesmo quando o problema não é convexo.

Definição 16 (Dualidade Forte). A dualidade forte é uma propriedade de problemas onde o melhor limite inferior obtido através da função dual de Lagrange é igual ao valor do ponto de ótimo do problema primal, i.e.:

$$
\ell\left(\boldsymbol{\lambda}^{*}, \boldsymbol{\nu}^{*}\right)=f\left(\mathbf{x}^{*}\right)
$$

Em outras palavras, a dualidade forte existe quando o gap de dualidade ótimo é nulo.

As figuras 17 e 18 são apresentadas a fim de ilustrar as diferenças entre dualidade fraca e dualidade forte. 


\section{Dualidade Fraca}

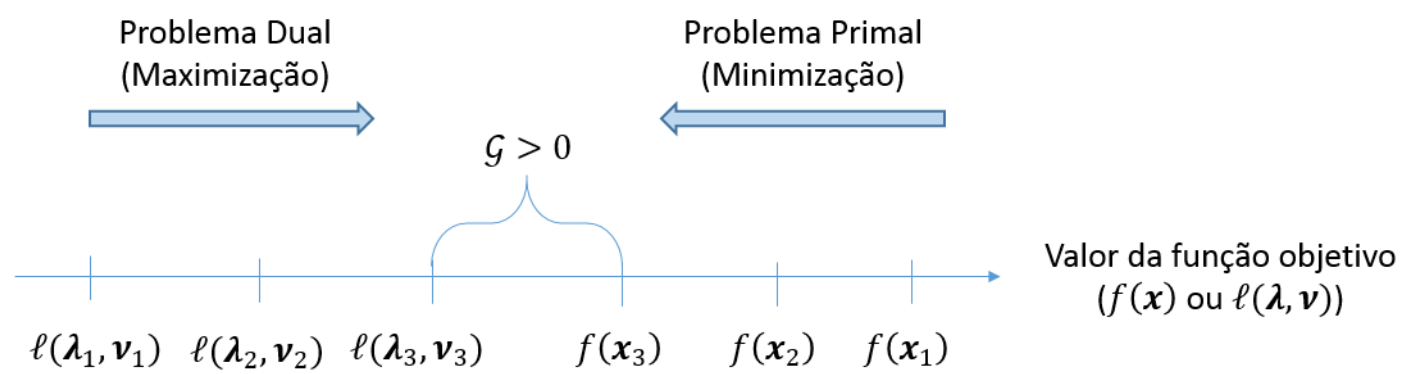

Figura 17: Exemplo de dualidade fraca. A reta representa os possíveis valores da função objetivo (tanto primal $f$ quanto dual $\ell$ ). O gap entre os pontos ilustra a definição de dualidade fraca.

\section{Dualidade Forte}

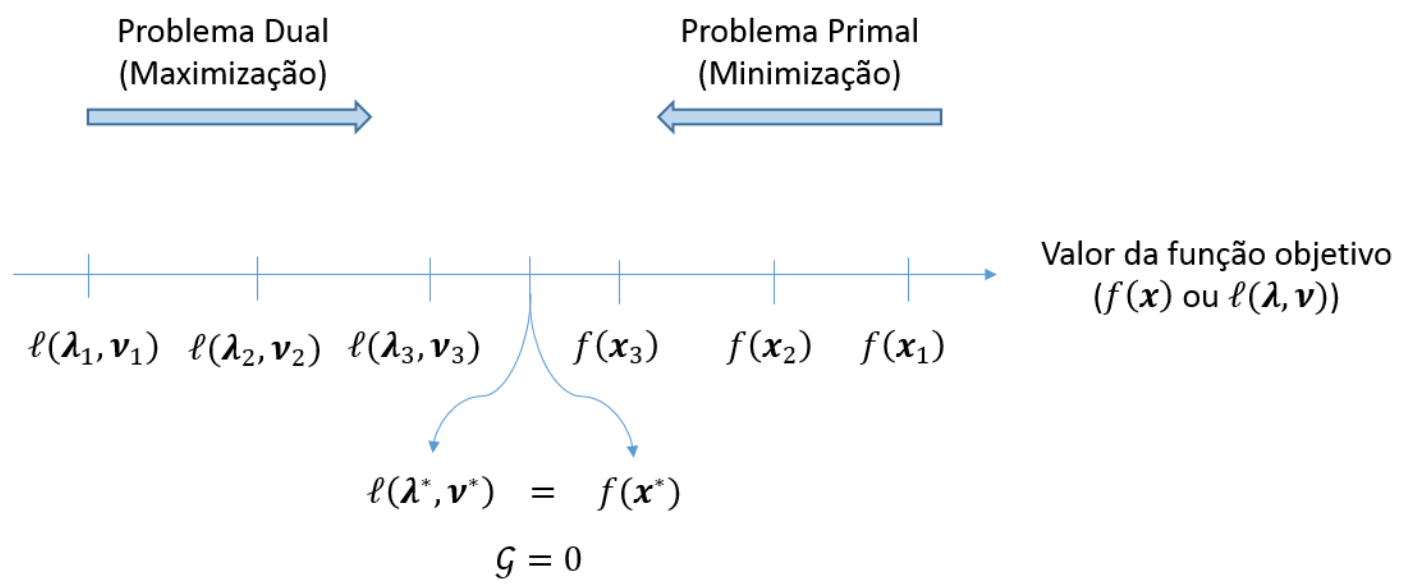

Figura 18: Exemplo de dualidade forte. A reta representa os possíveis valores da função objetivo (tanto primal $f$ quanto dual $\ell$ ). O gap entre os pontos ótimos do problema primal e dual é nulo, o que ilustra a definição de dualidade forte.

É evidente que existem problemas que não possuem a propriedade da dualidade forte. Todavia, é necessário e fundamental estabelecer as condições para que o gap de dualidade seja nulo. Para isso, são apresentados a seguir os conceitos de interior relativo de um conjunto (ROCKAFELLAR, 1970, Teorema 6.4 na Página 47) e a condição de Slater (SLATER, 1950; BOYD; VANDENBERGHE, 2004). 
Definição 17 (Interior Relativo). Seja $C \in \mathbb{R}^{n}$ um conjunto convexo não-vazio. $O$ interior relativo de $C$ é definido como:

$$
\text { relint } C=\{\mathbf{x} \in C|\forall \mathbf{y} \in C \exists \lambda>1| \lambda \mathbf{x}+(1-\lambda) \mathbf{y} \in C\}
$$

Definição 18 (Condição de Slater). Seja $\mathcal{D} \subset \mathbb{R}^{n}, h_{i}: \mathcal{D} \rightarrow \mathbb{R}, i=1, \ldots, k$ funções afim e $g_{i}: \mathcal{D} \rightarrow \mathbb{R}, i=1, \ldots, m$. As funções $g_{i}$ satisfazem a condição de Slater em $\mathcal{D}$ se existir $\mathbf{x} \in \operatorname{relint} \mathcal{D}$ tal que:

$$
g_{i}(\mathbf{x})<0, i=1, \ldots, m \text { e } h_{i}(\mathbf{x})=0, i=1, \ldots, k
$$

De forma semelhante, o problema de otimização em (3.6), reproduzido abaixo, satisfaz a condição de Slater se $\mathcal{D}$ é o domínio do problema de otimização e as funções $g_{i}$ com $i=1, \ldots, m$ satisfazem a condição de Slater.

$$
\begin{array}{ll}
\text { minimizar } & f(\mathbf{x}) \\
\text { sujeito ’̀ } & g_{i}(\mathbf{x}) \leq 0, \quad i=1, \ldots, m \\
& h_{i}(\mathbf{x})=0, \quad i=1, \ldots, k
\end{array}
$$

As condições necessárias para que o gap de dualidade seja nulo são descritas no teorema 3 a seguir. O teorema e a prova foram retirados das seções 5.2.3 e 5.3.2 em (BOYD; VANDENBERGHE, 2004). Todavia, outras formas de se chegar à mesma conclusão podem ser estudadas e verificadas no apêndice D em (Ben-Tal; NEMIROVSKI, 2013), páginas 88 a 91 em (BORWEIN; LEWIS, 2006), páginas 22 a 27 em (ROCKAFELLAR, 1993) e no artigo (EUSTAQUIO; KARAS; RIBEIRO, 2008).

Teorema 3 (Condição de Qualificação das Restrições). Considere o problema de 
otimização convexo:

$$
\begin{array}{ll}
\text { minimizar } & f(\mathbf{x}) \\
\text { sujeito à } & g_{i}(\mathbf{x}) \leq 0, \quad i=1, \ldots, m \\
& \mathbf{A x}=\mathbf{b}
\end{array}
$$

onde $f$ e $g_{i}, i=1, \ldots, m$ são funções $\mathbb{R}^{n} \rightarrow \mathbb{R}$, e $\mathbf{A x}=\mathbf{b}$ é o equivalente das funções $h_{i}, i=1, \ldots, k$ em (3.6). Assuma que a condição de Slater é satisfeita, i.e. $\exists \mathbf{y} \in \operatorname{relint} \mathcal{D} \mid g_{i}(\mathbf{y})<0, i=1, \ldots, m$ e $\mathbf{A y}=\mathbf{b}$. Então o gap de dualidade entre o problema acima e seu dual é nulo.

Demonstração. Para simplificar a prova assuma que posto $\mathbf{A}=k$ e que o domínio do problema $\mathcal{D}$ tem um interior ${ }^{2}$ não-vazio, i.e. $\operatorname{relint} \mathcal{D}=\operatorname{int} \mathcal{D}$. Deve-se assumir que $f\left(\mathbf{x}^{*}\right)$ é finito. Sendo assim, seja $\mathcal{A}$ um conjunto definido como:

$$
\mathcal{A}=\left\{(\mathbf{u}, \mathbf{v}, t) \mid \exists \mathbf{x} \in \mathcal{D} ; g_{i}(\mathbf{x}) \leq u_{i}, i=1, \ldots, m ; \mathbf{A x}-\mathbf{b}=\mathbf{v} ; f(\mathbf{x}) \leq t\right\}
$$

A convexidade do problema implica na convexidade de $\mathcal{A}$. Define-se um segundo conjunto convexo $\mathcal{B}$ como:

$$
\mathcal{B}=\left\{(\mathbf{0}, \mathbf{0}, s) \in \mathbb{R}^{m} \times \mathbb{R}^{k} \times \mathbb{R} \mid s<f\left(\mathbf{x}^{*}\right)\right\}
$$

A intersecção de $\mathcal{A}$ e $\mathcal{B}$ é o conjunto vazio: suponha que $(\mathbf{u}, \mathbf{v}, t) \in \mathcal{A} \cap \mathcal{B}$. Como $(\mathbf{u}, \mathbf{v}, t) \in \mathcal{B}$ necessariamente $\mathbf{u}=\mathbf{0}, \mathbf{v}=\mathbf{0}$ e $t<f\left(\mathbf{x}^{*}\right)$. Uma vez que $(\mathbf{u}, \mathbf{v}, t) \in \mathcal{A}$, então existe $\mathbf{x} \operatorname{com} g_{i}(\mathbf{x}) \leq 0, i=1, \ldots, m ; \mathbf{A x}-\mathbf{b}=\mathbf{0}$, e $f(\mathbf{x}) \leq t<f\left(\mathbf{x}^{*}\right)$ o que é impossível uma vez que $f\left(\mathbf{x}^{*}\right)$ é o valor ótimo do problema primal. Sendo assim, existe um hiperplano separador entre os dois conjuntos, i.e. existe $(\tilde{\boldsymbol{\lambda}}, \tilde{\boldsymbol{\nu}}, \mu) \neq \mathbf{0}$ e um $\alpha$ tal que:

$$
(\mathbf{u}, \mathbf{v}, t) \in \mathcal{A} \Longrightarrow \tilde{\boldsymbol{\lambda}}^{T} \mathbf{u}+\tilde{\boldsymbol{\nu}}^{T} \mathbf{v}+\mu t \geq \alpha
$$

\footnotetext{
${ }^{2} \mathrm{O}$ interior de um conjunto são todos os pontos que não pertencem a fronteira do conjunto.
} 
e

$$
(\mathbf{u}, \mathbf{v}, t) \in \mathcal{B} \Longrightarrow \tilde{\boldsymbol{\lambda}}^{T} \mathbf{u}+\tilde{\boldsymbol{\nu}}^{T} \mathbf{v}+\mu t \leq \alpha
$$

É possível concluir de (3.33) que $\tilde{\boldsymbol{\lambda}} \geq 0$ e $\mu \geq 0$, pois caso contrário $\tilde{\boldsymbol{\lambda}}^{T} \mathbf{u}+\mu t$ não possuiria limite inferior em $\mathcal{A}$ o que contradiz a implicação em (3.33). Já a condição em (3.34) significa que $\mu t \leq \alpha$ para todo $t \leq f\left(\mathrm{x}^{*}\right)$ e, portanto, $\mu f\left(\mathbf{x}^{*}\right) \leq \alpha$. Sendo assim para qualquer $\mathbf{x} \in \mathcal{D}$ concluí-se:

$$
\sum_{i=1}^{m} \tilde{\lambda}_{i} g_{i}(\mathbf{x})+\tilde{\boldsymbol{\nu}}^{T}(\mathbf{A} \mathbf{x}-\mathbf{b})+\mu f(\mathbf{x}) \geq \alpha \geq \mu f\left(\mathbf{x}^{*}\right)
$$

Agora assuma que $\mu>0$. Neste caso, pode-se dividir a expressão acima por $\mu \mathrm{e}$ obtêm-se:

$$
\mathcal{L}(\mathbf{x}, \tilde{\boldsymbol{\lambda}} / \mu, \tilde{\boldsymbol{\nu}} / \mu) \geq f\left(\mathbf{x}^{*}\right)
$$

para todo $\mathbf{x} \in \mathcal{D}$. Considere $\boldsymbol{\lambda}=\tilde{\boldsymbol{\lambda}} / \mu$ e $\boldsymbol{\nu}=\tilde{\boldsymbol{\nu}} / \mu$. Logo:

$$
\ell(\boldsymbol{\lambda}, \boldsymbol{\nu})=\inf _{\mathbf{x} \in \mathcal{D}} \mathcal{L}(\mathbf{x}, \boldsymbol{\lambda}, \boldsymbol{\nu}) \geq f\left(\mathbf{x}^{*}\right)
$$

Da dualidade fraca sabemos que $\ell(\boldsymbol{\lambda}, \boldsymbol{\nu}) \leq f\left(\mathrm{x}^{*}\right)$. Então, de fato $\ell(\boldsymbol{\lambda}, \boldsymbol{\nu})=f\left(\mathrm{x}^{*}\right)$ e a dualidade forte é satisfeita e que o ótimo dual é obtido quando $\mu>0$. Considere agora o caso $\mu=0$. Da desigualdade em (3.35), para todo $\mathbf{x} \in \mathcal{D}$ segue:

$$
\sum_{i=1}^{m} \tilde{\lambda}_{i} g_{i}(\mathbf{x})+\tilde{\boldsymbol{\nu}}^{T}(\mathbf{A} \mathbf{x}-\mathbf{b}) \geq 0
$$

Como a condição de Slater é satisfeita, i.e. para um determinado ponto $\tilde{\mathbf{x}}$ que satisfaz tal condição é verdade que $\tilde{\boldsymbol{\nu}}^{T}(\mathbf{A} \tilde{\mathbf{x}}-\mathbf{b})=0$, então da desigualdade acima pode-se concluir que:

$$
\sum_{i=1}^{m} \tilde{\lambda}_{i} g_{i}(\tilde{\mathbf{x}}) \geq 0
$$

Todavia, também da condição de Slater tem-se que $g_{i}(\tilde{\mathbf{x}})<0$. Como $\tilde{\boldsymbol{\lambda}} \geq \mathbf{0}$ conclui-se que $\tilde{\boldsymbol{\lambda}}=\mathbf{0}$. Como $(\tilde{\boldsymbol{\lambda}}, \tilde{\boldsymbol{\nu}}, \mu) \neq \mathbf{0}$ e $\tilde{\boldsymbol{\lambda}}=\mathbf{0}, \mu=0$; então $\tilde{\boldsymbol{\nu}} \neq \mathbf{0}$. Logo, a desigualdade (3.38) implica que para todo $\mathbf{x} \in \mathcal{D}, \tilde{\boldsymbol{\nu}}^{T}(\mathbf{A x}-\mathbf{b}) \geq 0$. Como $\tilde{\mathbf{x}}$ $\operatorname{satisfaz} \tilde{\boldsymbol{\nu}}^{T}(\mathbf{A} \tilde{\mathbf{x}}-\mathbf{b})=0$ e $\tilde{\mathbf{x}} \in \operatorname{int} \mathcal{D}$, existem pontos em $\mathcal{D} \operatorname{com} \tilde{\boldsymbol{\nu}}^{T}(\mathbf{A x}-\mathbf{b})<0$ 
a menos que $\mathbf{A}^{T} \tilde{\boldsymbol{\nu}}=0$, o que contradiz a suposição de que posto $\mathbf{A}=k$.

Quando o critério de dualidade forte é satisfeito a solução do problema dual e do primal são equivalentes, i.e.

$$
\underset{\boldsymbol{\lambda}, \boldsymbol{\nu}}{\arg \min } \sup _{\mathbf{x}} \mathcal{L}(\mathbf{x}, \boldsymbol{\lambda}, \boldsymbol{\nu}) \equiv \underset{\mathbf{x}}{\arg \max } f(\mathbf{x})
$$

Uma vez estabelecidos os critérios para a dualidade forte faz-se necessário estabelecer as condições necessárias para a otimalidade de uma solução do problema de otimização em (3.6). As condições de Karush-Kuhn-Tucker (KKT) são condições necessárias de primeira ordem para que um determinado ponto do domínio do problema seja ótimo. Estas condições receberam o nome dos matemáticos que as propuseram, i.e. Willian Karush em sua dissertação de mestrado (KARUSH, 1939) e o trabalho de Harold Willian Kuhn e Albert Willian Tucker (KUHN; TUCKER, 1951). O teorema 4 e sua prova foram retirados de (NOCEDAL; WRIGHT, 2006, Teorema 12.1 na Página 321) e (KROGSTAD, 2010).

Teorema 4 (Condições Necessárias de Primeira Ordem - Condições de KKT). Considere o problema de otimização convexo:

$$
\begin{array}{ll}
\text { minimizar } & f(\mathbf{x}) \\
\text { sujeito } \grave{a} & g_{i}(\mathbf{x}) \leq 0, \quad i=1, \ldots, m \\
& h_{i}(\mathbf{x})=0, \quad i=1, \ldots, k
\end{array}
$$

Seja $\Omega \in \mathcal{D}$ um conjunto tal que $\Omega=\left\{\mathbf{x} \mid h_{i}(\mathbf{x})=0, i=1, \ldots, k ; g_{i}(\mathbf{x}) \leq\right.$ $0, i=1, \ldots, m\}$. Adicionalmente, seja $\mathbf{x}^{*} \in \Omega$ um ponto que satisfaz as seguintes 
condições:

$$
\begin{aligned}
& \nabla_{\mathbf{x}} \mathcal{L}\left(\mathbf{x}^{*}, \boldsymbol{\lambda}^{*}, \boldsymbol{\nu}^{*}\right)=0, \\
& g_{i}\left(\mathbf{x}^{*}\right) \leq 0, \quad i=1, \ldots, m \\
& h_{i}\left(\mathbf{x}^{*}\right)=0, \quad i=1, \ldots, k \\
& \lambda_{i}^{*} \geq 0, \quad i=1, \ldots, m \\
& \lambda_{i}^{*} g_{i}\left(\mathbf{x}^{*}\right)=0 \quad i=1, \ldots, m
\end{aligned}
$$

então $\mathbf{x}^{*}$ é um ótimo global.

Demonstração. Note que $\Omega$ é um conjunto convexo. O Lagrangiano em $\mathrm{x} \in \Omega$ $\operatorname{com} \boldsymbol{\lambda}=\boldsymbol{\lambda}^{*}$ e $\boldsymbol{\nu}=\boldsymbol{\nu}^{*}$ é:

$$
\mathcal{L}\left(\mathbf{x}, \boldsymbol{\lambda}^{*}, \boldsymbol{\nu}^{*}\right)=f(\mathbf{x})+\sum_{i=1}^{m} \lambda_{i}^{*} g_{i}(\mathbf{x})+\sum_{i=1}^{k} \nu_{i}^{*} h_{i}(\mathbf{x})
$$

como $\lambda_{i}^{*} \geq 0, i=1, \ldots, m$, o Lagrangiano é convexo. Como $\nabla_{\mathbf{x}} \mathcal{L}\left(\mathbf{x}^{*}, \boldsymbol{\lambda}^{*}, \boldsymbol{\nu}^{*}\right)=0$ em $\mathbf{x}=\mathbf{x}^{*}$, então $\mathbf{x}^{*}$ minimiza $\mathcal{L}\left(\mathbf{x}^{*}, \boldsymbol{\lambda}^{*}, \boldsymbol{\nu}^{*}\right)$ em $\mathbf{x}$. Dessa forma, da correspondência entre Lagrangiano e a função dual de Lagrange segue:

$$
\begin{aligned}
\ell\left(\boldsymbol{\lambda}^{*}, \boldsymbol{\nu}^{*}\right) & =\mathcal{L}\left(\mathbf{x}^{*}, \boldsymbol{\lambda}^{*}, \boldsymbol{\nu}^{*}\right) \\
& =f\left(\mathbf{x}^{*}\right)+\sum_{i=1}^{m} \lambda_{i}^{*} g_{i}\left(\mathbf{x}^{*}\right)+\sum_{i=1}^{k} \nu_{i}^{*} h_{i}\left(\mathbf{x}^{*}\right)
\end{aligned}
$$

Das condições (3.44) e (3.46) conclui-se:

$$
\ell\left(\boldsymbol{\lambda}^{*}, \boldsymbol{\nu}^{*}\right)=f\left(\mathbf{x}^{*}\right)
$$

De fato, quando o problema de otimização é convexo com funções de restrição e função objetivo diferenciáveis, e a condição de Slater é satisfeita, então as condições de KKT são necessárias e suficientes para a otimalidade. Em outras palavras, $\mathbf{x}$ é um ponto de ótimo se, e somente se, existe $(\boldsymbol{\lambda}, \boldsymbol{\nu})$ que junto 
a x satisfazem simultaneamente as condições de KKT, equações (3.42) a (3.46) (BOYD; VANDENBERGHE, 2004, Página 244).

Uma vez que as condições de primeira ordem para otimalidade são necessárias e suficientes para os casos abordados nesta Tese, as condições de segunda ordem serão omitidas. Para uma leitura aprofundada das condições de segunda ordem para otimalidade, bem como a prova dos teoremas sugere-se consultar: teoremas 12.5 e 12.6 nas páginas 332-333 de (NOCEDAL; WRIGHT, 2006), página 174 em (BORWEIN; LEWIS, 2006) e páginas 12-16 em (KROGSTAD, 2010).

Isso conclui o conteúdo desta seção. Com os conceitos expostos aqui é possível compreender a aplicação de ferramentas de otimização convexa em problemas relacionados a sistemas de telecomunicações sendo que alguns destes problemas são discutidos no capítulo 4.

\subsection{Fundamentos de Programação Fracional Não Linear}

A programação fracional é uma área da otimização que trata de problemas em que a função custo é a razão de duas funções distintas. É possível ainda classificar o problema quanto à natureza das funções que compõe a fração: linear quando ambas as funções são lineares e não linear quando pelo menos uma das funções é não linear.

Sob um ponto de vista prático, é muito comum na área de otimização depararse com problemas que consistem na maximização de razões. Historicamente, um dos primeiros registros de problemas fracionais está no artigo de 1937 de John von Neumann (VON NEUMANN, 1937). Em seu trabalho Neumann propõe um modelo econômico de equilíbrio no qual a taxa de crescimento, definida pela fração de funções lineares, deve ser maximizada. 
São quase oitenta anos de contribuições e pesquisa nesta área da otimização, o que implica em uma extensiva bibliografia de métodos e algoritmos propostos para solucionar programas fracionais (SCHAIBLE, 1982). Todas estas abordagens podem ser classificadas em quatro grupos principais (BHATT, 1989):

1. Métodos simplex ajustados a funções objetivo não lineares;

2. Abordagens paramétricas;

3. Transformações paramétricas em um programa linear equivalente;

\section{Linearização}

O artigo clássico de (CHARNES; COOPER, 1962) propõe uma transformação paramétrica para o programa fracional linear e é considerado um dos pioneiros na área de programação fracional (SCHAIBLE, 1983). Neste trabalho de Tese, todavia, os problemas encontrados são de natureza não linear o que inviabiliza a aplicação de métodos como o de Charnes e Cooper. Desta forma, um método comum empregado na solução de programas fracionais não lineares foi proposto em 1967 por Werner Dinkelbach (DINKELBACH, 1967) inspirado no trabalho de (JAGANNATHAN, 1966).

Antes de proceder à explicação do método de Dinkelbach, considere o seguinte problema fracional não linear:

$$
\begin{aligned}
\text { maximizar } & q(\mathbf{x})=\frac{f(\mathbf{x})}{g(\mathbf{x})} \\
\text { sujeito à } & h_{i}(\mathbf{x}) \leq 0, i=1, \ldots, m
\end{aligned}
$$

onde $q, f, g, h_{i}: \mathbb{R}^{n} \rightarrow \mathbb{R}, i=1, \ldots, m$. O domínio do problema é o conjunto $\mathcal{D}$ definido como $\mathcal{D}=\left\{\mathbf{x} \in \mathbb{R}^{n} \mid h_{i}(\mathbf{x}) \leq 0, g(\mathbf{x})>0\right\}$. Um caso especial de 
problemas fracionais não lineares ocorre quando $f$ é uma função côncava e $g$ é uma função convexa: se estas condiçoes são satisfeitas então o problema é denominado programa fracional côncavo.

O método de Dinkelbach para a solução do problema (3.50) consiste na solução iterativa de problemas paramétricos como:

$$
\begin{aligned}
\text { maximizar } & f(\mathbf{x})-q g(\mathbf{x}) \\
\text { sujeito à } & h_{i}(\mathbf{x}) \leq 0, i=1, \ldots, m
\end{aligned}
$$

onde $q$ é tratado como parâmetro. As demais funções seguem a definição dada no problema (3.50). Desta forma, solucionando o problema paramétrico (3.51) e atualizando o valor do parâmetro $q$, o método de Dinkelbach funciona de forma análoga ao método de Newton para encontrar a raiz da equação $F(q)=0$ onde a função $F: \mathbb{R} \rightarrow \mathbb{R}$ é definida como (CROUZEIX; FERLAND; SCHAIBLE, 1985):

$$
F(q)=\max _{\mathbf{x} \in \mathcal{D}}\{f(\mathbf{x})-q g(\mathbf{x})\}
$$

Encontrar a raiz desta equação é especialmente útil quando o custo computacional para resolver o problema paramétrico é muito menor que para encontrar a solução do problema fracional não linear. Todavia, faz-se necessário demonstrar que a solução do problema fracional e do problema paramétrico são equivalentes. O teorema que estabelece esta relação foi proposto por (JAGANNATHAN, 1966), porém a demonstração convenientemente apresentada a seguir é uma reprodução do teorema 4.1 do trabalho de (CROUZEIX; FERLAND; SCHAIBLE, 1985).

O pseudocódigo do método de Dinkelbach que operacionaliza (3.52) é apresentado no Algoritmo 3.1 a seguir.

Para demonstrar que a solução dos problemas são equivalentes e que o mé- 


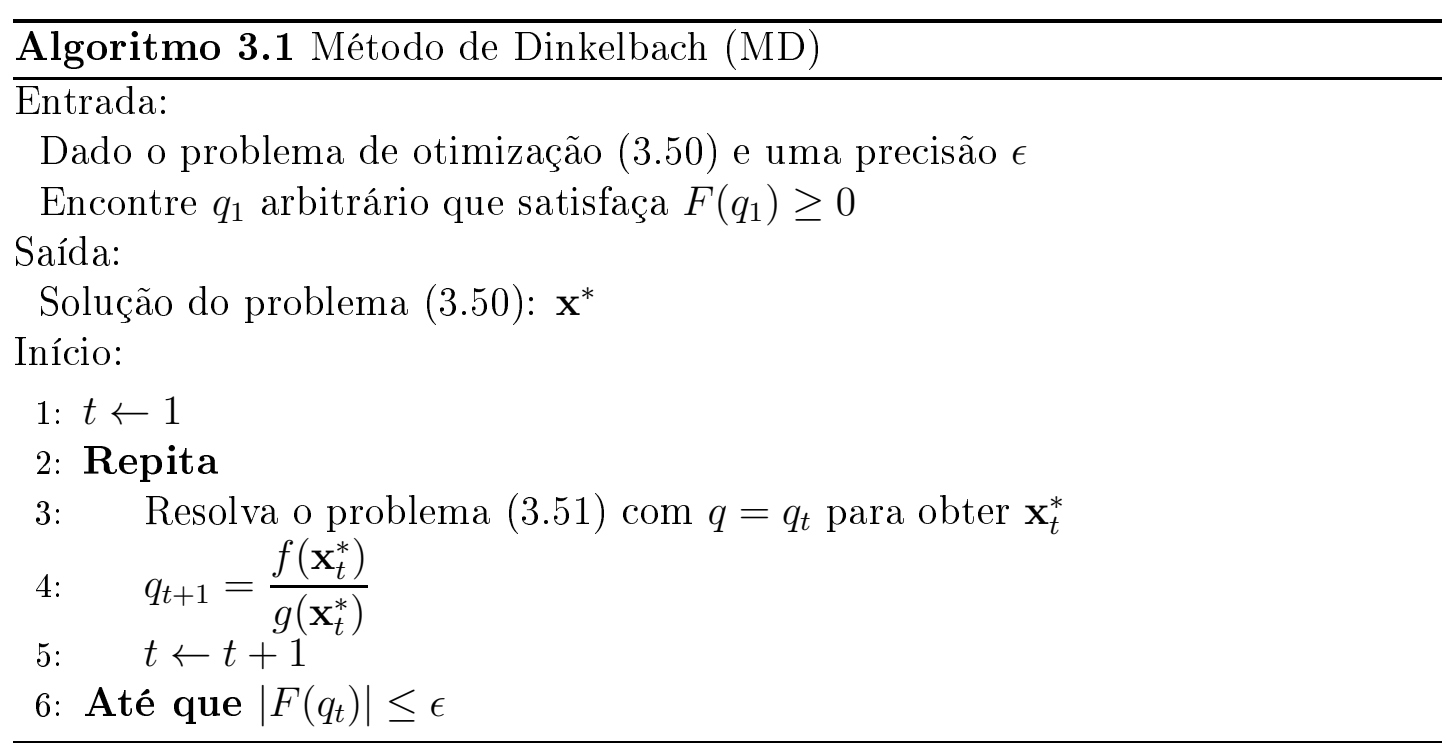

todo de Dinkelbach converge para a solução ótima de (3.50) são introduzidas as seguintes proposições e um corolário retirados de (CROUZEIX; FERLAND; SCHAIBLE, 1985):

Proposição 1. Os seguintes enunciados são verdadeiros:

a) F é não crescente e semicontínua superior;

b) $F(q)>0$ se, e somente se $q<q^{*}$; logo, $F\left(q^{*}\right) \leq 0$;

c) Se o problema (3.50) tem uma solução, então $F\left(q^{*}\right)=0$;

d) Se $F\left(q^{*}\right)=0$ então o problema fracional linear e o problema paramétrico tem o mesmo conjunto de soluções ótimas, que pode ser um conjunto vazio;

Demonstração. $\quad$ a) A monotonicidade de $F$ é consequência de $g$ ser uma função positiva, i.e. $g(\mathbf{x})>0, \forall \mathbf{x} \in \mathcal{D}$. Adicionalmente, $F$ é contínua conjuntamente em $(\mathbf{x}, q)$ e portanto é semicontínua superior em $q$.

b) Primeiramente, suponha que $F(q)>0$. Então existe $\tilde{\mathbf{x}} \in \mathcal{D}$ tal que $f(\tilde{\mathbf{x}})-$ $q g(\tilde{\mathbf{x}})>0$. Portanto:

$$
q<f(\tilde{\mathbf{x}}) / g(\tilde{\mathbf{x}}) \leq q^{*} \Rightarrow q<q^{*}
$$


De forma semelhante, considere agora que $q<q^{*}$. Então existe um $\hat{\mathbf{x}} \in \mathcal{D}$ tal que $f(\hat{\mathbf{x}}) / g(\hat{\mathbf{x}})>q$. Logo:

$$
f(\hat{\mathbf{x}})-q g(\hat{\mathbf{x}})>0 \Rightarrow F(q)>0
$$

c) Seja $\mathbf{x}^{*}$ a solução ótima de (3.50). Logo, $\mathbf{x}^{*} \in \mathcal{D}$ e $q^{*}=f\left(\mathbf{x}^{*}\right) / g\left(\mathbf{x}^{*}\right)$. Isto implica que $f\left(\mathbf{x}^{*}\right)-q^{*} g\left(\mathbf{x}^{*}\right)=0$ e como, de acordo com $(\mathbf{b}), F(q)>0$ e $q<q^{*}$, segue que $F\left(q^{*}\right)=0$.

d) Em (c) mostrou-se que uma solução ótima para o problema fracional linear (3.50) é uma solução ótima para o problema paramétrico (3.51). Agora, assuma que $F\left(q^{*}\right)=0$ e que $\mathbf{x}^{*}$ é uma solução ótima para o problema paramétrico (3.51), então, de:

$$
f\left(\mathbf{x}^{*}\right)-q^{*} g\left(\mathbf{x}^{*}\right)=0, \text { segue que } \frac{f\left(\mathbf{x}^{*}\right)}{g\left(\mathbf{x}^{*}\right)}=q^{*}
$$

o que implica que $\mathbf{x}^{*}$ é a solução ótima do problema fracional não linear $(3.50)$.

A proposição abaixo descreve a relação entre o par, $F(q)$ e o correspondente x que maximiza $f(\mathbf{x})-q g(\mathbf{x})$, com valores arbitrários do argumento de $F$ para o qual não se conhece $\mathbf{x}$ que maximiza $f(\mathbf{x})-q g(\mathbf{x})$. Esta proposição é utilizada para provar a proposição 4 .

Proposição 2. Seja q tal que $F(q)$ é finita e $\mathcal{M}(q)$ é não vazio, onde $\mathcal{M}(q)$ é o conjunto de possiveis soluções para o problema paramétrico (3.52) com parâmetro q. Considere $\mathbf{x} \in \mathcal{M}(q)$. Então:

$$
F(\mu)=F(q)+(q-\mu) g(\mathbf{x}), \quad \forall \mu \in \mathbb{R}
$$


Demonstração. Uma vez que $\mathbf{x} \in \mathcal{M}(q)$ segue que,

$$
F(q)=f(\mathbf{x})-q g(\mathbf{x})
$$

e portanto,

$$
\begin{aligned}
F(q) & =-(q-\mu) g(\mathbf{x})+f(\mathbf{x})-\mu g(\mathbf{x}) \\
F(q)+(q-\mu) g(\mathbf{x}) & =f(\mathbf{x})-\mu g(\mathbf{x}) \\
F(q)+(q-\mu) g(\mathbf{x}) & =F(\mu)
\end{aligned}
$$

Proposição 3. Suponha que exista um $b>0$ tal que $g(\mathbf{x})>b$ para todo $\mathbf{x} \in \mathcal{D}$. Então, para $\mu>q$ a seguinte desigualdade é verdadeira:

$$
F(\mu)+(\mu-q) b \leq F(q)
$$

Logo, $F(q)$ é decrescente no intervalo em que é finita.

Demonstração. Para todo $\mathbf{x} \in \mathcal{D}$ :

$$
\begin{aligned}
f(\mathbf{x})-q g(\mathbf{x}) & =f(\mathbf{x})-\mu g(\mathbf{x})+(\mu-q) g(\mathbf{x}) \\
& \geq f(\mathbf{x})-\mu g(\mathbf{x}+(\mu-q) b
\end{aligned}
$$

o que implica que:

$$
f(\mathbf{x})-q g(\mathbf{x}) \geq f(\mathbf{x})-\mu g(\mathbf{x})+(\mu-1) b, \quad \forall \mathbf{x} \in \mathcal{D}
$$

Portanto:

$$
\inf _{\mathbf{x} \in \mathcal{D}} f(\mathbf{x})-q g(\mathbf{x}) \geq \inf _{\mathbf{x} \in \mathcal{D}} f(\mathbf{x})-\mu g(\mathbf{x})+(\mu-1) b, \quad \forall \mathbf{x} \in \mathcal{D}
$$

Proposição 4. Seja t uma iteração do método de Dinkelbach descrito no algoritmo 3.1, $\mathbf{x}_{t}^{*}$ uma solução para o problema paramétrico na iteração t e $\mathcal{M}(q)$ o 
conjunto de soluções possíveis para o problema paramétrico com parâmetro q tal que $\mathbf{x}_{t}^{*} \in \mathcal{M}\left(q_{t}\right)$. Então:

a) $q_{t}-q_{t+1}=-F\left(q_{t}\right) / g\left(\mathbf{x}_{t}^{*}\right)$;

b) $q_{t} \leq q^{*}$ para todo t. Se $q_{t}<q^{*}$ então $q_{t}<q_{t+1} \leq q^{*}$;

\section{Demonstração.}

a) Seja $\mathbf{x}_{t}^{*}$ uma possível solução do problema paramétrico (3.51) na iteração $t$. Então:

$$
\begin{aligned}
F\left(q_{t}\right) & =f\left(\mathbf{x}_{t}^{*}\right)-q_{t} g\left(\mathbf{x}_{t}^{*}\right) \\
\frac{F\left(q_{t}\right)}{g\left(\mathbf{x}_{t}^{*}\right)} & =\frac{f\left(\mathbf{x}_{t}^{*}\right)-q_{t} g\left(\mathbf{x}_{t}^{*}\right)}{g\left(\mathbf{x}_{t}^{*}\right)} \\
\frac{F\left(q_{t}\right)}{g\left(\mathbf{x}_{t}^{*}\right)} & =\frac{f\left(\mathbf{x}_{t}^{*}\right)}{g\left(\mathbf{x}_{t}^{*}\right)}-q_{t} \\
\frac{F\left(q_{t}\right)}{g\left(\mathbf{x}_{t}^{*}\right)} & =q_{t+1}-q_{t}
\end{aligned}
$$

b) Como visto anteriormente, se $q_{t}<q^{*}$ então $F\left(q_{t}\right)>0$ (proposição $1-\mathbf{b}$ ). Logo, na igualdade em a), $F\left(q_{t}\right) / g\left(\mathbf{x}_{t}^{*}\right)$ é positivo uma vez que $g(\mathbf{x})>0$ para todo $\mathbf{x} \in \mathcal{D}$. Isto implica que $q_{t+1}>q_{t}$ e por consequência $q_{t}<q_{t+1} \leq q^{*}$.

Proposição 5. Se o problema fracional não linear (3.50) tem uma solução ótima $\mathbf{x}^{*}$ e $\mathcal{M}\left(q_{t}\right) \neq \emptyset$, com $t=1,2, \ldots$, ent $\tilde{a} o:$

$$
\left(q_{t+1}-q^{*}\right) \leq\left(q_{t}-q^{*}\right)\left(1-\frac{g\left(\mathbf{x}^{*}\right)}{g\left(\mathbf{x}_{t}^{*}\right)}\right), \quad t=1,2, \ldots
$$

Demonstração. Da proposição 4 segue que:

$$
F\left(q_{t}\right) / g\left(\mathbf{x}_{t}^{*}\right)=q_{t+1}-q_{t}
$$


Portanto,

$$
\begin{aligned}
q_{t+1} & =q_{t}+F\left(q_{t}\right) / g\left(\mathbf{x}_{t}^{*}\right) \\
q_{t+1}-q^{*} & =q_{t}-q^{*}+F\left(q_{t}\right) / g\left(\mathbf{x}_{t}^{*}\right)
\end{aligned}
$$

A existência de uma soluçao $\mathbf{x}^{*}$ para o problema fracional não linear (3.50) implica que $F\left(q^{*}\right)=0$ e $\mathbf{x}^{*} \in \mathcal{M}\left(q^{*}\right) \neq \emptyset$ de acordo com a proposição 1 (b) e (c). Desta forma é possível aplicar o conceito da proposição 2 que implica que:

$$
F\left(q_{t}\right)=F\left(q^{*}\right)+\left(q^{*}-q_{t}\right) g\left(\mathbf{x}^{*}\right)
$$

Combinando a equação (3.67) com (3.68) obtêm-se:

$$
q_{t+1}-q^{*}=\left(q_{t}-q^{*}\right)\left(1-\frac{g\left(\mathbf{x}^{*}\right)}{g\left(\mathbf{x}_{t}^{*}\right)}\right)
$$

Corolário 1. Se o problema fracional não linear (3.50) tem uma solução ótima $\mathbf{x}^{*}$, se $\mathcal{M}\left(q_{t}\right) \neq \emptyset, t=1,2, \ldots$, e se $\sup _{t}\left\{g\left(\mathbf{x}_{t}^{*}\right), t=1,2, \ldots\right\}<\infty$, onde sup é o supremo ${ }^{3}$ do conjunto, ou seja, o maior valor real assumido pela função $g$ ao longo das iterações t; então $q_{t}$ converge linearmente para $q^{*}$.

Teorema 5 (Convergência do Método de Dinkelbach). Assuma que o dominio do problema fracional não linear em $(3.50), \mathcal{D}$, é compacto, i.e. fechado ${ }^{4}$ e limitado ${ }^{5}$. Então os seguintes enunciados são verdadeiros:

a) Os problemas (3.50) e (3.51) sempre têm uma solução ótima, q* é finito e $F\left(q^{*}\right)=0$. Portanto $F(q)=0$ implica que $q=q^{*}$.

b) A função F é finita, contínua e decrescente em $\mathbb{R}$.

\footnotetext{
${ }^{3}$ De forma genérica o supremo de um subconjunto dos números reais é o menor valor real maior ou igual à todos os elementos do subconjunto.

${ }^{4}$ Conjuntos fechados contém todos os seus pontos limites.

${ }^{5}$ Todos os seus pontos estão a uma distância fixa uns dos outros.
} 
c) A sequência $\left\{q_{t}\right\}$, se não for finita, converge linearmente para $q^{*}$ e cada subsequência de $\left\{\mathbf{x}_{t}^{*}\right\}$ converge para a solução ótima de (3.50).

\section{Demonstração.}

a) A compacidade de $\mathcal{D}$, a continuidade de $f$ e $g$ e as afirmações da proposição 1 implicam que tanto o programa linear não fracional quando sua versão paramétrica possuem soluções ótimas, que $F\left(q^{*}\right)=0$ e portanto $q^{*}$ é finito.

b) A continuidade de $F$ segue nos mesmos moldes da semicontinuidade superior na proposição 1 (a), agora considerando a compacidade de $\mathcal{D}$. A monotonicidade estrita, i.e. o fato de ser decrescente, segue diretamente da proposição 3.

c) Seja $\left\{\mathbf{x}_{t^{\prime}}^{*}\right\}$ uma subsequência convergente de $\left\{\mathbf{x}_{t}^{*}\right\}$ que converge para $\hat{\mathbf{x}} \in \mathcal{D}$. Como $\mathbf{x}_{t^{\prime}}^{*} \in \mathcal{D}, \mathcal{D}$ é compacto e de acordo com o corolário 1 tem-se que:

$$
F\left(q_{t^{\prime}}\right)=f\left(\mathbf{x}_{t^{\prime}}^{*}\right)-q_{t^{\prime}} g\left(\mathbf{x}_{t^{\prime}}^{*}\right)
$$

logo, da continuidade de $F$,

$$
F\left(q^{*}\right)=f(\hat{\mathbf{x}})-q^{*} g(\hat{\mathbf{x}})
$$

Como $F\left(q^{*}\right)=0$, conclui-se que $\hat{\mathbf{x}}$ é uma solução ótima do problema linear fracional em (3.50).

Para fins didáticos e com o objetivo de compreender o modo de funcionamento do método de Dinkelbach apresenta-se na figura 19 uma interpretaçao geométrica da função $F$ a partir de duas iterações do algoritmo, $t$ e $(t+1)$-ésima iteração.

\subsection{Fundamentos de Teoria de Jogos}

Nesta seção serão abordados os principais conceitos no ramo da matemática aplicada conhecido como teoria de jogos. Na primeira subseção será apresentado 


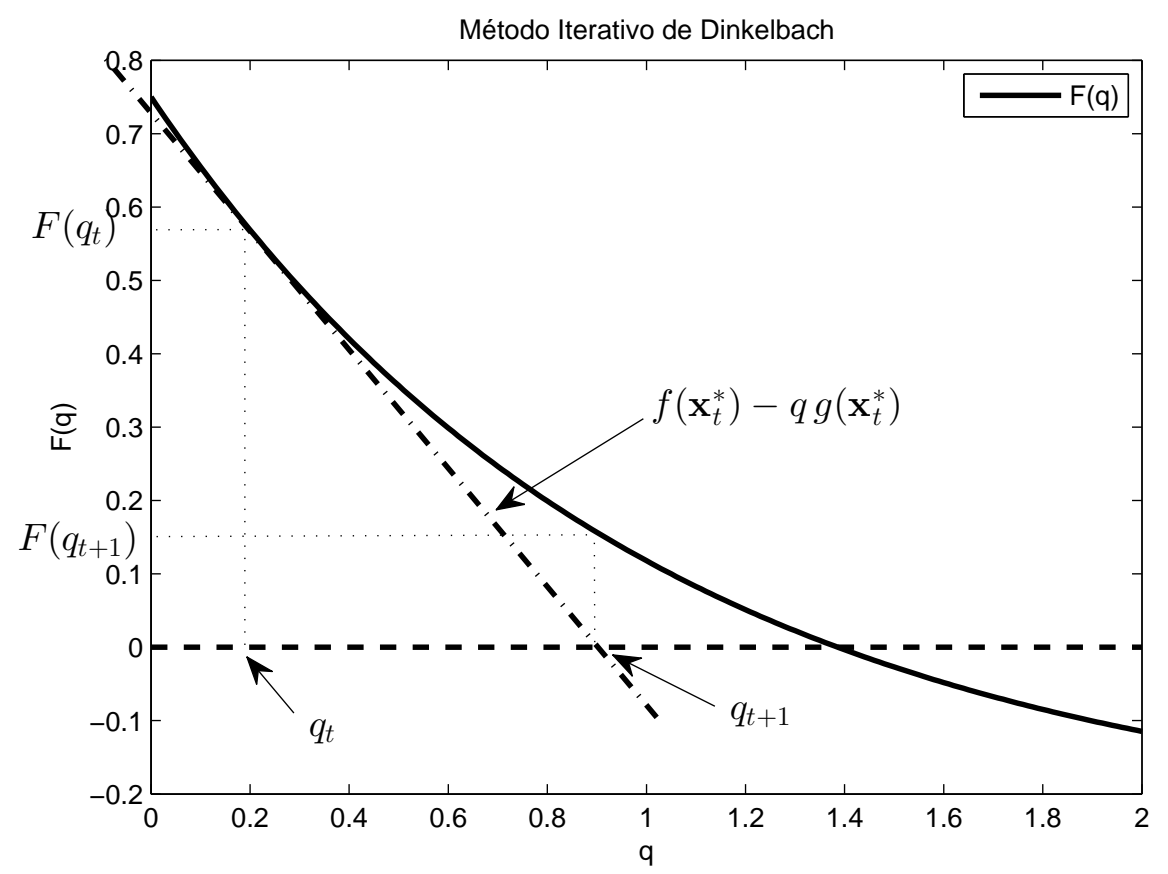

Figura 19: Interpretaçao geométrica da função $F$ para o método de Dinkelbach.

a definição de teoria de jogos bem como um histórico do desenvolvimento da área. Na segunda subseção serão apresentados os conceitos e termos utilizados em teoria de jogos, bem como uma classificação dos jogos de acordo com uma série de propriedades. Finalmente, as definições matemáticas e os principais teoremas relacionados a teoria de jogos são apresentados na última subseção.

\subsubsection{Definição e Breve Histórico}

De acordo com (MYERSON, 1997) a teoria de jogos é "o estudo de modelos matemáticos de conflito e cooperação entre indivíduos inteligentes e racionais que participam de uma tomada de decisão". Em outras palavras, a teoria de jogos é o estudo do processo cognitivo de tomada de decisão de forma estratégica sob uma perspectiva formal matemática. Desta forma, a teoria de jogos provê técnicas matemáticas para a análise de situações onde dois ou mais indivíduos tomam decisões que afetam diretamente um ao outro.

A primeira discussão relacionada à área de teoria de jogos foi publicada na 
obra de Pierre Rémond de Montmort, Essay D'Analyse sur les jeux de hazard ${ }^{6}$, no qual o autor menciona M. de Waldegrave, um homem com o qual trocava cartas sobre problemas de probabilidade (MONTMORT, 1713, Página 318). Em 13 de novembro de 1713, em uma carta dirigida a Nicolas Bernoulli, Waldegrave propõe uma solução que é um equilíbrio de estratégias mistas para uma versão do jogo de cartas "Le Her" com dois jogadores. Foi a primeira vez em que se tem registro do uso do conceito de estratégias mistas para prover uma solução (BELLHOUSE, 2007).

Embora os primeiros registros do que hoje é conhecido como teoria de jogos datem do século XVIII, é de comum acordo, segundo (SCHWALBE; WALKER, 2001), que a teoria de jogos moderna iniciou-se com os trabalhos de (ZERMELO, 1913), (BOREL, 1921), (VON NEUMANN, 1928) e o primeiro livro sobre teoria de jogos seja (VON NEUMANN; MORGENSTERN, 1944). Muitos escritores acreditam que em 1913 Zermelo mostrou que o jogo de xadrêz é estritamente determinado, ou seja, em cada estágio do jogo ao menos um dos jogadores tem uma estratégia à disposição que o levará à vitória ou conduzirá o jogo ao empate. O trabalho de (BOREL, 1921) por sua vez, foi responsável por reescrever a solução dos problema de minimax (problemas onde deseja-se minimizar a perda máxima).

Em 1928 John von Neumann demonstrou em seu trabalho (VON NEUMANN, 1928) que todo jogo finito de soma zero com duas pessoas possuía uma solução em estratégias mistas. Finalmente, em 1944, junto com o economista Oscar Morgenstern, von Neumann publicou o livro clássico de teoria de jogos intitulado "The Theory of Games and Economic Behaviour" (VON NEUMANN; MORGENSTERN, 1944).

Outro importante matemático que contribuiu substancialmente para o desenvolvimento da teoria de jogos foi o americano ganhador do Prêmio do Banco

\footnotetext{
${ }^{6}$ Ensaio Sobre Análise de Jogos de Azar
} 
Central da Suécia de Economia em Memória de Alfred Nobel ${ }^{7}$ em 1994 John Forbes Nash. Nash publicou em 1950 o artigo "Equilibrium points in n-person games" no qual prova a existência de um equilíbrio de estratégias mistas para jogos não cooperativos denominado equilíbrio de Nash (NASH, 1950b). Além deste trabalho, Nash ainda publicou outros três artigos: (NASH, 1950a) onde descreve a teoria da barganha e prova a existência de uma solução para o problema da barganha de Nash, (NASH, 1951) onde descreve a idéia de jogos não cooperativos e (NASH, 1953) onde apresenta o conceito geral de jogos cooperativos com duas pessoas além de desenvolver definições de soluções para tais jogos.

\subsubsection{Conceitos e Classificação}

Alguns conceitos são fundamentais para a compreensão dos modelos matemáticos em teoria de jogos. Nesta seção apresentar-se-ão os termos utilizados no ramo de teoria de jogos e seus significados bem como a definição matemática dos mesmos.

Desta forma, na linguagem de teoria de jogos, um jogo refere-se a qualquer situação social envolvendo dois ou mais indivíduos. Estes indivíduos envolvidos no jogo são denominados jogadores e podem ser considerados racionais e/ou inteligentes, adjetivos que são utilizados em teoria de jogos de forma técnica, de tal forma que um jogador é dito racional se pode tomar decisões de forma consistente em busca de seus objetivos. O mesmo jogador é inteligente se ele detem conhecimento acerca de toda a situação sob a qual se desenrrola o jogo. Esta última característica, de forma geral, significa que se um indivíduo desenvolve uma teoria que descreve o comportamento dos jogadores inteligentes em um determinado jogo e acredita-se que esta teoria está correta, então cada jogador compreende esta teoria e as predições e inferências que podem ser feitas a partir dela (MYERSON,

\footnotetext{
${ }^{7}$ Por vezes confundido com Prêmio Nobel de Economia
} 
1997).

Assume-se em teoria de jogos que o objetivo de cada jogador é maximizar seus ganhos, os quais são mensurados através de uma escala de utilidade. No trabalho de (VON NEUMANN; MORGENSTERN, 1944) foi demonstrado que para qualquer agente inteligente responsável por tomadas de decisão (jogadores inteligentes) existe uma maneira de atribuir quantidades/valores de utilidade a cada um dos possíveis resultados da tomada de decisão, de tal forma que cada jogador toma a decisão que maximiza o valor esperado de sua utilidade. Este resultado é denominado teorema da maximização da utilidade esperada (MYERSON, 1997).

\subsubsection{Classificação e Tipos de Jogos}

Em teoria de jogos, determinadas características dos jogos podem ser utilizadas para classificá-los. Nesta subseção serão listadas diferentes propriedades a partir das quais os jogos podem ser distintamente classificados. As propriedades são (PAVEL, 2012):

1. Natureza da Utilidade: jogos podem ser classificados como determinísticos ou estocásticos. Jogos estocásticos são aqueles onde os ganhos de cada jogador relacionados a uma estratégia são variáveis aleatórias ao contrário de jogos determinísticos onde os valores de utilidade são fixos (HALCK; DAHL, 1999);

2. Cooperatividade: os jogos podem ser cooperativos ou não cooperativos. De forma sucinta os jogos cooperativos são aqueles onde os jogadores tomam suas decisões de forma a potencializar a utilidade de todos os jogadores, logo, têm conhecimento de toda a estrutura do jogo e também da forma como os demais jogadores calculam seus ganhos. Já em jogos não cooperativos o objetivo de cada jogador é maximizar a própria utilidade de forma 
egoísta, i.e. em detrimento da utilidade dos demais jogadores (NASH, 1953).

3. Simetria: jogos podem ser simétricos ou assimétricos. Os jogos são denominados simétricos quando os ganhos de uma estratégia em particular dependem apenas da estratégia e não do jogador que decide utilizá-la. No caso de jogos assimétricos, os ganhos dependem tanto da estratégia quanto do jogador que a utiliza (NASH, 1951);

4. Ganhos: jogos podem ser classificados em soma zero ou soma não nula. Em jogos de soma zero a adição dos ganhos de todos os jogadores, i.e. dos valores de utilidade, resulta em zero. Isto significa que em jogos de soma zero os ganhos dos jogadores que tem utilidade positiva são equivalentes as perdas dos jogadores com utilidade negativa. Esta relação não é válida para jogos com soma não nula (MYERSON, 1997);

5. Jogadas: jogos podem ser jogados de forma sequencial ou simultânea. Jogos simultâneos são aqueles onde todos os jogadores decidem sua estratégia (jogam) ao mesmo tempo, também são conhecidos como jogos de estratégia. Jogos sequenciais são aqueles onde cada jogador decide sua estratégia enquanto os demais aguardam para jogar (MALCOLM, 2011);

6. Informação: jogos podem ter informação perfeita ou imperfeita. Quando os jogadores têm completo entendimento do histórico de suas ações e dos demais jogadores o jogo tem informação perfeita, caso contrário o jogo é classificado como de informação imperfeita. Adicionalmente os jogos podem ter informação completa ou não: um jogo tem informação completa quando todos os jogadores sabem a estrutura do jogo e as funções utilidade dos demais jogadores porém não conhecem as decisões (ou histórico de decisões) dos demais jogadores (HALCK; DAHL, 1999);

7. Finitude: jogos podem ser classificados em finitos, onde o conjunto de estra- 
tégias e o número de jogadas são finitos ou em infinitos, quando o conjunto de estratégias tem infinitos elementos (MYERSON, 1997).

8. Estratégias: em jogos de estratégias mistas os jogadores escolhem a probabilidade de utilização de uma determinada estratégia. Quando os jogadores decidem pelas estratégias em si (e não pela probabilidade), o jogo possuí estratégias puras (PAVEL, 2012).

Neste trabalho os jogos propostos para solução de problemas de otimização em telecomunicações (Capítulo 4 apresentam as seguintes características:

- Determinísticos: pois a função utilidade proposta é determinística;

- Não Cooperativos: pois não há troca de informação entre os jogadores o que permite a implementação de algoritmos distribuídos;

- Assimétricos: pois os ganhos relacionados às estratégias estão diretamente ligados ao jogador que as utiliza;

- Soma não nula: pois os valores de utilidade são não-negativos, i.e., a eficiência energética é não-negativa e portanto não há perda de utilidade por parte de nenhum jogador;

- Simultâneos: pois os jogadores escolhem suas estratégias de forma concomitante;

- Com informação completa: pois os jogadores conhecem a estrutura do jogo (topologia da rede, número de subportadoras, largura de banda dos subcanais, etc.) porém não tem conhecimento das decisões dos demais jogadores (as potências de transmissão escolhidas pelos demais usuários do sistema); 
- Infinitos: pois o conjunto de estratégias existentes é um intervalo do conjunto dos números reais e, portanto, existem infinitas estratégias disponíveis para cada jogador;

- Estratégias puras: como cada jogador decide qual estratégia (potência de transmissão) utilizar e não a probabilidade de utilizar cada uma das possíveis estratégias, o jogo é de estratégias puras.

\subsubsection{Descrição Matemática}

Matematicamente, a forma mais simples de apresentar um jogo é através do uso de sua forma estratégica (MYERSON, 1997). Logo, um jogo $\Gamma$ possui um conjunto não vazio de jogadores $\mathcal{J}=\{1, \ldots, n\}$, onde $n$ é o número total de jogadores, um conjunto não vazio de estratégias para cada jogador $\mathcal{E}_{i}, i \in$ $\mathcal{J}$ e um conjunto de funções utilidade que quantificam cada uma das possíveis estratégias de cada jogador em um valor de utilidade $u_{i}, i \in \mathcal{J}$. Portanto, um jogo representado na forma estratégica é uma t-upla,

$$
\Gamma=\left(\mathcal{J},\left(\mathcal{E}_{i}\right)_{i \in \mathcal{J}},\left(u_{i}\right)_{i \in \mathcal{J}}\right)
$$

onde as funções utilidade são do tipo $u_{i}:\left\{\underset{j \in \mathcal{J}}{\left.\times \mathcal{E}_{j}\right\}} \rightarrow \mathbb{R}\right.$, onde $\times$ é o operador de produto cartesiano. Um perfil de estratégias é a combinação das estratégias que os jogadores assumem. O conjunto de todas as possíveis combinações de estratégias entre os $n$ jogadores é o conjunto $\mathcal{E}$, definido como

$$
\mathcal{E}=\left\{\underset{j \in \mathcal{J}}{\times \mathcal{E}_{j}}\right\}
$$

Sendo assim, para um perfil $\mathrm{e}=\left[\mathrm{e}_{1}, \mathrm{e}_{2}, \ldots, \mathrm{e}_{n}\right]^{T} \in \mathcal{E}$ o valor resultante de $u_{i}($ e $)$ é a utilidade esperada para o jogador $i$ dada a combinação de estratégias e 
assumidas pelos jogadores em $\mathcal{J}$.

Em teoria de jogos é importante prever como o jogo $\Gamma$ desenrolar-se-á, i.e. determinar o seu resultado. De forma análoga, o objetivo é prever quem ganhará a partida de xadrez ou ainda quem está mais próximo da vitória. Essas predições são denominadas soluções do jogo e descrevem quais estratégias serão adotadas pelos jogadores no decorrer de um jogo genérico (MYERSON, 1997).

Uma das características mais básicas de todo jogo é o conceito de solução minimax ou estratégia segura. A idéia da solução de minimax é minimizar a máxima perda esperada para cada jogador. De forma similar é possivel considerar a maximização dos ganhos mínimos dos jogadores. Esta última solução é conhecida como maximin. Evidentemente, de acordo com os objetivos dos jogodores dentro do jogo e das próprias regras que compõem o jogo uma destas duas soluções se adapta melhor do que a outra (MYERSON, 1997).

Além destas duas soluções apresentadas de forma sucinta, outros dois conceitos de solução são importantes e fundamentais para a compreensão deste trabalho de Tese. A primeira é o conceito de melhor resposta apresentado em (FUNDENBERG; TIROLE, 1991, Página 29) e (GIBBONS, 1992, Páginas 33-49). Para apresentar o conceito de melhor resposta, considere a notação $e_{-i}$ para designar o perfil de estratégia de todos os jogadores exceto o jogador $i$, ou seja $\mathrm{e}_{-i}=\left[\mathrm{e}_{1}, \ldots, \mathrm{e}_{i-1}, \mathrm{e}_{i+1}, \ldots, \mathrm{e}_{n}\right]^{T}$.

Definição 19 (Melhor Resposta). A melhor resposta é a estratégia que maximiza os ganhos de utilidade para um dado perfil estratégico dos demais jogadores. Matematicamente, seja $e_{-i}$ as estratégias dos jogadores com exceção do i-ésimo jogador. Então, e é a estratégia de melhor resposta para $i$ se satatisfaz:

$$
u_{i}\left(e_{-i}, e_{i}^{*}\right) \geq u_{i}\left(e_{-i}, e_{i}\right), \quad \forall e_{i} \in \mathcal{E}_{i}
$$


O último conceito, apresentado neste texto, de solução em teoria de jogos é conceito de equilíbrio de Nash, proposto em (NASH, 1950b):

Definição 20 (Equilíbrio de Nash). Uma enupla $e^{*}=\left(e_{1}^{*}, \ldots, e_{n}^{*}\right)$ de estratégias é um equilíbrio de Nash se, e somente se para todo $i \in \mathcal{J}$

$$
u_{i}\left(e_{-i}^{*}, e_{i}^{*}\right)=\max _{e_{i} \in \mathcal{E}_{i}}\left[u_{i}\left(e_{-i}^{*}, e_{i}\right)\right]
$$

Em outras palavras, um equilíbrio de Nash é uma enupla de estratégias onde qualquer mudança unilateral por parte de um jogador leva a pontos onde os ganhos de utilidade são inferiores àquelas do equilíbrio de Nash. Outra interpretação pode ser dada ao conceito de equilíbrio de Nash: se todos os jogadores decidem por uma estratégia de melhor resposta de todos os demais jogadores de forma simultânea, então têm-se um equilíbrio de Nash (MYERSON, 1997).

Com os conceitos apresentados nesta seção é possível estabelecer jogos em sistemas de telecomunicações e encontrar soluções para os mesmos nos moldes do equilíbrio de Nash. Esta aplicação será apresentada no capítulo 4 e respectivos resultados númericos analisados no capítulo 5.

\subsection{Heurísticas}

Heurística é uma palavra que tem origem no grego e significa 'encontrar', 'descobrir'. Tem a mesma origem da palavra eureka que significa 'encontrei' (HARPER, 2015). Na matemática, engenharia e otimização combinatória as heurísticas são ferramentas utilizadas, em muitos casos, quando um método determinístico para solução de determinado problema não existe ou é ineficiente, i.e. exige uma quantidade de tempo muito elevada para encontrar uma solução ou o problema possuí características que impedem o uso de algoritmos determinísticos bem estabelecidos na literatura (RARDIN; UZSOY, 2001). 
Os métodos heurísticos ou algoritmos heurísticos constituem métodos não determinísticos de busca, i.e. buscam soluções boas e factíveis para problemas de otimização sem a certeza de que encontrarão a solução ótima, o que justifica a sua natureza não determinística (GILLI, 2004). Estas ferramentas ganharam grande destaque no final da década de 80 e início dos anos 90. Todavia, os primeiros trabalhos relacionados a heurísticas datam de meados do século XX quando as contribuições de (BOCK, 1958 apud GILLI; WINKER, 2007) e (CROES, 1958 apud GILLI; WINKER, 2007) foram publicadas.

Atualmente, é comum relacionar as heurísticas a algoritmos bio-inspirados, i.e. algoritmos cujo funcionamento tem como base o comportamento de organismos ou de mecanismos naturais. Os algoritmos evolucionários são um exemplo deste tipo de heurística pois reproduzem os mecanismos de evolução propostos por Charles Darwin (DARWIN, 2009) para encontrar a solução ótima de problemas de otimização.

Por outro lado, inspirados por estudos da biologia e considerando a cooperação entre indivíduos da mesma espécie, os algoritmos de otimização por enxame de partículas simulam o comportamento de bandos de aves em busca de alimento (KENNEDY; EBERHART, 1995) e o algoritmo dos vaga-lumes mimetizam o comportamento dos pirilampos ao utilizar sua bioluminescência para comunicarse com outros vaga-lumes (YANG, 2008).

Entretanto, é importante salientar que nem todos os algoritmos heurísticos são bio-inspirados. O algoritmo de recozimento simulado (do inglês, simulated annealing) (KIRKPATRICK; GELATT; VECCHI, 1983) é um exemplo: ele é inspirado pelo processo de recozimento, uma técnica utilizada na metalurgia para obtenção de estados de baixa energia em um sólido.

Esta seção está organizada da seguinte forma: a primeira subseção apresenta os conceitos básicos e como é a modelagem do problema para que o mesmo possa 
ser solucionado por uma heurística, a segunda subseção apresenta o algoritmo dos vaga-lumes e a terceira subseção apresenta o algoritmo de otimização por enxame de partículas.

\subsubsection{Conceitos Básicos}

Inicia-se esta seção relembrando o enunciado padrão de um problema de otimização:

$$
\begin{array}{ll}
\text { minimizar } & f(\mathbf{x}) \\
\text { sujeito à } & g_{i}(\mathbf{x}) \leq 0, \quad i=1, \ldots, m \\
& h_{i}(\mathbf{x})=0, \quad i=1, \ldots, k
\end{array}
$$

onde a função $f$ é denominada função custo ou função objetivo, $g$ e $h$ são funções de restrição que delimitam o domínio do problema.

Com intuito de modelar o problema acima para que possa ser solucionado por um algoritmo heurístico é importante recapitular a classificação dos problemas de otimização apresentada na subseção 3.1.1. Sendo assim, é preciso verificar o número de objetivos no problema, se as variáveis de decisão são contínuas ou discretas e qual o domínio do problema.

As duas primeiras informações podem ser extraídas de forma imediata observando-se a função objetivo e as variáveis de decisão. O terceito item, i.e. o domínio do problema, todavia, deve ser analisado com cautela. O algoritmo heurístico não deve levar em consideração ou avaliar soluções candidatas que não façam parte do domínio do problema. Esta averiguação pode ser feita de forma iterativa no algoritmo ou através da função objetivo com o uso de um termo penalizador (SMITH; COIT, 1997). 
Nesta Tese de doutorado, os algoritmos heurísticos empregados verificam a cada iteração se as soluções candidatas são factíveis, i.e., se pertencem ao domínio do problema. Quando uma solução não factível é encontrada a mesma é substituída por uma solução factível aleatória.

Adicionalmente, uma vez que heurísticas não são métodos determinísticos, é preciso estabelecer medidas de desempenho para verificar a qualidade da solução obtida por meio do algoritmo heurístico. Em determinados problemas de otimização, a função utilizada pela heurística não caracteriza de forma direta uma medida de desempenho. Uma medida de de desempenho comumente utilizada na literatura é o erro quadrático médio normalizado (do inglês, normalized mean squared error, NMSE).

Considere que y seja a solução obtida pelo método heurístico e que $\mathbf{x}^{*}$ seja a solução ótima para o problema. O erro quadrático médio normalizado é dado por,

$$
\mathrm{NMSE}=\frac{\left\|\mathbf{y}-\mathbf{x}^{*}\right\|^{2}}{\left\|\mathbf{x}^{*}\right\|^{2}}
$$

Nesta Tese a medida de desempenho considerada é a própria eficiência energética, i.e., o valor da própria função custo será utilizado para verificar a qualidade da solução.

\subsubsection{Algoritmo dos Vaga-lumes}

O algoritmo dos vaga-lumes é uma heurística bio-inspirada baseada na inteligência coletiva de vaga-lumes e os seus padrões de emissão de luz. Foi criado por (YANG, 2008) e o seu funcionamento baseia-se em dois fatores que envolvem os vaga-lumes de um determinado ambiente: a distância entre os indivíduos e a intensidade da luz emitida pelos mesmos. 
Conforme (YANG, 2009) descreve, existem espécies distintas de vaga-lumes que utilizam o fenômeno da bio-luminescência para diferentes fins. Algumas espécies utilizam o cintilar para atrair parceiros para o acasalamento, outras espécies utilizam-no como mecanismo de segurança e há ainda espécies como as da família Photuris que brilham para atrair presas de tal forma que suas fêmeas são capazes de imitar os padrões de lampejos de outras espécies que, evidentemente, são únicos e particulares.

A analogia em relação a problemas de otimização é feita de tal forma que a intensidade da luz emitida por um vaga-lume é maior quanto melhor for a solução representada pelo individuo. Por outro lado, quanto maior é a distância entre dois vaga-lumes, menor é a intensidade da luz recebida, e vice-versa. Desta forma, os vaga-lumes distribuídos dentro do conjunto que forma o domínio do problema interagem de forma cooperativa a fim de alcançar a solução ótima (YANG, 2008).

Para propor o algoritmo, (YANG, 2008) assumiu três regras básicas:

1. Todos os vaga-lumes são desprovidos de gênero e podem atrair ou serem atraídos;

2. A atratividade é proporcional à intensidade da luz emitida de tal forma que o vaga-lume menos brilhante é movido em direção ao mais cintilante. Se não existe vaga-lume com intensidade de luz superior a um em particular então este vaga-lume em particular move-se de forma aleatória;

3. A intensidade da luz produzida pelo vaga-lume é diretamente relacionada à função objetivo do problema tratado.

Sendo assim, para um problema de otimização onde deseja-se maximizar uma determinada função objetivo, por exemplo, a intensidade da luz pode ser diretamente proporcional à própria função custo. No caso de problemas de otimização onde o objetivo é a minimização de uma função é suficiente recordar 
que minimizar uma função é equivalente a maximizar o negativo da função, i.e. $\arg \min f(\mathbf{x})=\arg \max -f(\mathbf{x})$.

O texto a partir deste ponto parte do pressuposto que o problema de otimização para o qual o algoritmo dos vaga-lumes será utilizado é um problema cujo objetivo é maximizar a função custo. Para este caso, o pseudocódigo do algoritmo dos vaga-lumes é apresentado no algoritmo 3.2.

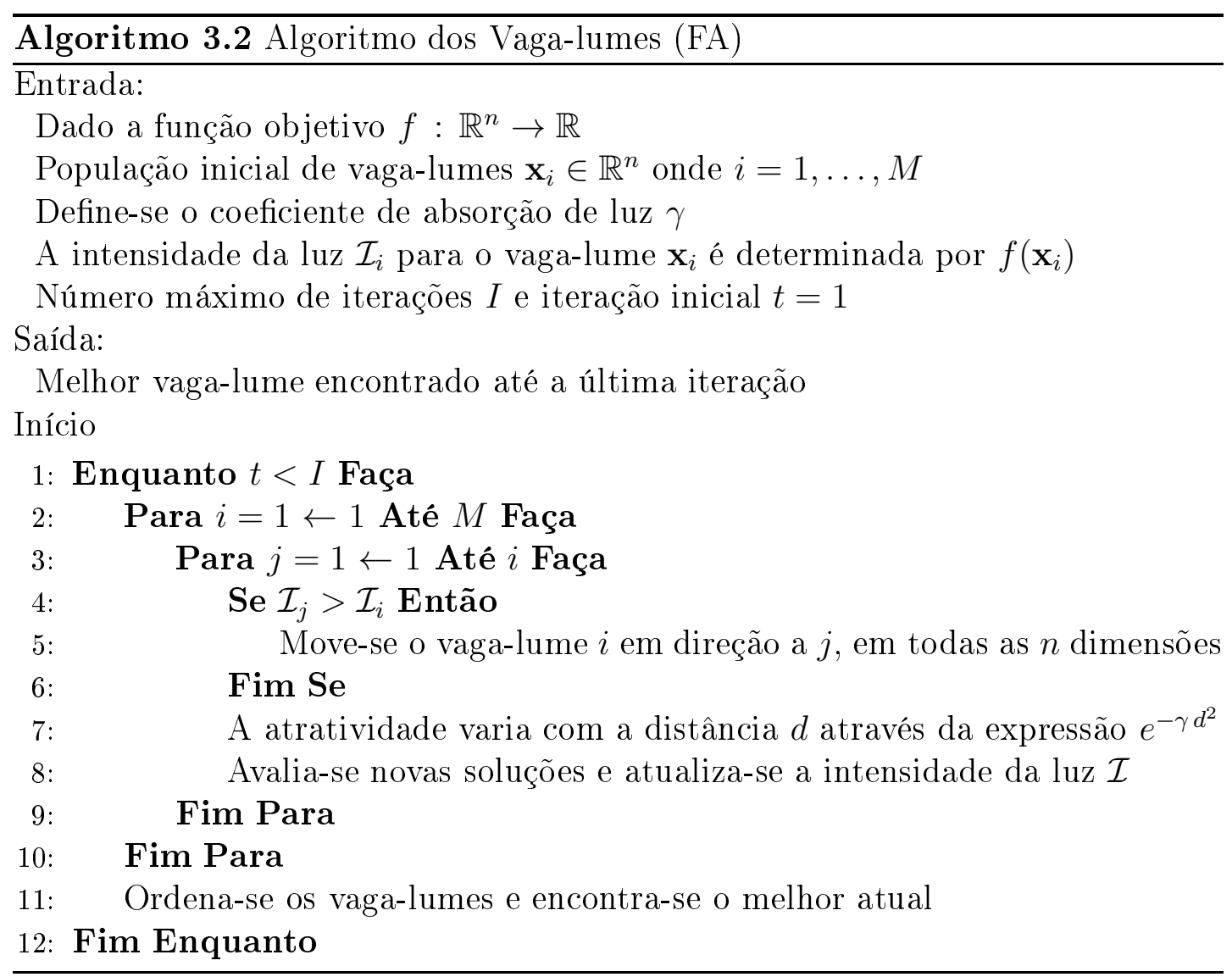

Note que ao contrário da intensidade da luz que é uma característica inerente ao indivíduo, a atratividade é na realidade uma relação entre dois vaga-lumes. Portanto, a atratividade entre dois indivíduos $i$ e $j$ é definida como (YANG, 2008):

$$
\beta_{i j}=\beta_{0} e^{-\gamma d_{i j}^{2}}
$$

onde $\beta_{i j}$ é a atratividade entre $i$ e $j$, i.e. a intensidade com que $j$ atrai $i ; \beta_{0}$ 
é a atratividade quando a distância é nula e é considerada comum a todos os indivíduos da população, $\gamma$ é uma característica do meio onde estão dispostos os vaga-lumes denominada coeficiente de absorção de luz. Finalmente, $d_{i j}$ é a distância Euclidiana entre os dois vaga-lumes:

$$
d_{i j}=\left\|\mathbf{x}_{i}-\mathbf{x}_{j}\right\|=\sqrt{\sum_{k=1}^{n}\left(x_{i, k}-x_{j, k}\right)^{2}}
$$

Conforme descrito no passo 5 do algoritmo 3.2 o vaga-lume $i$ menos brilhante deve mover-se em direção ao vaga-lume $j$ cuja intensidade de luz produzida $\mathcal{I}_{j}$ é maior que a do primeiro $\mathcal{I}_{i}$. Este movimento é determinado de acordo com a equação (YANG, 2008):

$$
\mathbf{x}_{i}[t+1]=\mathbf{x}_{i}[t]+\beta_{0} e^{-\gamma d_{i j}^{2}}\left(\mathbf{x}_{j}[t]-\mathbf{x}_{i}[t]\right)+\alpha\left(\tilde{\mathbf{x}}[t]-\frac{1}{2}\right)
$$

onde $\mathbf{x}_{i}[t+1]$ é a nova posição do vaga-lume $i$ na iteração $t+1, \mathbf{x}_{i}[t]$ e $\mathbf{x}_{j}[t]$ são as posições dos vaga-lumes $i$ e $j$ na iteração $t$, respectivamente; $\beta_{0}$ é a atratividade base, $\gamma$ é o coeficiente de absorção do meio, $d_{i j}$ é a distância entre os vaga-lumes $i$ e $j, \alpha$ é um parâmetro de passo aleatório e $\tilde{\mathbf{x}}[t]=\left[\tilde{x}_{1}, \ldots, \tilde{x}_{n}\right]^{T}$ é um vetor de variáveis aleatórias que assume distribuição uniforme no intervalo $[0,1]$, i.e. $\tilde{x}_{k} \sim \mathcal{U}(0,1), k=1, \ldots, n$.

Para ilustrar o movimento dos vaga-lumes em duas dimensões, considere um cenário onde $\mathcal{I}_{j}>\mathcal{I}_{i}$. Desta forma, o vaga-lume $i$ move-se em direção a $j$. A figura 20 descreve geometricamente o movimento do vaga-lume $i$ apresentando de forma sistemática cada elemento da equação (3.80) no plano cartesiano, i.e. $n=2$.

De acordo com (YANG, 2009), em grande parte das implementações o parâmetro $\beta_{0}$ assume valor unitário e $\alpha \in[0,1]$. Já o parâmetro $\gamma$ caracteriza a 


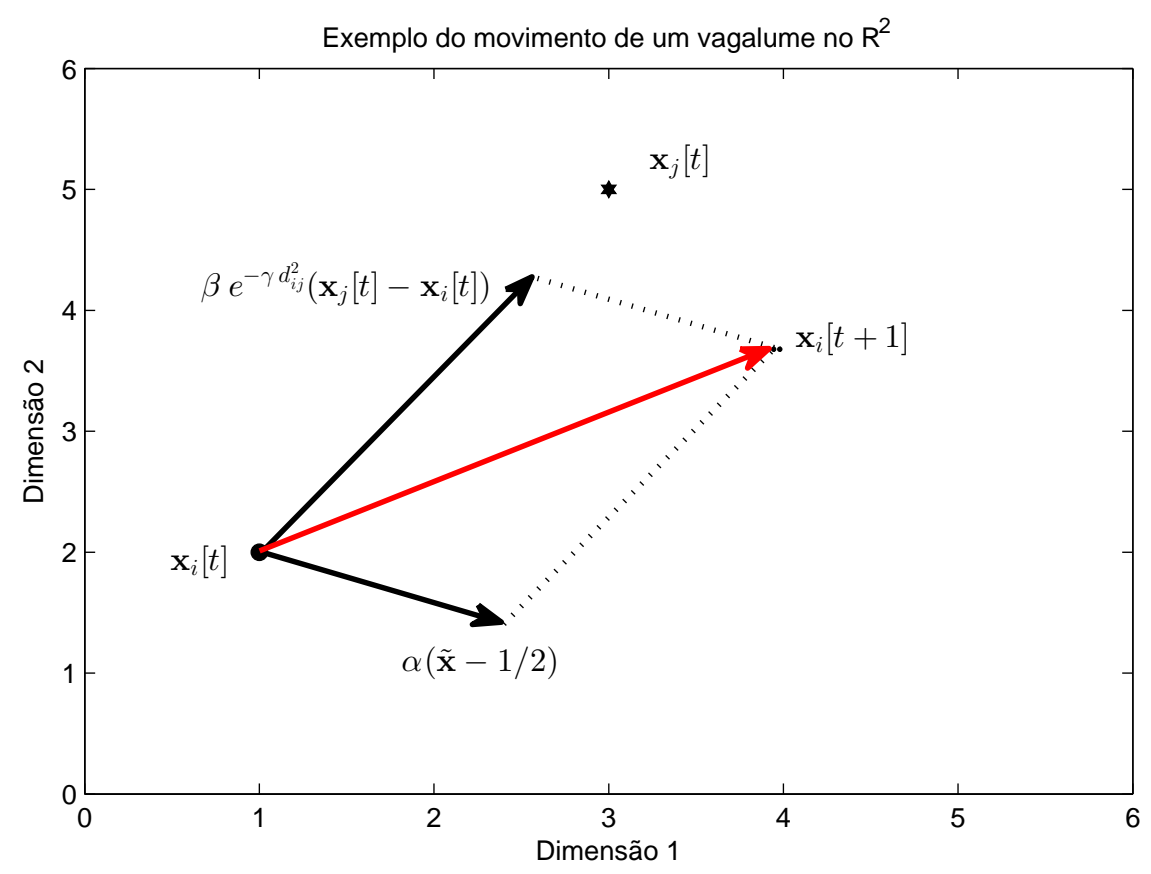

Figura 20: Representação geométrica em duas dimensões do movimento dos vagalumes descrito pela equação (3.80). Neste caso $j$ produz luz mais intensa que $i$ e, portanto, $i$ move-se em direção a $j$.

variação da atratividade e, portanto, é de grande importância para determinar a velocidade de convergência da heurística. Desta forma, na maioria das aplicações do algoritmo o valor de $\gamma$ oscila entre 0.01 e 100 .

A aplicação do algoritmo dos vaga-lumes para sistemas de telecomunicações será apresentado no capítulo 4 e os resultados obtidos com esta técnica no capítulo 5. Uma análise sistemática dos parâmetros de entrada do algoritmo para as aplicações pretendidas será apresentada com o intuito de determinar qual a melhor combinação de parâmetros de entrada que garantem maior velocidade de convergência e, simultaneamente, qualidade da solução.

\subsubsection{Otimização por Enxame de Partículas}

Criado por (KENNEDY; EBERHART, 1995) a otimização por enxame de partículas é uma heurística criada com o objetivo inicial de simular o comportamento social através de uma representação estilizada do movimento de organismos 
dentro de um bando ou cardume.

De acordo com os próprios criadores, o funcionamento do particle swarm optimization (PSO) é melhor compreendido se exposto através do raciocínio a partir do qual foi criado. Uma vez que o intuito do estudo era simular um meio social simplificado, i.e. o comportamento dos indivíduos dentro de um grupo, os agentes eram considerados pássaros à prova de colisão e o objetivo era simular a coreografia de um bando de pássaros (KENNEDY; EBERHART, 1995).

Para alcançar este objetivo, o modelo proposto baseava-se em duas ações: igualar a velocidade de cada agente à de seu vizinho mais próximo e a inserção de distúrbios aleatórios na velocidade dos agentes. A primeira ação, por si só, já era capaz de produzir o sincronismo observável em bandos de aves, todavia, após algum tempo de simulação o movimento dos agentes entrava em um estado no qual a direção do movimento não era alterada e, a partir desse momento, surgia a necessidade da introdução de comportamento estocástico no movimento de cada agente (KENNEDY; EBERHART, 1995).

Do ponto de vista de otimização, o PSO é uma heurística bio-inspirada que funciona com a cooperação entre indivíduos da mesma espécie e busca melhorar iterativamente as soluções candidatas factíveis com respeito a uma métrica comum (função objetivo) de tal sorte que ao final do algoritmo uma solução ótima ou sub-ótima seja encontrada e a função objetivo seja maximizada/minimizada de acordo com o problema de otimização em questão (KENNEDY, 1997).

Neste trabalho abordar-se-á apenas a versão contínua da heurística PSO. Sendo assim, considere o problema de otimização a seguir: 


$$
\begin{array}{ll}
\text { minimizar } & f(\mathbf{x}) \\
\text { sujeito à } & g_{i}(\mathbf{x}) \leq 0, \quad i=1, \ldots, m \\
& h_{i}(\mathbf{x})=0, \quad i=1, \ldots, k
\end{array}
$$

onde $f$ é a função objetivo, $g$ e $h$ são funções de restrição, de tal forma que $f, g, h: \mathbb{R}^{n} \rightarrow \mathbb{R}$. Desta forma $\mathbf{x}_{i} \in \mathbb{R}^{n}$ representa a posição do indivíduo de uma população composta por $M$ partículas. A cada iteração $t$ do algoritmo a posição $\mathbf{x}_{i}[t]$ é atualizada de acordo com a velocidade do agente ${ }^{8} i$. Matematicamente a atualização da posição da $i$-ésima partícula é dada por (na $(t+1)$-ésima iteração) (KENNEDY; EBERHART, 1995):

$$
\mathbf{x}_{i}[t+1]=\mathbf{x}_{i}[t]+\mathbf{v}_{i}[t+1], \quad \forall i=1, \ldots, M
$$

onde $\mathbf{v}_{i}[t+1]$ é a velocidade da partícula na iteração $t+1$. A velocidade, por sua vez, é definida de acordo com a seguinte equação (KENNEDY; EBERHART, 1995):

$$
\mathbf{v}_{i}[t+1]=\omega \mathbf{v}_{i}[t]+c_{1} \mathbf{U}_{i, 1}[t]\left(\mathbf{x}_{i}^{\text {best }}[t]-\mathbf{x}_{i}[t]\right)+c_{2} \mathbf{U}_{i, 2}[t]\left(\mathbf{x}_{g}^{\text {best }}[t]-\mathbf{x}_{i}[t]\right)
$$

onde $\omega \in[0,1]$ é a inércia, em outras palavras, é a parcela de velocidade da iteração $t$ que é mantida na iteração $t+1$. Os valores $\mathbf{x}_{i}^{\text {best }}[t]$ e $x_{g}^{b e s t}[t]$ são as posições das partículas encontradas até a iteração $t$ que possuem o melhor resultado em termos de função objetivo, sendo que o primeiro vetor armazena a melhor posição individual encontrada (local) e o segundo a melhor posição entre todas as partículas (global). As matrizes diagonais $\mathbf{U}_{i, 1}[t]$ e $\mathbf{U}_{i, 2}[t]$ de dimensão $n \times n$

\footnotetext{
${ }^{8}$ Agente, partícula e indivíduo são utilizados como sinônimos nesta seção.
} 
são matrizes cujos elementos são variáveis aleatórias de distribuição uniforme no intervalo $[0,1]$. Finalmente, os parâmetros $c_{1}$ e $c_{2}$ são coeficientes de aceleração relativos a influência das soluções locais e da solução global, respectivamente, no cálculo da velocidade.

Considerando o caso $n=2$ é possível criar uma representação geométrica tanto para a velocidade quanto para o movimento da partícula nos mesmos moldes da figura 20, onde o movimento dos vaga-lumes foi ilustrado no plano cartesiano.

Desta forma, apresenta-se a figura 21, um esboço geométrico para o cálculo da velocidade de cada partícula e como é atualizada a posição das partículas a cada iteração. Em outras palavras, a figura 21 é uma representação geométrica bidimimensional das equações (3.82) - a) na figura - e (3.83) - b) na figura.

A fim de reduzir a probabilidade da partícula ter sua posição atualizada para um ponto que não pertence ao domínio do problema, isto é, que não satisfaz as restrições do problema (3.81) incorpora-se à heurística o conceito de velocidade máxima $V_{\max }$ de tal forma que $-V_{\max } \leq \mathbf{v}_{i}[t] \leq V_{\max }$, ou ainda (ABRAO et al., 2011):

$$
\mathbf{v}_{i}[t]=\min \left\{V_{\max } ; \max \left\{-V_{\max } ; \mathbf{v}_{i}[t]\right\}\right\}
$$

O pseudocódigo da otimização por enxame de partículas é apresentado no Algoritmo 3.3.

A aplicação do PSO para sistemas de telecomunicações será apresentado no capítulo 4 e os resultados numéricos obtidos com esta técnica no capítulo 5. Uma análise sistemática dos parâmetros de entrada do algoritmo PSO para as aplicações em questão será apresentada com intuito de determinar qual a melhor combinação de parâmetros de entrada que garante melhores velocidades de convergência e, simultaneamente, qualidade da solução. 

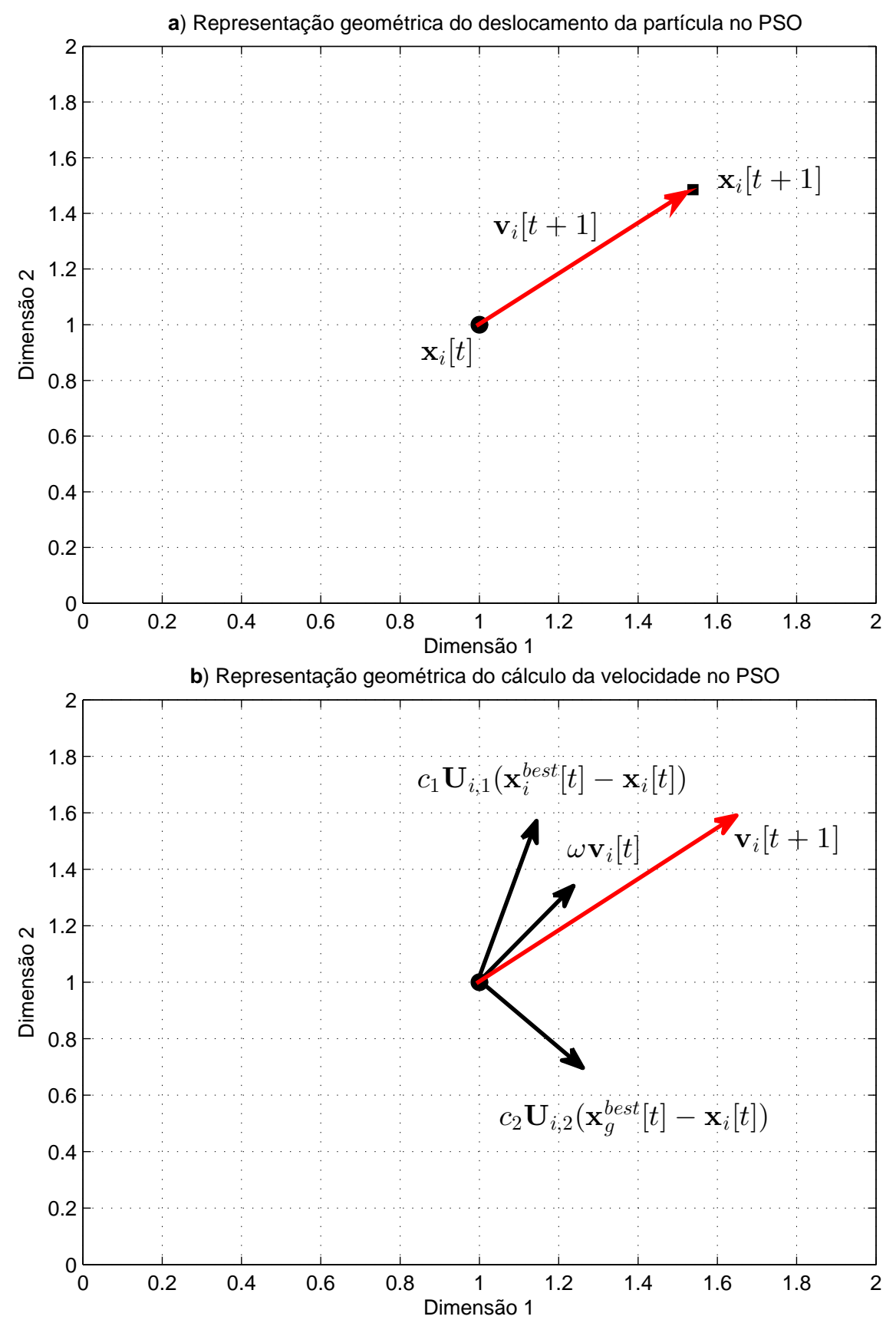

Figura 21: Representação geométrica bidimensional para a atualização da posição de uma partícula (a) e para o cálculo da velocidade (b) no algoritmo de otimização por enxame de partículas. Fonte: do autor 


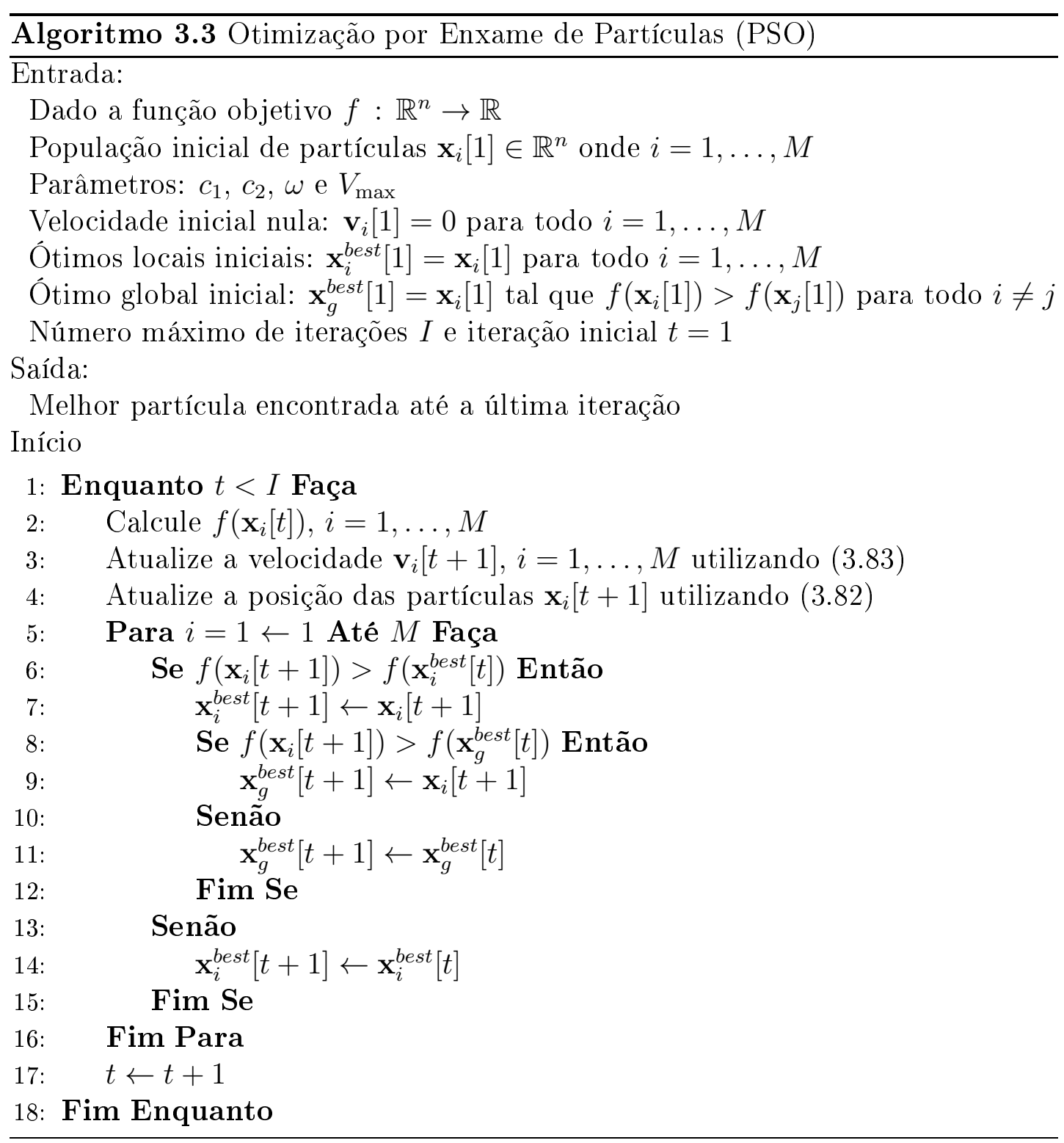




\section{TÉCNICAS DE OTIMIZAÇÃO APLICADAS À ALOCAÇÃ̃O DE RECURSOS EM REDES SEM FIO}

Em redes de comunicações sem fio o cenário do ponto de vista espectral e energético é inóspito: o espectro é limitado e, normalmente, regulamentado de tal forma que faixas específicas são reservadas a determinados tipos de serviços de comunicação como radiodifusão de sistemas de televisão digital, redes locais sem fio, telefonia, entre outros. Além deste fato, os efeitos da propagação do sinal tem impacto significativo, uma vez que alteram profundamente as características do sinal recebido podendo impedir a recuperação da informação no receptor.

O recurso energético é limitado principalmente nos terminais móveis de redes de telecomunicações. Os equipamentos apresentam limitações significativas de disponibilidade de energia, e, evidentemente, o usuário da rede móvel deseja utilizar o serviço com qualidade e durante um intervalo de tempo satisfatório. Por outro lado, as companhias de telecomunicações, responsáveis pela manutenção das estações rádio-base e, de forma geral, de toda a infra-estrutura de rede, procuram maximizar seu lucros poupando, de forma responsável, todos os possíveis gastos com manutenção, o que inclui a energia consumida pelas estações.

Por esses motivos, o gerenciamento de recursos escassos em redes sem fio, nominalmente, energia e espectro, são fundamentais para o bom funcionamento do sistema, satisfação dos usuários e potencialização dos lucros das companhias que prestam serviços. Não obstante, é importante notar que a satisfação do 
usuário e os lucros da empresa são, normalmente, objetivos conflitantes. Portanto, gerenciar os recursos da rede é um problema fundamental e desafiador.

Considerando os dois sistemas de telecomunicações apresentados no capítulo 2, apresentar-se-á a seguir uma série de problemas de otimização em redes de telecomunicações: desde problemas clássicos como o controle de potência em redes de múltiplo acesso, como também problemas mais atuais e ainda em aberto que visam a melhoria da eficiência energética das redes atuais de quarta geração, como as redes LTE e WiMax, bem como redes que integrarão futuros padrões de redes sem fio de quinta geração.

Os problemas foram convinentemente separados em duas seções: a primeira seção apresenta os problemas de otimização em sistemas de comunicação com múltiplo acesso por espalhamento espectral e a segunda em sistemas com múltiplo acesso por divisão de frequências ortogonais.

\subsection{Alocação de Recursos em Sistemas com Espa- lhamento Espectral}

Os sistemas onde o espalhamento espectral é utilizado como forma de múltiplo acesso são geralmente limitados por interferência, i.e. uma vez que todos os transmissores utilizam o mesmo espectro para enviar a informação e o fazem simultaneamente, tem-se a denominada interferência de múltiplo acesso, fator que limita o número de usuários ativos bem como a vazão total da rede.

Adicionalmente, os diferentes usuários transmitem de localidades geográficas distintas devido à característica de mobilidade ilimitada destas redes. A interferência de múltiplo acesso juntamente com esta última característica são responsáveis pelo efeito perto-longe, i.e. usuários próximos da estação rádio-base tendem a causar elevados níveis de interferência no sinal dos usuários que estão 
distantes.

Sendo assim, o controle de potência de transmissão em redes com múltiplo acesso por divisão de código é fundamental para a mitigação do efeito pertolonge. Esse controle permite que usuários distantes do receptor transmitam com potência superior àqueles que estão próximo (ou, equivalentemente, os que estão perto transmitam com potência inferior aos usuários distantes) de tal forma que os sinais dos usuários recebidos pela estação rádio-base tem amplitude equivalente, ou de forma análoga, a potência dos sinais dos usuários na entrada do receptor tem variância baixa ou quase nula.

Uma vez que os sistemas de múltiplo acesso por espalhamento espectral apresentados no capítulo 2 podem ter uma única portadora ou múltiplas subportadoras e pelo fato deste último ter complexidade ${ }^{1}$ maior que o primeiro, é conveniente apresentar primeiramente os problemas relacionados a sistemas DS/CDMA.

Visando uma melhor organização, esta seção será dividida de acordo com o problema e solução(ões) propostas.

\subsubsection{Controle de Potência em Sistemas DS/CDMA}

Considere o enlace de subida de um sistema DS/CDMA com $U$ usuários. Cada usuário possui sequência de espalhamento $F_{i}$ e um ganho de canal complexo $\mathrm{h}_{i}$, onde $i$ é o indexador do usuário. No problema clássico de controle de potência, o objetivo é satisfazer a relação sinal-interferência mais ruído mínima (pré ou pós detecção) de cada usuário com a menor potência possível. Matematicamente, têm-se o seguinte problema de otimização:

\footnotetext{
${ }^{1}$ Complexidade em termos de implementação do sistema e, também, quanto à análise dos problemas de otimização inerentes discutidos neste trabalho.
} 


$$
\begin{array}{ll}
\operatorname{minimizar} & \mathbf{p}=\left[p_{1}, p_{2}, \ldots, p_{U}\right]^{T} \\
\text { sujeito à } & (\mathrm{C} .1): p_{i} \in\left[0, P_{\max }\right], \quad \forall i=1, \ldots, U \\
& (\mathrm{C} .2): \delta_{i} \geq \delta_{i}^{*}, \quad \forall i=1, \ldots, U
\end{array}
$$

onde $P_{\max }$ é a potência máxima de transmissão, $\delta_{i}^{*}$ é a relação sinal-interferência mais ruído mínima a ser garantida para o $i$-ésimo usuário e $\delta_{i}$ é a SINR de prédetecção instantânea do usuário $i$ definida como:

$$
\delta_{i}=\frac{F_{i} p_{i}\left|\mathrm{~h}_{i}\right|^{2}}{F_{i} \sigma^{2}+\sum_{\substack{j=1 \\ j \neq i}}^{U} p_{j}\left|\mathrm{~h}_{j}\right|^{2}}
$$

onde $\sigma^{2}$ é a potência do ruído de fundo (AWGN).

Note que a SINR é uma função linear da potência e proporcional à mesma para uma interferência de múltiplo acesso e ruído fixos. Portanto, a solução para o problema de otimização em (4.1) é o ponto para o qual $\delta_{i}=\delta_{i}^{*}$ para todo $i=1, \ldots, U$. De acordo com (BOCK; EBSTEIN, 1964) o controle de potência pode ser modelado como um programa linear. Para isto, considere a matriz de canal $U \times U$ definida como:

$$
\mathbf{H}=\left[\begin{array}{cccc}
\mathrm{h}_{1,1} & \mathrm{~h}_{1,2} & \cdots & \mathrm{h}_{1, U} \\
\mathrm{~h}_{2,1} & \mathrm{~h}_{2,2} & \cdots & \mathrm{h}_{2, U} \\
\vdots & \vdots & \ddots & \vdots \\
\mathrm{h}_{U, 1} & \mathrm{~h}_{U, 2} & \cdots & \mathrm{h}_{U, U}
\end{array}\right]
$$

onde $h_{i, j}$ é o ganho de canal do interferente $j$ sobre o sinal do usuário $i$. Comparando $\mathbf{H}$ com o vetor de ganhos complexos de canal $\mathbf{h}=\left[\mathrm{h}_{1}, \mathrm{~h}_{2}, \ldots, \mathrm{h}_{U}\right]$ é evidente 
que as linhas de $\mathbf{H}$ são identicas e equivalentes a $\mathbf{h}$.

Considere, agora, a seguinte matriz de interferência normalizada $\mathbf{Z} \in \mathbb{R}^{U \times U}$ cujos elementos são definidos como,

$$
Z_{i j}=\left\{\begin{aligned}
0, & i=j \\
\frac{\delta_{i}\left|\mathrm{~h}_{i, j}\right|^{2}}{\left|\mathrm{~h}_{i, i}\right|^{2}}, & i \neq j
\end{aligned}\right.
$$

Considere também o seguinte vetor de ruído normalizado $\mathbf{n} \in \mathbb{R}^{1 \times U}$ cujos elementos são,

$$
\mathbf{n}=\left[\frac{\delta_{1} F_{1} \sigma^{2}}{\left|\mathrm{~h}_{1}\right|^{2}}, \frac{\delta_{2} F_{2} \sigma^{2}}{\left|\mathrm{~h}_{2}\right|^{2}}, \ldots, \frac{\delta_{U} F_{U} \sigma^{2}}{\left|\mathrm{~h}_{U}\right|^{2}}\right]^{T}
$$

Desta forma, é possível mostrar que encontrar a solução do problema em (4.1) é equivalente a solucionar o seguinte sistema linear (BOCK; EBSTEIN, 1964),

$$
(\mathbf{I F}-\mathbf{Z}) \mathbf{p}=\mathbf{n}
$$

onde $\mathbf{F}$ é a matriz diagonal $U \times U$ cujas entradas são os comprimentos das sequências de espalhamento de todos os usuários $F_{1}, F_{2}, \ldots, F_{U}$.

Quando as sequências de espalhamento dos usuários possuem o mesmo comprimento $F$ é possível simplificar o sistema linear conforme:

$$
(F \mathbf{I}-\mathbf{Z}) \mathbf{p}=\mathbf{n}
$$

Para verificar que de fato os problemas são correspondentes, o seguinte exemplo é apresentado: 
Exemplo 2. Considere um sistema $D S / C D M A$ com $U=2$ usuários com relações sinal-interferência mais ruído mínimas $\delta_{1}^{*}$ e $\delta_{2}^{*}$. Por simplicidade, considere que os usuários possuem sequências de espalhamento de comprimento equivalente tal que $F_{1}=F_{2}=F$; e que os seus ganhos complexos de canal são $h_{1}, h_{2}$, respectivamente. De acordo com a equação (4.7) têm-se:

$$
\left[\begin{array}{cc}
F & -\frac{\delta_{1}^{*}\left|h_{2}\right|^{2}}{\left|h_{1}\right|^{2}} \\
-\frac{\delta_{2}^{*}\left|h_{1}\right|^{2}}{\left|h_{2}\right|^{2}} & F
\end{array}\right]\left[\begin{array}{c}
p_{1} \\
p_{2}
\end{array}\right]=\left[\begin{array}{c}
\frac{\delta_{1}^{*} F \sigma^{2}}{\left|h_{1}\right|^{2}} \\
\frac{\delta_{2}^{*} F \sigma^{2}}{\left|h_{2}\right|^{2}}
\end{array}\right]
$$

Note que o sistema acima possui duas equações:

$$
\begin{aligned}
& F p_{1}-\frac{p_{2} \delta_{1}^{*}\left|h_{2}\right|^{2}}{\left|h_{1}\right|^{2}}=\frac{\delta_{1}^{*} F \sigma^{2}}{\left|h_{1}\right|^{2}} \\
& F p_{2}-\frac{p_{1} \delta_{2}^{*}\left|h_{1}\right|^{2}}{\left|h_{2}\right|^{2}}=\frac{\delta_{2}^{*} F \sigma^{2}}{\left|h_{2}\right|^{2}}
\end{aligned}
$$

Desenvolvendo a equação (4.9) obtêm-se,

$$
\begin{aligned}
F p_{1}\left|h_{1}\right|^{2}-p_{2} \delta_{1}^{*}\left|h_{2}\right|^{2} & =\delta_{1}^{*} F \sigma^{2} \\
\frac{F p_{1}\left|h_{1}\right|^{2}}{\delta_{1}^{*}}-p_{2}\left|h_{2}\right|^{2} & =F \sigma^{2} \\
\frac{1}{\delta_{1}^{*}} & =\frac{F \sigma^{2}+p_{2}\left|h_{2}\right|^{2}}{F p_{1}\left|h_{1}\right|^{2}} \\
\delta_{1}^{*} & =\frac{F p_{1}\left|h_{1}\right|^{2}}{F \sigma^{2}+p_{2}\left|h_{2}\right|^{2}}
\end{aligned}
$$

O que demonstra que, de fato, encontrar a solução para o problema de otimização (4.1) é equivalente ao sistema linear em (4.7).

A existência e unicidade de um vetor solução $\mathbf{p}^{*}$ para o sistema linear em (4.7) foi amplamente discutido em (BOCK; EBSTEIN, 1964) e (STANCZAK; WICZANOWSKI; BOCHE, 2009). Em ambos trabalhos o teorema de Perron-Frobenius é utilizado para apresentar as condições de uma solução ótima factível para o problema, i.e. que $\mathbf{p}^{*}$ seja não negativo e não nulo. Este estudo é sintetizado no teorema a seguir. 
Teorema 6 (Existência e Unicidade do Problema de Controle de Potência). Seja $\mathbf{Z}$ uma matriz não-negativa e $F>0$ um escalar. Existe um $\mathbf{p}^{*}$ cujos elementos são não negativos, i.e. $\mathbf{p}^{*} \geq 0$, e diferente do vetor nulo, $\mathbf{p} \neq \mathbf{0}$, que satisfaz a igualdade:

$$
(F \mathbf{I}-\mathbf{Z}) \mathbf{p}=\mathbf{n}
$$

para um $\mathbf{n}$ arbitrário e positivo se, e somente se, o raio espectral ${ }^{2}$ da matriz $\mathbf{Z}$, denotado por $\rho(\mathbf{Z})$, for menor que $F$, i.e. $\rho(\mathbf{Z})<F$.

Demonstração. Assuma que exista $\mathbf{p}^{*} \geq 0$, solução para $(F \mathbf{I}-\mathbf{Z}) \mathbf{p}=\mathbf{n}$. Desenvolvendo a equação matricial do sistema linear obtêm-se:

$$
\begin{gathered}
(F \mathbf{I}-\mathbf{Z}) \mathbf{p}=\mathbf{n} \\
F \mathbf{p}-\mathbf{Z} \mathbf{p}=\mathbf{n} \\
F \mathbf{p}=\mathbf{n}+\mathbf{Z} \mathbf{p}
\end{gathered}
$$

Como $\mathbf{n}$ é sempre positivo, então $\mathbf{Z} \mathbf{p}-F \mathbf{p}<0$. Uma vez que $\mathbf{Z}$ é não negativa então $\mathbf{Z} \mathbf{p} \geq 0$. Logo $F>0$ e $\mathbf{p}>0$ são condições necessárias para que $\mathbf{Z} \mathbf{p}-F \mathbf{p}<$ 0 . Considere o vetor coluna $\mathbf{v}$, não negativo e não nulo, um autovetor esquerdo da matriz $\mathbf{Z}$ associado ao raio espectral da mesma $\rho(\mathbf{Z})$. Pelo teorema de PerronFrobenius este autovetor existe e portanto $\mathbf{v}^{T} \mathbf{Z} \mathbf{p}=\rho(\mathbf{Z}) \mathbf{v}^{T} \mathbf{p}$. Uma vez que $\mathbf{Z} \mathbf{p}-F \mathbf{p}<0$ e $\mathbf{v}^{T} \mathbf{Z} \mathbf{p}=\rho(\mathbf{Z}) \mathbf{v}^{T} \mathbf{p}$ então $\rho(\mathbf{Z}) \mathbf{v}^{T} \mathbf{p}<F \mathbf{v}^{T} \mathbf{p}$. Como $\mathbf{v} \geq 0$ e $\mathbf{p}>0$ então $\mathbf{v}^{T} \mathbf{p} \geq 0$. Portanto $\rho(\mathbf{Z})<F$. Desta forma, resta demonstrar a suficiência da condição. Assuma, portanto, que $F>\rho(\mathbf{Z})$. Pelo teorema A.16 da página 355 em (STANCZAK; WICZANOWSKI; BOCHE, 2009) a seguinte série de Neumann converge:

$$
(F \mathbf{I}-\mathbf{Z})^{-1}=F^{-1}\left(\mathbf{I}-F^{-1} \mathbf{Z}\right)^{-1}=F^{-1} \sum_{j=0}^{\infty}(F-1 \mathbf{Z})^{j}
$$

\footnotetext{
${ }^{2} \mathrm{O}$ raio espectral de uma matriz quadrada é o valor do autovalor de maior magnitude em módulo.
} 
Uma vez que $\mathbf{Z}$ é não negativa então $(F \mathbf{I}-\mathbf{Z})^{-1} \geq 0$. Adicionalmente, uma vez que $\left(F^{-1} \mathbf{Z}\right)^{0}=\mathbf{I}$, cada linha de $(F \mathbf{I}-\mathbf{Z})^{-1}$ possui ao menos um elemento positivo. Logo, como $\mathbf{n}>0$ então $(F \mathbf{I}-\mathbf{Z})^{-1} \mathbf{n}>0$ para qualquer $\mathbf{n}>0$. Já que $\mathbf{p}=(F \mathbf{I}-\mathbf{Z})^{-1} \mathbf{n}$, então $\mathbf{p}>0$.

O teorema 6 apresenta o raio espectral da matriz $\mathbf{Z}$ menor que o comprimento da sequência de espalhamento como condição para a existência e unicidade de uma solução positiva para o problema de controle de potência em redes DS/CDMA. O teorema ainda afirma que esta solução ótima pode ser obtida a partir da equação,

$$
\mathbf{p}=(F \mathbf{I}-\mathbf{Z})^{-1} \mathbf{n}
$$

Note que a equação acima envolve a inversão de uma matriz. De acordo com (GOLUB; Van Loan, 2012) a inversão de uma matriz $U \times U$ é uma operação cuja complexidade computacional é da ordem de $\mathcal{O}\left(U^{3}\right)$. Logo, para sistemas com elevado número de usuários, a operação de inversão de matriz pode não ser viável de ser executada antes que os ganhos complexos de canal dos usuários mudem. Outra dificuldade é o fato de que a solução através da equação (4.18) necessita da informação das condições de canal de todos os usuários e portanto não pode ser implementada de forma distribuída ${ }^{3}$.

Para solucionar o problema de controle de potência em redes DS/CDMA de forma distribuída um algoritmo de controle de potência para o enlace de subida foi proposto no trabalho de (GROSS; ABRãO; JESZENSKY, 2011), onde o desempenho do mesmo é discutido (e comparado a outros algoritmos na literatura) e sua convergência é provada matematicamente. O algoritmo baseia-se no conceito de equilíbrio de Verhulst cujo objetivo geral era descrever a dinâmica

\footnotetext{
${ }^{3} \mathrm{~A}$ implementação no modo distribuído é uma característica desejável em algortimos que gerenciam recursos no enlace de subida de redes de comunicação sem fio, tendo em vista controlar a potência de transmissão em cada unidade móvel.
} 
populacional com base nas limitações de alimento e espaço, ou seja, o modelo de Verhulst descreve como se comporta o crescimento da população de indivíduos de uma espécie ao longo do tempo em cenários onde os recursos são limitados (VERHULST, 1838).

Operacionalmente, o algoritmo pode ser descrito por uma equação iterativa, já adaptada ao problema de alocação de potência em redes de múltiplo acesso do tipo DS/CDMA (GROSS; ABRãO; JESZENSKY, 2011):

$$
p_{i}[t+1]=\left(1+\alpha_{v}\right) p_{i}[t]+\alpha_{v}\left[\frac{\delta_{i}[t]}{\delta_{i}^{*}}\right] p_{i}[t], \quad \forall i=1, \ldots, U
$$

onde $i$ é o indexador de usuário, $p_{i}[t+1]$ é a potência de transmissão na próxima iteração, $\alpha_{v} \in[0,1]$ é o coeficiente de aceleração do algoritmo, $p_{i}[t]$ é a potência de transmissão na iteração atual, $\delta_{i}[t]$ é a relação sinal-interferência mais ruído da iteração atual ${ }^{4}$ e $\delta_{i}^{*}$ é a relação sinal-interferência mais ruído desejada (mínima) para o usuário $i$, capaz de garantir a qualidade de serviço mínima para o $i$-ésimo usuário.

É possível, portanto, implementar a recursão da equação (4.19) no $i$-ésimo equipamento de usuário móvel uma vez que todos os parâmetros $\left(\alpha_{v}, \delta_{i}^{*}\right.$ e $\left.p_{i}[t]\right)$ são locais, i.e. o terminal móvel tem conhecimento dos seus valores. O valor da SINR atual, $\delta_{i}[t]$ pode ser obtido na estação rádio-base que detecta o sinal do usuário $i$. A estação estima o valor da relação sinal-interferência mais ruído, quantiza este valor em um número conveniente de bits e transmite essa informação para o $i$-ésimo usuário através do canal de serviço no enlace direto. Isto permite que cada usuário controle sua potência de transmissão de forma independente, o que justifica o termo algoritmo distribuído de controle de potência. A figura 22 apresenta o diagrama de blocos das operações envolvidas no controle de potência

\footnotetext{
${ }^{4}$ Referente a transmissão com a potência $p_{i}[t]$ em um sistema de múltiplo acesso.
} 
distribuído.

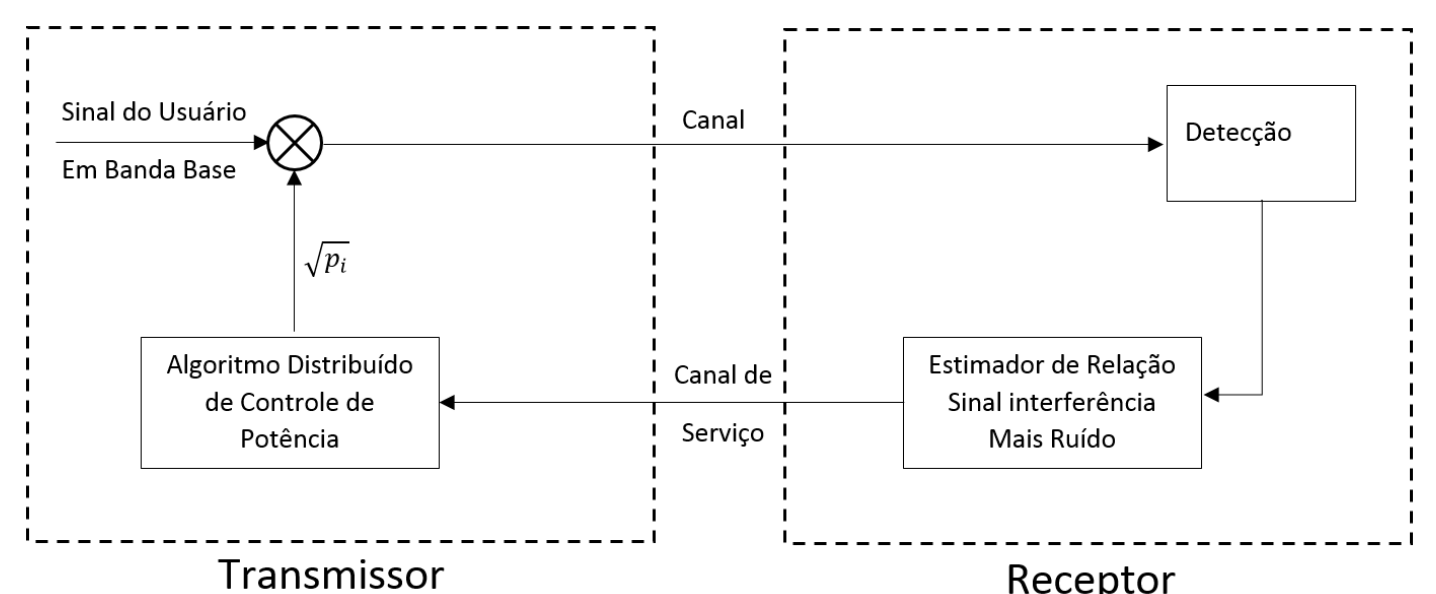

Figura 22: Diagrama de blocos para a operação de um algoritmo de controle de potência distribuído.

Foi demonstrado em (SAMPAIO et al., 2010) que o algoritmo distribuído de controle de potência (do inglês, distributed power control algorithm, DPCA) baseado no equilíbrio de Verhulst, que neste texto recebe o acrônimo DPCAVerhulst, converge rapidamente, em unidades de iterações para canais lentamente variantes no tempo, o que induz a sua implementação em problema práticos quando comparados a outros algoritmos que possuem convergência mais lenta.

\subsubsection{Controle de Potência em Sistemas MC-DS/CDMA}

Note que o problema de otimização relacionado ao controle de potência em redes DS/CDMA pode ser estendido para sistemas multiportadora com múltiplo acesso por divisão de código de sequência direta. Nestes sistemas, conforme descrito no capítulo 2, um total de $N$ sub-canais ortogonais são utilizados de tal forma que cada um deles pode ser considerado um canal DS/CDMA de banda estreita.

Para sistemas com múltiplas subportadoras, a solução clássica do controle de potência foi apresentada pela primeira vez por (GALLAGER, 1968). A solução foi denominada, naquele trabalho, de solução water-pouring; que em tradução 
livre significa derramando água. A idéia de Gallager é que os sistema multiportadora funcionaria como um grande recipiente cujo fundo seria irregular devido aos diferentes ganhos de canal instantâneos apresentados pelo conjunto de $N$ canais. Desta forma, a solução idealizada por ele era análoga a derramar água no recipiente de tal forma que um nível d'água comum a todos os subcanais seria encontrado e a quantidade de água em cada subcanal corresponderia à quantidade de potência a ser alocada para aquele usuário naquele subcanal. A solução de Gallager se consolidou na literatura com a denominação solução de water-filling.

A figura 23 apresenta uma interpretação geométrica da solução de waterfilling quando o sistema possuí $N=8$ subportadoras e um usuário. A área em cinza escuro diz respeito ao inverso do ganho de potência do canal enquanto as áreas em cinza claro são equivalentes à potência de transmissão para o usuário na subportadora correspondente. Note que, quanto pior a condição de canal, maior é a área cinza escuro, e vice-versa. Logo, o nível d'água $\mu_{\mathrm{WF}}$, que é comum a todas as subportadoras, pode ser inferior ao inverso do ganho de potência do canal, como nas subportadoras 5 e 7 . Neste caso, estas subportadoras devem ser consideradas desligadas e o usuário não efetua nenhuma transmissão nas mesmas durante o período equivalente ao tempo de coerência do canal.

O problema de controle de potência para sistemas MC-DS/CDMA pode ser matematicamente descrito como:

$$
\begin{array}{ll}
\operatorname{minimizar} & \mathbf{P} \\
\text { sujeito à } & \text { (C.1) }: \sum_{k=1}^{N} p_{i, k} \in\left[0, P_{\max }\right], \quad \forall i=1, \ldots, U \\
& \text { (C.2) : } \sum_{k=1}^{N} r_{i, k} \geq r_{i}^{*}, \quad \forall i=1, \ldots, U
\end{array}
$$

sendo $\mathbf{P} \in \mathbb{R}^{U \times N}$ a matriz de alocação de potências, $P_{\max }$ é a potência máxima 


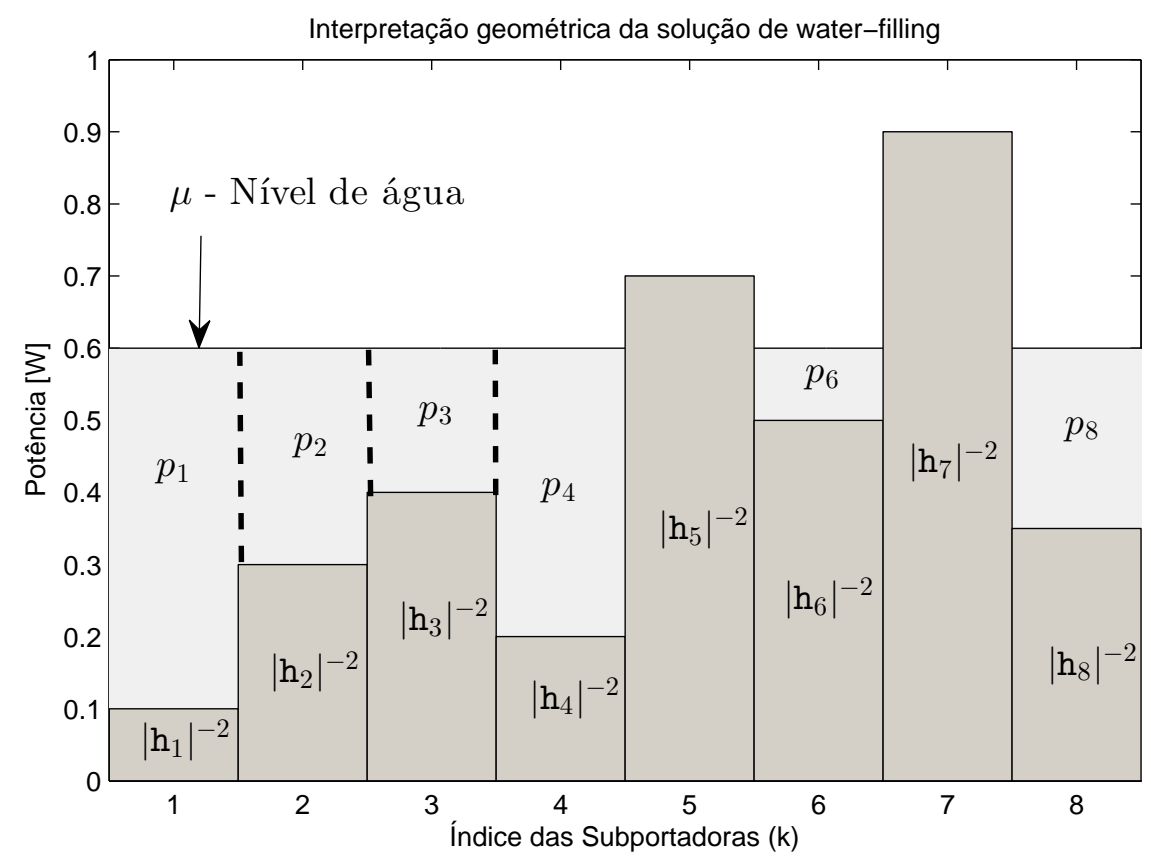

Figura 23: Interpretação geométrica para a solução de water-filling considerando $N=8$ subportadoras e $U=1$ usuário no sistema.

de transmissão disponível para cada usuário, $r_{i, k}$ é a taxa de transmissão de informação do $i$-ésimo usuário na $k$-ésima subportadora, e $r_{i}^{*}$ é a taxa de transmissão mínima para o usuário $i$. A equivalência entre a taxa de transmissão mínima e a relação sinal-interferência mais ruído mínima em sistemas MC-DS/CDMA é estabelecida pela capacidade de canal de Shannon (SHANNON, 1948) tal que para um único subcanal esta relação é dada por,

$$
r_{i, k}^{*}=B \log _{2}\left(1+\delta_{i, k}^{*}\right) \Rightarrow \delta_{i, k}^{*}=2^{\frac{r_{i, k}^{*}}{B}}-1
$$

enquanto para $N$ canais esta relação é dada por:

$$
r_{i}^{*}=\sum_{k=1}^{N} B \log _{2}\left(1+\delta_{i, k}^{*}\right) \Rightarrow r_{i}^{*}=B \log _{2}\left(\prod_{k=1}^{N}\left(1+\delta_{i, k}^{*}\right)\right) \Rightarrow 2 \stackrel{r_{i}^{*}}{B}=\delta_{i}^{*}
$$

onde $\delta_{i}^{*}=\prod_{k=1}^{N}\left(1+\delta_{i, k}^{*}\right)$. Sendo assim, é fácil notar que o problema (4.20) tem solução semelhante àquela do controle de potência em sistemas DS/CDMA: a solução do problema é a matriz de alocação de potências $\mathbf{P}$ para a qual $\sum_{k=1}^{N} r_{i, k}=r_{i}^{*}$ para todo $i=1, \ldots, U$. A partir desta afirmação e da interpretação geométrica 
da solução de water-filling na figura 23 é possível deduzir que existe um nível d'água para cada usuário $i$, denotado por $\mu_{i}^{*}$, tal que:

$$
\begin{aligned}
& \sum_{k=1}^{N} B \log _{2}\left(1+\left(\mu_{i}^{*}-\frac{F_{i} \sigma^{2}+\sum_{j \neq i}^{U} p_{j, k}\left|\mathrm{~h}_{j, k}\right|^{2}}{F_{i}\left|\mathrm{~h}_{i, k}\right|^{2}}\right) \frac{F_{i}\left|\mathrm{~h}_{i, k}\right|^{2}}{F_{i} \sigma^{2}+\sum_{j \neq i}^{U} p_{j, k}\left|\mathrm{~h}_{j, k}\right|^{2}}\right)=r_{i}^{*} \\
& \sum_{k=1}^{N} B \log _{2}\left(\mu_{i}^{*} \frac{F_{i}\left|\mathrm{~h}_{i, k}\right|^{2}}{F_{i} \sigma^{2}+\sum_{j \neq i}^{U} p_{j, k}\left|\mathrm{~h}_{j, k}\right|^{2}}\right)=r_{i}^{*}
\end{aligned}
$$

ou de forma equivalente e de acordo com a equação (4.22):

$$
\prod_{k=1}^{N}\left(\mu_{i}^{*} \frac{F_{i}\left|\mathrm{~h}_{i, k}\right|^{2}}{F_{i} \sigma^{2}+\sum_{j \neq i}^{U} p_{j, k}\left|\mathrm{~h}_{j, k}\right|^{2}}\right)=2^{\left(\frac{r_{i}^{*}}{B}\right)}=\delta_{i}^{*}
$$

É importante observar que em (4.23) e (4.24) o nível d'água é aplicado somente às subportadoras onde,

$$
\mu_{i}^{*} \geq \frac{F_{i} \sigma^{2}+\sum_{j \neq i}^{U} p_{j, k}\left|\mathrm{~h}_{j, k}\right|^{2}}{F_{i}\left|\mathrm{~h}_{i, k}\right|^{2}}
$$

Logo, rearranjando a equação (4.24) é possível obter o valor do nível d’água ótimo para os $N$ subcanais ativos, i.e.

$$
\left(\mu_{i}^{*}\right)=\left[2\left(\frac{r_{i}^{*}}{B}\right) \prod_{k=1}^{N}\left(\frac{F_{i} \sigma^{2}+\sum_{j \neq i}^{U} p_{j, k}\left|\mathrm{~h}_{j, k}\right|^{2}}{F_{i}\left|\mathrm{~h}_{i, k}\right|^{2}}\right)\right]^{\frac{1}{N}}
$$

As operações envolvidas na obtenção do nível d'água ótimo em (4.26) para o usuário $i$ são desenvolvidas na equação (4.27). 


$$
\begin{aligned}
& \prod_{k=1}^{N}\left(\mu_{i}^{*} \frac{F_{i}\left|\mathrm{~h}_{i, k}\right|^{2}}{F_{i} \sigma^{2}+\sum_{j \neq i}^{U} p_{j, k}\left|\mathrm{~h}_{j, k}\right|^{2}}\right)=2\left(\frac{r_{i}^{*}}{B}\right) \\
& \left(\mu_{i}^{*}\right)^{N} \prod_{k=1}^{N}\left(\frac{F_{i}\left|\mathrm{~h}_{i, k}\right|^{2}}{F_{i} \sigma^{2}+\sum_{j \neq i}^{U} p_{j, k}\left|\mathrm{~h}_{j, k}\right|^{2}}\right)=2\left(\frac{r_{i}^{*}}{B}\right) \\
& \left(\mu_{i}^{*}\right)^{N}=2\left(\frac{r_{i}^{*}}{B}\right) \prod_{k=1}^{N}\left(\frac{F_{i} \sigma^{2}+\sum_{j \neq i}^{U} p_{j, k}\left|\mathrm{~h}_{j, k}\right|^{2}}{F_{i}\left|\mathrm{~h}_{i, k}\right|^{2}}\right) \\
& \left(\mu_{i}^{*}\right)=\left[2^{\left(\frac{r_{i}^{*}}{B}\right) \prod_{k=1}^{N}\left(\frac{F_{i} \sigma^{2}+\sum_{j \neq i}^{U} p_{j, k}\left|\mathrm{~h}_{j, k}\right|^{2}}{F_{i}\left|\mathrm{~h}_{i, k}\right|^{2}}\right)}\right]^{\frac{1}{N}}
\end{aligned}
$$

Adicionalmente, é possivel definir a função da diferença entre a taxa de informação satisfeita e a taxa de informação mínima cujo argumento é o nível d'água $\mu$, a partir da equação $(4.24)$

$$
g(\mu)=\prod_{k=1}^{N}\left(\mu \frac{F_{i}\left|\mathrm{~h}_{i, k}\right|^{2}}{F_{i} \sigma^{2}+\sum_{j \neq i}^{U} p_{j, k}\left|\mathrm{~h}_{j, k}\right|^{2}}\right)-2^{\left(\frac{r_{i}^{*}}{B}\right)}
$$

Observe que para $\mu=\mu_{i}^{*} \Rightarrow g(\mu)=0$. Logo, o problema de controle de potência em sistemas MC-DS/CDMA pode ser reduzido a encontrar a raíz da função $g$ para cada usuário (PALOMAR; FONOLLOSA, 2005).

Como visto anteriormente, subcanais onde a condição (4.25) não é satisfeita estarão desligados, o que de forma prática significa que suas potências de transmissão são nulas. Portanto, o operador de water-filling para o $i$-ésimo usuário considerando a potência dos interferentes fixas é definido como (PANG; SCU- 
TARI; WANG, 2008),

$$
\mathrm{WF}\left(\mathbf{p}_{i}, \mathbf{p}_{-i}\right)=\max \left(0, \mu_{i}^{*}-\frac{F_{i} \sigma^{2}+\sum_{j \neq i}^{U} p_{j, k}\left|\mathrm{~h}_{j, k}\right|^{2}}{F_{i}\left|\mathrm{~h}_{i, k}\right|^{2}}\right), \quad \forall k=1, \ldots, N
$$

onde $\mathbf{p}_{i}=\left[p_{i, 1}, p_{i, 2}, \ldots, p_{i, N}\right]$ é o vetor de potências de transmissão do usuário $i$ e $\mathbf{p}_{-i}$ é constituido pelas potências de todos os usuários com exceção do usuário $i$, i.e.

$$
\mathbf{p}_{-i}=\left[\mathbf{p}_{1}, \ldots, \mathbf{p}_{i-1}, \mathbf{p}_{i+1}, \ldots, \mathbf{p}_{U}\right]
$$

O algoritmo iterativo baseado na solução de water-filling proposta em (GALLAGER, 1968) é denominado algoritmo iterativo de water-filling (IWFA). O algoritmo verifica quais subportadoras devem ser desligadas e então aplica o operador de water-filling descrito em (4.29) considerando apenas os subcanais que permaneceram ligados na iteração atual. Para apresentar o algoritmo IWFA considere a seguinte notação:

$$
\beta_{i, k}=\frac{p_{i, k}}{\delta_{i, k}}=\frac{F_{i} \sigma^{2}+\sum_{j \neq i}^{U} p_{j, k}\left|\mathrm{~h}_{j, k}\right|^{2}}{F_{i}\left|\mathrm{~h}_{i, k}\right|^{2}}
$$

onde $\beta_{i, k}$ é a interferência de múltiplo acesso mais ruído normalizados pelo ganho em potência do canal do usuário $i$ na $k$-ésima subportadora e pelo comprimento da sequência de espalhamento $F_{i}$. O pseudocódigo do IWFA é apresentado no Algoritmo 4.1.

Note que o algoritmo iterativo de water-filling é distribuído uma vez que o mesmo depende apenas do vetor $\boldsymbol{\beta}_{i}$ de cada usuário $i$ definidos pela equação (4.31). Este fato pode ser constatado observando-se que a estação rádio-base estima a relação sinal-interferência mais ruído de cada usuário em cada subportadora e transmite estas informações para o equipamento dos usuários. Pela 


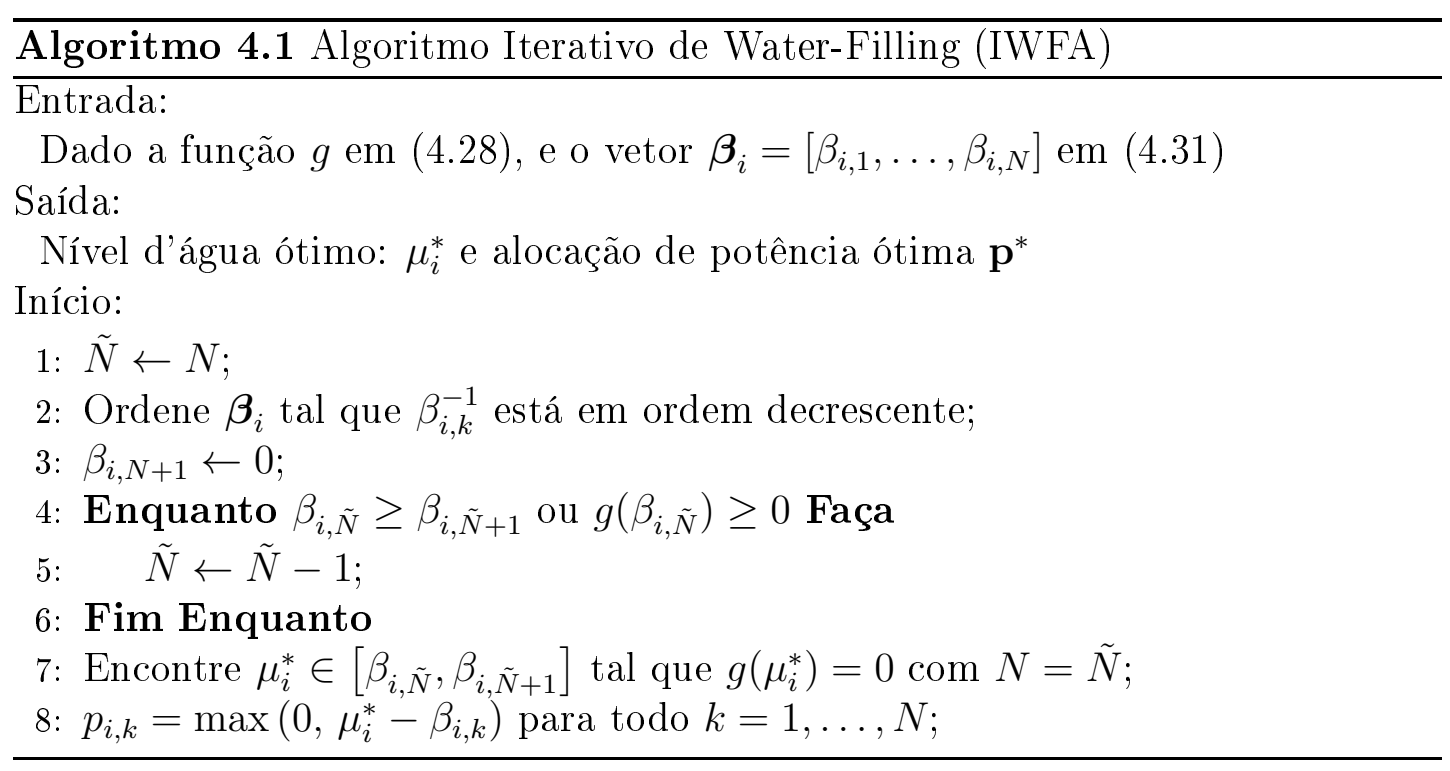

equação (4.31) o usuário então computa os valores das variáveis $\beta_{i, k}$ uma vez que ele tem conhecimento da potência que utilizou para transmistir. Em seguida, utilizando o algoritmo iterativo de water-filling o usuário encontra o novo vetor de potências de transmissão a ser utilizado. Isto justifica a característica distribuída do IWFA.

As figuras 24 e 25 apresentam uma interpretação gráfica para o algoritmo iterativo de water-filling enquanto este é executado pelo usuário 1 em suas $N=8$ subportadoras para o controle de potência.

\subsubsection{Eficiência Energética em Sistemas MC-DS/CDMA Cooperativos}

Como visto anteriormente o problema de maximização de eficiência energética em redes de múltiplo acesso foi apresentado em (GOODMAN; MANDAYAM, 2000) onde os autores definem a eficiência energética como a quantidade máxima de bits de informação efetivamente recebidos por unidade de energia. A necessidade de redução da energia consumida para transmissão de informação é um aspecto fundamental a ser considerado nos padrões de quinta geração de telecomunicações. Desta forma, buscando alternativas aos métodos de transmissão 


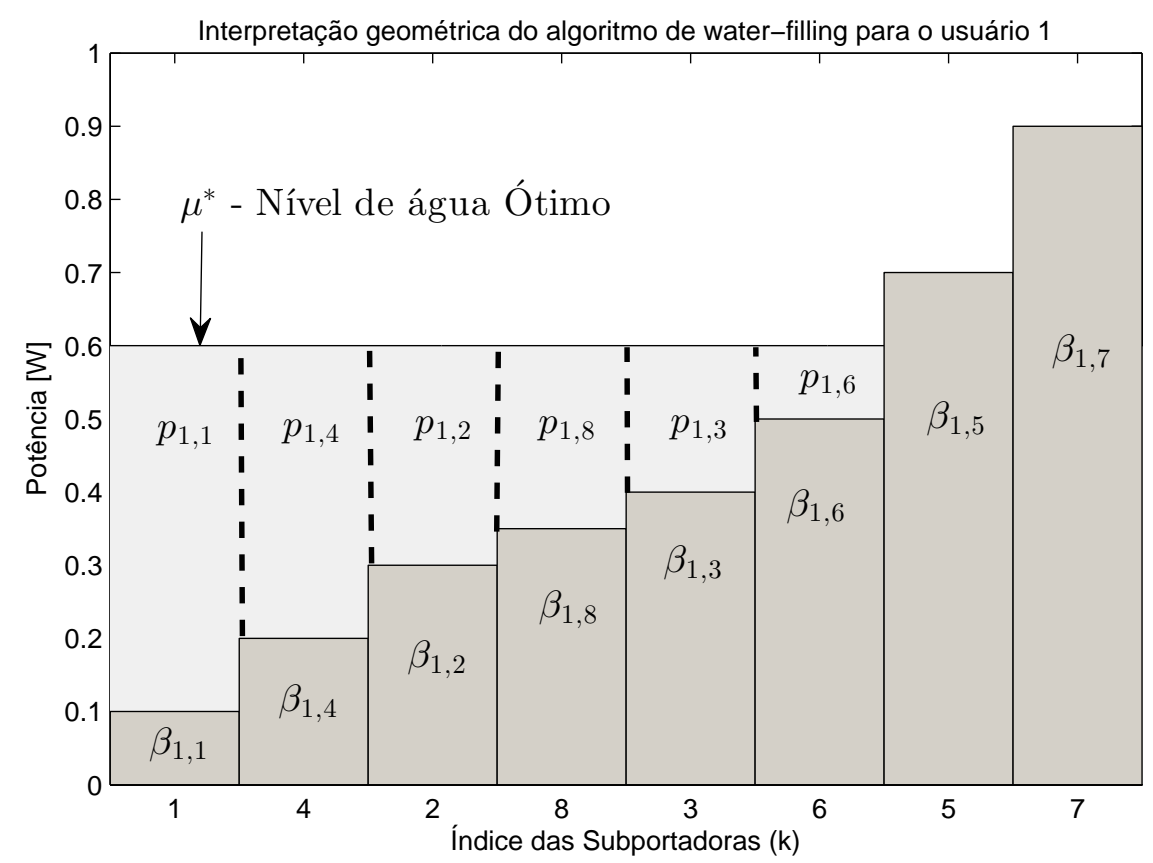

Figura 24: Interpretação gráfica para o usuário 1 do algoritmo iterativo de waterfilling considerando $N=8$ subportadoras.

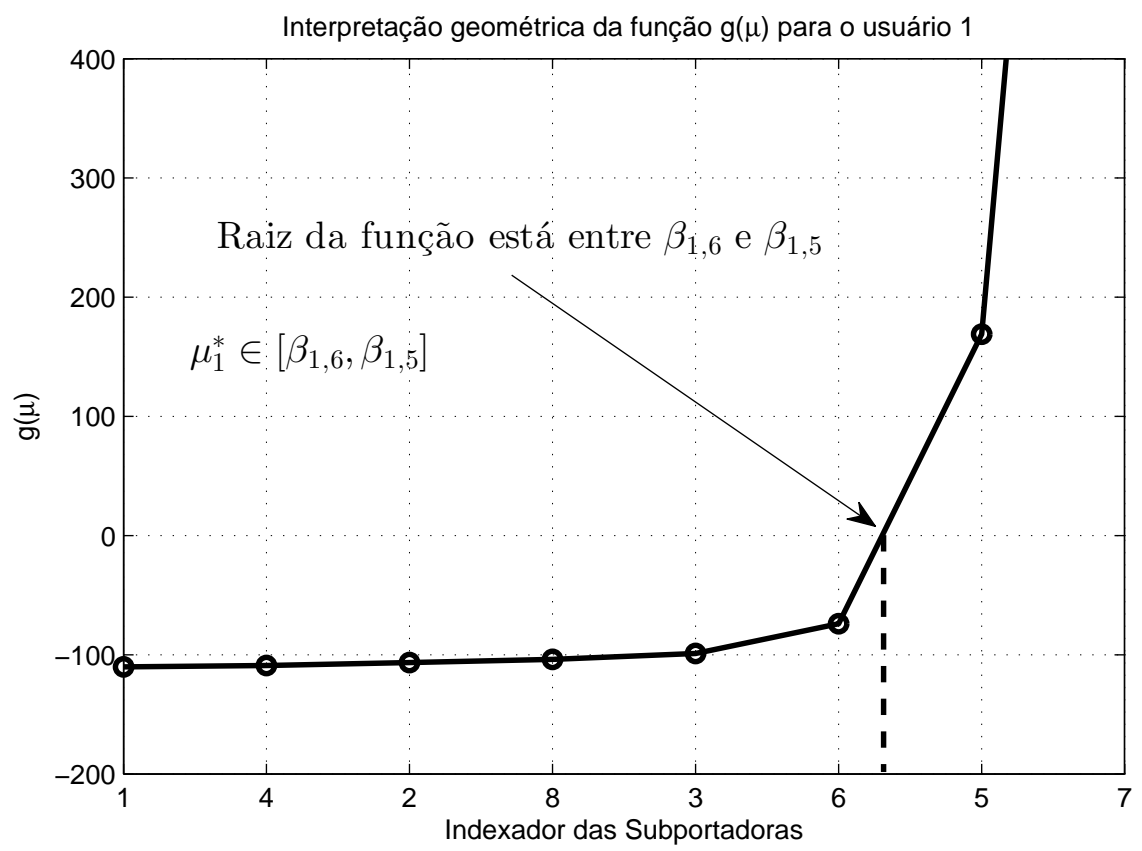

Figura 25: Interpretação gráfica para o usuário 1 da função $g(\mu)$ utilizada no algoritmo iterativo de water-filling considerando $N=8$ subportadoras. 
clássicos é possível considerar a utilização de sistemas cooperativos como os propostos inicialmente por (MEULEN, 1971).

No enlace de subida de sistemas macro-celulares cooperativos, a informação transmitida por um terminal móvel passa por um repetidor que é responsável por encaminhar o sinal à estação rádio-base. Uma vez que a degradação do canal não é linear com a distância percorrida fica evidente que a potência necessária para obter a mesma relação sinal-ruído no receptor é maior quando o caminho é percorrido sem saltos (GOLDSMITH, 2005).

Nesta seção considera-se um sistema de comunicação macro-celular cooperativo multiportadora com múltiplo acesso por divisão de código de sequência direta utilizando o protocolo de retransmissão amplifica e encaminha, como foi descrito na seção 2.1.3, com $U$ usuários, uma estação retransmissora e uma estação rádiobase com disposição geográfica de acordo com a figura 26.

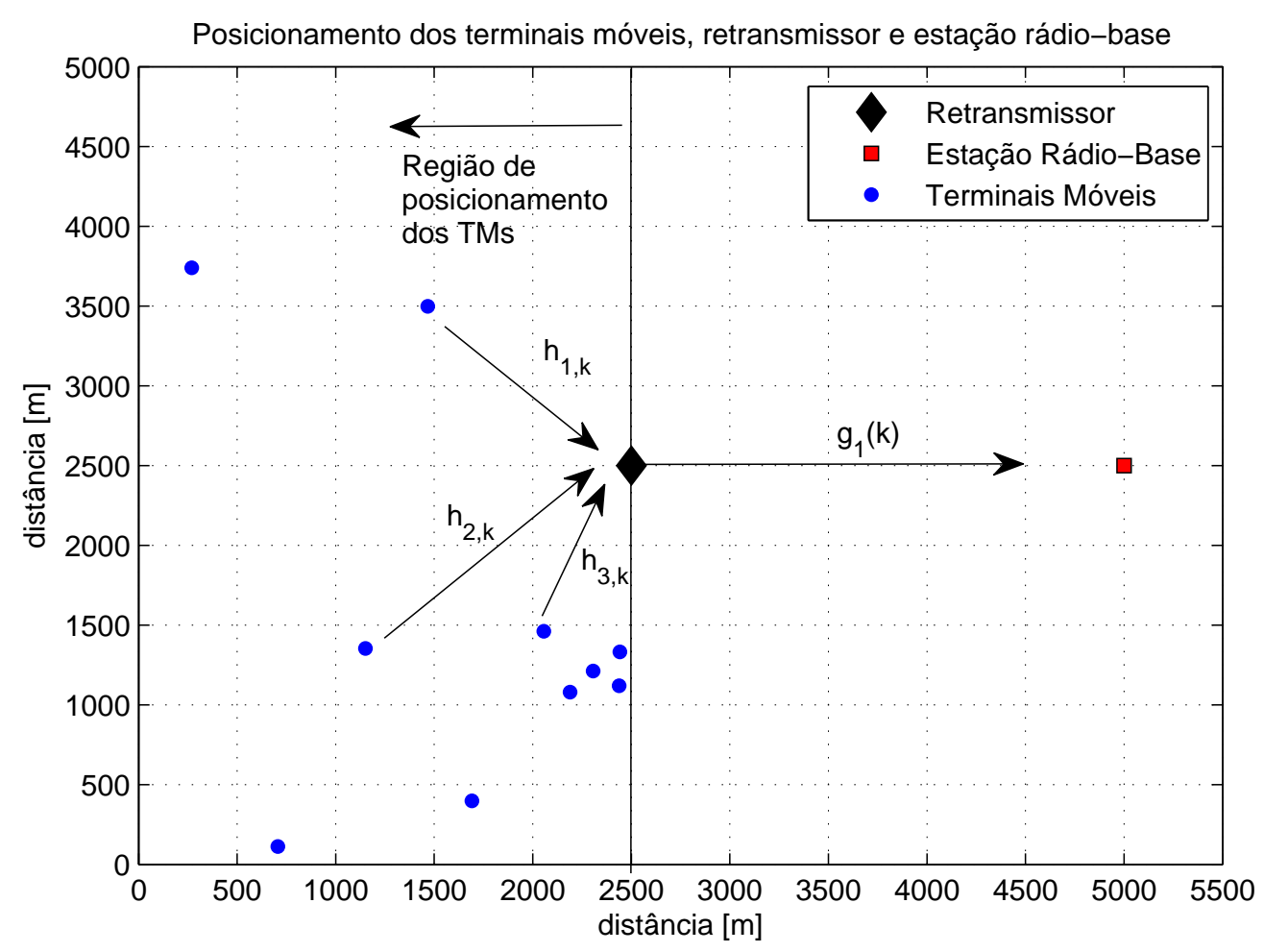

Figura 26: Disposição geográfica dos terminais móveis (usuários), estação retransmissora (retransmissor) e estação rádio-base no sistema MC-DS/CDMA cooperativo considerado nesta seção. 
Note que os usuários são uniformemente distribuídos à esquerda do retransmissor de tal forma que não há usuários entre o retransmissor e a estação rádiobase. Adicionalmente, o canal direto entre terminal móvel e estação rádio-base é desconsiderado: primeiramente porque assume-se que não há linha de visada entre transmissor e receptor; em segundo lugar, porque a elevada distância entre os terminais móveis e a estação rádio-base atenua os sinais de tal forma que o nível de potência dos sinais recebidos é muito pequeno e os mesmos tornam-se indistinguíveis e impossíveis de serem detectados. É conveniente supor que os sinais diretos incorporem o ruído de fundo aditivo Gaussiano branco.

Nestes sistemas, a relação sinal-interferência mais ruído observada para o usuário $i$ na subportadora $k$ após a detecção na estação rádio-base é definida pela equação (2.55), convenientemente reproduzida abaixo:

$$
\delta_{i, k}=\frac{F_{i} p_{i, k}\left|\mathrm{~h}_{i, k}\right|^{2}\left|\mathrm{~g}_{k}\right|^{2}\left|\mathbf{d}_{i}^{H} \mathbf{A} \mathbf{s}_{i}\right|^{2}}{P_{N} \sigma_{2, k}^{2}\left\|\mathbf{d}_{i}\right\|^{2}+F_{i} \sigma_{1, k}^{2}\left|\mathrm{~g}_{k}\right|^{2} \|\left.\mathbf{A}^{H} \mathbf{d}_{i}\right|^{2}+\left|\mathrm{g}_{k}\right|^{2} \sum_{\substack{j=1 \\ j \neq i}}^{U} p_{j, k}\left|\mathrm{~h}_{j, k}\right|^{2}\left|\mathbf{d}_{i}^{H} \mathbf{A} \mathbf{s}_{j}\right|^{2}}
$$

onde $P_{N}$ é a potência média do sinal recebido no retransmissor tal que para sinais descorrelacionados e com símbolos de potência unitária,

$$
P_{N}=\sigma^{2} F_{i}+\sum_{i=1}^{U} p_{i, k}\left|\mathrm{~h}_{i, k}\right|^{2}
$$

e,

- $\delta_{i, k}$ é a relação sinal-interferência mais ruído pós detecção para o usuário $i$ na $k$-ésima subportadora,

- $F_{i}$ é o comprimento da sequência de espalhamento do usário $i$, 
- $p_{i, k}$ é potência de transmissão do usuário $i$ na subportadora $k$,

- $\mathrm{h}_{i, k}$ é o ganho complexo do canal entre usuário e retransmissor para o $i$-ésimo usuário na subportadora $k$,

- $\mathrm{g}_{k}$ é ganho complexo de canal entre retransmissor e estação rádio-base na subportadora $k$,

- $\mathbf{d}_{i}$ é o filtro linear de recepção para o $i$-ésimo usuário na $k$-ésima subportadora,

- A é a matriz de amplificação do sinal no retransmissor,

- $\mathbf{s}_{i}$ é a sequência de espalhamento do usuário $i$,

- $\sigma_{1, k}^{2}$ é a potência de ruído AWGN no primeiro salto (terminal móvel - retransmissor),

- $\sigma_{2, k}^{2}$ é a potência de ruído AWGN no segundo salto (retransmissor - estação base),

O modelo de eficiência energética proposto em (GOODMAN; MANDAYAM, 2000) apresenta a taxa de transmissão efetiva como o produto da taxa de codificação ${ }^{5}$ pela taxa de transmissão instantânea e pela probabilidade de recepção correta. Assumindo que a taxa de transmissão instantânea é dada pela capacidade de canal e que a probabilidade de recepção correta é equivalente ao complemento da taxa de erro de bit média, a eficiência energética para sistemas MC-DS/CDMA cooperativos pode ser descrita como (SAMPAIO et al., 2014):

$$
\xi=\frac{\sum_{i=1}^{U} \sum_{k, 1}^{N} \ell_{i, k} B \log _{2}\left(1+\delta_{i, k}\right) f\left(\delta_{i, k}\right)^{V}}{P_{\mathrm{C}}+P_{\mathrm{C}_{\mathrm{R}}}+\varrho_{\mathrm{R}} p_{\mathrm{R}}+\sum_{i=1}^{U} \sum_{k=1}^{N} \varrho_{i} p_{i, k}+\sum_{i=1}^{U} \sum_{k, 1}^{N}\left(\vartheta_{i}+v_{i}\right) r_{i, k}} \quad\left[\frac{\text { bits }}{\text { Joule }}\right]
$$

\footnotetext{
${ }^{5} \mathrm{~A}$ razão entre número de bits de informação transmitidos pelo total de bits transmitidos.
} 
onde,

- $\ell$ é a taxa de codificação (número de bits de informação por número de bits enviados),

- $B$ é a largura de banda de cada subportadora ortogonal,

- $\delta$ é a relação sinal-interferência mais ruído,

- $f(\delta)$ é a função de penalização que impõe a taxa de bits recebidos corretamente,

- $V$ é o número de bits enviados dentro de um quadro de transmissão,

- $P_{\mathrm{C}}$ é a potência fixa consumida pelos circuitos dos usuários transmissores,

- $P_{\mathrm{C}_{\mathrm{R}}}$ é a potência fixa consumida pelos circuitos no retransmissor,

- $\varrho_{\mathrm{R}}$ é a ineficiência do amplificador de potência do retransmissor,

- $p_{\mathrm{R}}$ é a potência de transmissão do retransmissor,

- $\varrho_{i}$ é a ineficiência do amplificador de potência usuário $i$,

- $p_{i, k}$ é a potência de transmissão do $i$-ésimo usuário na $k$-ésima subportadora,

- $r_{i, k}$ é a taxa de transmissão do usuário $i$ na subportadora $k$,

- $\vartheta_{i}$ é a taxa de crescimento da potência de transmissão em relação ao aumento da taxa de transmissão de informação,

- $v_{i}$ é a taxa de crescimento da potência extra consumida pelo circuito transmissor para um dado aumento na taxa de transmissão de informação,

Por simplicidade, neste trabalho, as taxas de crescimento lineares da potência consumida pelo transmissor em função da taxa de transmissão são consideradas 
nulas, i.e. $\vartheta_{i}=v_{i}=0$, para todo $i=1, \ldots, U$, uma vez que a potência consumida pelos circuitos das unidades móveis não apresentam grande variação em função da taxa de transmissão e são da ordem de dezenas a centenas de miliwatts (LOODARICHEH; MALLICK; BHARGAVA, 2014). Adicionalmente, a função de penalização é a função complementar da taxa de erro de bit média, i.e., a taxa de acerto de bits. Para canais com desvanecimento Rayleigh, a taxa de erro de bit média para modulações $M$-QAM de constelação retangular é expressa pela equação (2.38) e convenientemente reproduzida abaixo:

$$
\overline{\mathrm{BER}}_{i, k} \approx \frac{2(\sqrt{M}-1)}{\sqrt{M} \log _{2}(M)}\left(1-\sqrt{\frac{3 \delta_{i, k} \log _{2}(M)}{2(M-1)+3 \delta_{i, k} \log _{2}(M)}}\right)
$$

portanto, a função $f\left(\delta_{i, k}\right)$ pode ser definida como:

$$
f\left(\delta_{i, k}\right)=\left(1-\overline{\mathrm{BER}}_{i, k}\right)=\left(1-\frac{2(\sqrt{M}-1)}{\sqrt{M} \log _{2}(M)}\left(1-\sqrt{\frac{3 \delta_{i, k} \log _{2}(M)}{2(M-1)+3 \delta_{i, k} \log _{2}(M)}}\right)\right)
$$

Logo, é possível reescrever a função da eficiência energética do sistema em (4.34) como,

$$
\xi \triangleq \frac{\Re}{P_{\mathrm{T}}}=\frac{\sum_{i=1}^{U} \sum_{k, 1}^{N} \ell_{i, k} r_{i, k}\left[1-\frac{2(\sqrt{M}-1)}{\sqrt{M} \log _{2}(M)}\left(1-\sqrt{\frac{3 \delta_{i, k} \log _{2}(M)}{2(M-1)+3 \delta_{i, k} \log _{2}(M)}}\right)\right]^{V}}{P_{\mathrm{C}}+P_{\mathrm{C}_{\mathrm{R}}}+\varrho_{\mathrm{R}} p_{\mathrm{R}}+\sum_{i=1}^{U} \sum_{k=1}^{N} \varrho_{i} p_{i, k}}
$$

onde,

$$
r_{i, k}=B \log _{2}\left(1+\delta_{i, k}\right)
$$

Observação 3. É fundamental salientar que o modelo apresentado de eficiência energética é uma estimativa da eficiência energética real do sistema e não repre- 
senta, necessariamente, os valores exatos contemplados por diferentes cenários com suas respectivas modulações, níveis de potência de transmissão, topologias e receptores multi-usuário lineares.

Desta forma, define-se como problema de maximização da eficiência energética em sistemas MC-DS/CDMA cooperativos o seguinte problema de otimização (SAMPAIO et al., 2014):

$$
\begin{array}{ll}
\text { maximizar } & \xi=\frac{\mathfrak{R}}{P_{\mathrm{T}}} \\
\text { sujeito à } & \text { (C.1) }: \sum_{k=1}^{N} p_{i, k} \in\left[0, P_{i, \max }\right], \quad \forall i=1, \ldots, U \\
& \text { (C.2) }: \sum_{k=1}^{N} r_{i, k} \geq r_{i}^{*}, \quad \forall i=1, \ldots, U
\end{array}
$$

Encontrar a solução ótima para o problema (4.39) não é uma tarefa fácil. Neste trabalho de doutorado cinco soluções distintas para o problema de maximização da eficiência energética em sistemas MC-DS/CDMA cooperativos foram propostas e analisadas. As soluções estão organizadas em duas subseções distintas: a primeira apresenta três algoritmos determinísticos propostos nos trabalhos (SAMPAIO et al., 2014) e (SAMPAIO et al., 2013b); a segunda seção apresenta dois algoritmos heurísticos aplicados ao problema publicado no trabalho (ADANYIA et al., 2015), de co-autoria do candidato.

\subsubsection{Abordagem de Teoria de Jogos para Maximização da Eficiên- cia Energética em Sistemas MC-DS/CDMA Cooperativos}

A semelhança entre os conceitos de teoria de jogos e os problemas de alocação de recursos em redes sem fio é evidente. De fato, a estrutura dos jogos não cooperativos compartilha a maior parte das características observadas no enlace reverso de sistemas de comunicação móvel: ambos podem ser projetados de forma 
distribuída; os jogadores (ou usuários no caso de cenários de comunicação sem fio) geralmente agem de forma egoísta reagindo a alguma forma de realimentação de acordo com as decisões tomadas anteriormente e, finalmente, utilizando funções utilidade adequadas os métodos baseados em teoria de jogos podem resolver quase todos os problemas de alocação de recursos no elo reverso de redes de comunicação sem fio.

Nesta seção serão apresentados duas abordagens distintas para o problema de otimização descrito em (4.39): a primeira, trata-se de separar o problema em $N$ jogos não cooperativos com o intuito de encontrar a melhor resposta em termos de relação sinal-interferência mais ruído para um determinado nível de interferência percebido em cada uma das subportadoras. Na sequência, um algoritmo de controle distribuído é utilizado para alocar a potência que garante melhor resposta em SINR.

A segunda abordagem consiste em encontrar a solução para um único jogo não cooperativo. O problema de maximização da eficiência energética em sistemas multiportadora é transformado em um problema de maximização da eficiência energética em sistemas DS/CDMA considerando o ganho médio dos canais de comunicação. Desta forma, esta segunda abordagem pode ser sintetizada em dois passos distintos: a melhor resposta em SINR é encontrada para o ganho médio de canal para cada usuário e, na sequência, a potência que garante a melhor resposta em SINR para cada usuário é alocada em todas as $N$ subportadoras.

Inicia-se a análise pela primeira abordagem. Considere primeiramente os $N$ jogos não cooperativos definidos pela t-upla:

$$
\Gamma_{k}=\left(\mathcal{J},\left(\mathcal{E}_{i}^{k}\right)_{i \in \mathcal{J}},\left(u_{i}^{k}\right)_{i \in \mathcal{J}}\right), \quad k=1, \ldots, N
$$

onde $\mathcal{J}=\{1,2, \ldots, U\}$ é o conjunto de jogadores, $\left(\mathcal{E}_{i}^{k}\right)$ é o conjunto de estraté- 
gias disponíveis para o usuário/jogador ${ }^{6} i$ na subportadora $k$ e $u_{i}^{k}$ é sua função utilidade.

Note que maximizar a função de eficiência energética $\xi$ é equivalente a maximizar as eficiências energéticas de cada usuário em cada subportadora (SAMPAIO et al., 2014), i.e.

$$
\operatorname{maximizar} \xi \equiv \operatorname{maximizar} \xi_{i, k} \triangleq \frac{\ell_{i, k} r_{i, k} f\left(\delta_{i, k}\right)^{V}}{P_{\mathrm{C}}+P_{\mathrm{C}_{\mathrm{R}}}+\varrho_{\mathrm{R}} p_{\mathrm{R}}+\varrho_{i} p_{i, k}}
$$

para todo $i \in \mathcal{J}$ e $k=1, \ldots, N$. Portanto, a função utilidade do jogador $i$ no subcanal $k$ é definida como:

$$
u_{i}^{k} \equiv \xi_{i, k}=\frac{\ell_{i, k} B \log _{2}\left(1+\delta_{i, k}\right) f\left(\delta_{i, k}\right)^{V}}{P_{\mathrm{C}}+P_{\mathrm{C}_{\mathrm{R}}}+\varrho_{\mathrm{R}} p_{\mathrm{R}}+\varrho_{i} p_{i, k}}
$$

Sendo assim, a melhor resposta em potência para o jogo não cooperativo $\Gamma_{k}$ é definida $\operatorname{como}^{7}$,

$$
p_{i, k}^{*}=\arg \max _{p_{i, k}} u_{i}^{k}\left(p_{i, k}, \mathbf{p}_{-i, k}\right)
$$

isto é, $p_{i, k}^{*}$ será a melhor resposta para o jogador $i$ na subportadora $k$ caso seja o valor de potência (argumento) que maximiza a função utilidade dado que o vetor de potência dos demais usuários $\mathbf{p}_{-1, k}$ naquele subcanal é fixo.

Jogos não cooperativos podem ser solucionados encontrando-se o equilíbrio de Nash do problema (PANG; SCUTARI; WANG, 2008). Este, por sua vez, é o conjunto de estratégias onde qualquer mudança unilateral não incrementa o valor da função utilidade do jogador, i.e. $\mathbf{p}_{k}^{*}=\left[p_{1, k}^{*}, \ldots, p_{U, k}^{*}\right]$ é um equilíbrio de Nash

\footnotetext{
${ }^{6}$ Usuário e jogador nesta seção são utilizados como sinônimos.

${ }^{7} \mathrm{~A}$ definição de melhor resposta foi apresentada na Definição 19 na página 166.
} 


$$
u_{i}^{k}\left(\mathbf{p}_{-i, k}^{*}, p_{i, k}^{*}\right) \geq u_{i}^{k}\left(\mathbf{p}_{-i, k}^{*}, p_{i, k}\right), \quad \forall p_{i, k} \in \mathcal{E}_{i}^{k}, \text { e } \forall i=1, \ldots, U
$$

Em outras palavras, um equilíbrio de Nash é um conjunto de estratégias de melhor resposta para todos os usuários simultaneamente.

Em síntese, o problema de otimização do usuário $i$ relacionado ao jogo $\Gamma_{k}$ é descrito como,

$$
\begin{array}{rc}
\text { maximizar } & u_{i}^{k}=\frac{\ell_{i, k} B \log _{2}\left(1+\delta_{i, k}\right) f\left(\delta_{i, k}\right)^{V}}{P_{\mathrm{C}}+P_{\mathrm{C}_{\mathrm{R}}}+\varrho_{\mathrm{R}} p_{\mathrm{R}}+\varrho_{i} p_{i, k}} \\
\text { sujeito à } & (\mathrm{C} .1): p_{i, k} \in \mathcal{E}_{i}^{k}, \quad \forall i=1, \ldots, U
\end{array}
$$

sendo,

$$
\mathcal{E}_{i}^{k} \triangleq\left\{p_{i, k} \in \mathbb{R}_{+} \mid p_{i, k} \leq \frac{P_{\max }}{N} \text { e } r_{i, k} \geq \frac{r_{i}^{*}}{N}\right\}
$$

Note que a função utilidade depende da relação sinal-interferência mais ruído do usuário na subportadora e também da potência de transmissão. Uma vez que a SINR é uma função da potência de transmissão para uma interferência e ruído fixos, é possível estabelecer a seguinte relação a partir de (4.31),

$$
p_{i, k}=\delta_{i, k} \beta_{i, k}
$$

onde

$$
\beta_{i, k}=\frac{P_{N} \sigma_{2, k}^{2}\left\|\mathbf{d}_{i}\right\|^{2}+\left.F_{i} \sigma_{1, k}^{2}\left|\mathrm{~g}_{k}\right|^{2}|| \mathbf{A}^{H} \mathbf{d}_{i}\right|^{2}+\left|\mathrm{g}_{k}\right|^{2} \sum_{j=1, j \neq i}^{U} p_{j, k}\left|\mathrm{~h}_{j, k}\right|^{2}\left|\mathbf{d}_{i}^{H} \mathbf{A} \mathbf{s}_{j}\right|^{2}}{F_{i}\left|\mathrm{~h}_{i, k}\right|^{2}\left|\mathrm{~g}_{k}\right|^{2}\left|\mathbf{d}_{i}^{H} \mathbf{A} \mathbf{s}_{i}\right|^{2}}
$$

Desta forma, é possível reescrever a função utilidade empregando somente a SINR 
como argumento:

$$
u_{i}^{k}=\frac{\mathfrak{R}\left(\delta_{i, k}\right)}{\mathfrak{G}\left(\delta_{i, k}\right)} \triangleq \frac{\ell_{i, k} B \log _{2}\left(1+\delta_{i, k}\right) f\left(\delta_{i, k}\right)^{V}}{P_{\mathrm{C}}+P_{\mathrm{C}_{\mathrm{R}}}+\varrho_{\mathrm{R}} p_{\mathrm{R}}+\varrho_{i} \delta_{i, k} \beta_{i, k}}
$$

Na abordagem de teoria de jogos proposta, os valores de interferência e ruído são considerados constantes durante todo o intervalo de otimização. Esta característica aliada às decisões egoístas de cada jogador permite a implementação dos algoritmos propostos de forma distribuída no enlace reverso do sistema multiportadora CDMA. É importante observar que encontrar a melhor resposta (4.43) é equivalente a maximizar a função utilidade em (4.42). É de conhecimento comum a nulidade da derivada de funções no(s) ponto(s) de máximo ou mínimo. Aplicando este conceito à função utilidade obtêm-se:

$$
\frac{\partial u_{i}^{k}}{\partial \delta_{i, k}}=0
$$

Conforme discutido no capítulo 3, se uma função é côncava (convexa) ou quase côncava (quase convexa) o ponto de máximo (mínimo) é aquele em que a condição (4.50) é satisfeita; este ponto será o máximo (mínimo) global da função utilidade. A fim de mostrar que a função utilidade proposta no contexto desta seção, equação (4.49), é quase côncava em $\delta_{i, k}$, faz-se necessário primeiro confirmar que o numerador da função utilidade é uma curva sigmóide (vide definição 21). Esta afirmação está ilustrada na figura 27, onde a linha em azul representa o numerador da função utilidade e a linha verde denota a segunda derivada do numerador. O ponto onde a segunda derivada é nula é denominado ponto de inflexão da função, $\delta_{\text {in }}$. Note na figura que a segunda derivada para valores menores que $\delta_{\text {in }}$ é não negativa e para valores maiores que $\delta_{\text {in }}$ é não positiva. De acordo com (RODRIGUEZ, 2003), uma função que representa uma curva sigmóide é definida como:

Definição 21 (Curva Sigmóide). Uma função $f: \mathbb{R} \rightarrow \mathbb{R}$ é uma curva sigmóide se tem as seguintes características: 


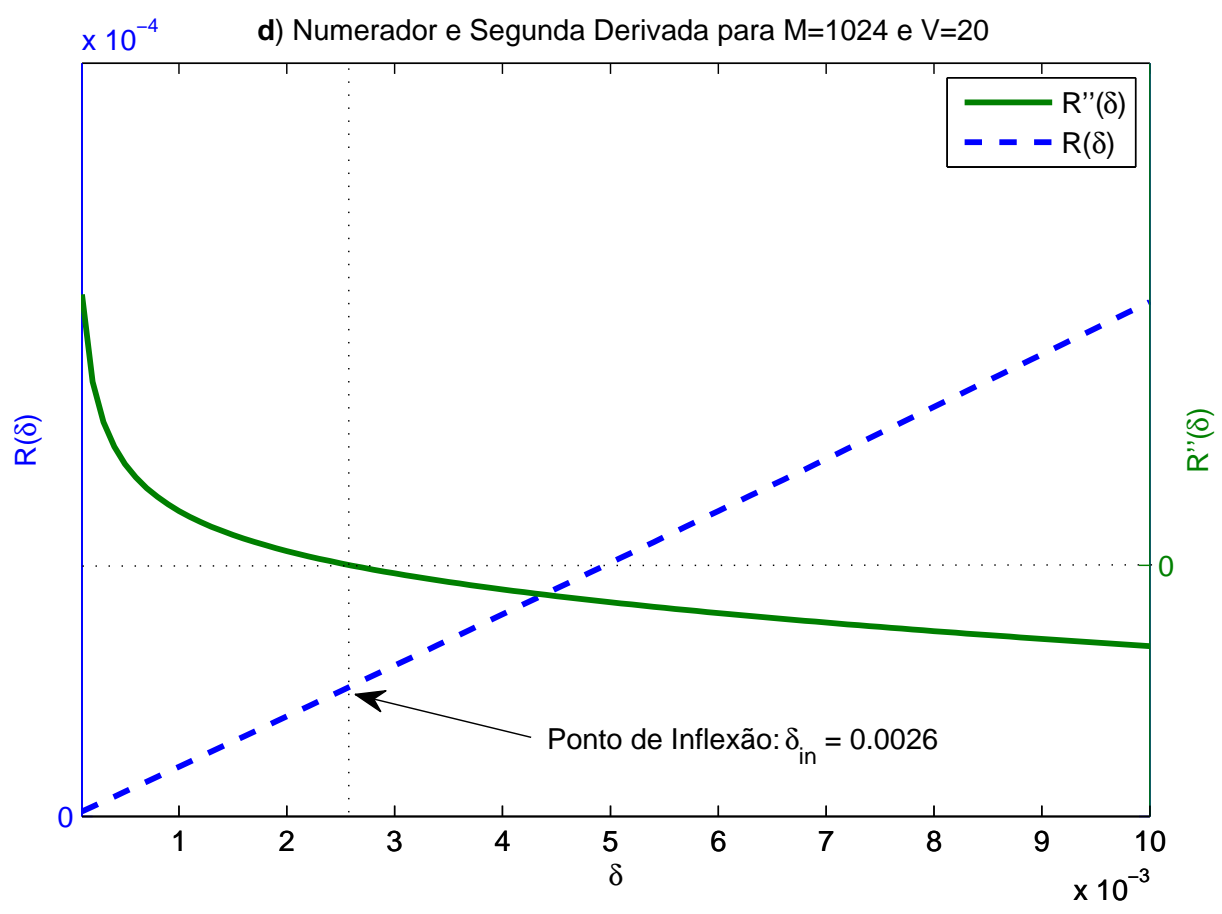

Figura 27: Numerador e sua segunda derivada em função da SINR para os parâmetros: $M=1024$ e $V=20$.

1. Seu dominio é não negativo, i.e. o intervalo $[0, \infty)$;

2. A imagem é o intervalo $[0, L]$, onde $L$ é o maior valor assumido pela função;

3. É uma função crescente;

4. É estritamente convexa no intervalo $\left[0, x_{\mathrm{in}}\right]$ com $x_{\mathrm{in}}>0$, onde $x_{\mathrm{in}}$ é o ponto de inflexão;

5. É estritamente côncava no intervalo $\left[x_{\mathrm{in}}, L_{c}\right]$, com $L_{c}>x_{\mathrm{in}}$, onde $L_{c}$ é o limite superior do intervalo no qual a função é estritamente côncava;

6. Tem uma derivada contínua;

É possível demonstrar numericamente que o numerador da função utilidade $u_{i}^{k}$ em (4.49) é uma curva sigmóide:

Lema 7 (Numerador da Função Utilidade é uma Curva Sigmóide). A função: $\mathfrak{R}\left(\delta_{i, k}\right)=\ell_{i, k} B \log _{2}\left(1+\delta_{i, k}\right)\left[1-\frac{2(\sqrt{M}-1)}{\sqrt{M} \log _{2}(M)}\left(1-\sqrt{\frac{3 \delta_{i, k} \log _{2}(M)}{2(M-1)+3 \delta_{i, k} \log _{2}(M)}}\right)\right]^{V}$ 
é uma curva sigmóide em $\delta_{i, k}$, cujo ponto de inflexão pode ser aproximado por $\delta_{\text {in }}=\frac{V}{5 M}$.

Demonstração. Para que a função $\mathfrak{R}_{i, k}$ seja uma curva sigmóide em $\delta_{i, k}$ as seis condições na definição 21 devem ser atendidas. A condição (1) segue do fato que $\delta_{i, k} \geq 0$, por definição. A condição (2) segue do fato que $\ell_{i, k} \in[0,1], B>0$, a taxa de transmissão de informação $\log _{2}\left(1+\delta_{i, k}\right) \geq 0$ e, finalmente, a probabilidade de recepção correta de pacotes encontra-se no intervalo $[0,1]$, o que leva a concluir que $L>0$. Uma vez que $\mathfrak{R}_{i, k}$ é a multiplicação de quatro termos não negativos então $\mathfrak{R}_{i, k}$ é não negativa. A condição (3) segue do fato que $\mathfrak{R}_{i, k}$ é a multiplicação de uma função crescente $\left(\log _{2}\left(1+\delta_{i, k}\right)\right.$ por outra não descrescente (taxa de recepção correta de pacotes). Para provar a validade das condições (4) e (5) faz-se necessário encontrar o ponto de inflexão, $\delta_{\text {in }}$, da curva sigmóide. Empregando as seguintes substituições ${ }^{8}$ :

$$
\begin{aligned}
& \Psi_{1}\left(\delta_{i, k}\right)=\ell_{i, k} \log _{2}\left(1+\delta_{i, k}\right) \\
& \Psi_{2}\left(\delta_{i, k}\right)=\left[1-\frac{2(\sqrt{M}-1)}{\sqrt{M} \log _{2}(M)}\left(1-\sqrt{\frac{3 \delta_{i, k} \log _{2}(M)}{2(M-1)+3 \delta_{i, k} \log _{2}(M)}}\right)\right]
\end{aligned}
$$

tal que,

$$
\Re\left(\delta_{i, k}\right)=\Psi_{1}\left(\delta_{i, k}\right) \Psi_{2}\left(\delta_{i, k}\right)^{V}
$$

Logo, a primeira derivada de $\mathfrak{R}\left(\delta_{i, k}\right)$ é definida como:

$$
\mathfrak{R}^{\prime}\left(\delta_{i, k}\right)=\Psi_{1}^{\prime}\left(\delta_{i, k}\right) \Psi_{2}\left(\delta_{i, k}\right)^{V}+V \Psi_{1}\left(\delta_{i, k}\right) \Psi_{2}^{\prime}\left(\delta_{i, k}\right) \Psi_{2}\left(\delta_{i, k}\right)^{(V-1)}
$$

Por conseguinte, a segunda derivada resulta:

$$
\begin{aligned}
\Re^{\prime \prime}\left(\delta_{i, k}\right)= & \Psi_{1}^{\prime \prime}\left(\delta_{i, k}\right) \Psi_{2}\left(\delta_{i, k}\right)^{V}+2 V \Psi_{1}^{\prime}\left(\delta_{i, k}\right) \Psi_{2}^{\prime}\left(\delta_{i, k}\right) \Psi_{2}\left(\delta_{i, k}\right)^{(V-1)}+ \\
& +V \Psi_{1}\left(\delta_{i, k}\right) \Psi_{2}^{\prime \prime}\left(\delta_{i, k}\right) \Psi_{2}\left(\delta_{i, k}\right)^{(V-1)}+ \\
& +V(V-1) \Psi_{1}\left(\delta_{i, k}\right)\left(\Psi_{2}^{\prime}\left(\delta_{i, k}\right)\right)^{2} \Psi_{2}\left(\delta_{i, k}\right)^{(V-2)}
\end{aligned}
$$

\footnotetext{
${ }^{8}$ A notação é simplificada para se alcançar certa legibilidade, uma vez que a segunda derivada do numerador $\mathfrak{R}\left(\delta_{i, k}\right)$ resulta em uma expressão de alta complexidade.
} 
onde $\Psi_{1}^{\prime}\left(\delta_{i, k}\right), \Psi_{1}^{\prime \prime}\left(\delta_{i, k}\right), \Psi_{2}^{\prime}\left(\delta_{i, k}\right)$ e $\Psi_{2}^{\prime \prime}\left(\delta_{i, k}\right)$ são definidos nas equações (4.57) a (4.60). Note que encontrar um $\delta_{\text {in }}$ tal que $\mathfrak{R}^{\prime \prime}\left(\delta_{\text {in }}\right)=0$ é uma tarefa complexa uma vez que a definição $\mathfrak{R}^{\prime \prime}$ é uma equação transcendental. Uma alternativa é encontrar numericamente o valor do ponto de inflexão $\delta_{\text {in }}$ da função $\mathfrak{R}$ e ajustar os valores a uma expressão simples. Sendo assim, a tabela 1 apresenta os pontos de inflexão para diferente valores de ordem de modulação $M$ e de número de bits por pacote $V$. A partir dos dados apresentados na tabela 1 é fácil perceber que

Tabela 1: Valor do Ponto de Inflexão $\delta_{\text {in }}$ para Diferentes Parâmetros.

\begin{tabular}{c|cccccc}
\hline$V$ & 1 & 2 & 5 & 10 & 15 & 20 \\
\hline (4-QAM) & 0.1707 & 0.2706 & 0.4116 & 0.5472 & 0.6522 & 0.7427 \\
(16-QAM) & 0.0566 & 0.0966 & 0.1444 & 0.1834 & 0.2151 & 0.2457 \\
(64-QAM) & 0.0125 & 0.0231 & 0.0351 & 0.0416 & 0.0452 & 0.0481 \\
(256-QAM) & 0.0026 & 0.0052 & 0.0083 & 0.0098 & 0.0104 & 0.0107 \\
(1024-QAM) & 0.0006 & 0.0012 & 0.0020 & 0.0024 & 0.0025 & 0.0026 \\
(4096-QAM) & 0.0001 & 0.0003 & 0.0005 & 0.0006 & 0.0006 & 0.0006 \\
\hline
\end{tabular}

aumentando o valor de $V$ desloca-se o ponto de inflexão para a direita na linha dos números reais, i.e. valores crescentes de $\delta_{i, k}$. Por outro lado, elevando-se a ordem de modulação $M$ desloca-se o ponto de inflexão para a esquerda na linha dos números reais, i.e., para valores decrescentes de $\delta_{i, k}$. Portanto, assintoticamente, o numerador da função utilidade tem o seguinte comportamento: se $M \rightarrow \infty$ e $V<<M$, então a função torna-se côncava, pois o ponto de inflexão tende a zero. Já quando $V \rightarrow \infty$ e $V>>M$ a função torna-se convexa uma vez que o ponto de inflexão tende ao infinito. 


$$
\begin{aligned}
& \Psi_{1}^{\prime}\left(\delta_{i, k}\right)=\frac{\ell_{i, k}}{\log (2)\left(1+\delta_{i, k}\right)} \\
& \Psi_{1}^{\prime \prime}\left(\delta_{i, k}\right)=-\frac{\ell_{i, k}}{\log (2)\left(1+\delta_{i, k}\right)^{2}} \\
& \Psi_{2}^{\prime}\left(\delta_{i, k}\right)=\left(\frac{\log (2)(\sqrt{M}-1)}{\log (M)} \sqrt{\frac{3 \log (M) \delta_{i, k}+2 \log (2) M-2 \log (2)}{3 M \log (M) \delta_{i, k}}}\right) . \\
& \left(\frac{3 \log (M)}{3 \log (M) \delta_{i, k}+2 \log (2) M-2 \log (2)}-\frac{9(\log (M))^{2} \delta_{i, k}}{\left(3 \log (M) \delta_{i, k}+2 \log (2) M-2 \log (2)\right)^{2}}\right) \\
& \Psi_{2}^{\prime \prime}\left(\delta_{i, k}\right)=\left(\frac{1}{2 M(\log (M))^{2}\left(\delta_{i, k}\right)^{2}\left(3 \log (M) \delta_{i, k}-2 \log (2) M-2 \log (2)\right)^{4}}\right)\left(\sqrt{\frac{M \log (M) \delta_{i, k}}{9 \log (M) \delta_{i, k}+6 \log (2) M+2 \log (2) M-6 \log (2)}}\right) . \\
& \cdot\left[\left(2 \log (2)(\sqrt{M}-1) \delta_{i, k}\left(3 \log (M) \delta_{i, k}+2 \log (2) M-2 \log (2)\right) \cdot\right.\right. \\
& \left.\cdot\left(-9(\log (M))^{2}\left(3 \log (M) \delta_{i, k}+2 \log (2) M-2 \log (2)\right)^{2}\left(3 \log (M) \delta_{i, k}+2 \log (2) M-2 \log (2)\right)^{3} \delta_{i, k}\right)\right)+ \\
& +\log (2)(\sqrt{M}-1)(2 \log (2)-2 \log (2) M)\left(3 \log (M) \delta_{i, k}+2 \log (2) M-2 \log (2)\right) . \\
& \left.\cdot\left(3 \log (M)\left(2 \log (M) \delta_{i, k}+2 \log (2) M-2 \log (2)\right)^{2}-9(\log (M))^{2} \delta_{i, k}\right)\right]
\end{aligned}
$$


Uma expressão para o ponto de inflexão pode ser obtida adaptando os valores da tabela 1 em uma expressão adequada. Aplicando-se o método dos mínimos quadrados e através de uma busca não exaustiva, a expressão $\delta_{\text {in }}=\frac{V}{5 M}$ apresentou o menor erro quadrático médio normalizado da ordem de $10^{-1}$. Desta forma, para a combinação de parâmetros da tabela 1 e erro supracidato, a função $\mathfrak{R}\left(\delta_{i, k}\right)$ é convexa para todo $\delta_{i, k} \in\left[0, \frac{V}{5 M}\right]$, e côncava no intervalo $\left[\frac{V}{5 M}, L_{c}\right]$, e, portanto, as condições (4) e (5) são satisfeitas.

Finalmente, a condição (6) é trivial uma vez que $\delta_{i, k} \geq 0$ e $\mathfrak{R}(0)=0$.

Do lema 7 segue a quase concavidade de $u_{i}^{k}$ (SAMPAIO et al., 2014):

Lema 8 (Quase Concavidade da Função Utilidade). A função utilidade $u_{i}^{k}$ é quase côncava em $\delta_{i, k}$.

Demonstração. Note que a função utilidade definida como $u_{i}^{k}: \mathbb{R}_{+} \rightarrow \mathbb{R}_{+}$, é uma função contínua tal que $u_{i}^{k}\left(\delta_{i, k}\right)=\mathfrak{R}\left(\delta_{i, k}\right) / \mathfrak{G}\left(\delta_{i, k}\right)$, onde $\mathfrak{G}$ é uma função afim positiva. Do lema 7 segue que $\mathfrak{R}$ é uma curva sigmóide. Da definição de curva sigmóide, existe um $\delta_{\text {in }}$ que satisfaz: $\forall \delta_{i, k} \in\left[0, \delta_{\text {in }}\right] \Rightarrow \mathfrak{R}$ é convexa e $\forall \delta_{i, k} \in$ $\left[\delta_{\text {in }}, \infty\right) \Rightarrow \mathfrak{R}$ é côncava. Para valores menores que $\delta_{\text {in }}$ no domínio da função, $u_{i}^{k}$ é a razão entre uma função convexa e uma função afim positiva. De acordo com (AVRIEL et al., 2010, Tabela 5.5 na Página 165) esta razão é uma função quase convexa. Por outro lado, para valores maiores que $\delta_{\text {in }}$ a função utilidade é a razão entre uma função côncava e uma afim positiva. De acordo com (AVRIEL et al., 2010) esta razão é uma função quase côncava. Sendo assim, da definição de quase convexidade através da desigualdade de Jensen em (A.30), segue que $\forall x_{1}, x_{2} \in\left[0, \delta_{\text {in }}\right]$ e para todo $\lambda \in[0,1], u_{i}^{k}\left(\lambda x_{1}+(1-\lambda) x_{2}\right) \leq \max \left\{u_{i}^{k}\left(x_{1}\right), u_{i}^{k}\left(x_{2}\right)\right\}$. Note que para $x_{1}=0$ e $x_{2}=\delta_{\text {in }}$ a desigualdade se reduz a:

$$
u_{i}^{k}\left((1-\lambda) \delta_{\text {in }}\right) \leq u_{i}^{k}\left(\delta_{\text {in }}\right)
$$


A equação (4.61) implica que $u_{i}^{k}$ é não decrescente no intervalo $\left[0, \delta_{\text {in }}\right]$. Portanto, $u_{i}^{k}$ é quase côncava e quase convexa em $\delta \in\left[0, \delta_{\text {in }}\right]$. Uma vez que $u_{i}^{k}$ é quase côncava no intervalo $\left[0, \delta_{\text {in }}\right]$ e no intervalo $\left[\delta_{\text {in }}, \infty\right)$, e $u_{i}^{k}$ é contínua, então $u_{i}^{k}$ é quase côncava para todo $\delta \geq 0$.

Uma vez que a função utilidade é quase côncava, pode-se utilizar a condição (4.50) para se obter a melhor resposta em relação sinal-interferência mais ruído:

$$
\begin{aligned}
& \frac{\partial u_{i}^{k}}{\partial \delta_{i, k}}=0 \\
& \frac{\partial}{\delta_{i, k}} \frac{\mathfrak{R}\left(\delta_{i, k}\right)}{\mathfrak{G}\left(\delta_{i, k}\right)}=0 \\
& \frac{\mathfrak{R}^{\prime}\left(\delta_{i, k}\right) \mathfrak{G}\left(\delta_{i, k}\right)-\mathfrak{R}\left(\delta_{i, k}\right) \mathfrak{G}^{\prime}\left(\delta_{i, k}\right)}{\left(\mathfrak{G}\left(\delta_{i, k}\right)\right)^{2}}=0 \\
& \mathfrak{R}^{\prime}\left(\delta_{i, k}\right)\left(P_{\mathrm{C}}+P_{\mathrm{C}_{\mathrm{R}}}+\varrho_{\mathrm{R}} p_{\mathrm{R}}+\varrho_{i} \delta_{i, k} \beta_{i, k}\right)-\mathfrak{R}\left(\delta_{i, k}\right)\left(\varrho_{i} \beta_{i, k}\right)=0
\end{aligned}
$$

onde $\mathfrak{R}\left(\delta_{i, k}\right)$ e $\mathfrak{R}^{\prime}\left(\delta_{i, k}\right)$ são definidos em (4.54) e (4.55), respectivamente.

O teorema abaixo prova a existência de um equilíbrio de Nash para o jogo não cooperativo proposto (RENY, 2005, Teorema 2.2 na Página 2).

Teorema 9 (Existência de um Equilíbrio de Nash). Se cada $\mathcal{E}_{i}^{k}, i \in \mathcal{J}$, é um subconjunto não vazio, compacto e convexo de um espaço métrico, e cada $u_{i}^{k}$ é contínua e quase côncava em $\delta_{i, k}$, então o jogo $\Gamma_{k}$ possuí ao menos um equilíbrio de Nash de estratégias puras.

Demonstração. Para cada jogador $i$ e cada vetor de estratégias dos demais jogadores $\boldsymbol{\delta}_{-i, k} \in \mathcal{E}_{-i}^{k}$, onde $\mathcal{E}_{-i}^{k}=\times_{\substack{j \in \mathcal{J} \\ j \neq i}} \mathcal{E}_{j}^{k}$, denote por $\mathfrak{Y}\left(\boldsymbol{\delta}_{-i, k}\right)$ o conjunto de pontos em $\mathcal{E}_{i}^{k}$ que maximiza $u_{i}^{k}\left(\cdot, \boldsymbol{\delta}_{-i, k}\right)$. Como $u_{i}^{k}$ é contínua e $\mathcal{E}_{i}^{k}$ é compacto então $\mathfrak{Y}\left(\boldsymbol{\delta}_{-i, k}\right)$ é um conjunto não vazio, i.e. existe ao menos um ponto do conjunto de estratégias que maximiza a utilidade do jogador $i$. Considere a correspondência de reação ${ }^{9}$

\footnotetext{
${ }^{9} \mathrm{~A}$ correspondência é de reação pois trata-se das estratégias de melhor resposta que podem
} 
$\mathfrak{L}_{i}^{k}: \mathcal{E}_{-i}^{k} \rightarrow \mathcal{E}_{i}^{k}$ definida como os pontos que maximizam a função utilidade do usuário $i$ quando as estratégias utilizadas pelos demais usuários são $\boldsymbol{\delta}_{-i, k} \in \mathcal{E}_{-i}^{k}$, i.e. $\mathfrak{L}_{i}^{k}\left(\boldsymbol{\delta}_{-i, k}\right)=\left\{\delta_{i, k}^{*} \in \mathcal{E}_{i}^{k} \mid u_{i}^{k}\left(\delta_{i, k}^{*}, \boldsymbol{\delta}_{-i, k}\right) \geq u_{i}^{k}\left(\delta_{i, k}, \boldsymbol{\delta}_{-i, k}\right), \forall \delta_{i, k} \in \mathcal{E}_{i}^{k}\right\}$. Uma vez que o conjunto de estratégias disponíveis aos demais usuários, $\mathcal{E}_{-i}^{k}$, é compacto e a função utilidade $u_{i}^{k}$ é contínua, então o conjunto de pontos que maximizam a utilidade do jogador $i$ dado as estratégias dos demais jogadores, $\mathfrak{Y}\left(\boldsymbol{\delta}_{-i, k}\right)$, é um conjunto não vazio, o que implica que a correspondência de reação $\mathfrak{L}_{i}^{k}$ é hemi contínua superior ${ }^{10}$. Da quase concavidade de $u_{i}^{k}$ em $\delta_{i, k}$ segue que $\mathfrak{L}_{i}^{k}\left(\boldsymbol{\delta}_{-i}^{k}\right)$ é convexa. Em suma, a correspondência de reação do jogador $i$ é uma correspondência hemi contínua superior, cujos valores assumidos são conjuntos convexos e não vazios. Estas três características são herdadas pela correspondência simultânea de todos os jogadores definida como, $\mathfrak{L}^{k}: \mathcal{E}^{k} \rightarrow \mathcal{E}^{k}$, onde $\mathcal{E}^{k}=\times_{j \in \mathcal{J}} \mathcal{E}_{j}^{k}$ e $\mathfrak{L}^{k}=\times_{j \in \mathcal{J}} \mathfrak{L}_{i}^{k}\left(\boldsymbol{\delta}_{-i, k}\right)$ para todo $\boldsymbol{\delta}_{k} \in \mathcal{E}^{k}$. Note que correspondências que apresentam hemi continuidade superior, cujos valores assumidos são conjuntos não vazios e convexos, são denominadas mapas de Kakutani (GRANAS; DUGUNDJI, 2003). Pelo teorema de pontos fixos de Glicksbeg (GLICKSBERG, 1952) se $\mathcal{E}^{k}$ é um subconjunto não vazio, compacto e convexo de um espaço métrico e a correspondência $\mathfrak{L}^{k}$ é um mapa de Kakutani então $\mathfrak{L}^{k}$ tem um ponto fixo, i.e. $\exists \boldsymbol{\delta}_{k}^{*} \in \mathcal{E}^{k}$ tal que $\boldsymbol{\delta}_{k}^{*} \in \mathfrak{L}^{k}\left(\boldsymbol{\delta}_{k}^{*}\right)$. Este ponto $\boldsymbol{\delta}_{k}^{*}$ é, portanto, um equilíbro de Nash de estratégias puras.

Sendo assim, uma vez que ao menos um equilíbrio de Nash existe para o problema de maximização da eficiência energética em sistemas MC-DS/CDMA cooperativos, o algoritmo de maximização da eficiência energética apresentado no algoritmo 4.2 foi proposto em (SAMPAIO et al., 2013b).

ser selecionadas pelo jogador esboçando, assim, a reação do mesmo às estratégias utilizadas pelos demais jogadores.

${ }^{10}$ Uma correspondência $C: X \rightarrow Y$ é hemi contínua superior em um ponto $\mathbf{x} \in X$ se para todo conjunto aberto $\Theta$ contendo $C(\mathbf{x})$ existe uma vizinhança $V_{\mathbf{x}}$ de $\mathbf{x}$ tal que $C(\mathbf{z}) \subset \Theta$, $\forall z \in V_{\mathbf{x}}$. 


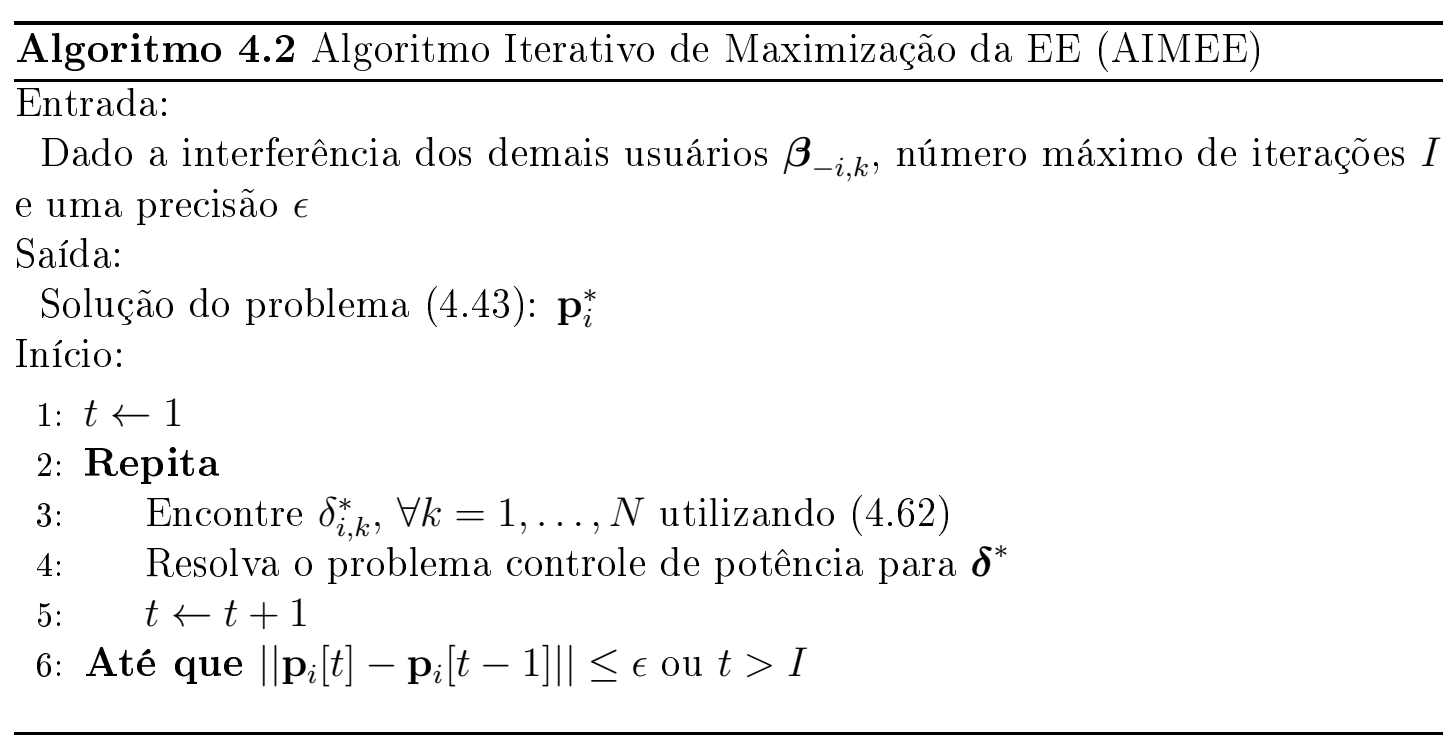

Onde $\boldsymbol{\delta}^{*}$ é a matriz $U \times N$ de SINR ótimas sujos elementos são $\delta_{i, k}$.

Note que o algortimo 4.2 é referente ao usuário $i$ apenas. Logo, no enlace reverso dos sistemas MC-DS/CDMA cada usuário é responsável por executar o seu algoritmo e realizar a alocação de recursos de forma individual, justificando assim, a característica distribuída do algoritmo proposto. No passo 3 do algoritmo, o usuário busca a melhor resposta em SINR para cada subportadora de acordo com a interferência e ruído observados $\boldsymbol{\beta}_{-i, k}$. O passo 4, por sua vez, trata do controle de potência clássico em sistemas multiportadora na presença de interferência de múltiplo acesso. Este passo pode ser solucionado de duas formas distintas:

1. Primeiro, considerando o algoritmo iterativo de water-filling adaptado para o problema do passo 4 no algoritmo 4.2, cujo pseudocódigo está descrito no algoritmo 4.1. A combinação do algoritmo 4.2 com o algoritmo IWFA é denominada EE-IWFA;

2. Segundo, tratando cada subportadora como um sistema independente e empregando o controle de potência distribuído baseado no equilíbrio de Verhulst, apresentado na equação iterativa (4.19). Esta combinação é denominada EE-VDPCA; 
O algoritmo 4.2 converge para um equilíbrio de Nash pois dado a quase concavidade e continuidade de $u_{i}^{k}$ o jogo não cooperativo é um jogo potencial de melhor resposta e portanto a dinâmica de melhor resposta converge para o equilíbrio de Nash (VOORNEVELD, 2000).

Os resultados de simulação destas duas soluções distintas serão apresentados no capítulo 5 de forma conjunta com as demais soluções propostas.

Outra forma de solucionar o problema de maximização da eficiência energética em redes do tipo MC-DS/CDMA cooperativas é considerando o ganho de canal médio ao longo das $N$ subportadoras e solucionando o problema como em um sistema com apenas uma portadora. Considere as seguintes definições:

$$
\overline{\mathbf{h}}=\left[\overline{\mathrm{h}}_{1}, \overline{\mathrm{h}}_{2}, \ldots, \overline{\mathrm{h}}_{i}, \ldots, \overline{\mathrm{h}}_{U}\right]
$$

onde os ganhos médios de canal para o sistema MC-DS/CDMA cooperativo da figura 9 são dados por

$$
\overline{\mathrm{h}}_{i}=\frac{1}{N} \sum_{k=1}^{N}\left|\mathrm{~h}_{i, k}\right|^{2} \text {, e } \overline{\mathrm{g}}=\frac{1}{N} \sum_{k=1}^{N}\left|\mathrm{~g}_{k}\right|^{2}
$$

Considerando o ganho médio de canal, o problema de otimização (4.45) pode ser reescrito como,

$$
\begin{array}{cc}
\text { maximizar } & u_{i}=\frac{\bar{\ell}_{i} B \log _{2}\left(1+\bar{\delta}_{i}\right) f\left(\bar{\delta}_{i}\right)^{V}}{P_{\mathrm{C}}+P_{\mathrm{C}_{\mathrm{R}}}+\varrho_{\mathrm{R}} p_{\mathrm{R}}+\varrho_{i} p_{i}} \\
\text { sujeito à } & (\mathrm{C} .1): p_{i} \in \overline{\mathcal{E}}_{i}, \quad \forall i=1, \ldots, U
\end{array}
$$


onde $\bar{\delta}_{i}$ é a SINR média a partir do ganho de canal médio $\overline{\mathrm{h}}_{i} \mathrm{e}$

$$
\overline{\mathcal{E}}_{i} \triangleq\left\{\bar{p}_{i} \in \mathbb{R}_{+} \mid \bar{p}_{i} \leq \frac{P_{i, \max }}{N} \text { e } \bar{r}_{i} \geq \frac{r_{i}^{*}}{N}\right\}
$$

sendo $\bar{p}_{i}$ a potência média de transmissão e $\bar{r}_{i}$ a taxa média de transmissão por subportadora.

Note que o problema (4.65) é, na verdade, equivalente a um caso especial do problema (4.45). Portanto o algoritmo 4.2 pode ser utilizado considerando que $N=1$. Uma vez que o problema (4.65) é uni-portadora, o passo 4 no algoritmo 4.2 será solucionado apenas pelo algoritmo distribuído de controle de potência baseado no equilíbrio de Verhulst. Esta terceira solução proposta é denominada EE-MDPCA e também será caracterizada numericamente no próximo capítulo.

\subsubsection{Abordagem pelo Método de Dinkelbach}

O método de Dinkelbach (DINKELBACH, 1967) apresentado na seção 3.3 pode ser aplicado ao problema de maximização da eficiência energética com restrições de qualidade de serviço mínima e potência de transmissão máxima, no enlace reverso de sistemas MC-DS/CDMA cooperativos, de forma centralizada.

A forma paramétrica do problema de otimização fracional quase côncavo apresentado em (4.39) é o problema côncavo definido como:

$$
\begin{array}{ll}
\underset{\mathbf{P} \in \mathcal{P}}{\operatorname{maximizar}} & \mathfrak{R}(\mathbf{P})-q_{t} P_{\mathrm{T}}(\mathbf{P}) \\
\text { sujeito à } & (\mathrm{C} .1): \sum_{k=1}^{N} p_{i, k} \in\left[0, P_{i, \max }\right], \quad \forall i=1, \ldots, U \\
& (\mathrm{C} .2): \sum_{k=1}^{N} r_{i, k} \geq r_{i}^{*}, \quad \forall i=1, \ldots, U
\end{array}
$$


onde $q_{t}=\mathfrak{R}\left(\mathbf{P}_{t}\right) / P_{\mathrm{T}}\left(\mathbf{P}_{t}\right)$ é um parâmetro obtido a partir da função fracional não linear original, $\mathbf{P}_{t}$ é a matriz de alocação de potência na $t$-ésima iteração do algoritmo; e $\mathfrak{R}(\mathbf{P})$ é a taxa de transmissão de informação efetiva do sistema em função da matriz de alocação de potência $\mathbf{P}$, definida como,

$$
\mathfrak{R}(\mathbf{P})=\sum_{i=1}^{U} \sum_{k=1}^{N} \ell_{i, k} r_{i, k} f\left(\delta_{i, k}\right)^{V}
$$

$i$ e $k$ são os indexadores de usuário e subportadora, respectivamente; $\ell_{i, k}$ é a taxa de codificação, $r_{i, k}$ a taxa de transmissão obtida pela capacidade de canal, $f\left(\delta_{i, k}\right)$ é a função ${ }^{11}$ de penalização definida em (4.36) e $V$ é o número de bits transmitidos por pacote. A função $P_{\mathrm{T}}(\mathbf{P})$ é a potência total de transmissão mais a potência consumida pelos circuitos apresentada no denominador da equação (4.37); e $\mathcal{P}$ é o domínio do problema, i.e. o conjunto de todas as matrizes de alocação factíveis, definido de acordo com:

$$
\mathcal{P} \triangleq\left\{\mathbf{P} \in \mathbb{R}_{+}^{U \times N} \mid \sum_{k=1}^{N} p_{i, k} \leq P_{i, \max }, \forall i=1, \ldots, U\right\}
$$

O pseudocódigo do algoritmo de Dinkelbach adaptado ao problema de maximização da eficiência energética em redes de comunicação cooperativas do tipo MC-DS/CDMA é descrito a seguir no algoritmo 4.3.

Observa-se que no algoritmo EE-MCDINK, a função $F$ é definida como,

$$
F(q)=\max _{\mathbf{P} \in \mathcal{P}}\left\{\Re(\mathbf{P})-q P_{\mathrm{T}}(\mathbf{P})\right\}
$$

Note que o passo 3 é um problema côncavo e, portanto, técnicas de otimização convexa podem ser aplicadas. Neste trabalho, a ferramenta de programação convexa disciplinada CVX (GRANT; BOYD, 2014), (GRANT; BOYD, 2008), foi

\footnotetext{
${ }^{11}$ Uma vez que a SINR é uma função linear das potências de transmissão de cada usuário $f$ também é uma função das potências de transmissão
} 


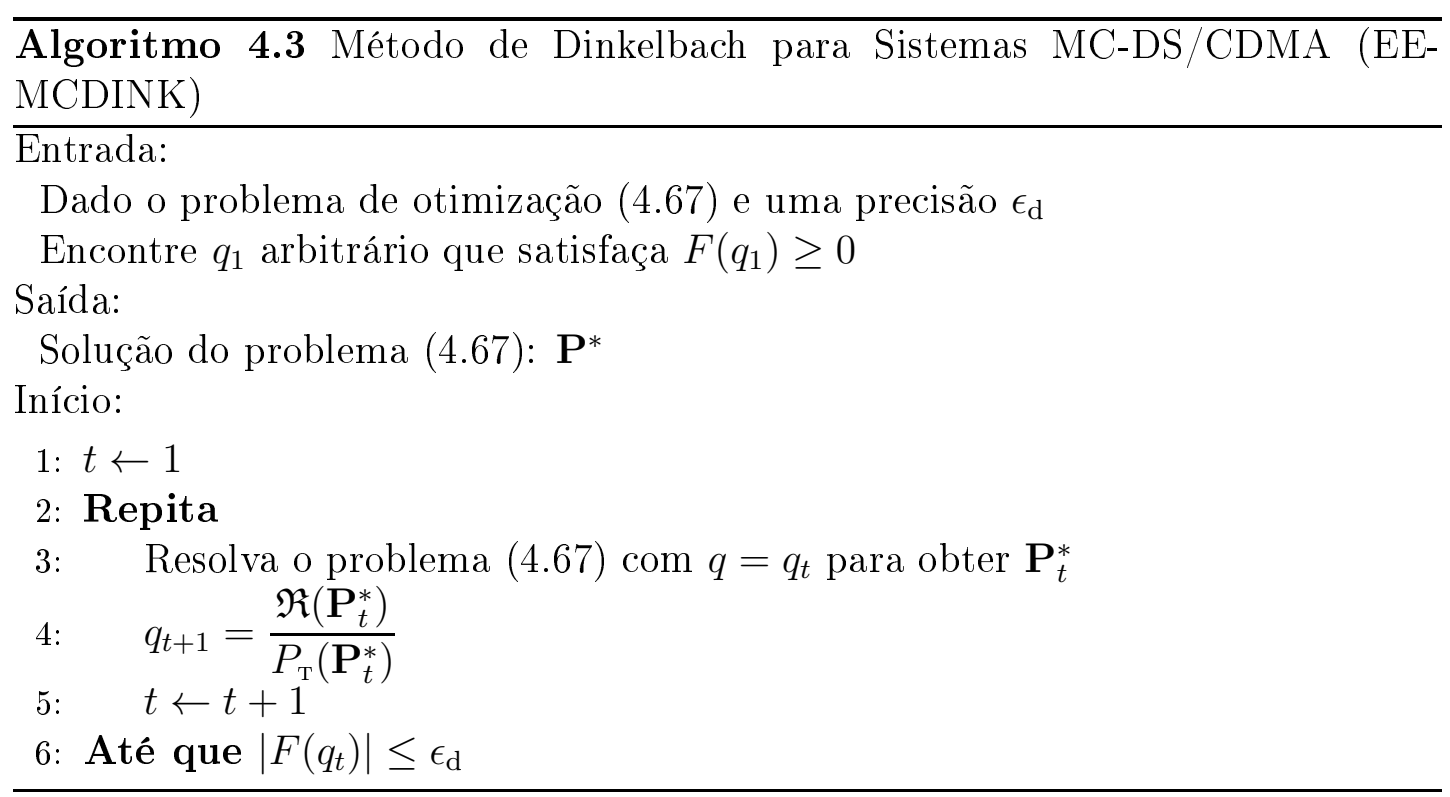

utilizada para solucionar o problema paramétrico (4.67).

\subsubsection{Abordagem por Métodos Heurísticos}

Os métodos heurísticos, nominalmente, o algoritmo dos vaga-lumes e o algoritmo de otimização por enxame de particulas foram empregados na maximização da eficiência energética do enlace reverso de redes cooperativas de múltiplo acesso por divisão de código de sequência direta com múltiplas subportadoras.

A função custo utilizada por ambos algoritmos é a eficiência energética do sistema e portanto os algoritmos foram implementados de forma centralizada na estação rádio-base, sendo esta a responsável por transmitir aos usuários os respectivos níveis de potência de transmissão que devem ser utilizados nas unidades móveis.

Sendo assim, a função objetivo $f$ descrita nos algoritmos 3.2 e 3.3 é descrita 
como:

$$
f(\mathbf{P})=\frac{\sum_{i=1}^{U} \sum_{k, 1}^{N} \ell_{i, k} B \log _{2}\left(1+\delta_{i, k}\right) f\left(\delta_{i, k}\right)^{V}}{P_{\mathrm{C}}+P_{\mathrm{C}_{\mathrm{R}}}+\varrho_{\mathrm{R}} p_{\mathrm{R}}+\sum_{i=1}^{U} \sum_{k=1}^{N} \varrho_{i} p_{i, k}}
$$

onde $\mathbf{P}$ é a matriz de alocação de potências. Na abordagem heurística desenvolvida neste trabalho, o domínio do problema é garantido verificando-se as restrições (C.1) e (C.2) apresentadas na definição do problema de otimização em (4.39), a partir de seus laços, e qualquer solução gerada que não pertença ao domínio do problema é descartada e um solução factível aleatória é gerada em seu lugar.

A otimização dos parâmetros dos algoritmos, aspectos numéricos de convergência bem como os resultados de desempenho obtidos a partir de simulações computacionais serão apresentados no próximo capítulo.

\subsection{Alocação de Recursos em Sistemas com Múl- tiplo Acesso por Divisão de Frequências Orto- gonais}

O sistema OFDMA é o modelo de múltiplo acesso utilizado nos padrões de redes de quarta geração LTE, LTE-A e WiMAX. A maior aplicação deste método de múltiplo acesso está no enlace de descida a fim de garantir altas taxas de transmissão de dados. Desta forma o controle de potência não é um problema com grande apelo para sistemas que utilizam OFDMA. Todavia, a maximização da vazão do sistema é um problema de otimização que atende diretamente aos propósitos de se utilizar esta técnica no enlace de descida de redes que transmitem em altas taxas.

Sendo assim, considere o enlace direto de um sistema OFDMA com $U$ usuários e $N$ subportadoras, onde $\mathrm{h}_{i, k}$ indica o ganho complexo de canal do usuário $i$ na 
subportadora $k$. A vazão do sistema obtida a partir da capacidade de canal de Shannon (SHANNON, 1948) é:

$$
\mathcal{C}=\sum_{i=1}^{U} \sum_{k=1}^{N} \phi_{i, k} r_{i, k}=\sum_{i=1}^{U} \sum_{k=1}^{N} \phi_{i, k} B \log _{2}\left(1+\delta_{i, k}\right)
$$

onde $\phi_{i, k} \in\{0,1\}$ é uma variável que representa se o usuário $i$ está ativo no subcanal $k\left(\phi_{i, k}=1\right)$ ou não $\left(\phi_{i, k}=0\right)$. A taxa de transmissão de informação do usuário $i$ na subportadora $k$ é $r_{i, k}$; define-se ainda, $\delta_{i, k}$ a relação sinal-ruído do usuário $i$ na subportadora $k$ :

$$
\delta_{i, k}=\frac{p_{i, k}\left|\mathrm{~h}_{i, k}\right|^{2}}{N_{0} B}
$$

sendo $p_{i, k}$ a potência de transmissão do $i$-ésimo terminal móvel no subcanal $k$, $N_{0}$ a densidade espectral de potência do ruído aditivo Gaussiano branco e $B$ a banda da subportadora.

Sendo assim, o problema de maximização da vazão do sistema OFDMA sem restrições de taxa é descrito como:

$$
\begin{array}{ll}
\text { maximizar } & \mathcal{C}=\sum_{i=1}^{U} \sum_{k=1}^{N} \phi_{i, k} B \log _{2}\left(1+\delta_{i, k}\right) \\
\text { sujeito à } \quad(\text { C. } 1): \sum_{i=1}^{U} \sum_{k=1}^{N} \phi_{i, k} p_{i, k} \in\left[0, P_{\max }\right] \\
\\
(\text { C. } 2): \sum_{i=1}^{U} \phi_{i, k} \leq 1, \quad \forall k=1, \ldots, N \\
(\text { C. } 3): \phi_{i, k} \in\{0,1\}, \quad \forall i=1, \ldots, U \text { e } k=1, \ldots, N
\end{array}
$$

onde $P_{\max }$ é a potência máxima de transmissão da estação rádio-base.

Evidentemente, o problema (4.74) tem duas variáveis de decisão: a matriz $\mathbf{P}$ 
de alocação de potência de transmissão e a matriz $\phi$ de alocação de subportadoras. Uma matriz $\mathbf{P}$ é denominada factível se pertence ao domínio de potência do problema, i.e.

$$
\mathbf{P} \in \mathcal{P} \triangleq\left\{\mathbf{P} \in \mathbb{R}_{+}^{U \times N} \mid \sum_{i=1}^{U} \sum_{k=1}^{N} \phi_{i, k} p_{i, k} \leq P_{\max }\right\}
$$

De forma equivalente, a matriz de alocação de subportadoras $\phi$ é denominada factível se pertence ao domínio de alocação de subcanais do problema, i.e.

$$
\phi \in \Omega \triangleq\left\{\begin{array}{l|l}
\phi \in\{0,1\}^{U \times N} & \sum_{i=1}^{U} \phi_{i, k} \leq 1, \forall k=1, \ldots, N
\end{array}\right\}
$$

O problema de maximização da vazão no enlace direto de sistemas OFDMA sem restrição de taxa de transmissão tem solução simples: dado a matriz de canal $\mathbf{H} \in \mathbb{C}^{U \times N}$, onde $\mathrm{h}_{i, k}$ é o ganho complexo de canal do usuário $i$ na subportadora $k$, a alocação de subportadoras pode ser feita de acordo com,

$$
\phi_{i, k}=\left\{\begin{array}{l}
1, \quad \text { se } \max \left[\left|\mathrm{h}_{1, k}\right|^{2}, \ldots,\left|\mathrm{h}_{U, k}\right|^{2}\right]=\left|\mathrm{h}_{i, k}\right|^{2} \\
0, \quad \text { caso contrário }
\end{array}\right.
$$

Uma vez que a alocação de subportadoras tenha sido feita o procedimento para alocação de potência é realizado através de uma solução simples de waterfilling como no caso uni-usuário apresentado na seção 4.1.2. Todavia, o objetivo neste caso é distinto do controle de potência: na maximização da vazão a solução ótima é assegurada quando a potência máxima de transmissão é alocada de forma ótima utilizando o conceito de solução de water-filling. 
No caso do problema (4.74) a solução via water-filling pode ser obtida por,

$$
\sum_{k=1}^{N}\left(\mu-\frac{N_{0} B}{\left|\mathrm{~h}_{k}\right|^{2}}\right)=P_{\max }
$$

onde $\left|\mathrm{h}_{k}\right|^{2}=\max \left[\left|\mathrm{h}_{1, k}\right|^{2}, \ldots,\left|\mathrm{h}_{U, k}\right|^{2}\right]$.

Desta forma, o nível d'água ótimo $\mu^{*}$ é dado por:

$$
\mu^{*}=\frac{1}{N} P_{\max }-\sum_{k=1}^{N}\left(\frac{N_{0} B}{\left|\mathrm{~h}_{k}\right|^{2}}\right)
$$

e a função $g(\mu)$ por,

$$
g(\mu)=\mu N-\left(P_{\max } \sum_{k=1}^{N}\left(\frac{N_{0} B}{\left|\mathrm{~h}_{k}\right|^{2}}\right)\right)
$$

Finalmente, a solução para o problema de maximização da vazão em sistemas OFDMA sem restrição de taxa de transmissão mínima é dado por,

$$
p_{i, k}=\left\{\begin{aligned}
\mu^{*}-\frac{N_{0} B}{\left|\mathrm{~h}_{k}\right|^{2}}, & \text { se }\left|\mathrm{h}_{i, k}\right|^{2}=\max \left[\left|\mathrm{h}_{1, k}\right|^{2}, \ldots,\left|\mathrm{h}_{U, k}\right|^{2}\right] \\
0, & \text { caso contrário }
\end{aligned}\right.
$$

Note que para encontrar o valor do nível d'água ótimo deve-se seguir os passos apresentados no algoritmo 4.1 .

Nas seções que se seguem, serão abordados os problemas de maximização da capacidade efetiva e maximização da eficiência energética efetiva no enlace direto de sistemas OFDMA. 


\subsubsection{Maximização da Capacidade Efetiva em Sistemas OFDMA}

Outra métrica que pode ser utilizada para otimizar a transmissão no elo direto de redes de múltiplo acesso por divisão ortogonal de frequência, é a capacidade efetiva do sistema proposto por (WU; NEGI, 2003) e descrito na seção 2.2.1. A capacidade efetiva do sistema considerando canais não seletivos em frequência sem linha de visada cujos ganhos de amplitude podem portanto ser modelados por uma distribuição de probabilidade estatística do tipo Rayleigh é definida como:

$$
\mathcal{C}_{\mathrm{e}}(\boldsymbol{\theta}, \boldsymbol{\phi}, \mathbf{P})=\sum_{i=1}^{U} \sum_{k=1}^{N}-\frac{\phi_{i, k}}{\theta_{i}} \log \left(\frac{N_{0} B}{p_{i, k}} e^{\frac{N_{0} B}{p_{i, k}}} E_{A_{i}}\left[\frac{N_{0} B}{p_{i, k}}\right]\right)
$$

onde $i$ e $k$ são os indexadores de usuário e subportadora, respectivamente, $\phi$ é a váriavel binária que representa a atividade do usuário $i$ na subportadora $k, p$ é a potência de transmissão, $N_{0}$ é a densidade espectral de potência do ruído, $B$ é a largura de banda de cada um dos subcanais ortogonais, $\theta_{i}$ o exponente de qualidade de serviço do usuário $i$ associado ao atraso estatístico máximo tolerável, $A_{i}=\frac{\theta_{i} T B}{\log (2)}, \boldsymbol{\theta}=\left[\theta_{1}, \theta_{2}, \ldots, \theta_{U}\right]^{T}$ o vetor de exponentes de QoS, e $\boldsymbol{\phi}$ a matriz de alocação de subportadora definida como,

$$
\phi \in \Omega \triangleq\left\{\phi \in\{0,1\}^{U \times N} \mid \sum_{i=1}^{U} \phi_{i, k} \leq 1, k=1, \ldots, N\right\}
$$

$\mathbf{P}$, por sua vez, é a matriz $U \times N$ de alocação de potências de transmissão, tal que,

$$
\mathbf{P} \in \mathcal{P} \triangleq\left\{\mathbf{P} \in \mathbb{R}_{+}^{U \times N} \mid \sum_{i=1}^{U} \sum_{k=1}^{N} \phi_{i, k} p_{i, k} \leq P_{\max }\right\}
$$

A formulação em (4.82) é válida assumindo que o comprimento máximo das 
filas $^{12}$ na estação rádio-base seja grande o suficiente para não gerar a condição de fila vazia. O problema de maximização da capacidade efetiva sujeito a restrições de capacidade efetiva mínima a ser garantida, potência máxima de transmissão disponível e expoentes de qualidade de serviço estatística relacionados ao atraso máximo tolerável $\boldsymbol{\theta}=\left[\theta_{1}, \theta_{2}, \ldots, \theta_{U}\right]^{T}$ pode ser formalmente formulado para o canal direto como,

$$
\begin{aligned}
\operatorname{maximizar} \quad \mathcal{C}_{\mathrm{e}}(\boldsymbol{\theta}, \boldsymbol{\phi}, \mathbf{P})=\sum_{i=1}^{U} \sum_{k=1}^{N}-\frac{\phi_{i, k}}{\theta_{i}} \log \left(\frac{N_{0} B}{p_{i, k}} e^{\frac{N_{0} B}{p_{i, k}}} E_{A_{i}}\left[\frac{N_{0} B}{p_{i, k}}\right]\right) \\
\text { sujeito à } \quad(\mathrm{C} .1): \sum_{k=1}^{N}-\frac{\phi_{i, k}}{\theta_{i}} \log \left(\frac{N_{0} B}{p_{i, k}} e^{\frac{N_{0} B}{p_{i, k}}} E_{A_{i}}\left[\frac{N_{0} B}{p_{i, k}}\right]\right) \geq \mathcal{C}_{\mathrm{e}}^{i, \mathrm{~min}}, \forall i \\
(\mathrm{C} .2): \sum_{i=1}^{U} \sum_{k=1}^{N} \phi_{i, k} p_{i, k} \in\left[0, P_{\max }\right] \\
(\mathrm{C} .3): \sum_{i=1}^{U} \phi_{i, k} \leq 1, \quad \forall k=1, \ldots, N \\
(\mathrm{C} .4): \phi_{i, k} \in\{0,1\}, \quad \forall i=1, \ldots, U \text { e } k=1, \ldots, N \\
(\text { C. } 5): \sum_{i=1}^{U} N_{i}=N, \quad N_{i} \in \mathbb{Z}_{+}
\end{aligned}
$$

onde $\mathcal{C}_{\mathrm{e}}^{i, \text { min }}$ expressa a restrição individual de QoS estatística em termos de capacidade efetiva mínima do usuário $i$. As condições (C.2), (C.3) e (C.4) seguem da modelagem matemática do enlace de descida do sistema OFDMA: impõe que apenas um usuário é alocado por subportadora, que a potência máxima de transmissão da estação rádio-base não é ultrapassada e que as variáveis de alocação de subportadora são binárias. Finalmente, na condição (C. 5) $N_{i}$ é o número de subcanais atribuídos ao usuário $i$, desta forma a condição garante que todas as subportadoras foram ativadas.

O problema de otimização em (4.85) é um programa não linear inteiro-misto:

\footnotetext{
${ }^{12}$ As filas participam do controle de enlace sendo utilizadas para armazenar informação quando a quantidade de informação a ser enviada no intervalo de tempo $T$ é maior que a taxa de transmissão no intervalo. Veja a figura 12.
} 
não linear, pois a natureza das funções (objetivo e de restrição) é não linear, inteiro-misto pois a matriz de alocação de potências é uma variável de decisão contínua, definida como o produto cartesiano de intervalos do conjunto dos números reais, enquanto a matriz de alocação de subportadora é composta por variáveis discretas (binárias).

Problemas de otimização do tipo inteiro misto complexos geralmente são classificados como de tempo polinomial não determinístico - difícil (do inglês, polynomial time non-deterministic - hard, NP-Hard) (GAREY; JOHNSON, 1979). Desta forma, a complexidade computacional intrínseca à obtenção da solução ótima do problema é proibitiva (REKLAITIS; RAVINDRAN, 1983). Problemas de otimização do tipo inteiro misto desta ordem de complexidade (NP-Hard) são comumente solucionados por métodos baseados no conceito de branch and bound (BOYD; VANDENBERGHE, 2004). Nestes métodos, uma árvore de decisão é construída considerando limites superiores e inferiores para a versão relaxada ${ }^{13}$ do problema original. O algoritmo converge quando a diferença dos limites é nula e/ou menor que um valor específico de precisão.

A versão relaxada do problema (4.85) considera que o indexador de subportadora torna-se contínuo, $\underline{\phi}_{i, k} \in[0,1]$ para todo $i=1, \ldots, U$ e $k=1, \ldots, N$. Note que essa relaxação é equivalente a um esquema de compartilhamento temporal, i.e. cada usuário utiliza o subcanal por uma fração de tempo que somados resultam igual a 1. Embora de forma geral os canais de comunicação não permaneçam constantes por tempo suficiente para que o compartilhamento do canal em frações de tempo seja possível, em sistemas reais (WONG et al., 1999) foi demonstrado em (YU; LUI, 2006) que a solução dual do problema de alocação de recursos em sistemas multiportadora é arbitrariamente próxima da solução do problema original quando o número de subportadoras tende a infinito.

\footnotetext{
${ }^{13}$ Relaxação é empregada visando transformar variáveis de decisão discretas em contínuas em um intervalo apropriado.
} 
Sendo assim, considere a versão relaxada da matriz de alocação de subportadoras $\underline{\phi}$ cujo domínio $\underline{\Omega}$ é definido como,

$$
\underline{\phi} \in \underline{\Omega} \triangleq\left\{\underline{\phi} \in[0,1]^{U \times N} \mid \sum_{i=1}^{U} \underline{\phi}_{i, k} \leq 1, k=1, \ldots, N\right\}
$$

A capacidade efetiva do sistema com compartilhamento temporal, i.e. considerando a forma relaxada de alocação de subportadora, é definido como,

$$
\underline{\mathcal{C}}_{\mathrm{e}}(\boldsymbol{\theta}, \underline{\boldsymbol{\phi}}, \mathbf{P})=\sum_{i=1}^{U} \sum_{k=1}^{N}-\frac{\underline{\phi}_{i, k}}{\theta_{i}} \log \left(\frac{N_{0} B}{p_{i, k}} e^{\frac{N_{0} B}{p_{i, k}}} E_{A_{i}}\left[\frac{N_{0} B}{p_{i, k}}\right]\right)
$$

onde $\underline{\phi}_{i, k} \in[0,1]$ é o elemento da $i$-ésima linha e $k$-ésima coluna da matriz $\underline{\phi}$. Como consequência, pode-se reescrever o problema de maximização da capacidade efetiva em (4.85), obtendo a seguinte forma relaxada,

$$
\begin{array}{ll}
\operatorname{maximizar} \quad \underline{\mathcal{C}}_{\mathrm{e}}(\boldsymbol{\theta}, \underline{\boldsymbol{\phi}}, \mathbf{P})=\sum_{i=1}^{U} \sum_{k=1}^{N}-\frac{\underline{\phi}_{i, k}}{\theta_{i}} \log \left(\frac{N_{0} B}{p_{i, k}} e^{\frac{N_{0} B}{p_{i, k}}} E_{A_{i}}\left[\frac{N_{0} B}{p_{i, k}}\right]\right) \\
\text { sujeito à } \quad(\mathrm{C} .1): \sum_{k=1}^{N}-\frac{\underline{\phi}_{i, k}}{\theta_{i}} \log \left(\frac{N_{0} B}{p_{i, k}} e^{\frac{N_{0} B}{p_{i, k}}} E_{A_{i}}\left[\frac{N_{0} B}{p_{i, k}}\right]\right) \geq \mathcal{C}_{\mathrm{e}}^{i, \text { min }}, \forall i \\
(\mathrm{C} .2): \sum_{i=1}^{U} \sum_{k=1}^{N} \underline{\phi}_{i, k} p_{i, k} \in\left[0, P_{\max }\right] \\
(\mathrm{C} .3): \sum_{i=1}^{U} \underline{\phi}_{i, k} \leq 1, \quad \forall k=1, \ldots, N \\
(\mathrm{C} .4): \underline{\phi}_{i, k} \in[0,1], \quad \forall i=1, \ldots, U \text { e } k=1, \ldots, N \\
(\mathrm{C} .5): \sum_{i=1}^{U} N_{i}=N, \quad N_{i} \in \mathbb{R}_{+}
\end{array}
$$

A característica do compartilhamento temporal, i.e. a relaxação do problema, garante que o problema de otimização (4.88) funcione como um limite superior da capacidade efetiva do sistema (BOYD; VANDENBERGHE, 2004).

Para prosseguir com a análise do problema (4.88), apresenta-se o seguinte 
lema:

Lema 10 (Concavidade da Capacidade Efetiva). A versão relaxada da função da capacidade efetiva em sistemas sem linha de visada com canais onde o ganho em amplitude do canal apresenta distribuição de Rayleigh,

$$
\underline{\mathcal{C}}_{e}(\boldsymbol{\theta}, \underline{\boldsymbol{\phi}}, \mathbf{P})=\sum_{i=1}^{U} \sum_{k=1}^{N}-\frac{\underline{\phi}_{i, k}}{\theta_{i}} \log \left(\frac{N_{0} B}{p_{i, k}} e^{\frac{N_{0} B}{p_{i, k}}} E_{A_{i}}\left[\frac{N_{0} B}{p_{i, k}}\right]\right)
$$

é côncava em $\mathbf{P}$ e $\underline{\phi}$.

Demonstração. Primeiramente, demonstra-se que:

$$
\mathrm{C}\left(p_{i, k}, \underline{\phi}_{i, k}\right)=-\frac{\underline{\phi}_{i, k}}{\theta_{i}} \log \left(\frac{N_{0} B}{p_{i, k}} e^{\frac{N_{0} B}{p_{i, k}}} E_{A_{i}}\left[\frac{N_{0} B}{p_{i, k}}\right]\right)
$$

é côncava. Uma vez que C é duplamente diferenciável o teste de segunda ordem pode ser aplicado para verificar sua concavidade. Desta forma, a matriz Hessiana de C é:

$$
\mathbf{H}_{\mathrm{C}}=\left[\begin{array}{cc}
\frac{\partial^{2} \mathrm{C}\left(p_{i, k}, \underline{\phi}_{i, k}\right)}{\partial p_{i, k}^{2}} & \frac{\partial^{2} \mathrm{C}\left(p_{i, k}, \underline{\phi}_{i, k}\right)}{\partial p_{i, k} \partial \underline{\phi}_{i, k}} \\
\frac{\partial^{2} \mathrm{C}\left(p_{i, k}, \underline{\phi}_{i, k}\right)}{\partial \underline{\phi}_{i, k} \partial p_{i, k}} & \frac{\partial^{2} \mathrm{C}\left(p_{i, k}, \underline{\phi}_{i, k}\right)}{\partial \underline{\phi}_{i, k}^{2}}
\end{array}\right]
$$

onde as derivadas parciais são dadas por,

$$
\begin{aligned}
& \frac{\partial^{2} \mathrm{C}\left(p_{i, k}, \underline{\phi}_{i, k}\right)}{\partial \underline{\phi}_{i, k}^{2}}= 0 \\
& \frac{\partial^{2} \mathrm{C}\left(p_{i, k}, \underline{\phi}_{i, k}\right)}{\partial p_{i, k} \partial \underline{\phi}_{i, k}}=\frac{\left(N_{0} B+p_{i, k}\right) E_{A_{i}}\left[\frac{N_{0} B}{p_{i, k}}\right]-\left(N_{0} B\right) E_{A_{i}-1}\left[\frac{N_{0} B}{p_{i, k}}\right]}{\theta_{i}\left(p_{i, k}\right)^{2} E_{A_{i}}\left[\frac{N_{0} B}{p_{i, k}}\right]}
\end{aligned}
$$




$$
\begin{gathered}
\frac{\partial^{2} \mathrm{C}\left(p_{i, k}, \underline{\phi}_{i, k}\right)}{\partial \underline{\phi}_{i, k} \partial p_{i, k}}=\frac{\left(N_{0} B+p_{i, k}\right) E_{A_{i}}\left[\frac{N_{0} B}{p_{i, k}}\right]-\left(N_{0} B\right) E_{A_{i}-1}\left[\frac{N_{0} B}{p_{i, k}}\right]}{\theta_{i}\left(p_{i, k}\right)^{2} E_{A_{i}}\left[\frac{N_{0} B}{p_{i, k}}\right]} \\
\frac{\partial^{2} \mathrm{C}\left(p_{i, k}, \underline{\phi}_{i, k}\right)}{\partial p_{i, k}^{2}}=\frac{\underline{\phi}_{i, k}}{\theta_{i}\left(p_{i, k}\right)^{2} E_{A_{i}}\left[\frac{N_{0} B}{p_{i, k}}\right]^{2}}\left(e^{-\frac{2 N_{0} B}{p_{i, k}}} p_{i, k}\right. \\
-e^{-\frac{N_{0} B}{p_{i, k}}\left(N_{0} B+\left(2-A_{i}\right) p_{i, k}\right) E_{A_{i}}\left[\frac{N_{0} B}{p_{i, k}}\right]} \\
\left.-\left(2 N_{0} B+A_{i} p_{i, k}\right) E_{A_{i}}\left[\frac{N_{0} B}{p_{i, k}}\right]^{2}\right)
\end{gathered}
$$

De acordo com o teorema 1.10 na página 11 do trabalho de (BERMAN; Shaked-Monderer, 2003), os seguintes enunciados são equivalentes:

1. $\mathbf{H}_{\mathrm{C}}$ é uma matriz semidefinida negativa;

2. Todos os menores principais ${ }^{14}$ de $\mathbf{H}_{\mathrm{C}}$ são não positivos;

Portanto, a não positividade dos dois menores principais de $\mathbf{H}_{\mathrm{C}}$ é suficiente para demonstrar que $\mathbf{H}_{\mathrm{C}}$ é semidefinida negativa. Sendo assim, considere os dois menores principais da matriz $\mathbf{H}_{\mathrm{C}}$

$$
\begin{aligned}
& \frac{\partial^{2} \mathrm{C}\left(p_{i, k}, \underline{\phi}_{i, k}\right)}{\partial p_{i, k}^{2}} \\
& -\left(\frac{\partial^{2} \mathrm{C}\left(p_{i, k}, \underline{\phi}_{i, k}\right)}{\partial \underline{\phi}_{i, k} \partial p_{i, k}}\right)\left(\frac{\partial^{2} \mathrm{C}\left(p_{i, k}, \underline{\phi}_{i, k}\right)}{\partial p_{i, k} \partial \underline{\phi}_{i, k}}\right)=-\left(\frac{\partial^{2} \mathrm{C}\left(p_{i, k}, \underline{\phi}_{i, k}\right)}{\partial \underline{\phi}_{i, k} \partial p_{i, k}}\right)^{2}
\end{aligned}
$$

De fato o segundo menor principal (4.97) é não positivo. Determinar a não positividade do primeiro menor principal (4.96), porém, é uma tarefa difícil. Considere, sem perda da generalidade, que $\phi_{i, k}=1$. A figura 28 apresenta a região para os parâmetros $A_{i}, N_{0} B$ e $p_{i, k}$ onde o menor principal é não positivo.

Isto significa que, para uma coleção razoável de valores numéricos práticos de

\footnotetext{
${ }^{14}$ Os menores principais de uma matriz quadrada são os determinantes de todas as submatrizes obtidas pela remoção de uma coluna $i$ e uma linha $j$ da matriz original tal que $i=j$, além do determinante da matriz original.
} 


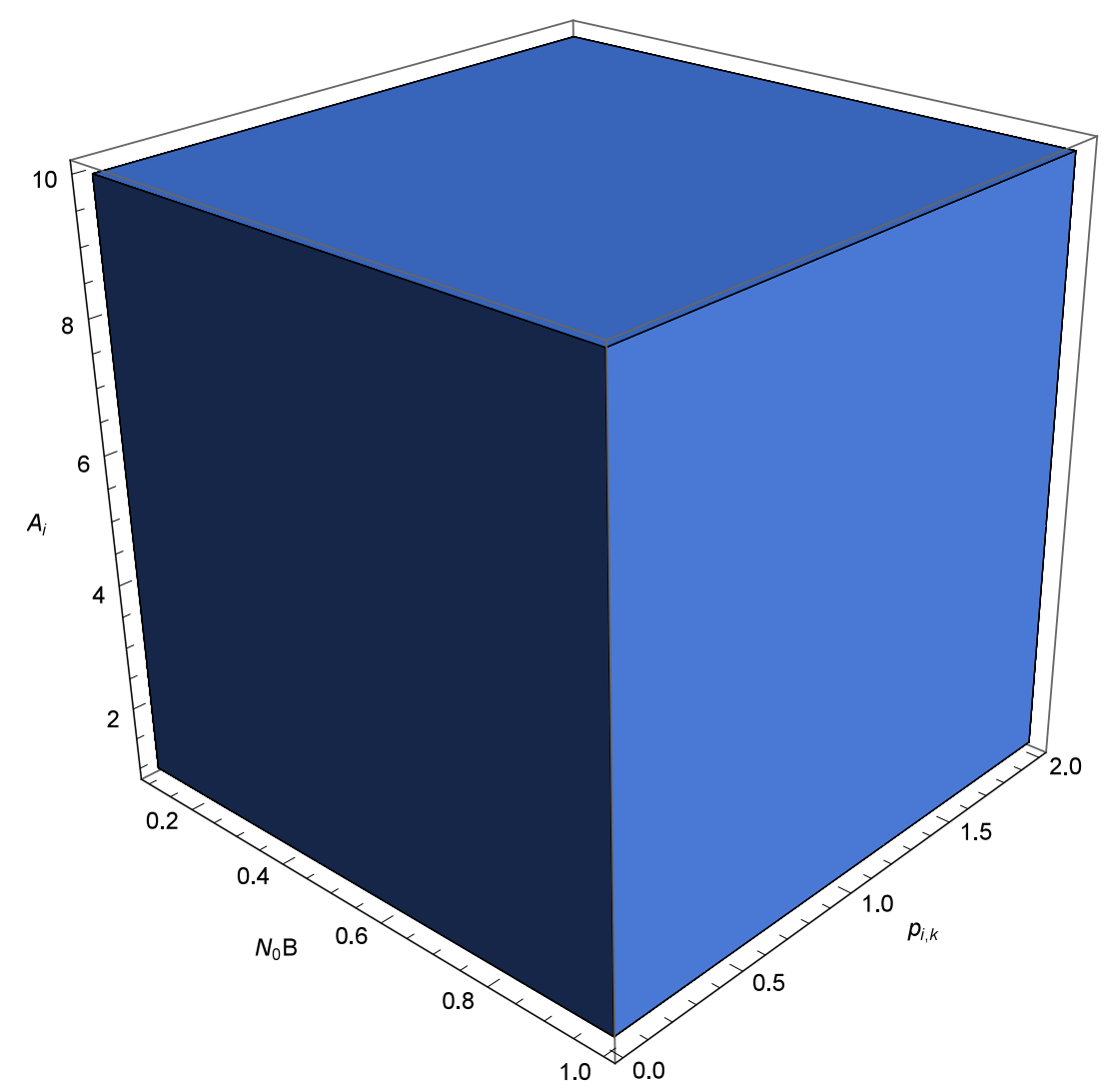

Figura 28: Região do espaço $\left\{A_{i} \times N_{0} \times p_{i, k}\right\}$ onde o menor principal (4.96) da matriz Hessiana da função $\mathrm{C}$ é não positivo.

$p_{i, k}, A_{i}$ e $N_{0}$ o menor principal de $\mathbf{H}_{\mathrm{C}}$ é não positivo.

Desta forma, a matriz Hessiana de c é semidefinida negativa para um conjunto de parâmetros encontrados em cenários práticos de telecomunicações. Sendo assim, de acordo com a condição de segunda ordem para a concavidade de funções, apresentada no Teorema 14 no Apêndice A, isto implica na concavidade de C. Finalmente, de acordo com (BOYD; VANDENBERGHE, 2004, Página 79) a operação de soma ponderada não negativa de funções côncavas é uma função côncava. Portanto, uma vez que C(·) em (4.90) é côncava, então:

$$
\underline{\mathcal{C}}_{\mathrm{e}}(\boldsymbol{\theta}, \underline{\boldsymbol{\phi}}, \mathbf{P})=\sum_{i=1}^{U} \sum_{k=1}^{N} \mathrm{C}\left(p_{i, k}, \underline{\phi}_{i, k}\right)
$$

a função da capacidade efetiva do sistema $\underline{\mathcal{C}}_{\mathrm{e}}(\boldsymbol{\theta}, \underline{\boldsymbol{\phi}}, \mathbf{P})$ é côncava em $\underline{\boldsymbol{\phi}}$ e $\mathbf{P}$. 
Note que o problema côncavo (4.88) satisfaz a condição de Slater (apresentada na definição 18), i.e. existe um $p_{i, k}$ e $\underline{\phi}_{i, k}$ que satisfazem as condições (C.1), (C.2) e (C.3) de forma estrita (SLATER, 1950). Logo, é possível resolver o problema dual de (4.88) para obter a solução primal com gap de dualidade $\mathcal{G}$ nulo. Desta forma, define-se o Lagrangiano em $\mathbf{P}$ e $\underline{\phi}$ do problema de otimização (4.88):

$$
\begin{aligned}
\mathcal{L}(\mathbf{P}, \boldsymbol{\phi}, \boldsymbol{\nu}) & =\sum_{i=1}^{U} \sum_{k=1}^{N}-\frac{\phi_{i, k}}{\theta_{i}} \log \left(\frac{N_{0} B}{p_{i, k}} e^{\frac{N_{0} B}{p_{i, k}}} E_{A_{i}}\left[\frac{N_{0} B}{p_{i, k}}\right]\right) \\
& +\sum_{i=1}^{U} \nu_{i}\left(\sum_{k=1}^{N}-\frac{\phi_{i, k}}{\theta_{i}} \log \left(\frac{N_{0} B}{p_{i, k}} e^{\frac{N_{0} B}{p_{i, k}}} E_{A_{i}}\left[\frac{N_{0} B}{p_{i, k}}\right]\right)-\mathcal{C}_{\mathrm{e}}^{i, \min }\right) \\
& +\nu_{0}\left(P_{\max }-\sum_{i=1}^{U} \sum_{k=1}^{N} \underline{\phi}_{i, k} p_{i, k}\right)
\end{aligned}
$$

onde $\boldsymbol{\nu}=\left[\nu_{0}, \nu_{1}, \ldots, \nu_{U}\right]$ é o vetor de variáveis duais. Adicionalmente, a seguinte relação é verdadeira ${ }^{15}$ :

$$
\underset{\boldsymbol{\nu}}{\arg \min } \sup _{\mathbf{P}, \underline{\boldsymbol{\phi}}} \mathcal{L}(\mathbf{P}, \underline{\boldsymbol{\phi}}, \nu) \equiv \underset{\mathbf{P}, \underline{\boldsymbol{\phi}}}{\arg \max } \quad \underline{\mathcal{C}}_{\mathrm{e}}(\boldsymbol{\theta}, \underline{\boldsymbol{\phi}}, \mathbf{P})
$$

Considerando a definição (4.99), a relação em (4.100) é desenvolvida,

$$
\begin{array}{r}
\sup _{\mathbf{P}, \underline{\boldsymbol{\phi}}} \mathcal{L}(\mathbf{P}, \underline{\boldsymbol{\phi}}, \boldsymbol{\nu})=\underset{\mathbf{P}, \underline{\boldsymbol{\phi}}}{\arg \max } \sum_{i=1}^{U} \sum_{k=1}^{N}-\frac{\underline{\phi}_{i, k}}{\theta_{i}} \log \left(\frac{N_{0} B}{p_{i, k}} e^{\frac{N_{0} B}{p_{i, k}}} E_{A_{i}}\left[\frac{N_{0} B}{p_{i, k}}\right]\right) \\
+\sum_{i=1}^{U} \nu_{i}\left(\sum_{k=1}^{N}-\frac{\underline{\phi}_{i, k}}{\theta_{i}} \log \left(\frac{N_{0} B}{p_{i, k}} e^{\frac{N_{0} B}{p_{i, k}}} E_{A_{i}}\left[\frac{N_{0} B}{p_{i, k}}\right]\right)-\mathcal{C}_{\mathrm{e}}^{i, \min }\right) \\
+\nu_{0}\left(P_{\max }-\sum_{i=1}^{U} \sum_{k=1}^{N} \underline{\phi}_{i, k} p_{i, k}\right) \\
=\underset{\mathbf{P}, \underline{\boldsymbol{\phi}}}{\arg \max } \sum_{i=1}^{U} \sum_{k=1}^{N}\left[-\frac{\frac{\phi}{i, k}_{\theta_{i}}\left(\nu_{i}+1\right)}{\theta_{i}} \log \left(\frac{N_{0} B}{p_{i, k}} e^{\frac{N_{0} B}{p_{i, k}}} E_{A_{i}}\left[\frac{N_{0} B}{p_{i, k}}\right]\right)-\nu_{0} \underline{\phi}_{i, k} p_{i, k}\right]
\end{array}
$$

\footnotetext{
${ }^{15}$ Esta relação foi estabelecida utilizando um problema convexo genérico no capítulo 3 (Veja a relação 3.40 ) e aqui é estendido para o problema (4.88).
} 
e leva à seguinte conclusão: o problema dual,

$$
\underset{\boldsymbol{\nu}}{\arg \min } \sup _{\mathbf{P}, \underline{\boldsymbol{\phi}}} \mathcal{L}(\mathbf{P}, \underline{\boldsymbol{\phi}}, \boldsymbol{\nu})
$$

pode ser solucionado resolvendo-se $U N$ subproblemas da forma:

$$
\underset{p_{i, k}, \underline{\phi}_{i, k}}{\arg \max }-\left[\nu_{0} \underline{\phi}_{i, k} p_{i, k}+\frac{\underline{\phi}_{i, k}\left(\nu_{i}+1\right)}{\theta_{i}} \log \left(\frac{N_{0} B}{p_{i, k}} e^{\frac{N_{0} B}{p_{i, k}}} E_{A_{i}}\left[\frac{N_{0} B}{p_{i, k}}\right]\right)\right]
$$

e, posteriormente, atualizando-se o vetor de variáveis duais $\boldsymbol{\nu}$. Uma vez que o problema (4.103) está na forma côncava padrão é possível utilizar as codições de KKT (Teorema 4) para encontrar a solução ótima. Sendo assim, para um vetor fixo $\boldsymbol{\nu}$ a alocação de potência para o usuário $i$ na $k$-ésima subportadora pode ser obtida através de:

$$
\left.\frac{\partial \mathcal{L}(\mathbf{P}, \underline{\boldsymbol{\phi}}, \boldsymbol{\nu})}{\partial p_{i, k}}\right|_{p_{i, k}=p_{i, k}^{*}}=0
$$

quando $\underline{\phi}_{i, k}=1$. Esta condição é satisfeita quando:

$$
-\nu_{0}\left(p_{i, k}\right)^{2}+\frac{p_{i, k}\left(\nu_{i}+1\right)}{\theta_{i}}+\frac{N_{0} B\left(\nu_{i}+1\right)}{\theta_{i}}\left(1-\frac{E_{A_{i}-1}\left[\frac{N_{0} B}{p_{i, k}}\right]}{E_{A_{i}}\left[\frac{N_{0} B}{p_{i, k}}\right]}\right)=0
$$

O ponto que satisfaz (4.105) pode ser computado através do método de Newton.

Uma vez que a potência de transmissão ótima tenha sido calculada, a alocação de subportadoras pode ser determinada usando condições de primeira ordem no Lagrangiano, i.e.

$$
\begin{aligned}
\frac{\partial \mathcal{L}(\mathbf{P}, \underline{\boldsymbol{\phi}}, \boldsymbol{\nu})}{\partial \underline{\phi}_{i, k}}= & -\frac{\left(\nu_{i}+1\right)}{\theta_{i}} \log \left(\frac{N_{0} B}{p_{i, k}} e^{\frac{N_{0} B}{p_{i, k}}} E_{A_{i}}\left[\frac{N_{0} B}{p_{i, k}}\right]\right)-\nu_{0} p_{i, k} \\
& =\Phi_{i, k} \begin{cases}<0 & \text { se } \underline{\phi}_{i, k}^{*}=0, \\
=0 & \text { se } \underline{\phi}_{i, k}^{*} \in(0,1), \\
>0 & \text { se } \underline{\phi}_{i, k}^{*}=1\end{cases}
\end{aligned}
$$

Note que em (4.106) a derivada é independente do valor de $\underline{\phi}_{i, k}$ e portanto o 
seu valor indica a taxa de variação do Lagrangiano, ou ainda, que: (1) a solução (valor ótimo) ocorre nos limites da região factível e portanto o Lagrangiano deve ser decrescente dentro da região factível, i.e. o intervalo $[0,1] ;(2)$ a derivada é nula e, portanto, a alocação de subportadora ótima é obtida no intervalo $[0,1]$. Uma vez que apenas um usuário pode transmitir em cada subportadora a seguinte condição pode ser aplicada de forma iterativa dentro do algoritmo de alocação de recursos com intuito de alocar a subportadora ao usuário que apresenta a maior taxa de variação do Lagrangiano, matematicamente:

$$
\phi_{i, k}= \begin{cases}1, & \text { se } \Phi_{i, k}=\max \left[\boldsymbol{\Phi}_{k}\right] \\ 0, & \text { caso contrário }\end{cases}
$$

onde $\boldsymbol{\Phi}_{k}=\left[\Phi_{1, k}, \ldots, \Phi_{U, k}\right]$.

As variáveis duais podem ser atualizadas utilizando-se o método do subgrandiente, conforme:

$$
\begin{gathered}
\nu_{0}[t+1]=\left[\nu_{0}[t]-\alpha_{\nu_{0}}[t]\left(\frac{\partial \mathcal{L}(\mathbf{P}, \underline{\boldsymbol{\phi}}, \boldsymbol{\nu})}{\partial \nu_{0}}\right)\right]^{+} \\
=\left[\nu_{0}[t]-\alpha_{\nu_{0}}[t]\left(P_{\max }-\sum_{i=1}^{U} \sum_{k=1}^{N} \underline{\phi}_{i, k} p_{i, k}\right)\right]^{+} \\
\nu_{i}[t+1]=\left[\nu_{i}[t]-\alpha_{\nu_{i}}[t]\left(\frac{\partial \mathcal{L}\left(\mathbf{P}, \boldsymbol{\phi}, \boldsymbol{\nu}, \nu_{0}\right)}{\partial \nu_{i}}\right)\right]^{+} \\
=\left[\nu_{i}[t]-\alpha_{\nu_{i}}[t]\left(\sum_{k=1}^{N}-\frac{\underline{\phi}_{i, k}}{\theta_{i}} \log \left(\frac{N_{0} B}{p_{i, k}} e^{\frac{N_{0} B}{p_{i, k}}} E_{A_{i}}\left[\frac{N_{0} B}{p_{i, k}}\right]\right)-\mathcal{C}_{\mathrm{e}}^{i, \min }\right)\right]^{+}
\end{gathered}
$$

para $i=1, \ldots, U$, onde $t$ é o indexador de iteração, $\alpha_{\nu_{j}}$ é o step-size para a variável $\nu_{j}$ no método do subgradiente e $[\cdot]^{+}=\max (0, \cdot)$.

O pseudocódigo para a maximização da capacidade efetiva do enlace direto 
de um sistema OFDMA é apresentado no algoritmo 4.4.

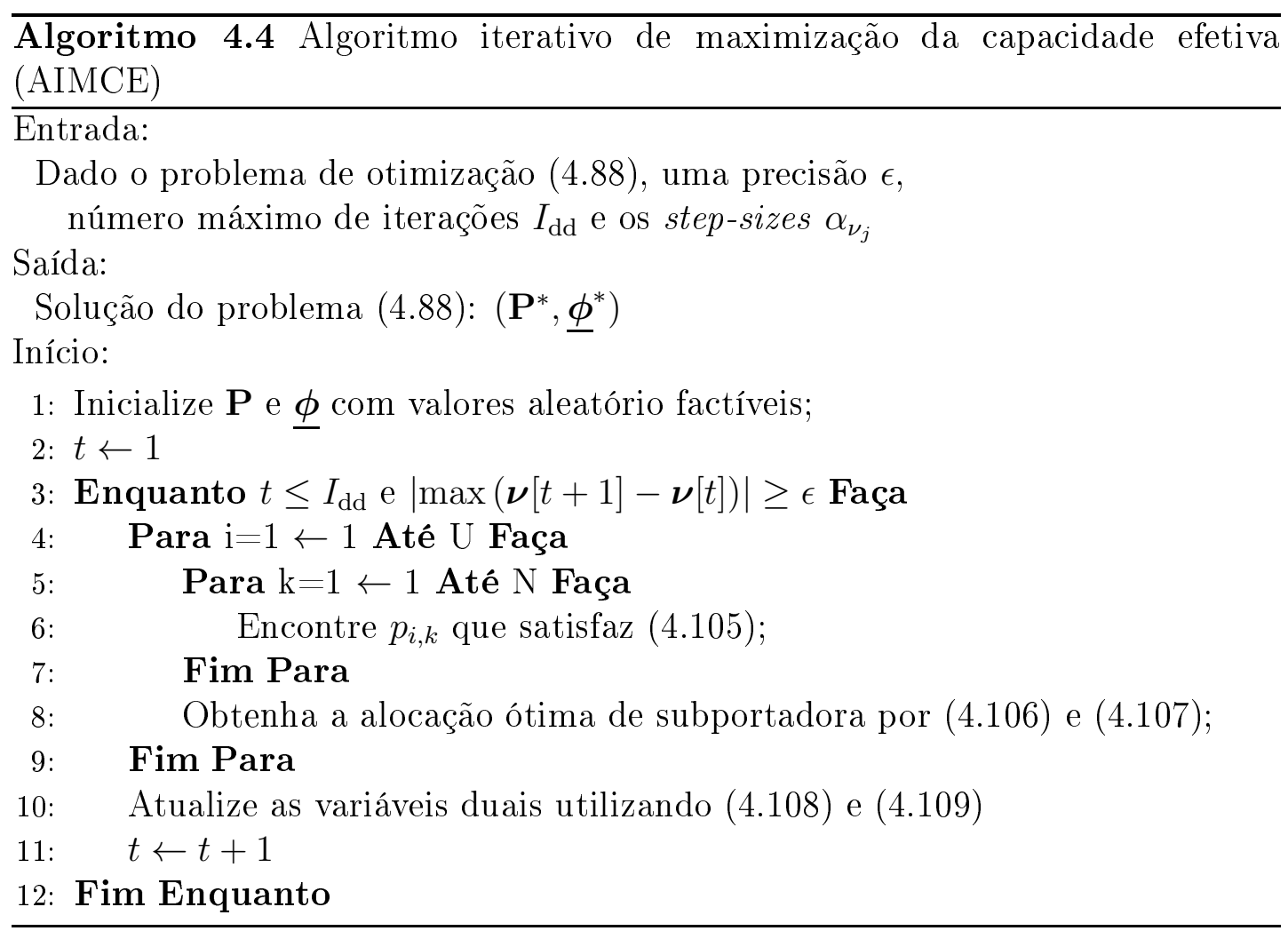

\subsubsection{Maximização da Eficiência Energética Efetiva em Sis- temas OFDMA}

O conceito de eficiência energética efetiva está diretamente ligado à capacidade efetiva do sistema. A eficiência energética efetiva é a máxima taxa de transmissão por unidade de energia que um sistema pode prover considerando um atraso máximo tolerável e uma probabilidade de violação deste atraso, ambos, representados através de um expoente de qualidade de serviço estatística $\theta_{i}$. Matematicamante a eficiência energética efetiva foi apresentada na equação (2.87) e é convenientemente reproduzida abaixo,

$$
\xi_{\mathrm{e}}=\frac{\sum_{i=1}^{U} \sum_{k=1}^{N}-\frac{\phi_{i, k}}{\theta_{i}} \log \left(\frac{N_{0} B}{p_{i, k}} e^{\frac{N_{0} B}{p_{i, k}}} E_{A_{i}}\left[\frac{N_{0} B}{p_{i, k}}\right]\right)}{T\left(P_{\mathrm{C}}+\sum_{i=1}^{U} \sum_{k=1}^{N} \varrho \phi_{i, k} p_{i, k}+\sum_{i=1}^{U} \sum_{k=1}^{N}(\vartheta+v) \phi_{i, k} r_{i, k}\right)}
$$


Uma vez que neste trabalho o consumo de potência de transmissão e dos circuitos no transmissor/receptor são considerados independentes das taxas de transmissão, i.e., $\vartheta=v=0$, a equação acima pode ser simplificada,

$$
\xi_{\mathrm{e}}=\frac{\mathcal{C}_{\mathrm{e}}(\boldsymbol{\theta}, \boldsymbol{\phi}, \mathbf{P})}{P_{\mathrm{T}}(\boldsymbol{\phi}, \mathbf{P})}=\frac{\sum_{i=1}^{U} \sum_{k=1}^{N}-\frac{\phi_{i, k}}{\theta_{i}} \log \left(\frac{N_{0} B}{p_{i, k}} e^{\frac{N_{0} B}{p_{i, k}}} E_{A_{i}}\left[\frac{N_{0} B}{p_{i, k}}\right]\right)}{T\left(P_{\mathrm{C}}+\sum_{i=1}^{U} \sum_{k=1}^{N} \varrho \phi_{i, k} p_{i, k}\right)}
$$

Sendo assim, o problema de otimização que busca maximizar a eficiência energética efetiva do enlace direto de sistemas OFDMA com restrições de capacidade efetiva mínima a ser garantida e potência máxima de transmissão é descrito formalmente como:

$$
\begin{aligned}
& \text { maximizar } \quad \xi_{\mathrm{e}}=\frac{\sum_{i=1}^{U} \sum_{k=1}^{N}-\frac{\phi_{i, k}}{\theta_{i}} \log \left(\frac{N_{0} B}{p_{i, k}} e^{\frac{N_{0} B}{p_{i, k}}} E_{A_{i}}\left[\frac{N_{0} B}{p_{i, k}}\right]\right)}{T\left(P_{\mathrm{C}}+\sum_{i=1}^{U} \sum_{k=1}^{N} \varrho \phi_{i, k} p_{i, k}\right)} \\
& \text { sujeito à } \quad(\text { C. } 1): \sum_{k=1}^{N}-\frac{\phi_{i, k}}{\theta_{i}} \log \left(\frac{N_{0} B}{p_{i, k}} e^{\frac{N_{0} B}{p_{i, k}}} E_{A_{i}}\left[\frac{N_{0} B}{p_{i, k}}\right]\right) \geq \mathcal{C}_{\mathrm{e}}^{i, \text { min }}, \forall i \\
& (\text { C. } 2): \sum_{i=1}^{U} \sum_{k=1}^{N} \phi_{i, k} p_{i, k} \in\left[0, P_{\max }\right] \\
& (\text { C. } 3): \sum_{i=1}^{U} \phi_{i, k} \leq 1, \quad \forall k=1, \ldots, N \\
& \text { (C.4) }: \phi_{i, k} \in\{0,1\}, \quad \forall i=1, \ldots, U \text { e } k=1, \ldots, N \\
& \text { (C.5) }: \sum_{i=1}^{U} N_{i}=N, \quad N_{i} \in \mathbb{Z}_{+}
\end{aligned}
$$

Note que a condição (C.1) é referente à capacidade efetiva mínima a ser garantida para cada usuário, (C.2) é a restrição de potência máxima de transmissão, (C.3) garante que apenas um usuário transmita por subportadora, (C.4) indica que a variável de alocação de subportadora $\phi_{i, k}$ é binária e, finalmente, (C.5), 
onde $N_{i}$ é o número de subportadoras alocadas para o usuário $i$, garante que todas as subportadoras estão ativas.

O problema de otimização acima é do tipo inteiro misto e portanto, conforme visto na seção anterior, é razoável relaxar o problema para a sua forma contínua, uma vez que este é um limite superior para o problema original (BOYD; VANDENBERGHE, 2004). Desta forma, considerando $\underline{\phi}_{i, k} \in[0,1]$ o seguinte problema de otimização contínuo será tratado:

$$
\begin{aligned}
\text { maximizar } \quad \underline{\xi}_{\mathrm{e}}=\frac{\sum_{i=1}^{U} \sum_{k=1}^{N}-\frac{\underline{\phi}_{i, k}}{\theta_{i}} \log \left(\frac{N_{0} B}{p_{i, k}} e^{\frac{N_{0} B}{p_{i, k}}} E_{A_{i}}\left[\frac{N_{0} B}{p_{i, k}}\right]\right)}{T\left(P_{\mathrm{C}}+\sum_{i=1}^{U} \sum_{k=1}^{N} \varrho \underline{\phi}_{i, k} p_{i, k}\right)} \\
\text { sujeito à } \quad(\mathrm{C} .1): \sum_{k=1}^{N}-\frac{\underline{\phi}_{i, k}}{\theta_{i}} \log \left(\frac{N_{0} B}{p_{i, k}} e^{\frac{N_{0} B}{p_{i, k}}} E_{A_{i}}\left[\frac{N_{0} B}{p_{i, k}}\right]\right) \geq \mathcal{C}_{\mathrm{e}}^{i, \min }, \forall i \\
(\mathrm{C} .2): \sum_{i=1}^{U} \sum_{k=1}^{N} \underline{\phi}_{i, k} p_{i, k} \in\left[0, P_{\max }\right] \\
(\mathrm{C} .3): \sum_{i=1}^{U} \underline{\phi}_{i, k} \leq 1, \quad \forall k=1, \ldots, N \\
\text { (C.4) }: \underline{\phi}_{i, k} \in[0,1], \quad \forall i=1, \ldots, U \text { e } k=1, \ldots, N \\
\text { (C.5) }: \sum_{i=1}^{U} N_{i}=N, \quad N_{i} \in \mathbb{R}_{+}
\end{aligned}
$$

Uma vez que a eficiência energética efetiva $\underline{\xi}_{\mathrm{e}}$ é a razão entre uma função côncava e uma função afim o seguinte lema é apresentado:

Lema 11 (Quase Concavidade da Eficiência Energética Efetiva). A função da eficiência energética efetiva:

$$
\underline{\xi}_{e}=\frac{\sum_{i=1}^{U} \sum_{k=1}^{N}-\frac{\underline{\phi}_{i, k}}{\theta_{i}} \log \left(\frac{N_{0} B}{p_{i, k}} e^{\frac{N_{0} B}{p_{i, k}}} E_{A_{i}}\left[\frac{N_{0} B}{p_{i, k}}\right]\right)}{T\left(P_{\mathrm{C}}+\sum_{i=1}^{U} \sum_{k=1}^{N} \varrho \underline{\phi}_{i, k} p_{i, k}\right)}
$$

é quase côncava em $\mathbf{P}$ e $\underline{\phi}$. 
Demonstração. Do lema 10 segue que o numerador de $\underline{\xi}_{\mathrm{e}}$ é uma função côncava. O denominador, por sua vez, é uma função afim positiva pois $T>0, P_{\mathrm{C}}>0$ e $\varrho>0$. Logo, de acordo com (AVRIEL et al., 2010, Tabela 5.5 na Página 165) esta razão é uma função quase côncava.

Sendo assim, é possível aplicar o método de Dinkelbach ao problema (4.113). O problema de otimização paramétrico inerente à (4.113), considerando o parâmetro $q$ fixo, é,

$$
\begin{aligned}
\operatorname{maximizar} \quad & \mathcal{C}_{\mathrm{e}}(\underline{\boldsymbol{\phi}}, \mathbf{P})-q P_{\mathrm{T}}(\underline{\boldsymbol{\phi}}, \mathbf{P}) \\
\text { sujeito à } \quad & (\mathrm{C} .1): \sum_{k=1}^{N}-\frac{\underline{\phi}_{i, k}}{\theta_{i}} \log \left(\frac{N_{0} B}{p_{i, k}} e^{\frac{N_{0} B}{p_{i, k}}} E_{A_{i}}\left[\frac{N_{0} B}{p_{i, k}}\right]\right) \geq \mathcal{C}_{\mathrm{e}}^{i, \mathrm{~min}}, \forall i \\
& (\mathrm{C} .2): \sum_{i=1}^{U} \sum_{k=1}^{N} \underline{\phi}_{i, k} p_{i, k} \in\left[0, P_{\max }\right] \\
& (\mathrm{C} .3): \sum_{i=1}^{U} \underline{\phi}_{i, k} \leq 1, \quad \forall k=1, \ldots, N \\
& (\mathrm{C} .4): \underline{\phi}_{i, k} \in[0,1], \quad \forall i=1, \ldots, U \text { e } k=1, \ldots, N \\
& (\mathrm{C} .5): \sum_{i=1}^{U} N_{i}=N, \quad N_{i} \in \mathbb{R}_{+}
\end{aligned}
$$

onde,

$$
\begin{aligned}
& \mathcal{C}_{\mathrm{e}}(\underline{\boldsymbol{\phi}}, \mathbf{P})=\sum_{i=1}^{U} \sum_{k=1}^{N}-\frac{\underline{\phi}_{i, k}}{\theta_{i}} \log \left(\frac{N_{0} B}{p_{i, k}} e^{\frac{N_{0} B}{p_{i, k}}} E_{A_{i}}\left[\frac{N_{0} B}{p_{i, k}}\right]\right) \\
& P_{\mathrm{T}}(\underline{\phi}, \mathbf{P})=T\left(P_{\mathrm{C}}+\sum_{i=1}^{U} \sum_{k=1}^{N} \varrho \underline{\phi}_{i, k} p_{i, k}\right)
\end{aligned}
$$

A função $F(q)$ é definida como:

$$
F(q)=\max _{\mathbf{P} \in \mathcal{P}, \underline{\phi} \in \underline{\Omega}}\left[\mathcal{C}_{\mathrm{e}}(\underline{\phi}, \mathbf{P})-q P_{\mathrm{T}}(\underline{\phi}, \mathbf{P})\right]
$$

onde $\mathcal{P}$ é o domínio de potência do problema de otimização definido na equação (4.84) e $\underline{\Omega}$ o domínio de alocação de subportadoras do problema de otimização 
definido na equação (4.86).

O pseudocódigo do algoritmo iterativo de Dinkelbach para maximização da eficiência energética efetiva no enlace direto de sistemas de múltiplo acesso por divisão ortogonal de frequência é apresentado no Algoritmo 4.5.

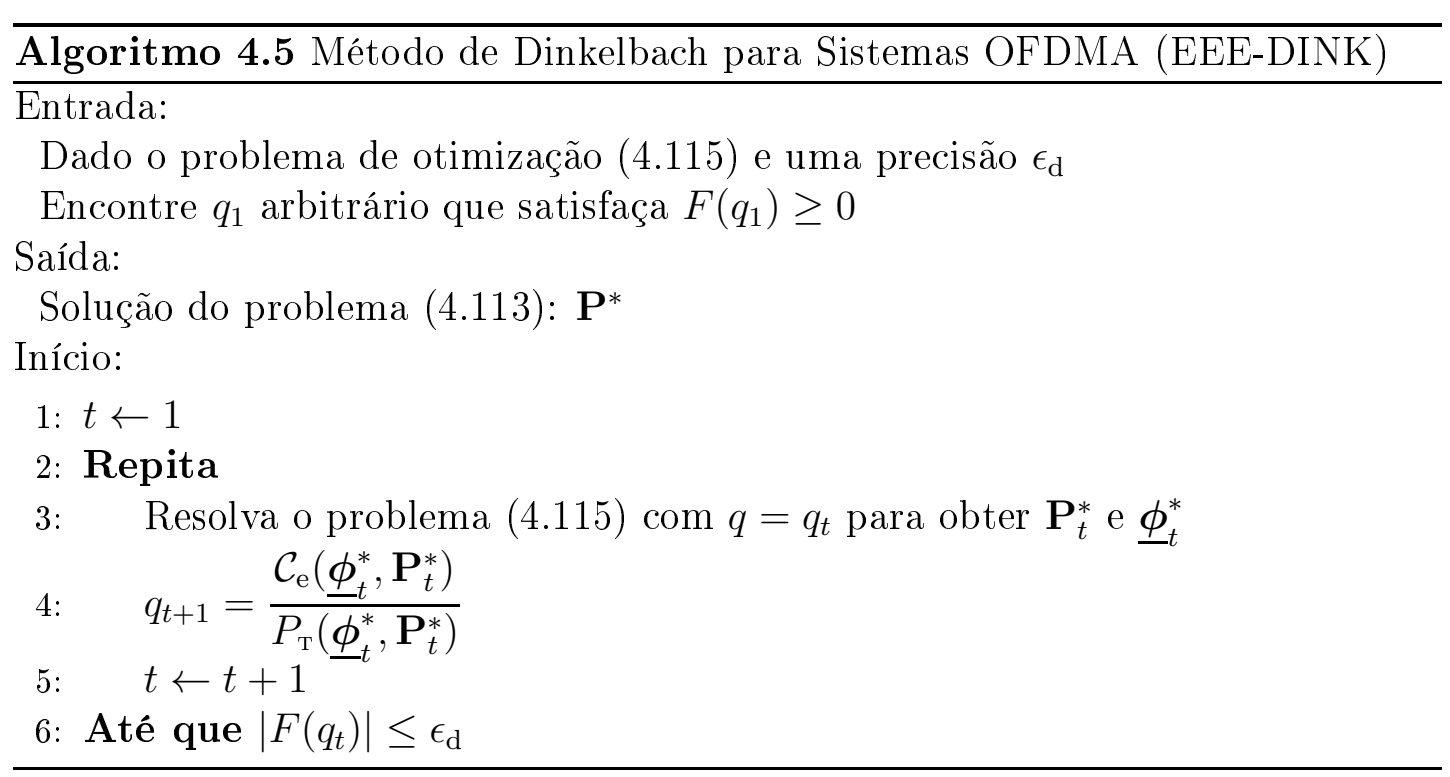

Note que o problema paramétrico em (4.115) possuí as mesmas restrições do problema de maximização da capacidade efetiva em (4.88), e portanto, satisfaz a condição de Slater ${ }^{16}$. Desta forma, é possível utilizar o método de decomposição dual de Lagrange para resolver o passo 3 no algoritmo iterativo de Dinkelbach (algoritmo 4.5).

O Lagrangiano do problema (4.115) em relação a $\mathbf{P}$ e $\underline{\phi}$ é:

$$
\begin{aligned}
\mathcal{L}(\mathbf{P}, \boldsymbol{\phi}, \boldsymbol{\nu})= & \sum_{i=1}^{U} \sum_{k=1}^{N}-\frac{\underline{\phi}_{i, k}}{\theta_{i}} \log \left(\frac{N_{0} B}{p_{i, k}} e^{\frac{N_{0} B}{p_{i, k}}} E_{A_{i}}\left[\frac{N_{0} B}{p_{i, k}}\right]\right) \\
& -q_{t}\left[T\left(P_{\mathrm{C}}+\varrho \sum_{i=1}^{U} \sum_{k=1}^{N} \underline{\phi}_{i, k} p_{i, k}\right)\right] \\
& +\sum_{i=1}^{U} \nu_{i}\left(\sum_{k=1}^{N}-\frac{\phi_{i, k}}{\theta_{i}} \log \left(\frac{N_{0} B}{p_{i, k}} e^{\frac{N_{0} B}{p_{i, k}}} E_{A_{i}}\left[\frac{N_{0} B}{p_{i, k}}\right]\right)-\mathcal{C}_{\mathrm{e}}^{i, \min }\right) \\
& +\nu_{0}\left(P_{\max }-\sum_{i=1}^{U} \sum_{k=1}^{N} \underline{\phi}_{i, k} p_{i, k}\right)
\end{aligned}
$$

\footnotetext{
${ }^{16}$ A condição de Slater foi apresentada na definição 18
} 
onde $\boldsymbol{\nu}=\left[\nu_{0}, \nu_{1}, \ldots, \nu_{U}\right]$ é o vetor de variáveis duais. Adicionalmente, a seguinte relação é verdadeira ${ }^{17}$ :

$$
\underset{\boldsymbol{\nu}}{\arg \min } \sup _{\mathbf{P}, \boldsymbol{\phi}} \mathcal{L}(\mathbf{P}, \boldsymbol{\phi}, \boldsymbol{\nu}) \equiv \underset{\mathbf{P}, \boldsymbol{\phi}}{\arg \max } \mathcal{C}_{\mathrm{e}}(\boldsymbol{\phi}, \mathbf{P})-q P_{\mathrm{T}}(\boldsymbol{\phi}, \mathbf{P})
$$

Considerando a definição (4.119), a relação em (4.120) é desenvolvida conforme,

$$
\begin{aligned}
\sup _{\mathbf{P}, \boldsymbol{\phi}} & \mathcal{L}(\mathbf{P}, \boldsymbol{\phi}, \boldsymbol{\nu})=\underset{\mathbf{P}, \boldsymbol{\phi}}{\arg \max } \sum_{i=1}^{U} \sum_{k=1}^{N}-\frac{\underline{\phi}_{i, k}}{\theta_{i}} \log \left(\frac{N_{0} B}{p_{i, k}} e^{\frac{N_{0} B}{p_{i, k}}} E_{A_{i}}\left[\frac{N_{0} B}{p_{i, k}}\right]\right) \\
+ & \sum_{i=1}^{U} \sum_{k=1}^{N}-\frac{\nu_{i} \underline{\phi}_{i, k}}{\theta_{i}} \log \left(\frac{N_{0} B}{p_{i, k}} e^{\frac{N_{0} B}{p_{i, k}}} E_{A_{i}}\left[\frac{N_{0} B}{p_{i, k}}\right]\right)-\sum_{i=1}^{U} \nu_{i} \mathcal{C}_{\mathrm{e}}^{i, \min } \\
+ & {\left[\nu_{0} P_{\max }-\nu_{0}\left(\sum_{i=1}^{U} \sum_{k=1}^{N} \underline{\phi}_{i, k} p_{i, k}\right)-q_{t} T \varrho\left(\sum_{i=1}^{U} \sum_{k=1}^{N} \underline{\phi}_{i, k} p_{i, k}\right)-q_{t} T P_{\mathrm{C}}\right] }
\end{aligned}
$$

$$
=\underset{\mathbf{P}, \boldsymbol{\phi}}{\arg \max } \sum_{i=1}^{U} \sum_{k=1}^{N}\left[-\frac{\phi_{i, k}\left(\nu_{i}+1\right)}{\theta_{i}} \log \left(\frac{N_{0} B}{p_{i, k}} e^{\frac{N_{0} B}{p_{i, k}}} E_{A_{i}}\left[\frac{N_{0} B}{p_{i, k}}\right]\right)-\left(\nu_{0}+q_{t} T \varrho\right) \underline{\phi}_{i, k} p_{i, k}\right]
$$

e leva à seguinte conclusão: o problema dual,

$$
\underset{\boldsymbol{\nu}}{\arg \min } \sup _{\mathbf{P}, \boldsymbol{\phi}} \mathcal{L}(\mathbf{P}, \boldsymbol{\phi}, \boldsymbol{\nu})
$$

pode ser resolvido encontrando-se a solução de $U N$ problemas da forma,

$$
\underset{p_{i, k}, \underline{\varphi}_{i, k}}{\arg \max }\left[-\frac{\underline{\phi}_{i, k}\left(\nu_{i}+1\right)}{\theta_{i}} \log \left(\frac{N_{0} B}{p_{i, k}} e^{\frac{N_{0} B}{p_{i, k}}} E_{A_{i}}\left[\frac{N_{0} B}{p_{i, k}}\right]\right)-\left(\nu_{0}+q_{t} T \varrho\right) \underline{\phi}_{i, k} p_{i, k}\right]
$$

e, posteriormente, atualizando-se o vetor de variáveis duais $\boldsymbol{\nu}$. Novamente, uma vez que o problema (4.123) está na forma côncava padrão é possível utilizar as codições de KKT para encontrar a solução ótima. Sendo assim, para um vetor fixo $\boldsymbol{\nu}$ a alocação de potência para o usuário $i$ na $k$-ésima subportadora pode ser

\footnotetext{
${ }^{17}$ Esta relação foi estabelecida a partir de um problema convexo genérico no capítulo 3 (Veja a relação 3.40 ) e aqui é estendida para o problema (4.115).
} 
computada através de:

$$
\left.\frac{\partial \mathcal{L}(\mathbf{P}, \boldsymbol{\phi}, \boldsymbol{\nu})}{\partial p_{i, k}}\right|_{p_{i, k}=p_{i, k}^{*}}=0
$$

que é equivalente, considerando $\underline{\phi}_{i, k}=1$, a encontrar o ponto $p_{i, k}$ que satisfaz a seguinte igualdade,

$$
-\left(\nu_{0}+q_{t} T \varrho\right)\left(p_{i, k}\right)^{2}+\frac{p_{i, k}\left(\nu_{i}+1\right)}{\theta_{i}}+\frac{N_{0} B\left(\nu_{i}+1\right)}{\theta_{i}}\left(1-\frac{E_{A_{i}-1}\left[\frac{N_{0} B}{p_{i, k}}\right]}{E_{A_{i}}\left[\frac{N_{0} B}{p_{i, k}}\right]}\right)=0
$$

Uma vez que alocação de potência ótima foi determinada, a alocação de subportadoras é conduzida. Desta forma, a condição de otimalidade,

$$
\left.\frac{\partial \mathcal{L}\left(\mathbf{P}^{*}, \boldsymbol{\phi}, \boldsymbol{\nu}\right)}{\partial \underline{\phi}_{i, k}}\right|_{\underline{\phi}_{i, k}=\underline{\phi}_{i, k}^{*}}=0
$$

é utilizada para determinar quais usuários são alocados em quais subportadoras. Considere a derivada parcial do Lagrangiano em relação a $\underline{\phi}_{i, k}$, isto é,

$$
\begin{aligned}
\frac{\partial \mathcal{L}\left(\mathbf{P}^{*}, \boldsymbol{\phi}, \boldsymbol{\nu}\right)}{\partial \underline{\phi}_{i, k}}= & {\left[-\frac{\left(\nu_{i}+1\right)}{\theta_{i}} \log \left(\frac{N_{0} B}{p_{i, k}} e^{\frac{N_{0} B}{p_{i, k}}} E_{A_{i}}\left[\frac{N_{0} B}{p_{i, k}}\right]\right)-\left(\nu_{0}-q_{t} T \varrho\right) p_{i, k}\right] } \\
= & \Phi_{i, k} \begin{cases}<0 & \text { se } \underline{\phi}_{i, k}^{*}=0 \\
=0 & \text { se } \underline{\phi}_{i, k}^{*} \in(0,1) \\
>0 & \text { se } \underline{\phi}_{i, k}^{*}=1\end{cases}
\end{aligned}
$$

Note que assim como no caso do problema de maximização da capacidade efetiva, a derivada em relação à alocação de subportadora é independente do valor de $\underline{\phi}_{i, k}$ e portanto o seu valor representa a taxa de variação do Lagrangiano, ou ainda, indica que: (1) a solução (valor ótimo) ocorre nos limites da região factível e portanto o Lagrangiano deve ser decrescente dentro da região factível, i.e. o intervalo $[0,1] ;(2)$ a derivada é nula e, portanto, a alocação de subportadora ótima é obtida no intervalo $[0,1]$. Uma vez que apenas um usuário pode transmitir em cada subportadora é conveniente alocar a subportadora para o usuário que apresenta a maior taxa de variação do Lagrangiano. Sendo assim, a seguinte condição pode ser aplicada de forma iterativa dentro do algoritmo de alocação de 
recursos:

$$
\underline{\phi}_{i, k}= \begin{cases}1, & \text { se } \Phi_{i, k}=\max \left(\boldsymbol{\Phi}_{n}\right) \\ 0, & \text { caso contrário }\end{cases}
$$

As variáveis duais podem ser atualizadas utilizando-se o método do subgrandiente, conforme:

$$
\begin{gathered}
\nu_{0}[t+1]=\left[\nu_{0}[t]-\alpha_{\nu_{0}}[t]\left(\frac{\partial \mathcal{L}(\mathbf{P}, \underline{\boldsymbol{\phi}}, \boldsymbol{\nu})}{\partial \nu_{0}}\right)\right]^{+} \\
=\left[\nu_{0}[t]-\alpha_{\nu_{0}}[t]\left(P_{\max }-\sum_{i=1}^{U} \sum_{k=1}^{N} \underline{\phi}_{i, k} p_{i, k}\right)\right]^{+} \\
\nu_{i}[t+1]=\left[\nu_{i}[t]-\alpha_{\nu_{i}}[t]\left(\frac{\partial \mathcal{L}\left(\mathbf{P}, \boldsymbol{\phi}, \boldsymbol{\nu}, \nu_{0}\right)}{\partial \nu_{i}}\right)\right]^{+} \\
=\left[\nu_{i}[t]-\alpha_{\nu_{i}}[t]\left(\sum_{k=1}^{N}-\frac{\underline{\phi}_{i, k}}{\theta_{i}} \log \left(\frac{N_{0} B}{p_{i, k}} e^{\frac{N_{0} B}{p_{i, k}}} E_{A_{i}}\left[\frac{N_{0} B}{p_{i, k}}\right]\right)-\mathcal{C}_{\mathrm{e}}^{i, \min }\right)\right]^{+}
\end{gathered}
$$

para $i=1, \ldots, U$, onde $t$ é o indexador de iteração, $\alpha_{\nu_{j}}$ é o step-size para a variável $\nu_{j}$ no método do subgradiente e $[\cdot]^{+}=\max (0, \cdot)$. O algoritmo 4.6 apresenta o pseudocódigo para o procedimento baseado na decomposição dual de Lagrange, responsável por solucionar o problema paramétrico (4.115) no passo 3 do algoritmo iterativo de Dinkelach para o problema de maximização da eficiência energética efetiva no enlace direto de redes OFDMA (algoritmo 4.5). 


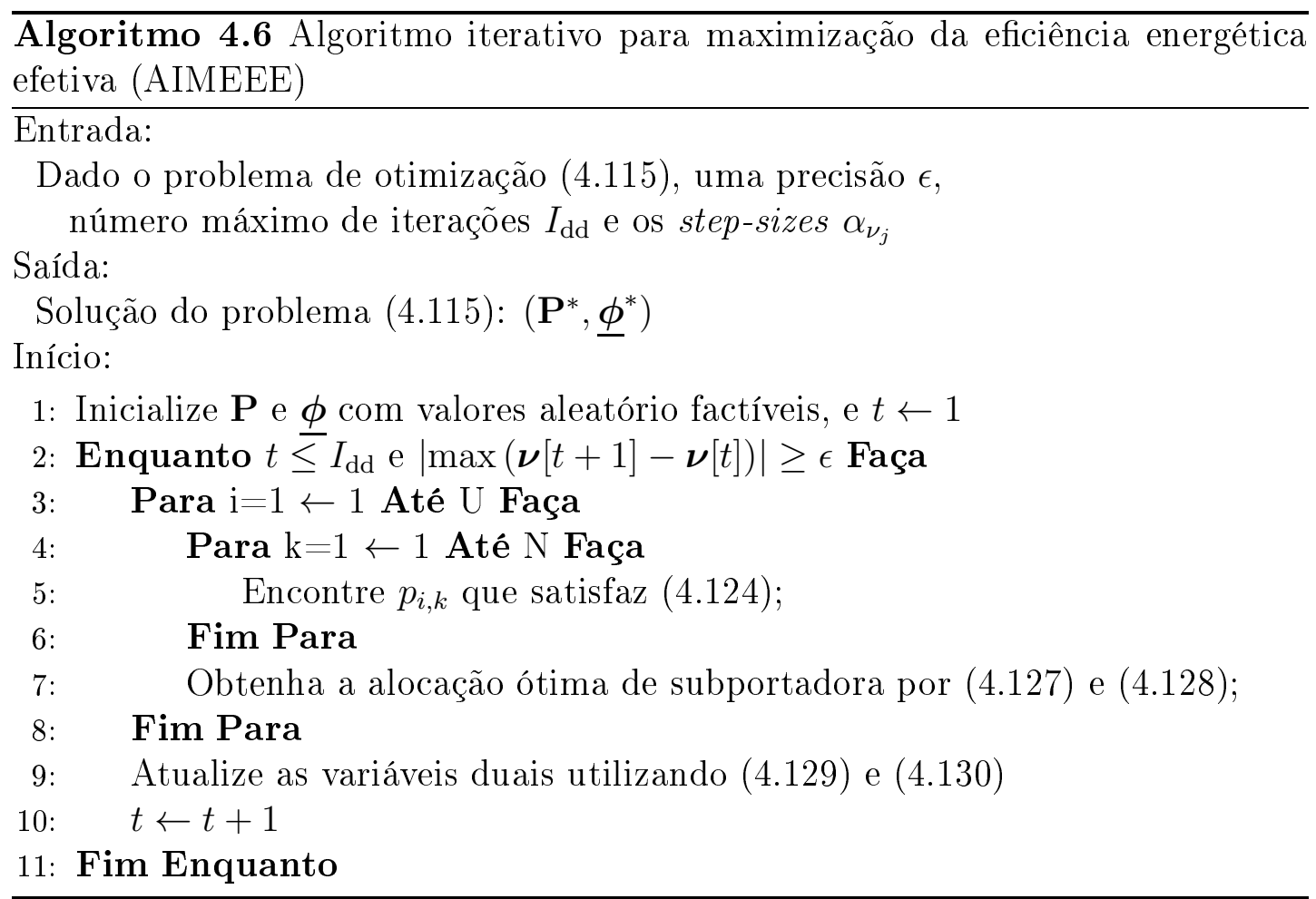




\section{RESULTADOS NUMÉRICOS DE SIMULAÇÃO PARA OS PROBLEMAS DE OTIMIZAÇÃO}

Com o intuito de facilitar a compreensão e análise dos resultados, este capítulo está subdivido em três grandes partes, relativas aos três principais problemas tratados neste trabalho de doutorado: a primeira seção apresenta os cenários de simulação e resultados numéricos para o problema de maximização da eficiência energética no enlace reverso de sistemas MC-DS/CDMA cooperativos ${ }^{1}$. A segunda seção apresenta o cenário e discute os resultados numéricos relacionados ao problema de maximização da capacidade efetiva no enlace direto de redes de múltiplo acesso por divisão de frequências ortogonais ${ }^{2}$. Finalmente, a terceira e última seção apresenta os cenários e resultados numéricos de simulação para o problema de maximização da eficiência energética efetiva do enlace direto de sistemas OFDMA ${ }^{3}$.

\subsection{Análise Numérica para o Problema de Maxi- mização da Eficiência Energética em Sistemas MC-DS/CDMA Cooperativos}

Foram apresentados no capítulo 4 seis formas distintas de solução para o problema de maximização da eficiência energética em redes MC-DS/CDMA coo-

\footnotetext{
${ }^{1}$ Problema descrito na seção 4.1.3.

${ }^{2}$ Problema descrito na seção 4.2.1.

${ }^{3}$ Problema descrito na seção 4.2.2.
} 
perativas considerando receptores multi-usuário lineares:

1. DinkOpt: Solução centralizada baseada no algoritmo de Dinkelbach utilizando programação convexa disciplinada (DINKELBACH, 1967; GRANT; BOYD, 2014);

2. EE-IWFA: Solução distribuída baseada em teoria de jogos com o controle de potência realizado pelo algoritmo iterativo de water-filling (SAMPAIO et al., 2014);

3. EE-VDPCA: Solução distribuída baseada em teoria de jogos com o controle de potência realizado pelo algoritmo distribuído de controle de potência utilizando o equilíbrio de Verhulst (SAMPAIO et al., 2014);

4. EE-MDPCA: Solução distribuída baseada em teoria de jogos com o controle de potência realizado pelo algoritmo distribuído de controle de potência utilizando o equilíbrio de Verhulst. O problema original é transformado em um problema uniportadora e a alocação de potência é feita de forma uniforme ao longo das subportadoras (SAMPAIO et al., 2014);

5. FA: Solução centralizada utilizando o algoritmo dos vaga-lumes (ADANYIA et al., 2015);

6. PSO: Solução centralizada utilizando o algoritmo de otimização por enxame de partículas;

Sendo assim, é conveniente dividir esta seção em duas partes: a primeira trata dos algoritmos distribuídos discutindo os seus resultados e a segunda trata dos algoritmos centralizados. Os cenário 1 e 2, descritos nas seções a seguir consideram um rede MC-DS/CDMA cooperativa cujos ativos (terminais móveis, retransmissor e estação rádio-base) estão geograficamente dispostos de acordo com a figura 
26. Os usuários são posicionados de forma aleatória considerando uma distribuição uniforme em toda a área de cobertura do retransmissor, conforme explicação na seção 4.1.3.

\subsubsection{Abordagens Distribuídas}

Primeiramente, serão abordados os três algoritmos distribuídos: o EE-IWFA, EE-VDPCA e EE-MDPCA. Para avaliar o desempenho dos mesmos considere o cenário de telecomunicações apresentado na tabela 2.

Tabela 2: Parâmetros Para o Cenário 1

\begin{tabular}{|c|c|}
\hline Parâmetros & Valores Adotados \\
\hline \multicolumn{2}{|c|}{ Sistema $M C-D S / C D M A$} \\
\hline Potência de Ruído AWGN & $\sigma^{2}=-90[\mathrm{dBm}]$ \\
\hline Potência dos Circuitos do Usuário & $P_{\mathrm{C}}=0,1[\mathrm{~W}]$ \\
\hline Potência dos Circuitos do Retransmissor & $P_{\mathrm{C}_{\mathrm{R}}}=0,5[\mathrm{~W}]$ \\
\hline Potência Disponível no Retransmissor & $p_{\mathrm{R}}=30[\mathrm{~W}]$ \\
\hline Ineficiência dos Amplificadores & $\varrho_{i}=\varrho_{\mathrm{R}}=2,5$, para $i=1, \ldots, U$ \\
\hline Taxa de codificação & $\ell=\frac{3}{4}$ \\
\hline Comprimento da Sequência & $F_{i}=128$, para todo $i=1, \ldots, U$ \\
\hline Receptor Linear & Descorrelacionador \\
\hline Bits por Pacote & $V \in\{1,10,20,50,100\}$ \\
\hline Número de Subportadoras & $N=16$ \\
\hline Matriz de Amplificação & Uniforme, $\mathbf{A}=\mathbf{I}_{F}\left(\frac{p_{\mathrm{R}}}{F N}\right)$ \\
\hline Banda das Subportadoras & $B=1 \mathrm{MHz}$ \\
\hline Potência Máxima & $P_{i, \max }=125[\mathrm{~mW}]$ \\
\hline Número de Usuários & $U \in\{5 ; 20\}$ \\
\hline \multicolumn{2}{|c|}{ Modelo de Canal } \\
\hline Perda de Percurso & proporcional a $d^{-2}$ \\
\hline Sombreamento & $\sigma^{2}=6 \mathrm{~dB}$ \\
\hline & obtido a partir da eq. (1.5) \\
\hline Desvanecimento & Rayleigh \\
\hline \multicolumn{2}{|c|}{ Parâmetros para o EE-VDPCA } \\
\hline$\overline{\alpha_{v}}$ & 0,5 \\
\hline Número de Iterações & 50 \\
\hline \multicolumn{2}{|c|}{ Parâmetros para o EE-IWFA } \\
\hline Número de Iterações & 50 \\
\hline \multicolumn{2}{|c|}{ Parâmetros para o Algoritmo EE-MDPCA } \\
\hline Número de Iterações & 1000 \\
\hline$\epsilon$ & $10^{-6}$ \\
\hline
\end{tabular}


Observação 4 (Matriz de Amplificação). A fim de reduzir ao máximo a complexidade de construção do retransmissor e, ao mesmo tempo, reduzir a potência consumida pelos circuitos do retransmissor, admite-se que a matriz de amplificação do sinal no retransmissor amplifica o sinal de forma uniforme, i.e. $\mathbf{A}=\mathbf{I}_{F}\left(\frac{p_{\mathrm{R}}}{F N}\right)$, onde F é o tamanho da sequência de espalhamento, $N$ o número de subportadoras, $\mathbf{I}_{F}$ é a matriz identidade de ordem $F$ e $p_{\mathrm{R}}$ é a potência disponível no retransmissor (ZAPPONE; BUZZI; JORSWIECK, 2011).

Observação 5 (Escolha do Detector). Neste trabalho apenas o detector multiusário linear denominado descorrelacionador, apresentado no capítulo 2, foi considerado. Esta decisão foi tomada uma vez que o descorrelacionador não necessita do conhecimento das condições de canal, apenas da inversa da matriz de correlação das sequências de espalhamento, que pode ser computada pela estação rádio-base e distribuída para os usuários sem a necessidade de atualização, com exceção de quando ocorrer a admissão ou a saída de um usuário da rede. Esta característica permite a implementação do algoritmos de forma distribuída. Adicionalmente, de acordo com (MESHKATI; SCHWARTZ; MANDAYAM, 2005) o descorrelacionador apresenta um desempenho ligeiramente inferior ao detector MMSE em termos de eficiência energética. Finalmente, o trabalho de (BETZ; POOR, 2008) apresenta que a solução para a abordagem de teoria de jogos em sistemas DS/CDMA utilizando o descorrelacionador é Pareto ótima ${ }^{4}$ enquanto que para o banco de filtros casados simples essa condição não é satisfeita.

Outros parâmetros importantes que precisam ser definidos são os requisitos de qualidade de serviço de cada usuário, relacionados à taxa de transmissão de informação mínima, e também a ordem de modulação de cada usuário. Sendo assim, considere as seguintes classes de usuários:

\footnotetext{
${ }^{4}$ Em teoria de jogos, uma solução é dita Pareto ótima quando nenhum ganho de utilidade pode ser obtido para um determinado jogador sem que ocorra uma redução maior na utilidade de outro jogador.
} 
1. Taxa de transferência de informação mínima 800Kbps e modulação 4-QAM;

2. Taxa de transferência de informação mínima 1500 Kbps e modulação 16 QAM;

3. Taxa de transferência de informação mínima 3000Kbps e modulação 64QAM;

O objetivo da ordem de modulação das classes não é, de fato, impor a ordem de modulação mas estimar a função de penalidade $f\left(\delta_{i, k}\right)$ que é o complemento da taxa de erro de bit média para canais com desvanecimento de pequena escala, cujos ganhos de amplitude assumem uma distribuição estatística de Rayleigh. Sendo assim, quanto maior a taxa de transmissão mínima de um usuário, maior a probabilidade do mesmo transmitir com altas ordens de modulação.

Sendo assim, a tabela 3 apresenta a quantidade de usuários em cada classe para o caso $U=5$ e para o caso $U=20$ :

Tabela 3: Quantidade de Usuários Por Classe para o Cenário 1

\begin{tabular}{l|ccc}
\hline Número de Usuários & Classe 1 & Classe 2 & Classe 3 \\
\hline 5 & 2 & 2 & 1 \\
20 & 8 & 8 & 4 \\
\hline
\end{tabular}

Com intuito de analisar o desempenho dos algoritmos EE-IWFA, EE-VDPCA e EE-MDPCA, simulações foram conduzidas no cenário 1 de tal forma que os resultados apresentados adiante são fruto da média dos resultados obtidos pelos algoritmos em 1000 amostras distintas de condição de canal. A figura 29 apresenta os resultados para o caso $U=5$ usuários e a figura 30 o caso $U=20$ usuários, dispostos conforme a tabela 3 .

Em todos os casos apresentados, quando o número de bits por pacote cresce, a diferença entre os algoritmos é praticamente imperceptível nas figuras 29 e 30 . Todavia, para valores pequenos de $V$ fica claro que o EE-IWFA possui um de- 


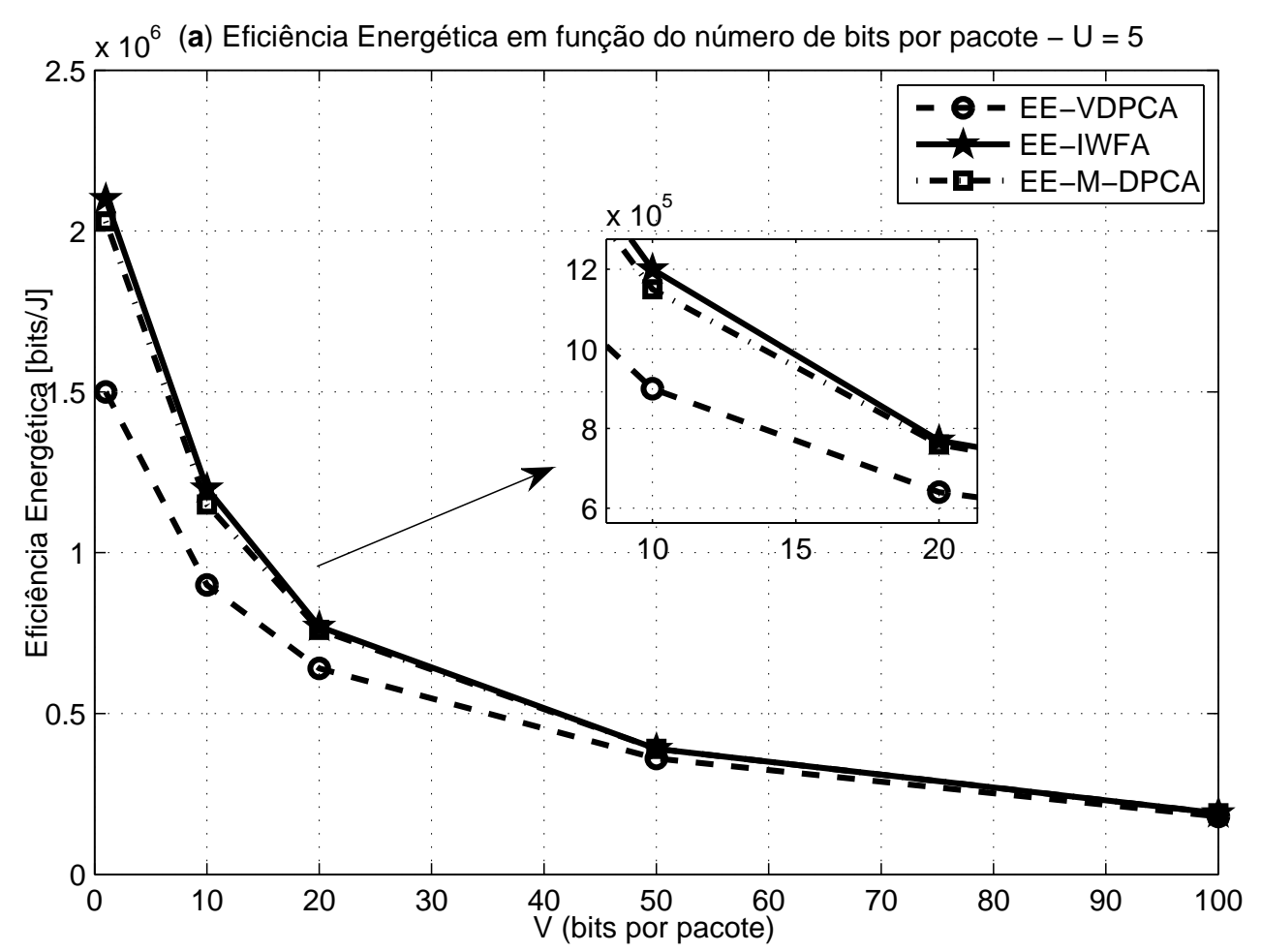

(b) Eficiência Espectral em função do número de bits por pacote $-U=5$

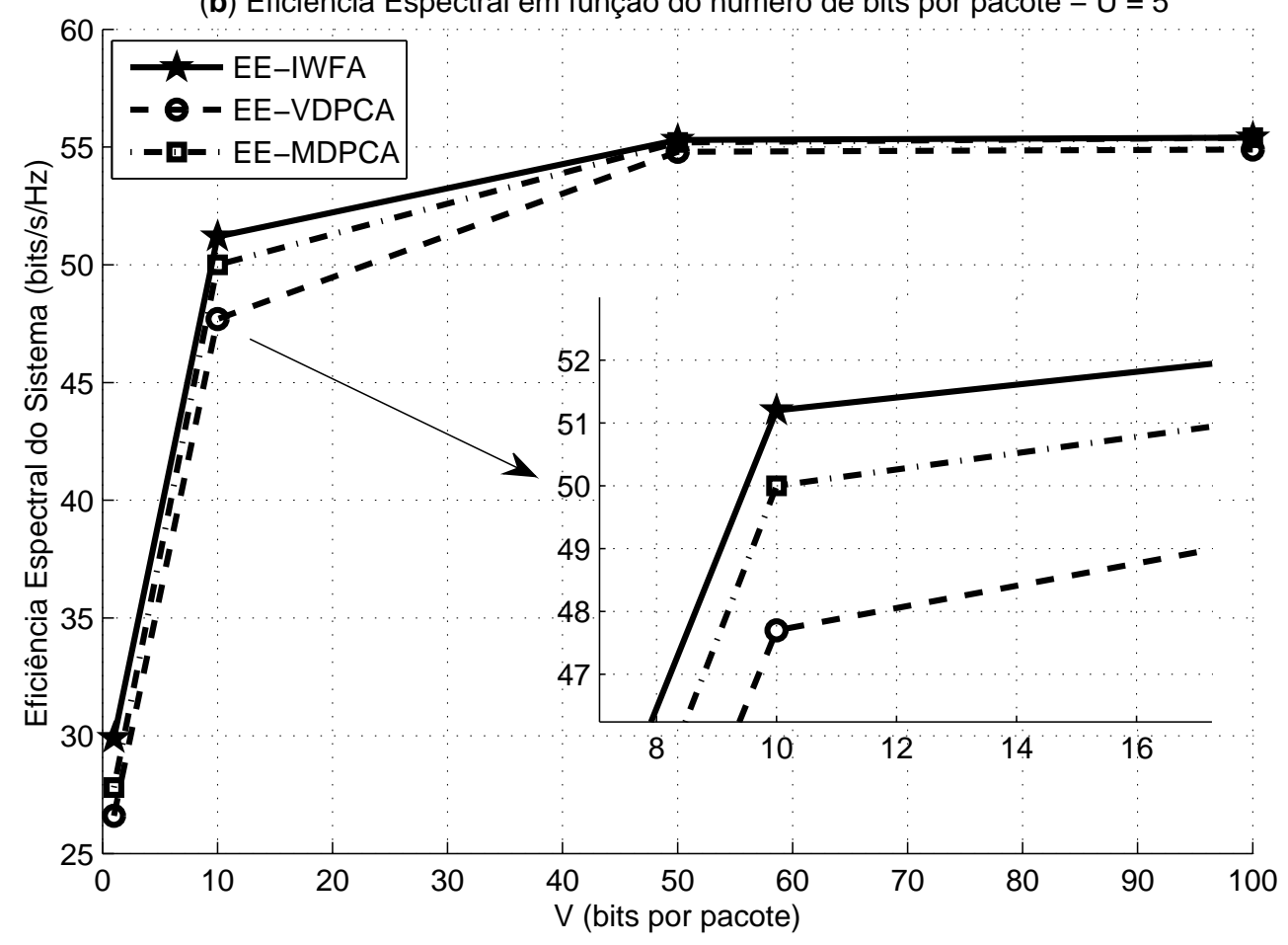

Figura 29: Eficiência energética (a) e eficiência espectral (b) em função do número de bits por pacote para cada um dos três algoritmos distribuídos, com $U=5$ usuários no sistema. 


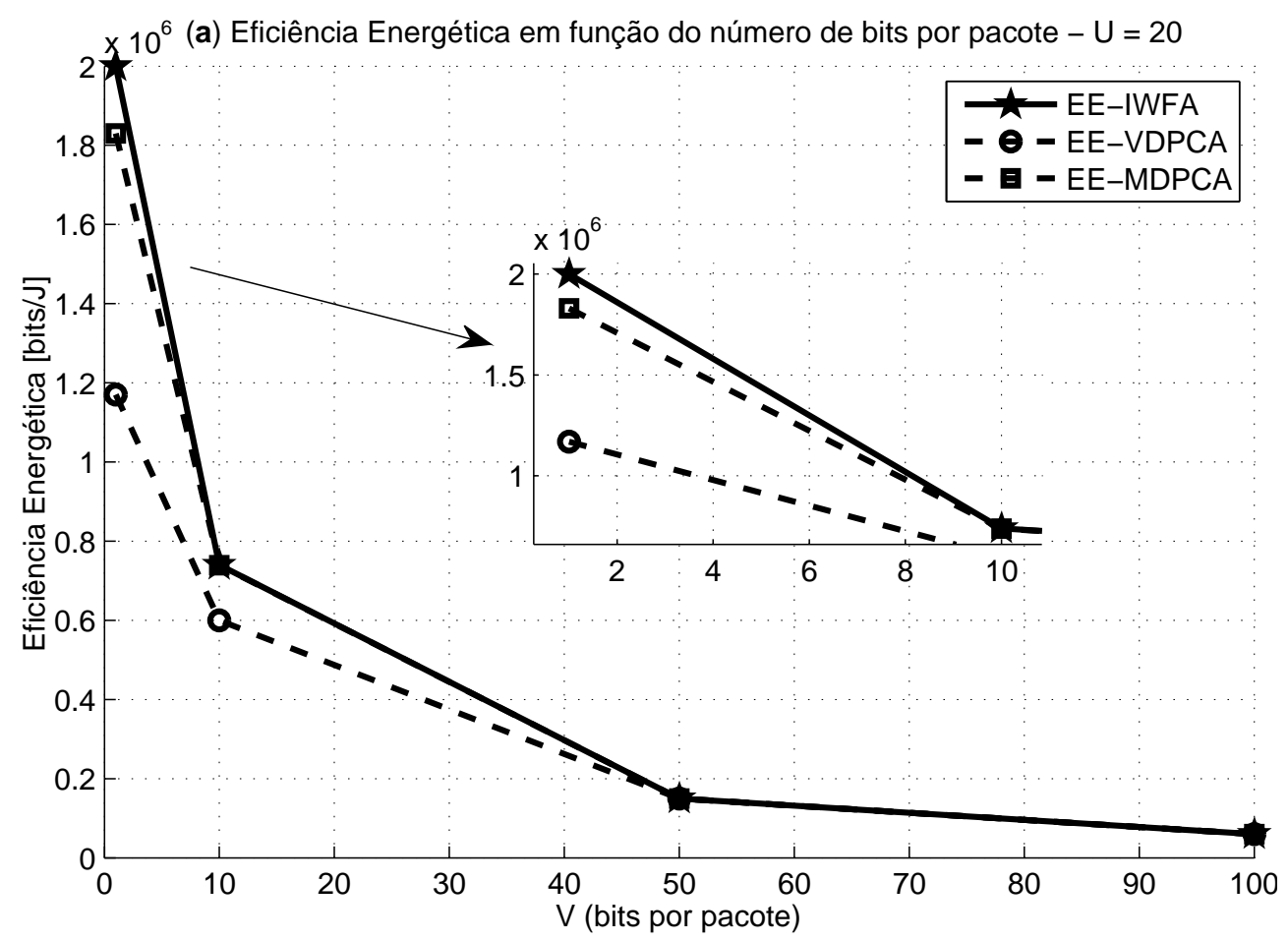

(b) Eficiência Espectral em função do número de bits por pacote $-U=20$

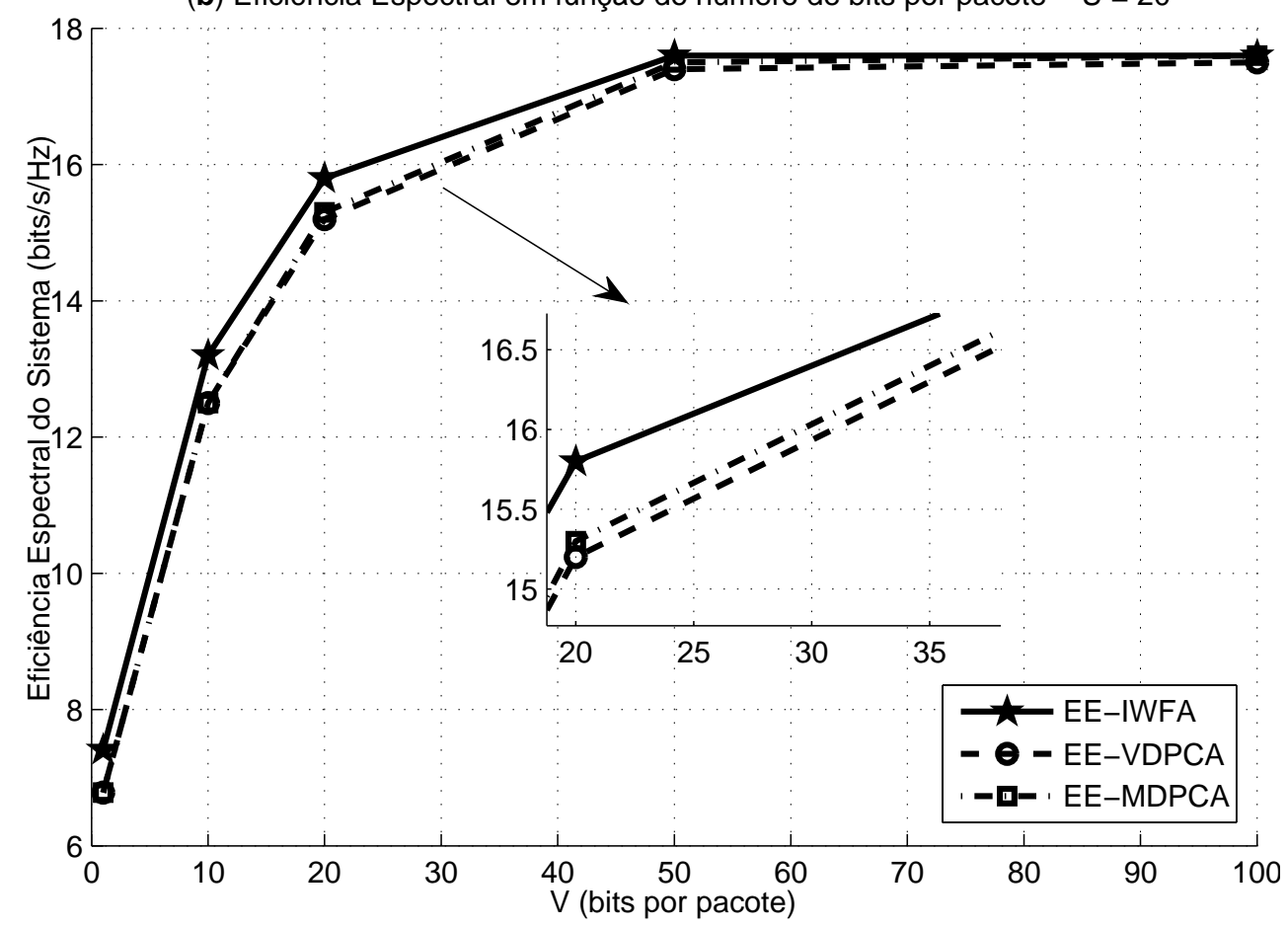

Figura 30: Eficiência energética (a) e eficiência espectral (b) em função do número de bits por pacote para cada um dos três algoritmos distribuídos, com $U=20$ usuários no sistema. 
sempenho superior às demais abordagens propostas tanto em termos de eficiência energética quanto espectral.

A fim de complementar a análise numérica das figuras 29 e 30, as tabelas 4, 5 e 6 apresentam a relação (em termos percentuais) entre os três algoritmos de acordo com três figuras de mérito: eficiência energética, eficiência espectral e potência média de transmissão por usuário. Esta última, é definida como a média aritmética das potências de transmissão do usuário ao longo de todas as subportadoras.

Tabela 4: Desempenho em Eficiência Energética entre os Três Algoritmos.

\begin{tabular}{l|ccc}
\hline Parâmetros & $\begin{array}{c}\text { EE-IWFA (\%) } \\
\text { (Valor de Referência) }\end{array}$ & EE-VDPCA (\%) & EE-MDPCA (\%) \\
\hline$U=5, V=1$ & 100 & 58 & 96 \\
$U=5, V=10$ & 100 & 75 & 96 \\
$U=5, V=50$ & 100 & 92 & 100 \\
$U=5, V=100$ & 100 & 94 & 100 \\
$U=20, V=1$ & 100 & 58 & 92 \\
$U=20, V=10$ & 100 & 81 & 99 \\
$U=20, V=50$ & 100 & 100 & 100 \\
$U=20, V=100$ & 100 & 100 & 100 \\
\hline
\end{tabular}

Tabela 5: Desempenho em Eficiência Espectral entre os Três Algoritmos.

\begin{tabular}{l|ccc}
\hline Parâmetros & $\begin{array}{c}\text { EE-IWFA (\%) } \\
\text { (Valor de Referência) }\end{array}$ & EE-VDPCA (\%) & EE-MDPCA (\%) \\
\hline$U=5, V=1$ & 100 & 91 & 91 \\
$U=5, V=10$ & 100 & 94 & 94 \\
$U=5, V=50$ & 100 & 98 & 98 \\
$U=5, V=100$ & 100 & 99 & 100 \\
$U=20, V=1$ & 100 & 88 & 93 \\
$U=20, V=10$ & 100 & 91 & 98 \\
$U=20, V=50$ & 100 & 99 & 100 \\
$U=20, V=100$ & 100 & 99 & 100 \\
\hline
\end{tabular}

Fica evidente, observando as figuras 29 e 30 bem como as tabelas 4, 5 e 6, que quando $V$ aumenta significativamente, os algoritmos tendem a alocar a potência máxima de transmissão. Sendo assim, é possível afirmar que $V$ é inversamente proporcional à eficiência energética e diretamente proporcional a eficiência espec- 
Tabela 6: Desempenho dos Algoritmos termos de Potência de Transmissão Média.

\begin{tabular}{l|ccc}
\hline Parâmetros & $\begin{array}{c}\text { EE-IWFA (\%) } \\
\text { (Valor de Referência) }\end{array}$ & EE-VDPCA (\%) & EE-MDPCA (\%) \\
\hline$U=5, V=1$ & 100 & 132 & 63 \\
$U=5, V=10$ & 100 & 124 & 77 \\
$U=5, V=50$ & 100 & 100 & 100 \\
$U=5, V=100$ & 100 & 100 & 100 \\
$U=20, V=1$ & 100 & 137 & 70 \\
$U=20, V=10$ & 100 & 107 & 80 \\
$U=20, V=50$ & 100 & 100 & 99 \\
$U=20, V=100$ & 100 & 100 & 100 \\
\hline
\end{tabular}

tral.

Analisando as configurações onde $V=1$, as três abordagens apresentam diferenças substanciais nos resultados de simulação. Em termos de eficiência energética o EE-VDPCA tem o pior desempenho enquanto o EE-MDPCA atinge 96\% da eficiência energética do algoritmo baseado na solução de water-filling. Por outro lado, em termos de eficiência espectral, o desempenho das abordagens é equivalente, com uma pequena vantagem para o EE-IWFA.

Uma vez que os algoritmos são distribuídos, é importante ponderar estes resultados de acordo com a complexidade computacional dos mesmos. Logo, para analisar tal complexidade as seguintes hipóteses são tomadas como verdadeiras:

- O procedimento de controle de potência no enlace reverso é executado mil vezes por segundo;

- Assuma que a janela de otimização é equivalente a um segundo;

- Todos os ganhos de amplitude do canal são considerados constantes durante a janela de otimização;

- O número máximo de iterações do algoritmo iterativo para maximização da eficiência energética ${ }^{5}$ é 1000 ;

\footnotetext{
${ }^{5}$ Descrito no Algoritmo 4.2.
} 
- No laço interno do algoritmo iterativo para maximização da eficiência energética apenas uma iteração do algoritmo de controle de potência utilizado é executada;

- Portanto, o número de iterações para todos os métodos é equivalente;

- Uma vez que o algoritmo é distribuído, a rotina de alocação de recursos é solucionada apenas para o próprio usuário;

- O algoritmo utilizado para computar o passo 3 do AIMEE é o mesmo para as três abordagens e portanto sua complexidade é desconsiderada no cálculo;

Sendo assim, a dimensionalidade do problema é reduzida ao número de subportadoras. É fácil observar que o EE-VDPCA e o EE-MDPCA consistem em realizar a atualização de alocação de potência através da equação (4.19), a qual possui complexidade computacional constante, i.e. o número de operações não depende do número de subportadoras. Portanto estas rotinas tem complexidade $\mathcal{O}(1)$. Todavia, o EE-VDPCA utiliza a equaçao (4.19) em cada uma das $N$ subportadora o que implica em um complexidade computacional $N \times \mathcal{O}(1)=\mathcal{O}(N)$.

De acordo com (ZENG; HOO; CIOFFI, 2001) a complexidade computacional do algoritmo EE-IWFA é $\mathcal{O}(N \log (N))$ devido ao processo de ordenação de vetor na sua rotina.

Considere agora o cenário 2, com parâmetros de sistema e canal sumarizados na tabela 7. Neste cenário são definidas três classes de usuários:

1. Taxa de transferência de informação mínima 256Kbps e modulação 4-QAM;

2. Taxa de transferência de informação mínima 512Kbps e modulação 16 QAM;

3. Taxa de transferência de informação mínima 1024Kbps e modulação 64 QAM; 
Tabela 7: Parâmetros Para o Cenário 2

\begin{tabular}{|c|c|}
\hline Parâmetros & Valores Adotados \\
\hline \multicolumn{2}{|c|}{ Sistema $M C$-DS/CDMA } \\
\hline Potência de Ruído AWGN & $\sigma^{2}=-90[\mathrm{dBm}]$ \\
\hline Potência dos Circuitos do Usuário & $P_{\mathrm{C}}=0,1[\mathrm{~W}]$ \\
\hline Potência dos Circuitos do Retransmissor & $P_{\mathrm{C}_{\mathrm{R}}}=0,5[\mathrm{~W}]$ \\
\hline Potência Disponível no Retransmissor & $p_{\mathrm{R}}=25[\mathrm{~W}]$ \\
\hline Ineficiência dos Amplificadores & $\varrho_{i}=\varrho_{\mathrm{R}}=2,5$, para $i=1, \ldots, U$ \\
\hline Taxa de codificação & $\ell=\frac{3}{4}$ \\
\hline Comprimento da Sequência & $F_{i}=16$, para todo $i=1, \ldots, U$ \\
\hline Receptor Linear & Descorrelacionador \\
\hline Bits por Pacote & $V=1$ \\
\hline Número de Subportadoras & $N=128$ \\
\hline Matriz de Amplificação & Uniforme, $\mathbf{A}=\mathbf{I}_{F}\left(\frac{p_{\mathrm{R}}}{F N}\right)$ \\
\hline Banda das Subportadoras & $B=78 \mathrm{KHz}$ \\
\hline Potência Máxima & $P_{i, \max }=125[\mathrm{~mW}]$ \\
\hline Número de Usuários & $U=5$ \\
\hline \multicolumn{2}{|c|}{ Modelo de Canal } \\
\hline Perda de Percurso & proporcional a $d^{-2}$ \\
\hline Sombreamento & $\begin{array}{l}\sigma^{2}=6 \mathrm{~dB} \\
\text { obtido a partir da eq. }(1.5)\end{array}$ \\
\hline Desvanecimento & Rayleigh \\
\hline \multicolumn{2}{|c|}{ Parâmetros para o $P S O$} \\
\hline $\begin{array}{l}\text { Velocidade máxima } \\
\text { Inércia }\end{array}$ & $\begin{array}{l}V_{\max }=\frac{P_{i, \max }}{10} \\
\omega=0,1\end{array}$ \\
\hline
\end{tabular}

de tal forma que 3 usuários são da classe 1, um usuário é da classe 2, e um usuário constituí a classe 3.

A fim de estabelecer parâmetros ótimos para $c_{1}$ e $c_{2}$ para o PSO e os parâmetros $\alpha, \beta_{0}, \gamma$ para a heurística $\mathrm{FA}$, analisou-se o tamanho da população $M$ e o número de iterações de cada algoritmo $I$. A figura 31 apresenta os resultados em termos de eficiência energética média ${ }^{6}$, em função do número máximo de iterações, considerando ainda três tamanhos distintos de população.

Note que as soluções descritas na figura 31 quando o tamanho da população é $M=50$ e o número de iterações é $I=500$ o PSO obteve uma eficiência energética marginalmente menor que o FA. Este último, por sua vez, atingiu

\footnotetext{
${ }^{6}$ Média tomada em 100 amostras diferentes de matriz de canal.
} 


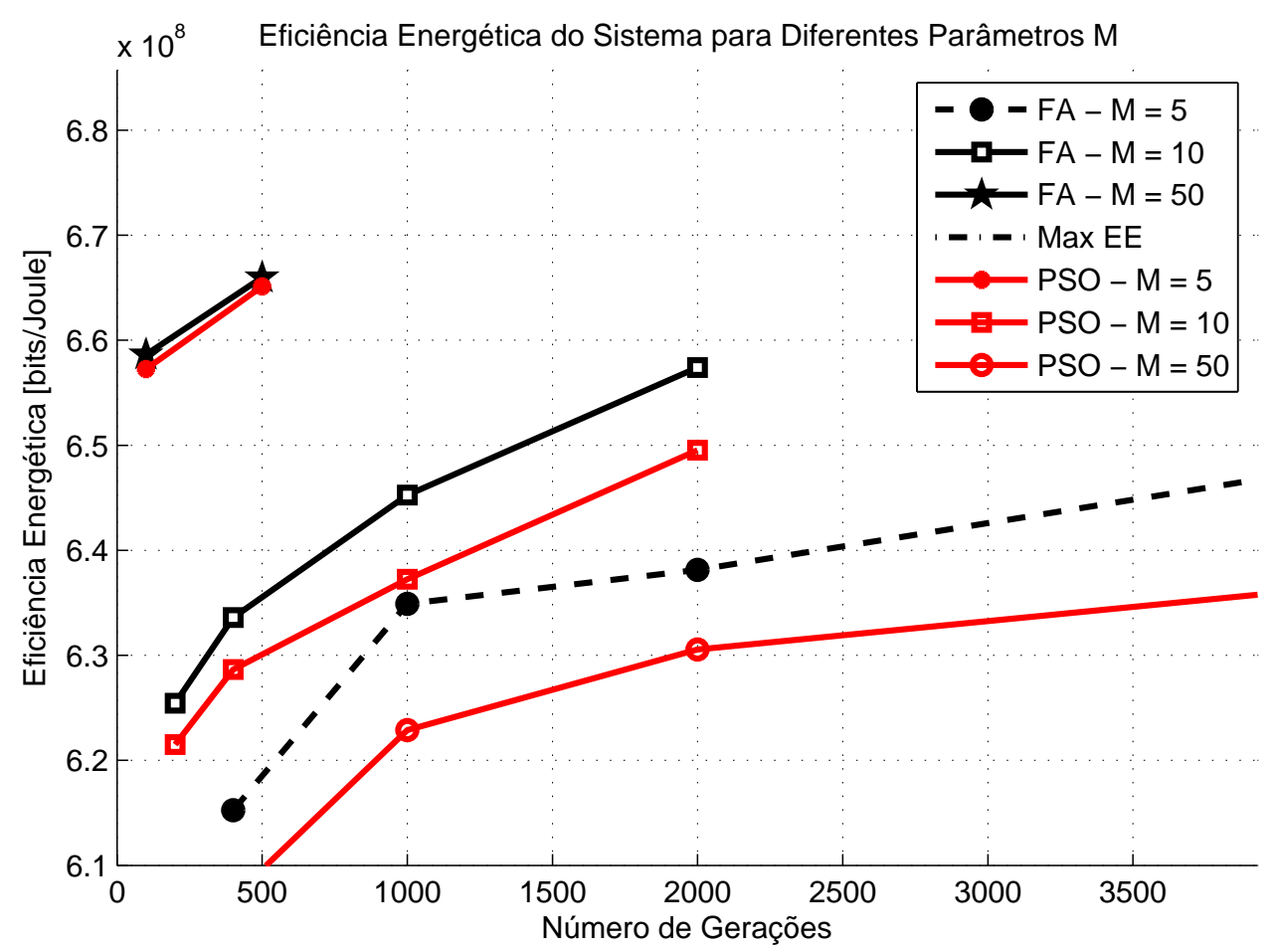

Figura 31: Eficiência energética para diferentes valores de tamanho de população e número máximo de iterações. Média em 100 amostras de matriz de ganhos de canal distintas.

aproximadamente $96 \%$ da eficiência energética máxima. No pior caso (quando $M=5$ e $I=400)$ o FA obteve aproximadamente $88 \%$ da eficiência máxima, enquanto o PSO atingiu $87 \%$ da máxima EE.

Na figura $31, c_{1}=c_{2}=\alpha=\beta_{0}=\gamma=1$ e o valor de referência, i.e., a eficiência energética máxima (EE Max, na figura) é obtida utilizando-se o algoritmo DinkOpt descrito no início deste capítulo. Uma vez que o melhor resultado em termos de eficiência energética é obtido quando $M=50$ e o número de interaçoes $I=500$, estes parâmetros foram utilizados para encontrar valores apropriados para os demais parâmetros.

Assim, é possível otimizar os parâmetros do algoritmo FA, i.e. $\alpha, \beta_{0}, \gamma$, por meio de uma busca não exaustiva e resultados numéricos de simulação. Desta forma, as tabelas 8, 9, 10 ilustram os resultados para um conjunto de valores dos parâmetros em questão. A partir dos resultados é possível inferir que os valores 
mais apropriados para os parâmetros do algoritmo dos vaga-lumes são $\beta_{0}=\gamma=1$ e $\alpha=10^{-3}$.

De forma similar, para o algoritmo de otimização por enxame de partículas os valores para diferentes parâmetros $c_{1}$ e $c_{2}$ estão apresentados na tabela 11, e a partir destes conclui-se que $c_{1}=c_{2}=2$ são os valores mais adequados ao problema discutido.

Tabela 8: Desempenho em Eficiência Energética Média para Diferentes parâme$\operatorname{tros} \alpha(\mathrm{FA})$.

\begin{tabular}{l|c}
\hline$\alpha$ & Eficiência Energética \\
\hline 1 & $6,659 \times 10^{8}$ \\
$10^{-1}$ & $6,678 \times 10^{8}$ \\
$10^{-2}$ & $6,826 \times 10^{8}$ \\
$10^{-3}$ & $6,829 \times 10^{8}$ \\
$10^{-4}$ & $6,699 \times 10^{8}$ \\
\hline
\end{tabular}

Tabela 9: Desempenho em Eficiência Energética Média para Diferentes parâme$\operatorname{tros} \beta_{0}(\mathrm{FA})$.

\begin{tabular}{l|c}
\hline$\beta_{0}$ & Eficiência Energética \\
\hline 10 & $6,601 \times 10^{8}$ \\
2 & $6,607 \times 10^{8}$ \\
1 & $6,829 \times 10^{8}$ \\
$10^{-1}$ & $6,829 \times 10^{8}$ \\
$10^{-2}$ & $6,205 \times 10^{8}$ \\
\hline
\end{tabular}

Tabela 10: Desempenho em Eficiência Energética Média para Diferentes parâme$\operatorname{tros} \alpha(\mathrm{FA})$.

\begin{tabular}{l|c}
\hline$\gamma$ & Eficiência Energética \\
\hline $10^{-1}$ & $6,827 \times 10^{8}$ \\
$10^{-2}$ & $6,828 \times 10^{8}$ \\
1 & $6,829 \times 10^{8}$ \\
5 & $6,829 \times 10^{8}$ \\
10 & $6,827 \times 10^{8}$ \\
\hline
\end{tabular}

\subsubsection{Síntese dos Resultados}

Para fins de comparação, os resultados em termos referênciais obtidos através das 6 soluções propostas para o problema de maximização da eficiência energé- 
Tabela 11: Desempenho em Eficiência Energética Média para Diferentes parâme$\operatorname{tros} c_{1}$ e $c_{2}(\mathrm{PSO})$.

\begin{tabular}{c|c|r}
\hline$c_{1}$ & $c_{2}$ & Eficiência Energética \\
\hline 1 & 1 & $6,651 \times 10^{8}$ \\
2 & 1 & $6,661 \times 10^{8}$ \\
3 & 1 & $6,660 \times 10^{8}$ \\
2 & 2 & $6,665 \times 10^{8}$ \\
1 & 3 & $6,661 \times 10^{8}$ \\
\hline
\end{tabular}

tica em sistemas cooperativos com múltiplas subportadoras ortogonais e múltiplo acesso por divisão de código de sequência direta são sintetizados na tabela 12 , considerando que $V=1, U=5$ e o número de iterações totais é equivalente entre todos os algoritmos. A tabela sintetiza as expressões de complexidade e os valores aproximados das frações médias de eficiência energética máxima para 100 realizações independentes de matriz de canal.

Tabela 12: Desempenho em Porcentagem da Eficiência Energética Ótima (Valores Aproximados).

\begin{tabular}{l|c|l}
\hline Algoritmo & \% do Valor da Eficiência Energética Ótima & Complexidade \\
\hline DinkOpt & 100 & - \\
EE-IWFA & 99 & $\mathcal{O}(N \log (N))$ \\
EE-VDPCA & 57 & $\mathcal{O}(N)$ \\
EE-MDPCA & 96 & $\mathcal{O}(1)$ \\
FA & 96 & $\mathcal{O}\left(M^{2}\right)$ \\
PSO & 95 & $\mathcal{O}(M)$ \\
\hline$M$ - Tamanho da população utilizada no método heurístico; \\
$N$ - Número de subportadoras do sistema MC-DS/CDMA; \\
\hline
\end{tabular}

A ordem de complexidade para os algoritmos FA e PSO foi obtida através da observação direta dos laços presentes nos algoritmos 3.2 e 3.3 .

\subsection{Resultados e Discussões para o Problema de Maximização da Capacidade Efetiva em Sis- temas OFDMA}

Antes de avaliar o desempenho do algoritmo para maximização da capacidade efetiva, é importante rever o significado do expoente de qualidade de serviço 
estatística $\theta$. Conforme definido na seção 2.2.1, $\theta$ quando relacionado a um atraso máximo tolerável $d_{\max }$ é definido como,

$$
\theta=-\frac{\log \left(P_{\mathrm{R}}\left(D \geq d_{\max }\right)\right)}{d_{\max }}
$$

A figura 32 apresenta a relação entre o atraso máximo tolerável $d_{\max }$ e a probabilidade de violação $P_{\mathrm{R}}\left(D \geq d_{\max }\right)$ para os quais o valor de $\theta$ encontra equivalência. Desta forma, para uma probabilidade de violação fixa (linha tracejada vermelha na figura 32) quanto maior é o atraso $d_{\max }$ menor é o valor do expoente de QoS. De forma análoga, para um atraso fixo (linha tracejada azul na figura 32), quanto maior a probabilidade de violação para um atraso arbitrário $D, P_{\mathrm{R}}\left(D \geq d_{\max }\right)$, menor é o valor do expoente de QoS.

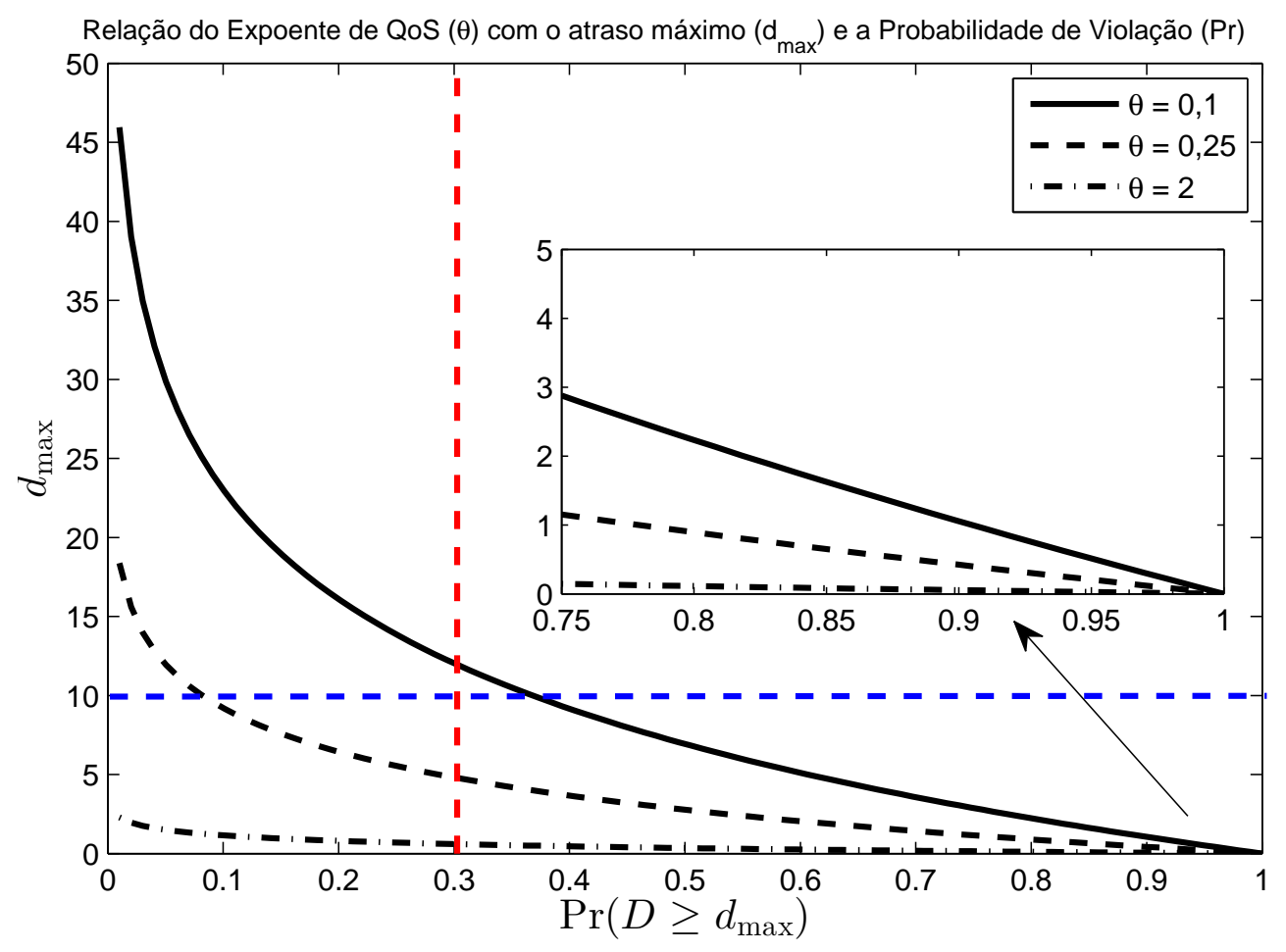

Figura 32: Relação entre os valores do expoente de qualidade de serviço estatística $\theta$, o atraso máximo tolerável em bits, $d_{\max }$, e a probabilidade de violação do atraso máximo para um atraso arbitrário $D, P_{\mathrm{R}}\left(D \geq d_{\mathrm{max}}\right)$.

Uma vez que a capacidade efetiva é uma função decrescente em relação ao 


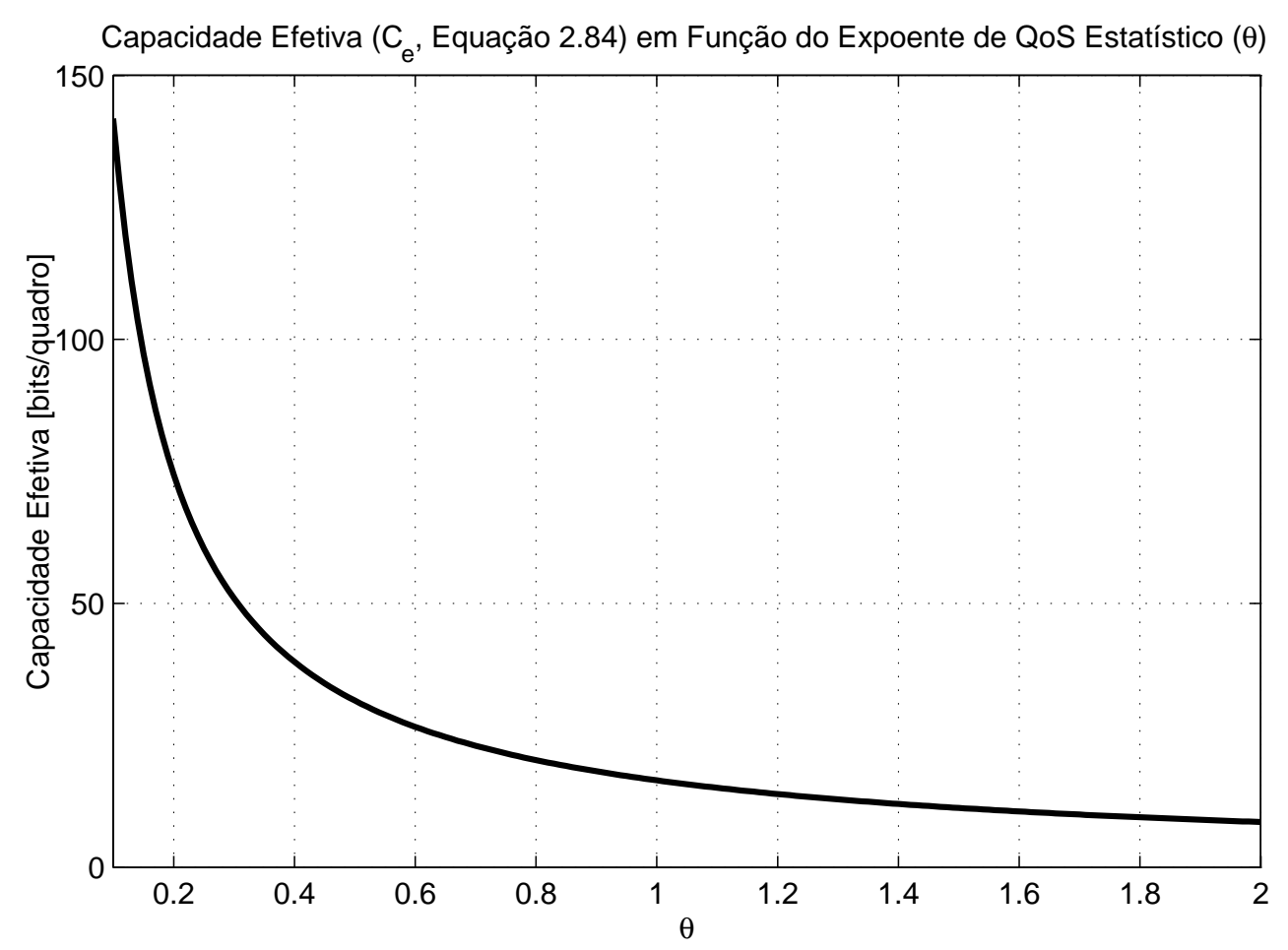

Figura 33: Capacidade efetiva em função do expoente de qualidade de serviço estatística para um cenário arbitrário.

valor de $\theta$ (veja figura 33 obtida a partir da equação (2.84)), é possível concluir que: para um atraso máximo fixo tolerável, quanto maior a probabilidade de violação do limite, maior é a capacidade efetiva do sistema. Por outro lado, para uma probabilidade fixa de violação do atraso máximo, quanto maior é o atraso tolerável maior é a capacidade efetiva do sistema. Em outras palavras: quando menos restritivas forem as condições de qualidade de serviço, maior será a capacidade efetiva. Ou seja, quando o atraso máximo tolerável tende ao infinito ou quando a probabilidade de violação tende a 1, a capacidade efetiva do sistema tende ao infinito.

Uma vez detalhados os conceitos pertinentes e o que representa o expoente de QoS estatística em relação à capacidade efetiva, atraso máximo e probabilidade de violação do mesmo, é possível avaliar o desempenho do algoritmo proposto para maximização da capacidade efetiva (Algoritmo AIMCE, Algoritmo 4.4), bem como observar a característica côncava da capacidade efetiva. Para isto um 
estudo em cenário simples foi conduzido. A tabela 13 apresenta os valores dos parâmetros de simulação adotados para o cenário 3 .

Tabela 13: Parâmetros de Simulação para o Cenário 3

\begin{tabular}{|c|c|}
\hline Parâmetro & Valor Adotado \\
\hline Banda Total do Sistema & $\mathcal{W}=100[\mathrm{KHz}]$ \\
\hline Número de Subportadoras & $N=3$ \\
\hline Banda de cada Subcanal & $B=\mathcal{W} / N=33,3[\mathrm{KHz}]$ \\
\hline Período de Transmissão do Quadro & $T=667[\mu \mathrm{seg}]$ \\
\hline Densidade Espectral de Potência do Ruído & $N_{0}=10^{-12}[\mathrm{~W} / \mathrm{Hz}]$ \\
\hline Potência Máxima de Transmissão & $P_{\max }=1[\mathrm{~W}]$ \\
\hline Número de Usuários no Sistema & $U=2$ \\
\hline Expoente de QoS dos Usuários & $\theta_{1}=0,1$ e $\theta_{2}=0,25$ \\
\hline
\end{tabular}

Uma vez que o expoente de QoS do usuário 1 é menor que o do usuário 2, e que o objetivo é a maximização da capacidade efetiva, é razoável considerar que 2 das 3 subportadoras do sistema estão destinadas ao usuário 1. Agora, considere que para uma determinada potência de transmissão $p_{2,3}$ (a potência de transmissão do usuário 2 na subportadora 3$), p_{1,1}=p_{1,2}=\left(P_{\max }-p_{2,3}\right) / 2$. Isto é, a potência de transmissão em cada subportadora do usuário 1 é equivalente à metade da diferença entre a potência máxima de transmissão e a potência de transmissão para a subportadora do usuário 2.

A figura 34 apresenta a capacidade efetiva do sistema como função da potência de transmissão do usuário 2. As linhas verticais tracejadas em azul, verde e vermelho apresentam os valores mínimos de potência para o usuário 2 que satisfazem a capacidade mínima efetiva indicada por $C_{\min }$. A capacidade efetiva mínima é uma medida de qualidade de serviço que descreve a menor capacidade efetiva com a qual um usuário do sistema deve transmitir. Note que o valor de $C_{\text {min }}$ delimita uma reta - para o caso bidimensional ilustrado - e para o domínio do problema delimita um hiperplano separador. Adicionalmente, é importante observar que para $C_{\min }=67$ bits por quadro, o valor da capacidade efetiva máxima do sistema não se altera. Todavia, com restrições mais exigentes como 
$C_{\min }=70$ ou $C_{\min }=72$ bits por quadro, o ponto de máximo (círculo vermelho) não pertence ao domínio do problema e a solução passa, então, a ser diferente do caso $C_{\min }=67$.

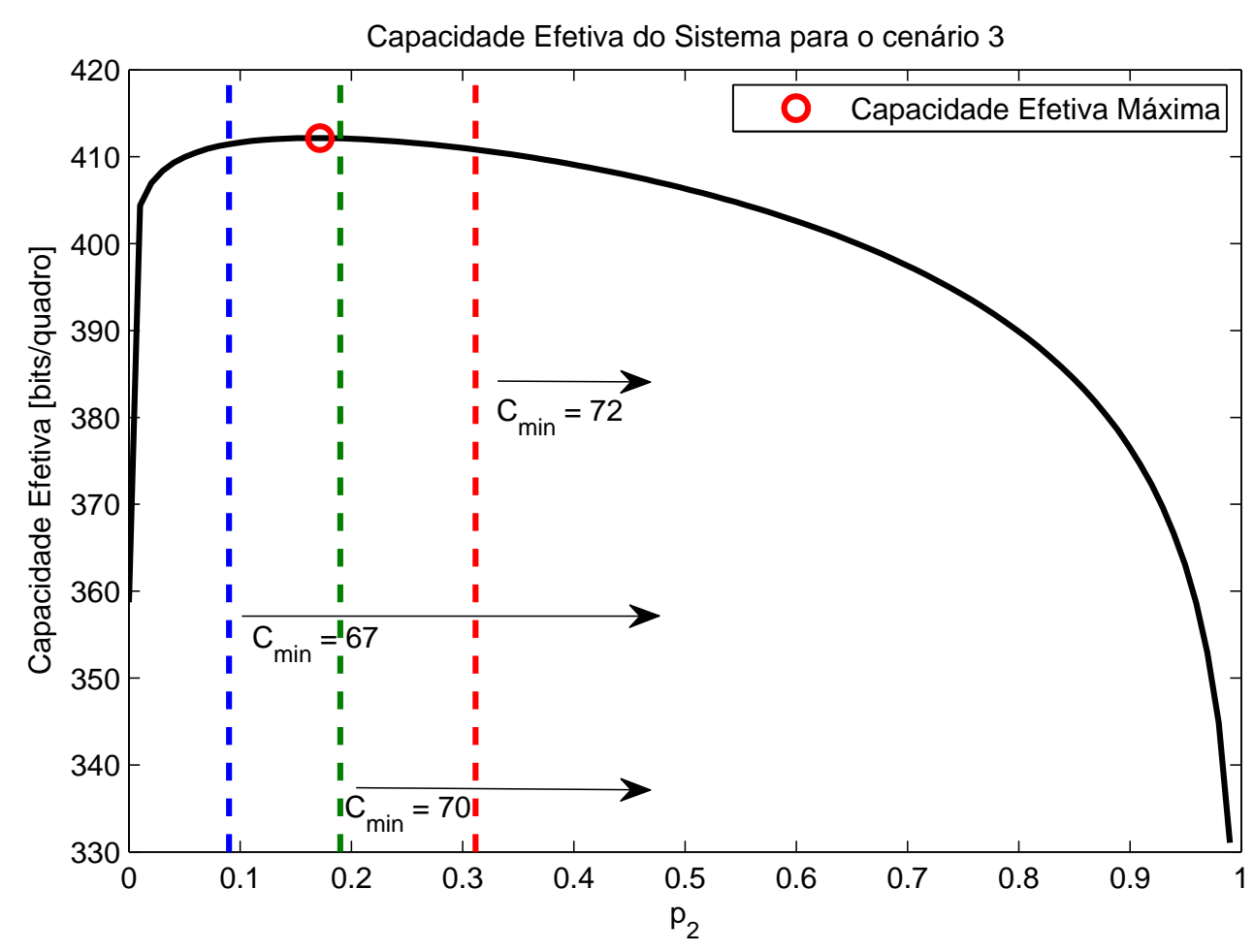

Figura 34: Capacidade efetiva em função da potência de transmissão do usuário 2, cenário 3 (valores de parâmetros definidos na tabela 13).

De fato, esta informação pode ser verificada na tabela 14, a qual apresenta as soluções ótimas em termos de potência de transmissão e capacidade efetiva para o cenário 3 considerando os 3 diferentes requisitos mínimos de capacidade efetiva apresentados na figura 34 .

Uma fato importante a ser considerado sobre a tabela 14 é a diferença de potência do usuário 2 para $C_{\min }=67$ e para $C_{\min }=72$. Note que para aumentar 2,5 bits por quadro na capacidade efetiva do usuário 2 (de 69, 5 para 72 ) é necessário aproximadamente o dobro de potência (aumento de 0,1667 para 0,3118).

Para ilustrar o funcionamento do algoritmo de maximização da capacidade efetiva baseado na decomposição dual de Lagrange, as figuras 35, 36 e 37 apre- 
Tabela 14: Solução Ótima do Problema de Maximização da Capacidade Efetiva (CE) Para o Cenário 3

\begin{tabular}{l|c|c|c}
\hline Parâmetro & $C_{\min }=67$ & $C_{\min }=70$ & $C_{\min }=72$ \\
\hline Potência Total Ótima do Usuário 1 $[W]$ & 0,8333 & 0,8109 & 0,6882 \\
Potência Total Ótima do Usuário 2 $[W]$ & 0,1667 & 0,1891 & 0,3118 \\
Potência Total de Transmissão $[W]$ & 1 & 1 & 1 \\
\hline CE Total do Usuário 1 [bits/quadro] & 342,66 & 342,11 & 338,91 \\
CE Total do Usuário 2 [bits/quadro] & 69,50 & 70 & 72 \\
CE Total do Sistema [bits/quadro] & 412,16 & 412,11 & 410,91 \\
\hline
\end{tabular}

Os valores de CE apresentados nesta tabela ilustram a solução do problema de otimização (4.113) e não apresentam valores praticáveis, i.e. números inteiros

sentam a evolução do algoritmo, iteração-por-iteração, para os casos $C_{\min }=67$ (figura 35), $C_{\min }=70$ (figura 36) e $C_{\min }=72$ (figura 37). A precisão considerada é de $\epsilon=10^{-6}$; todas as váriaveis duais são iniciadas com valor unitário; a alocação de potência inicial é uniforme e a alocação de subportadora inicial é feita de forma aleatória. Adicionalmente, os valores indicados como ótimos foram obtidos através de busca exaustiva.

Cada figura apresenta dois gráficos, sendo um relativo à evolução da alocação de potência e outro um relação à evolução da capacidade efetiva do sistema. Note que, quanto mais restritiva a condição de capacidade efetiva mínima mais lenta é a convergência do algoritmo: o algoritmo atinge a convergência com precisão $\epsilon$ em 62 iterações para $C_{\min }=67,250$ iterações para $C_{\min }=70$ e 600 iterações para $C_{\min }=72$.

Duas características são notórias no problema de maximização da capacidade efetiva considerado: a primeira é que nenhuma informação a respeito do canal é necessária para o gerenciamento dos recursos (potência e espectro). A segunda é que este fato implica que cenários onde o número de subportadoras é maior que o número de usuários $(N>U)$ admitem múltiplas soluções equivalentes. Isto é verdade pelo fato da capacidade de um usuário não depender da subportadora em que o mesmo transmite uma vez que todos os canais são independentes e 
identicamente distribuídos.

Sem perda da generalidade considere o cenário 3, por exemplo, e considere que $C_{\min }=1$. Existem oito combinações diferentes de políticas de alocação de subportadoras, descritas como:
a) $\boldsymbol{\phi}=\left[\begin{array}{lll}1 & 1 & 1 \\ 0 & 0 & 0\end{array}\right]$,
b) $\boldsymbol{\phi}=\left[\begin{array}{lll}0 & 0 & 0 \\ 1 & 1 & 1\end{array}\right]$
c) $\boldsymbol{\phi}=\left[\begin{array}{lll}0 & 1 & 1 \\ 1 & 0 & 0\end{array}\right]$,
d) $\boldsymbol{\phi}=\left[\begin{array}{lll}1 & 0 & 0 \\ 0 & 1 & 1\end{array}\right]$
e) $\boldsymbol{\phi}=\left[\begin{array}{lll}0 & 0 & 1 \\ 1 & 1 & 0\end{array}\right]$,
f) $\boldsymbol{\phi}=\left[\begin{array}{lll}1 & 1 & 0 \\ 0 & 0 & 1\end{array}\right]$
g) $\boldsymbol{\phi}=\left[\begin{array}{lll}0 & 1 & 0 \\ 1 & 0 & 1\end{array}\right]$,
h) $\phi=\left[\begin{array}{lll}1 & 0 & 1 \\ 0 & 1 & 0\end{array}\right]$

As matrizes de alocação de subportadora a) e b) podem ser descartadas uma vez que elas não satisfazem à restrição de capacidade efetiva mínima, independente da alocação de potência, pois nestas matrizes apenas um usuário transmite. A correspondente capacidade efetiva do sistema em função da potência total de transmissão do usuário $2\left(\theta_{2}=0.25\right)$ é apresentada na figura 38. Note que em todas as matrizes onde o usuário 1 tem duas subportadoras destinadas a ele e 1 ao usuário 2 (d,e,g), a função da capacidade efetiva do sistema em relção a potência de transmissão do usuário 2 é equivalente. Da mesma forma, quando duas subportadoras são destinadas ao usuário 2 e uma subportadora ao usuário 1 (c,g,h), a capacidade efetiva do sistema em função da potência total de transmissão do usuário $^{7} 2$ é equivalente.

Embora a capacidade efetiva seja uma medida estatística que garante uma

\footnotetext{
${ }^{7}$ A soma das potências do usuário 2 nas duas subportadoras reservadas para sua transmissão.
} 

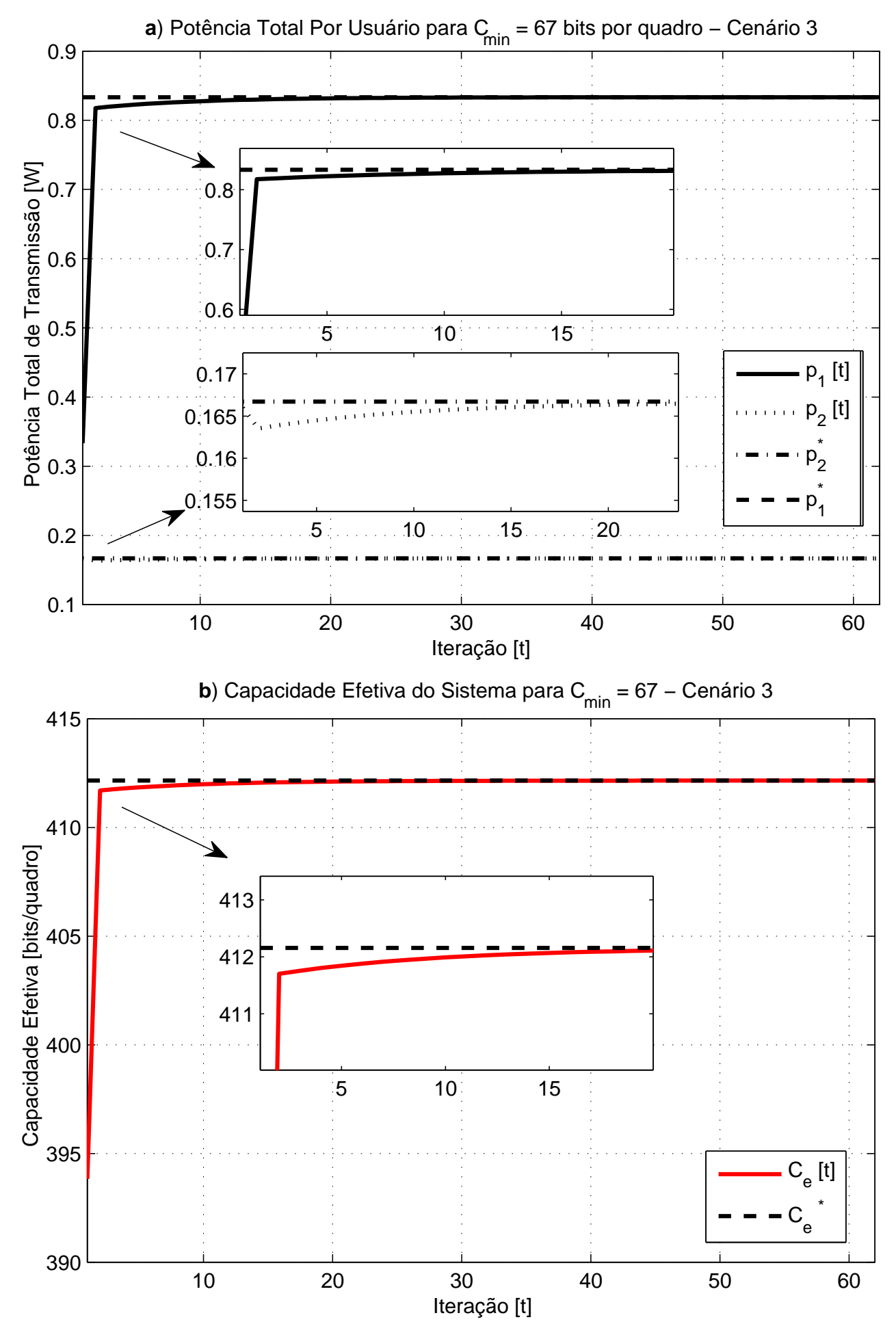

Figura 35: Evolução do algoritmo de maximização da capacidade efetiva baseado na decomposição dual de Lagrange: (a) em termos de potência total de transmissão por usuário; (b) em termos de capacidade efetiva total do sistema. Cenário $3 \mathrm{com} C_{\min }=67$. 


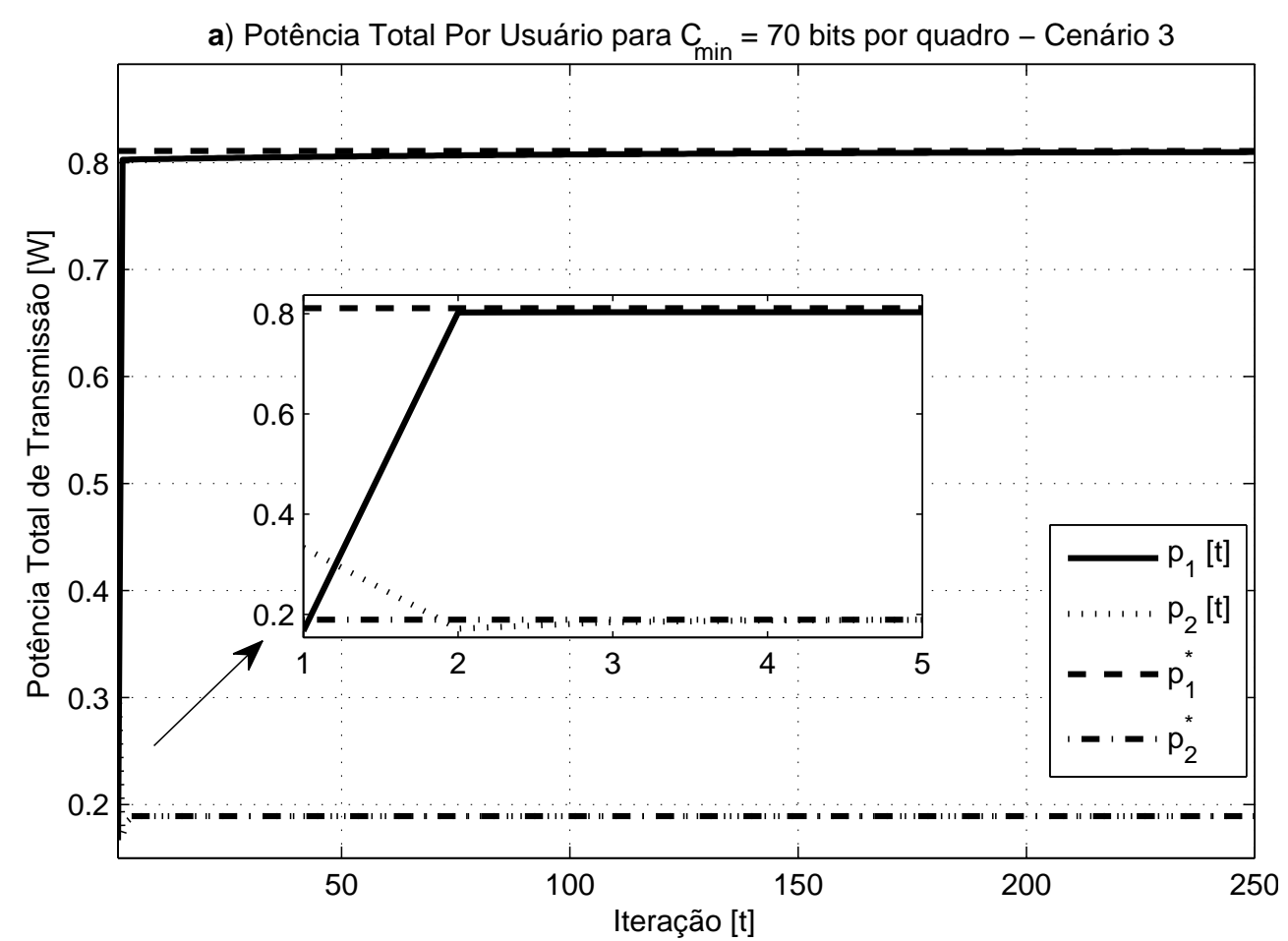

b) Capacidade Efetiva do Sistema para $C_{\min }=70$ - Cenário 3

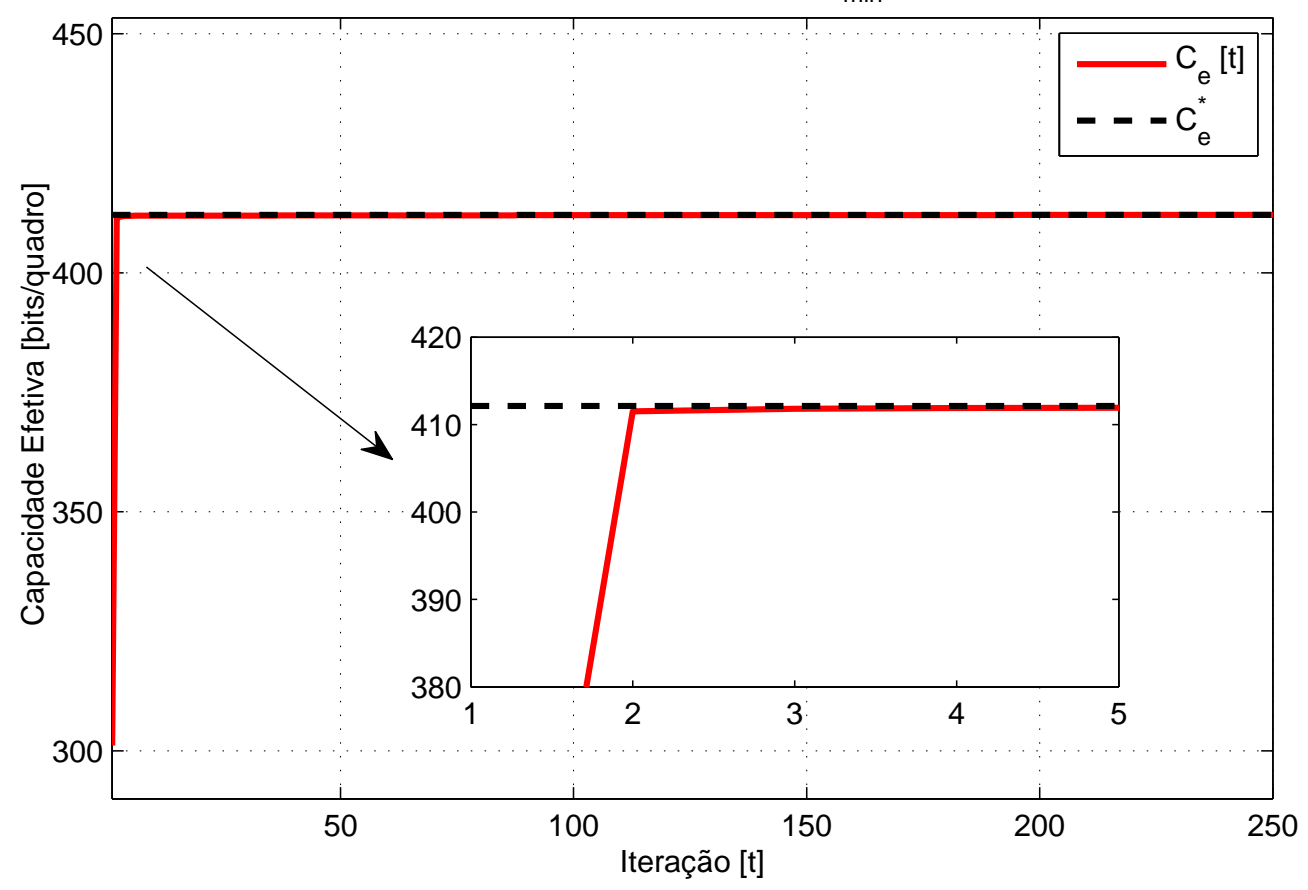

Figura 36: Evolução do algoritmo de maximização da capacidade efetiva baseado na decomposição dual de Lagrange: (a) em termos de potência total de transmissão por usuário; (b) em termos de capacidade efetiva total do sistema. Cenário 3 com $C_{\text {min }}=70$. 
a) Potência Total Por Usuário para $\mathrm{C}_{\min }=72$ bits por quadro - Cenário 3
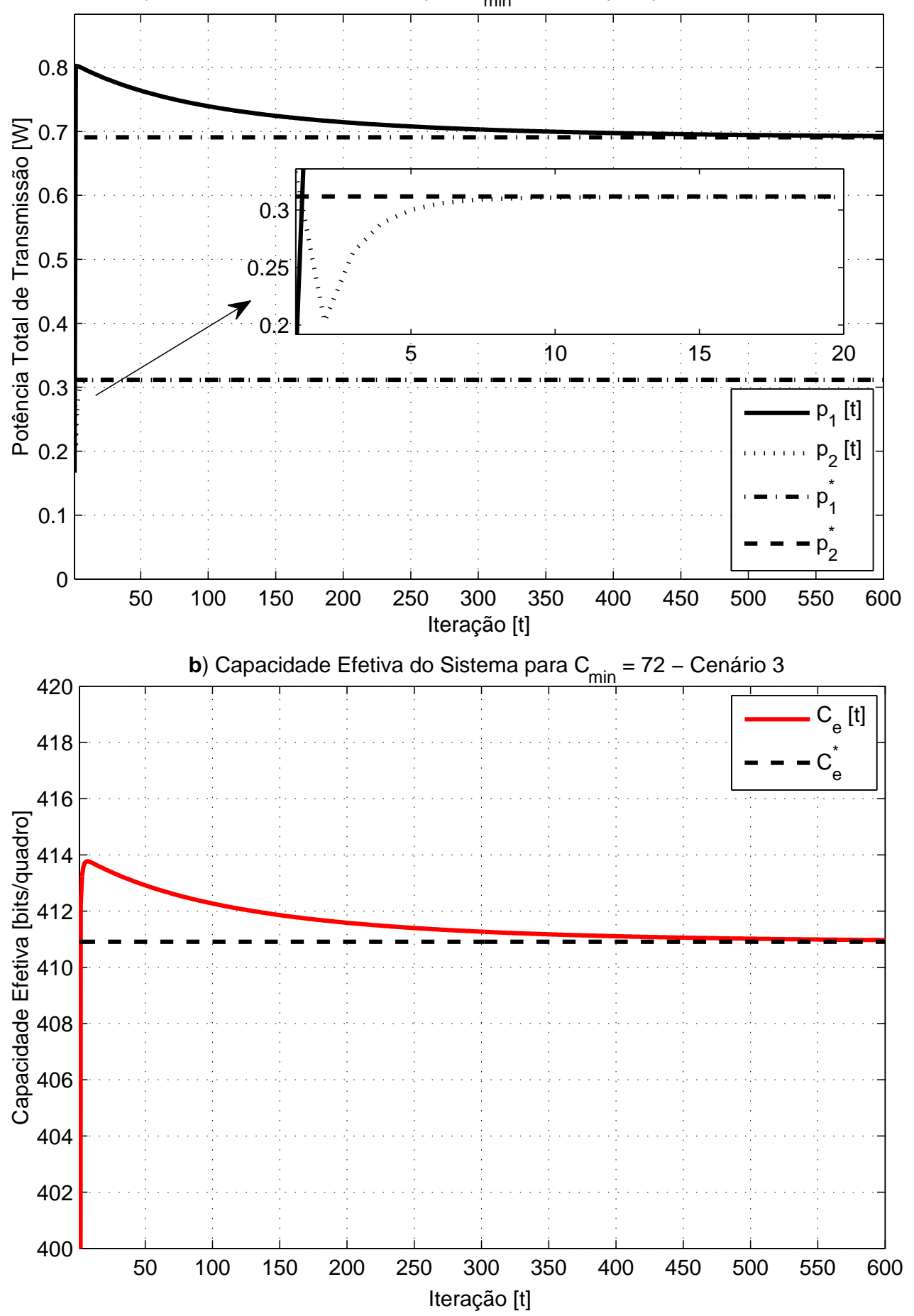

Figura 37: Evolução do algoritmo de maximização da capacidade efetiva baseado na decomposição dual de Lagrange: (a) em termos de potência total de transmissão por usuário; (b) em termos de capacidade efetiva total do sistema. Cenário $3 \operatorname{com} C_{\min }=72$. 


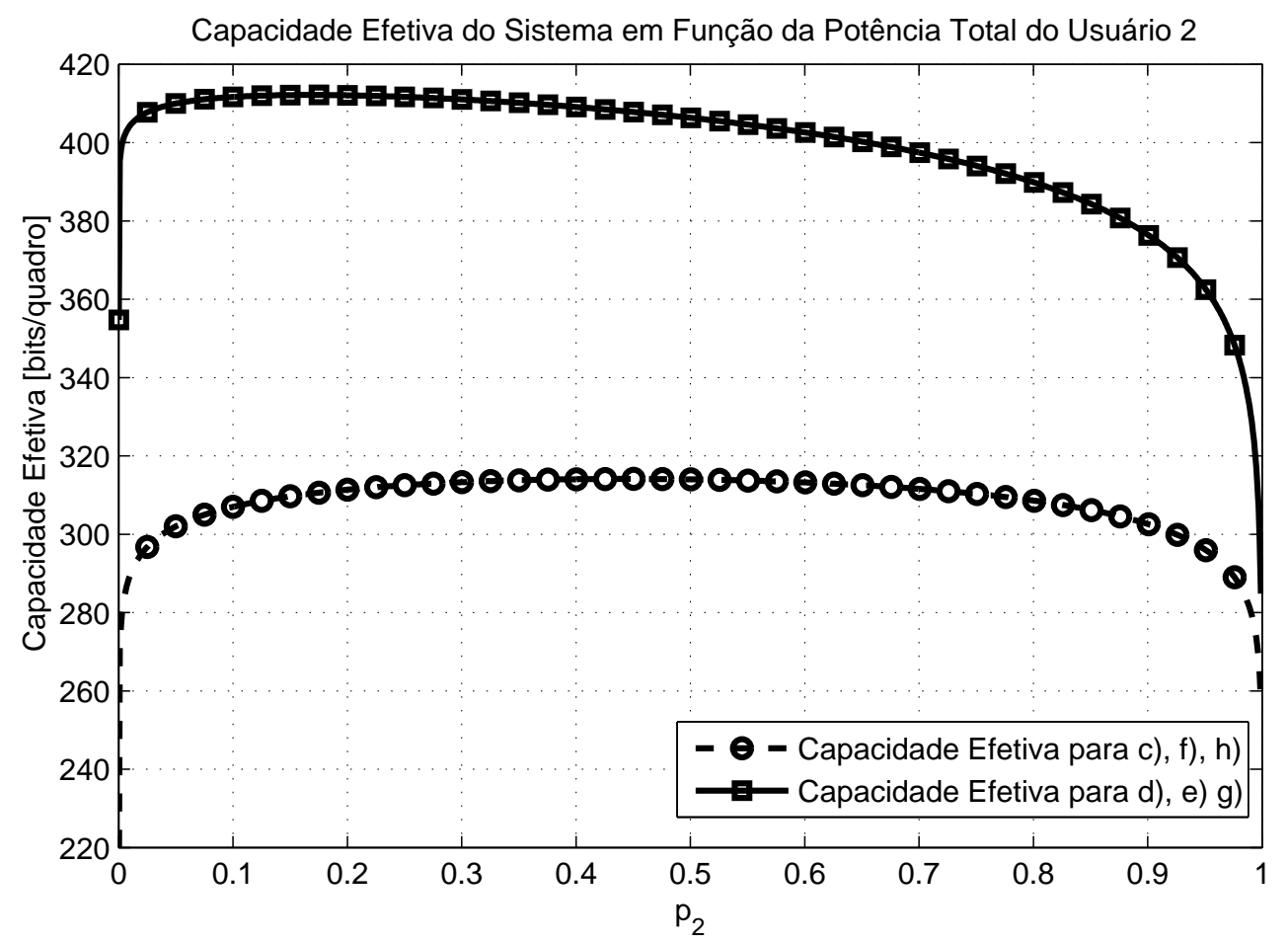

Figura 38: Capacidade efetiva em função da potência total de transmissão do usuário 2 para diferentes políticas de alocação de subportadoras descritas em (5.2).

certa tolerância ao atraso com um determinado nível de confiança ${ }^{8}$, é importante analisar a alocação de potência e subportadoras do ponto de vista instantâneo. Desta forma, considerando a alocação de potência e subportadora ótima para o cenário 3 com $C_{\min }=67$, a figura 39 ilustra os resultados instantâneos de taxa de transmissão para o usuário 2. Na figura 39 (a) o ganho de potência do canal do usuário $2\left(\left|\mathrm{~h}_{2}\right|^{2}\right)$ em função do tempo (quadros) é apresentado. As figuras 39(b) e 39(c) apresentam as taxas instantâneas de transmissão e, de forma específica em (c) é verificada a ocorrência de uma violação de qualidade de serviço, i.e., a taxa instantânea é menor que a capacidade efetiva do canal. Nesta ocasião os bits que não foram transmitidos são enviados para uma fila e aguardam a transmissão no próximo quadro.

De acordo com as simulações realizadas para o cenário 3 e considerando um

\footnotetext{
${ }^{8} \mathrm{O}$ nível de confiança está relacionado ao oposto da probabilidade de violação do atraso máximo.
} 
a) Ganho de Potência do Canal em Cada Quadro

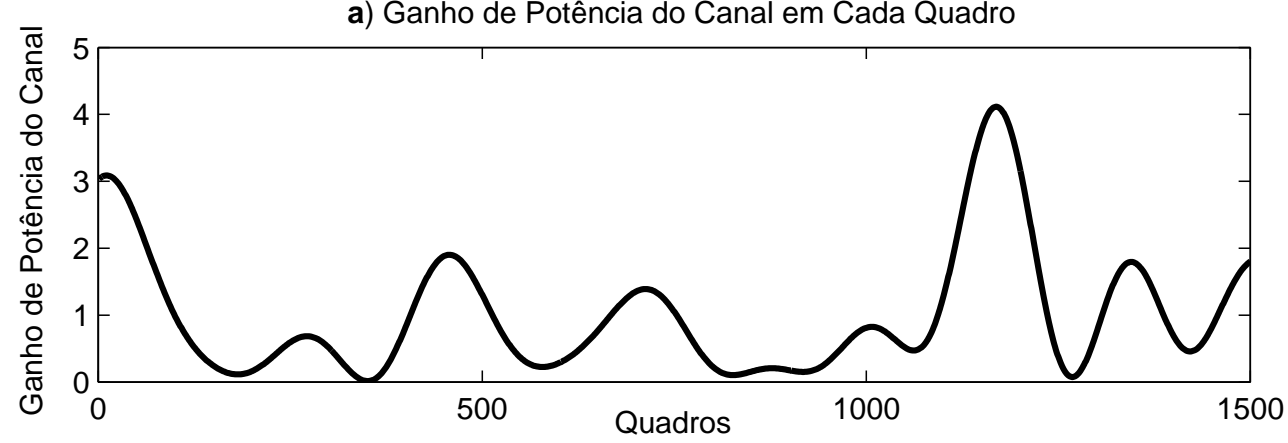

b) Taxa de Transmissão Instantânea do Usuário 2 - Cenário 3

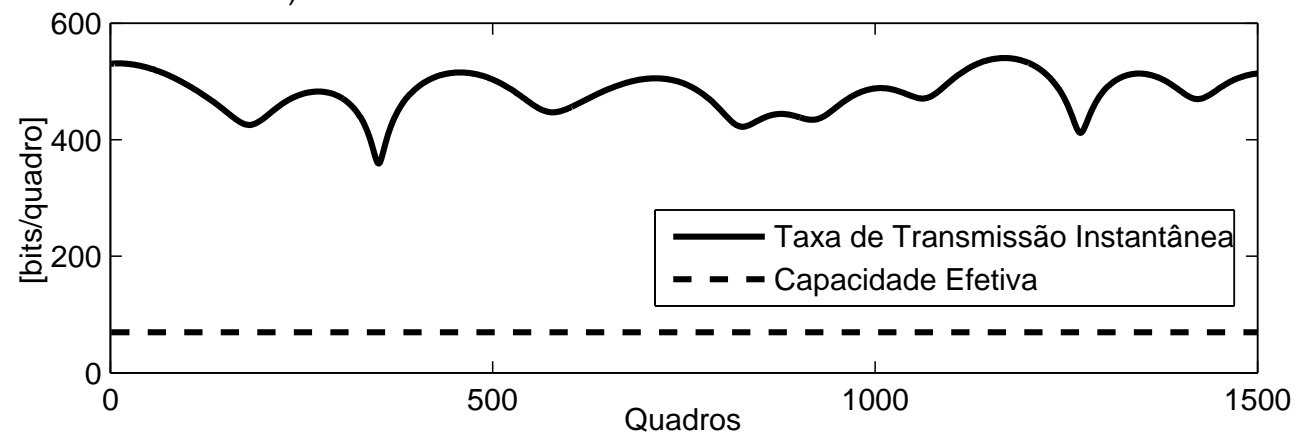

c) Taxa de Transmissão Instantânea para o Usuário 2 - Cenário 3

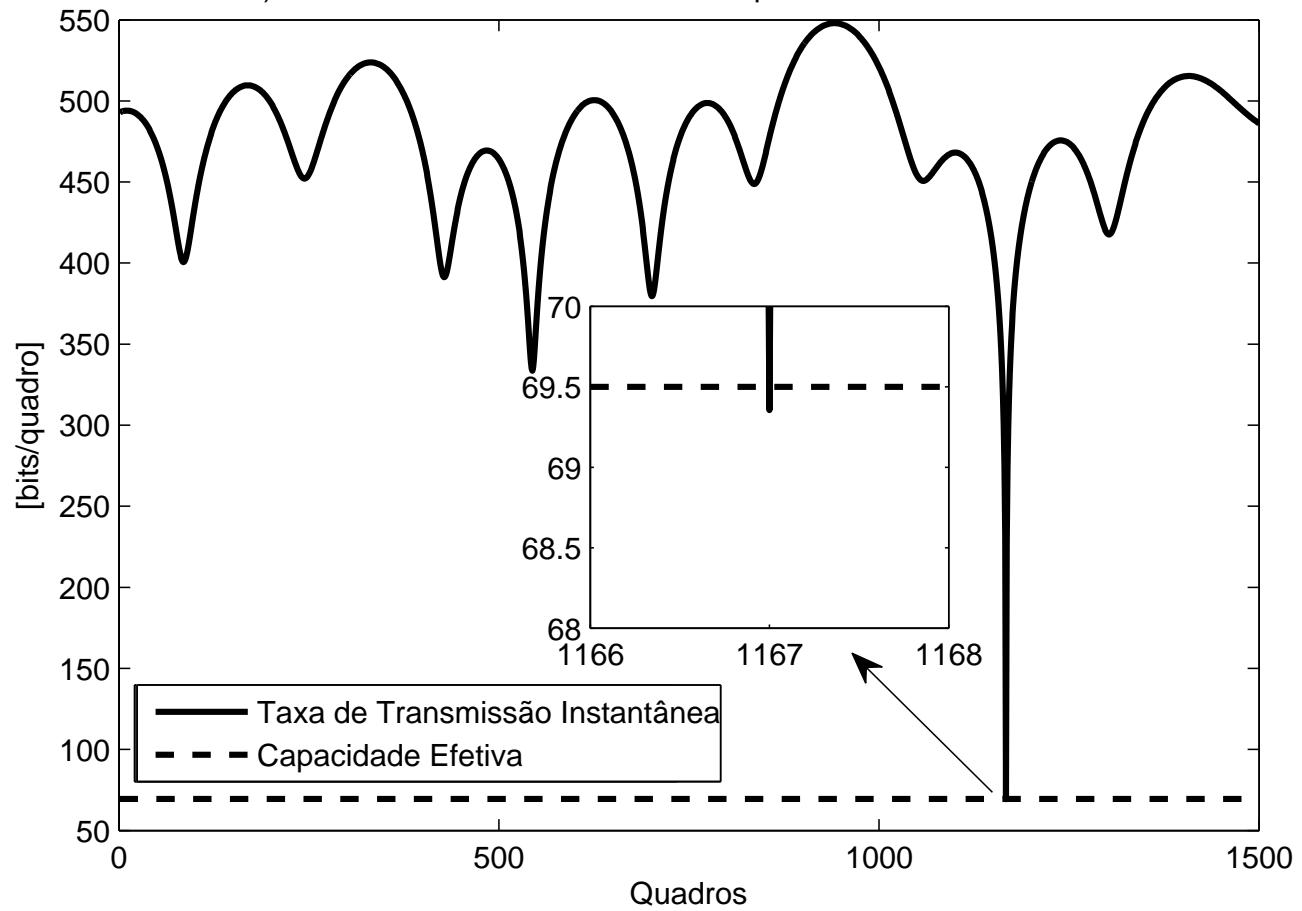

Figura 39: (a) Ganho de potência para a subportadora do usuário 2 no cenário 3. (b) e (c) Taxa instantânea para a potência ótima do usuário 2 que maximiza a capacidade efetiva do sistema. Em (c) existe a ocorrência de uma violação de QoS. Note que as figuras $(\mathbf{b})$ e (c) estão relacionadas à realizações de canal diferentes. 
ambiente de baixa e alta mobilidade, violações de qualidade de serviço ocorrem, em média, uma vez a cada $6 \times 10^{5}$ quadros. Considerando que cada quadro dura $667 \mu$ segundos, isto equivale a uma vioalação de QoS a cada 400 segundos, em média.

O cenário 4 sumarizado na tabela 15 foi utilizado como base para visualizar e verificar a funcionalidade do algoritmo proposto uma vez que em cenários realistas o número de dimensões (usuários e subportadoras) é elevado demais para que uma análise minuciosa seja feita. Todavia, observar a convergência e o comportamento do algoritmo em cenários realistas é de fundamental importância para garantir a robustez de funcionamento e de desempenho. Desta forma, a tabela 15 apresenta os valores dos parâmetros de um cenário de sistemas OFDMA tipicamente encontrados em sistemas de quarta geração (LTE/WiMAX).

Tabela 15: Parâmetros de Simulação do Cenário 4

\begin{tabular}{l|l}
\hline Parâmetro & Valor Adotado \\
\hline Banda Total do Sistema & $\mathcal{W}=20[\mathrm{MHz}]$ \\
Número de Subportadoras & $N=64$ \\
Número de Usuários no Sistema & $U=40$ \\
Expoente de QoS dos Usuários & Aleatório, $\mathcal{U}(0,1]$ \\
Capacidade Efetiva Mínima & $\mathcal{C}_{\mathrm{e}}^{i, \text { min }}=1[\mathrm{bits} /$ quadro], $\forall i$ \\
Banda de cada Subportadora & $B=\mathcal{W} / N=312,5[\mathrm{KHz}]$ \\
Périodo de Transmissão do Quadro & $T=667[\mu$ seg] \\
Densidade Espectral de Potência do Ruído & $N_{0}=10^{-12}[$ Watts $/$ Hertz] \\
Potência Máxima de Transmissão & $P_{\max }=20[$ Watts] \\
$\mathcal{U}(0,1]$ indica um processo estocástico de distribuição \\
uniforme no intervalo $(0,1]$.
\end{tabular}

Considerando a inicialização da alocação de potência de forma uniforme; de subportadoras de forma aleatória; variáveis duais unitárias e uma precisão $\epsilon=$ $10^{-6}$, a figura 40 apresenta um caso de evolução típica de alocação de potência e subportadora, no contexto do cenário 4.

Note que na figura 40, ao contrário das figuras para o cenário 3 (figuras 3537), não foi possível determinar o patamar da solução ótima pois existem, para 
a) Potência Total de Transmissão para cada usuário em cada Iteração - Cenário 4
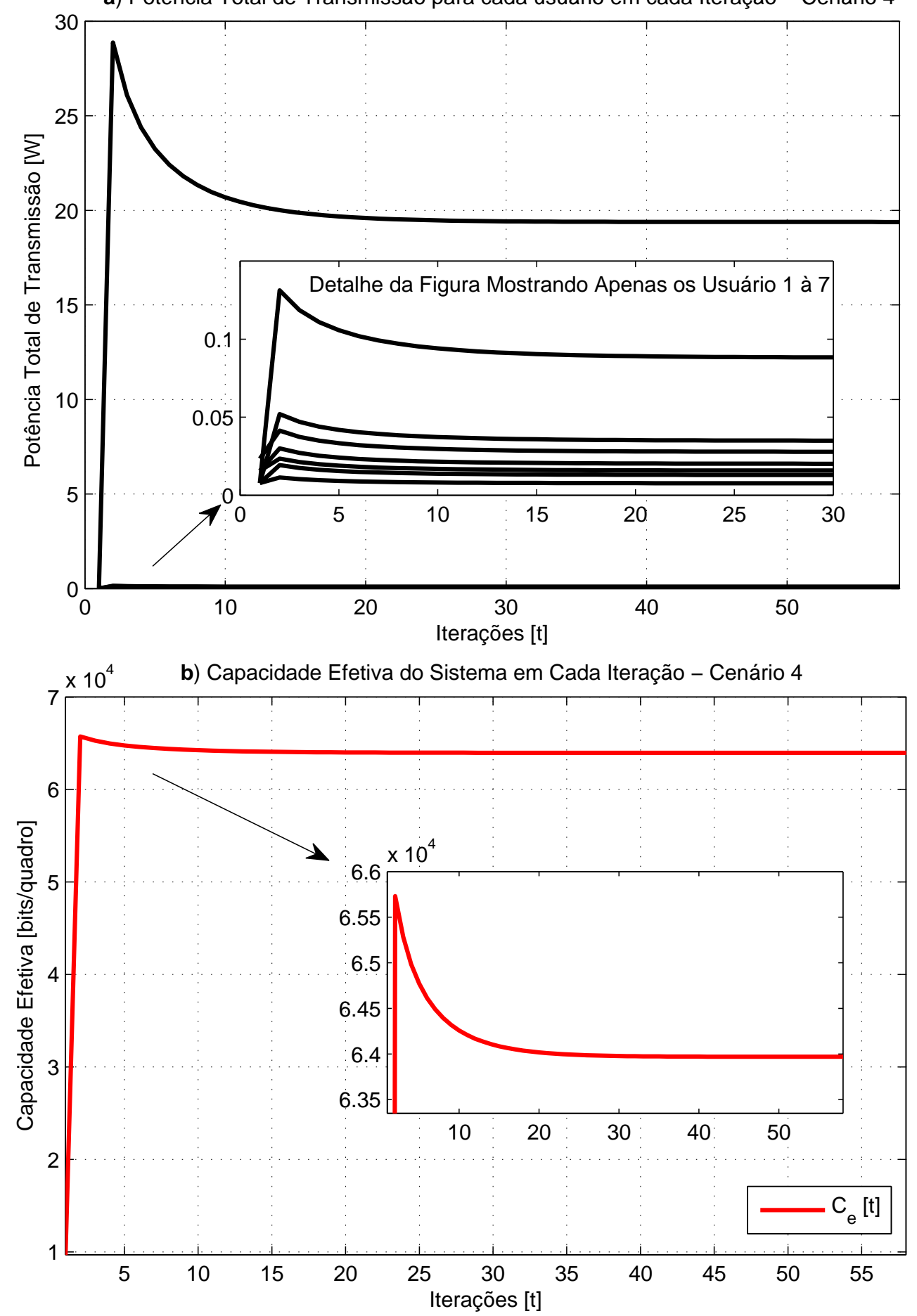

Figura 40: Evolução do algoritmo de maximização da capacidade efetiva baseado na decomposição dual de Lagrange: (a) em termos de potência total de transmissão por usuário; (b) em termos de capacidade efetiva total do sistema. Cenário $4 \operatorname{com} C_{\text {min }}=1$. 
o cenário $4,2^{40}$ matrizes distintas de alocação de subportadora. Isto equivale a aproximadamente $10^{12}$ possibilidades o que torna a busca exaustiva computacionalmente proibitiva, corroborando com a classificação NP-Hard do problema de maximização da capacidade efetiva em redes OFDMA.

\subsection{Resultados e Discussões para o Problema de Maximização da Eficiência Energética Efetiva em Sistemas OFDMA}

A fim de ilustrar as características do problema da maximização da eficiência energética efetiva e avaliar o desempenho da metodologia proposta, simulações foram conduzidas utilizando a plataforma MatLab 8.3. De forma semelhante à análise apresentada na seção anterior, analisa-se um cenário simples, primeiramente para se obter uma melhor visualização acerca do problema. Sendo assim a tabela 16 apresenta os parâmetros de simulação para o cenário 5.

Tabela 16: Parâmetros de Simulação para o Cenário 5

\begin{tabular}{l|l}
\hline Parâmetro & Valor Adotado \\
\hline Banda Total do Sistema & $\mathcal{W}=100[\mathrm{KHz}]$ \\
Número de Subportadoras & $N=3$ \\
Banda de cada Subcanal & $B=\mathcal{W} / N=33,3[\mathrm{KHz}]$ \\
Período de Transmissão do Quadro & $T=667[\mu \mathrm{seg}]$ \\
Densidade Espectral de Potência do Ruído & $N_{0}=10^{-12}[\mathrm{~W} / \mathrm{Hz}]$ \\
Potência Máxima de Transmissão & $P_{\max }=1[\mathrm{~W}]$ \\
Número de Usuários no Sistema & $U=2$ \\
Expoente de QoS dos Usuários & $\theta_{1}=0,1$ e $\theta_{2}=0,25$ \\
Capacidade Efetiva Mínima por Usuário & $C_{\mathrm{e}}^{i, \min }=1[\mathrm{bits} /$ quadro], $\forall i$ \\
Ineficiência do Amplificador de Potência & $\varrho=2,5$ \\
Potência Consumida por Circuitos & $P_{\mathrm{C}}=100[\mathrm{~mW}]$ \\
\hline
\end{tabular}

A eficiência de amplificadores de potência em algumas redes e topologias pode chegar a 40\%, como no trabalho de (FISCHER, 2008) e (ARNOLD et al., 2010). Isto justifica a utilização do parâmetro de ineficiência do amplificador de potência equivalente a $\varrho=2,5$. 
A fim de observar a relação entre eficiência energética efetiva e capacidade efetiva apresenta-se a figura 41. Uma vez que $\theta_{1}<\theta_{2}$, duas subportadoras são alocadas para o usuário 1 enquanto apenas uma é utilizada pelo usuário 2. Além das curvas de nível e da superfície referentes à eficiência energética efetiva, a figura apresenta a linha tracejada que indica as políticas de alocação de potência para as quais a capacidade efetiva é máxima, i.e., para um dado $P_{\max }$ arbitrário a linha preta tracejada indica a distribuição ótima de potência que garante a capacidade efetiva máxima e cuja soma é equivalente a $P_{\max }$.

Note na figura 41 que a linha da capacidade efetiva máxima não está distante do ponto de máxima eficiência energética efetiva. Isto indica que a relação de compromisso entre a eficiência energética efetiva e a capacidade efetiva é estreita em sistemas operando sob um regime restrito de potência. Em outras palavras, para um $P_{\max }$ suficientemente pequeno, a diferença entre o ponto que garante a eficiência energética efetiva máxima e a capacidade efetiva máxima é pequena (da ordem de milésimos de watts em cada dimensão), neste cenário.

Para demonstrar o desempenho do algoritmo para maximização da eficiência energética efetiva proposto ${ }^{9}$ a figura 42 apresenta a evolução do algoritmo de Dinkelbach para maximização da eficiência energética efetiva no enlace direto de sistemas OFDMA no cenário 5. A precisão do algoritmo nas simulações da figura 42 é $\epsilon=10^{-6}$. Note que o algoritmo converge de forma rápida (7 iterações) para a eficiência energética efetiva máxima. De fato, após a quarta iteração as alterações do nível de potência já são da ordem de unidades de miliwatts.

A fim de analisar um cenário realista, a tabela 17 apresenta os valores de parâmetros adotados considerando um cenário comumente encontrado em redes de quarta geração como LTE e WiMAX.

A figura 43 apresenta a evolução do algoritmo AIMEEE no cenário 6. Note

\footnotetext{
${ }^{9}$ AIMEEE apresentado no Algoritmo 4.5
} 

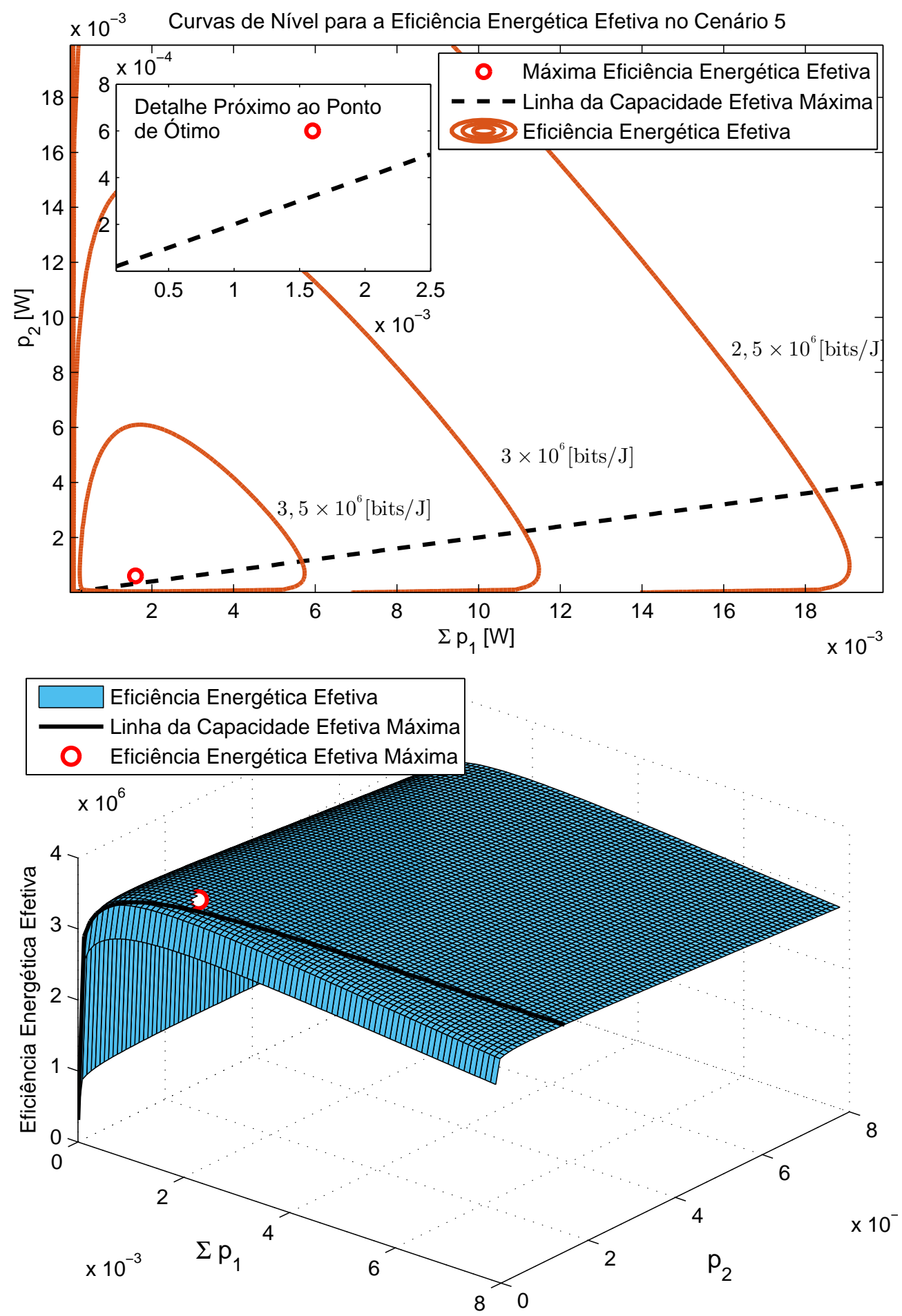

Figura 41: Curvas de nível e superfície tridimensional para a eficiência energética efetiva. A linha tracejada apresenta a combinação de valores de potência de transmissão para o usuário 1 e 2 onde a capacidade efetiva é máxima. 
(a) Eficiência Energética Efetiva para cada Iteração - Cenário 5

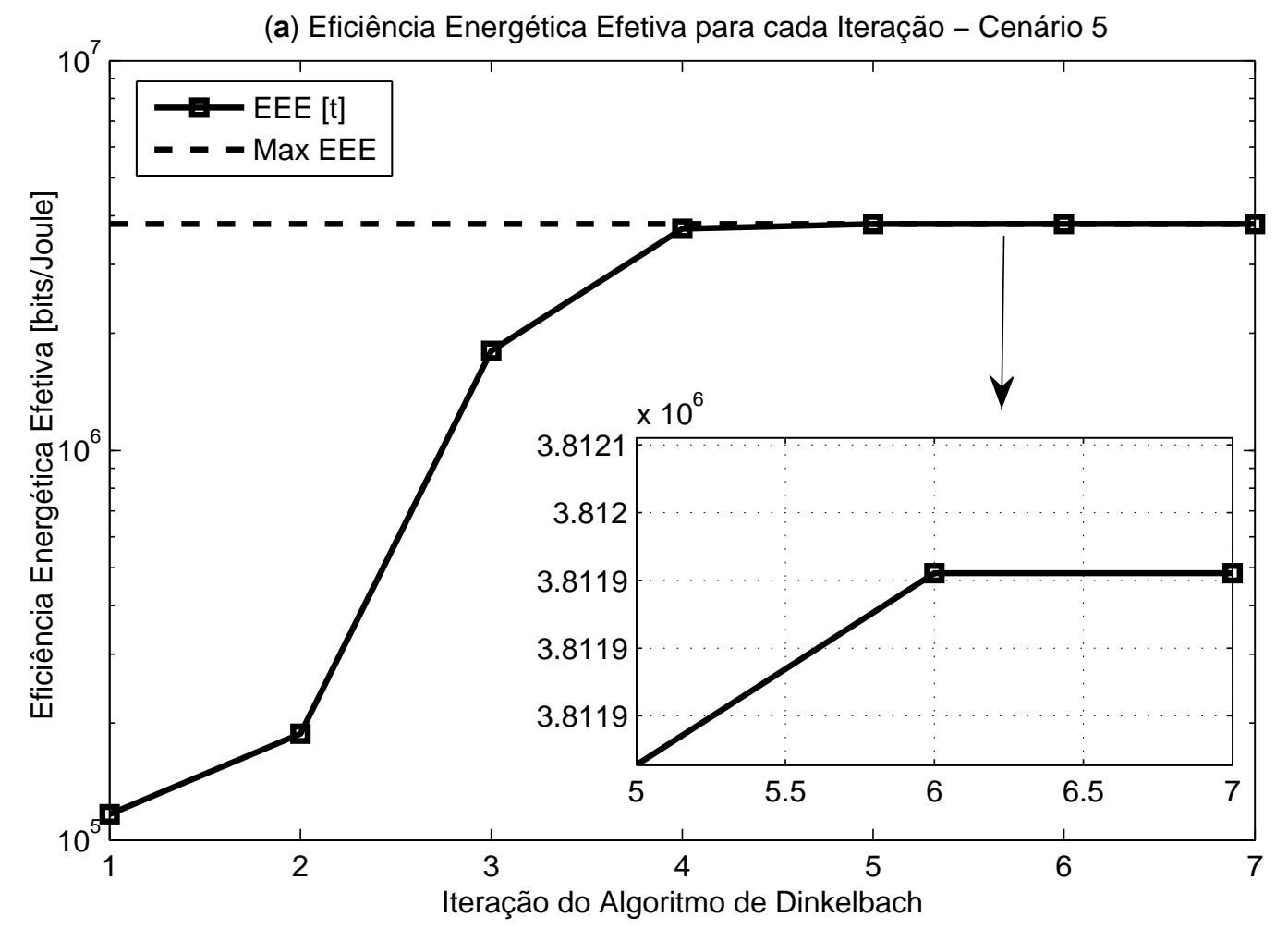

(b) Potência Total de Transmissão a cada Iteração - Cenário 5

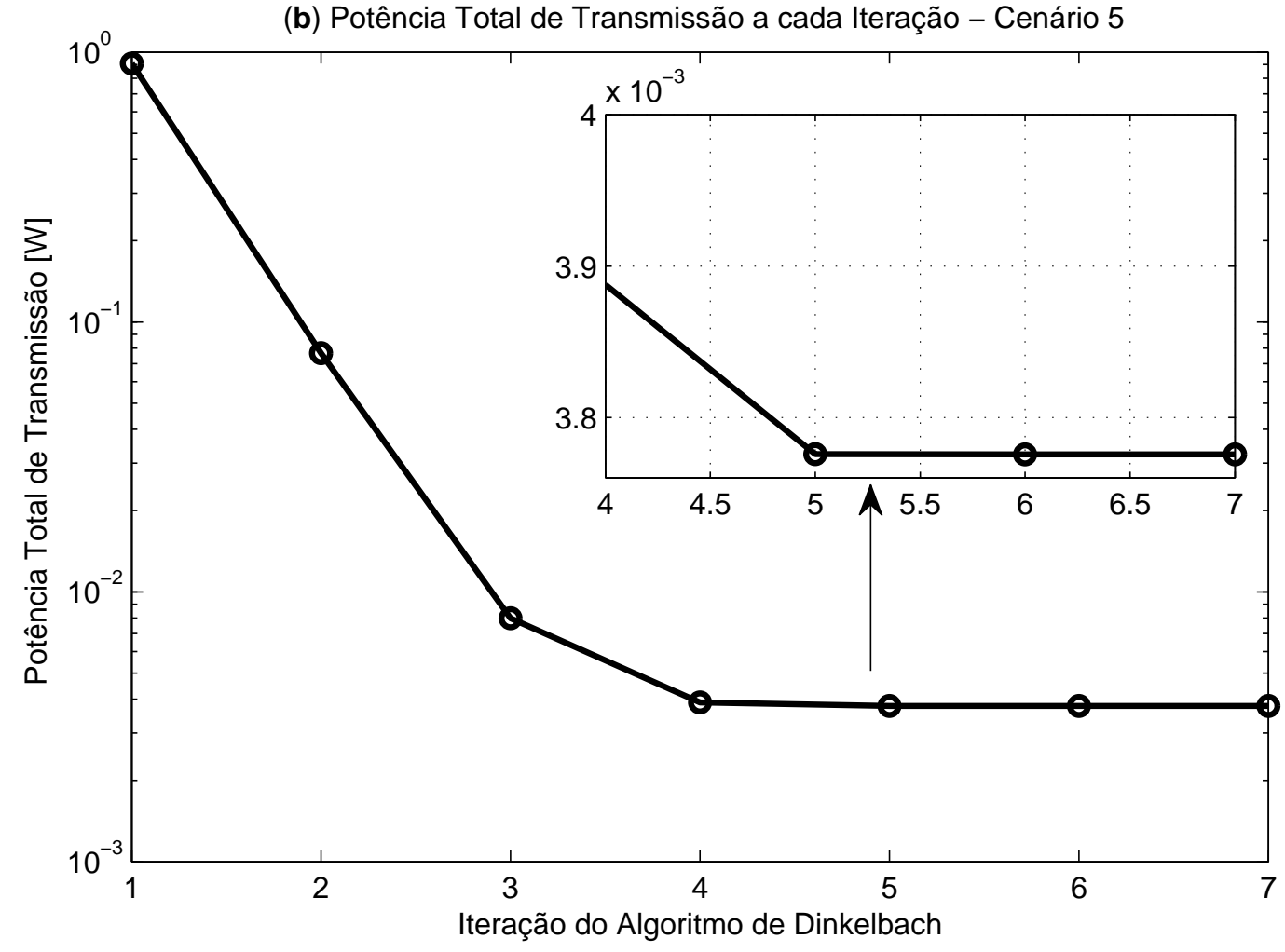

Figura 42: (a) Eficiência energética efetiva e (b) potência total de transmissão em cada iteração do algoritmo 4.5 para o cenário 5 (tabela 16). 

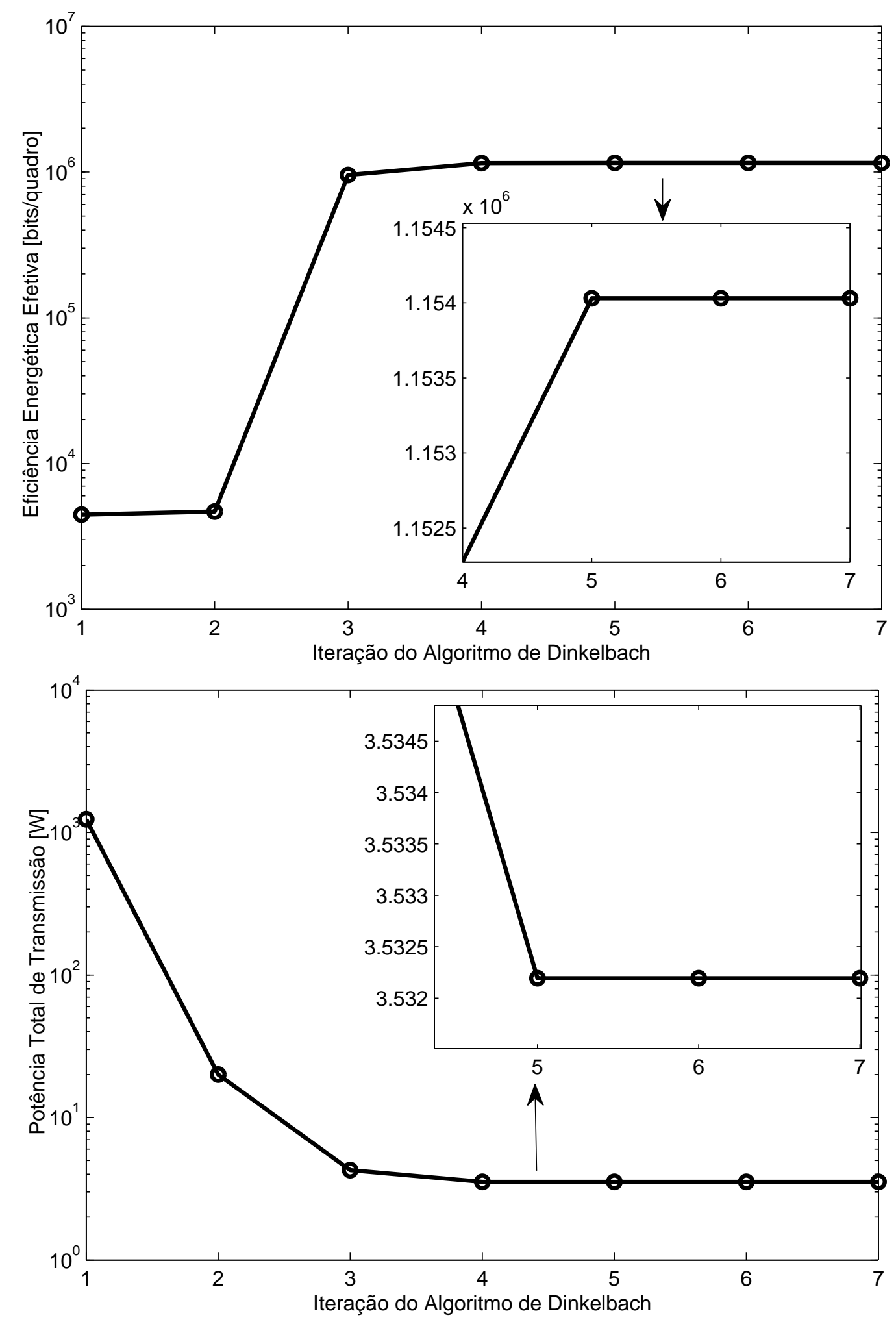

Figura 43: (a) Eficiência energética efetiva e (b) potência total de transmissão em cada iteração do algoritmo 4.5 para o cenário 6 (tabela 17). 
Tabela 17: Parâmetros de Simulação para o Cenário 6

\begin{tabular}{|c|c|}
\hline Parâmetro & Valor Adotado \\
\hline Banda Total do Sistema & $\mathcal{W}=20[\mathrm{MHz}]$ \\
\hline Núm & $N=128$ \\
\hline Bar & $B=\mathcal{W} / N=156.25[\mathrm{KHz}]$ \\
\hline Perí & $T=667[\mu$ seg $]$ \\
\hline do Ruído & $N_{0}=10^{-12}[\mathrm{~W} / \mathrm{Hz}]$ \\
\hline Potê & $P_{\max }=20[\mathrm{~W}]$ \\
\hline Núm & $U=50$ \\
\hline $\mathrm{Exl}$ & Aleatório, $\theta_{j}=\mathcal{U}(0,1]$ \\
\hline Ffoting Mínims & $C_{\mathrm{e}}^{i, \min }=1$ [bits/quadro], $\forall i$ \\
\hline Ine & $\varrho=2.5$ \\
\hline Consumida por Circui & $P_{\mathrm{C}}=100[\mathrm{~W}$ \\
\hline
\end{tabular}

que, embora a complexidade do problema de maximização da eficiência energética efetiva no cenário 6 seja maior que no cenário 5, dada sua dimensionalidade elevada quando comparada àquela do cenário 5, o algoritmo converge com o mesmo número de iterações do cenário 5. Sendo assim é possível conjecturar que a influência da dimensão do problema (número de usuários e subportadoras) tem baixo impacto na velocidade de convergência do algoritmo de alocação conjunta de potência e subportadora proposto, o AIMEEE. Para corroborar com esta afirmação apresenta-se a tabela 18 com o número médio de iterações necessárias para a convergência, considerando os valores de parâmetros do cenário 6 e diferentes combinações de números de usuários e subportadoras. Note que de fato a diferença entre as três configurações apresentadas em termos de iterações necessárias à convergência não sofrem grandes alterações conforme a complexidade do problema aumenta.

É importante observar que três parâmetros têm impacto significativo na fun-

Tabela 18: Número de Iterações Necessárias à Convergência para o Algoritmo AIMEEE

\begin{tabular}{ll|r}
\hline \# de Usuários & \# de Subportadoras & \# de Iterações \\
\hline$U=2$ & $N=3$ & 5,97 \\
$U=10$ & $N=16$ & 6,86 \\
$U=20$ & $N=32$ & 7,41
\end{tabular}


ção de eficiência energética: o expoente de qualidade de serviço estatística, a ineficiência do amplificador de potência e a potência consumida pelos circuitos. Sendo assim, para efeito de comparação com o cenário 5 apresenta-se o cenário 7 cujos valores de parâmetros do sistema estão descritos na tabela 19 .

Tabela 19: Parâmetros de Simulação para o Cenário 7

\begin{tabular}{|c|c|}
\hline Parâmetro & Valor Adotado \\
\hline Banda Total do Sistema & $\mathcal{W}=100[\mathrm{KHz}]$ \\
\hline Número de Subportadoras & $N=2$ \\
\hline Banda de cada Subcanal & $B=\mathcal{W} / N=50[\mathrm{KHz}]$ \\
\hline Período de Transmissão do Quadro & $T=667[\mu \mathrm{seg}]$ \\
\hline Densidade Espectral de Potência do Ruído & $N_{0}=10^{-12}[\mathrm{~W} / \mathrm{Hz}]$ \\
\hline Potência Máxima de Transmissão & $P_{\max }=1[\mathrm{~W}]$ \\
\hline Número de Usuários no Sistema & $U=2$ \\
\hline Expoente de QoS dos Usuários & $\theta_{1}=0,1$ e $\theta_{2}=0,25$ \\
\hline Capacidade Efetiva Mínima por Usuário & $C_{\min }=1[\mathrm{bit} /$ quadro $]$ \\
\hline Ineficiência do Amplificador de Potência & $\varrho=2,5$ \\
\hline Potência Consumida por Circuitos & $P_{\mathrm{C}}=100[\mathrm{~mW}]$ \\
\hline
\end{tabular}

A figura 44 apresenta os valores de potência de transmissão ótima que garantem a máxima eficiência energética efetiva para diferentes valores de expoente de qualidade de serviço estatística. Para a curva do cenário 5 são considerados os parâmetros da tabela 16 com exceção do valor de $\theta_{2}$. Adicionalmente, o usuário 2 transmite em apenas uma subportadora.

Já para a curva do cenário 6 , o usuário 2 também transmite apenas com uma subportadora, e os parâmetros da tabela 17, com exceção de $\theta_{2}$, são considerados nas simulações. Uma vez que o crescimento de $\theta$ implica em maiores restrições de qualidade de serviço, i.e. menor tolerância ao atraso e/ou maior confiabilidade ${ }^{10}$, é possível afirmar que quanto mais restritiva for a condição de transmissão em termos de requisitos de QoS menor é a potência de transmissão necessária para atingir a eficiência energética efetiva máxima do sistema. De fato, a potência ótima que maximiza a eficiência energética efetiva decai exponencialmente com o aumento das restrições relativas à tolerância ao atraso. Isto pode ser observado

\footnotetext{
${ }^{10} \mathrm{Ou}$ seja, menor probabilidade de violação da restrição de atraso máximo.
} 


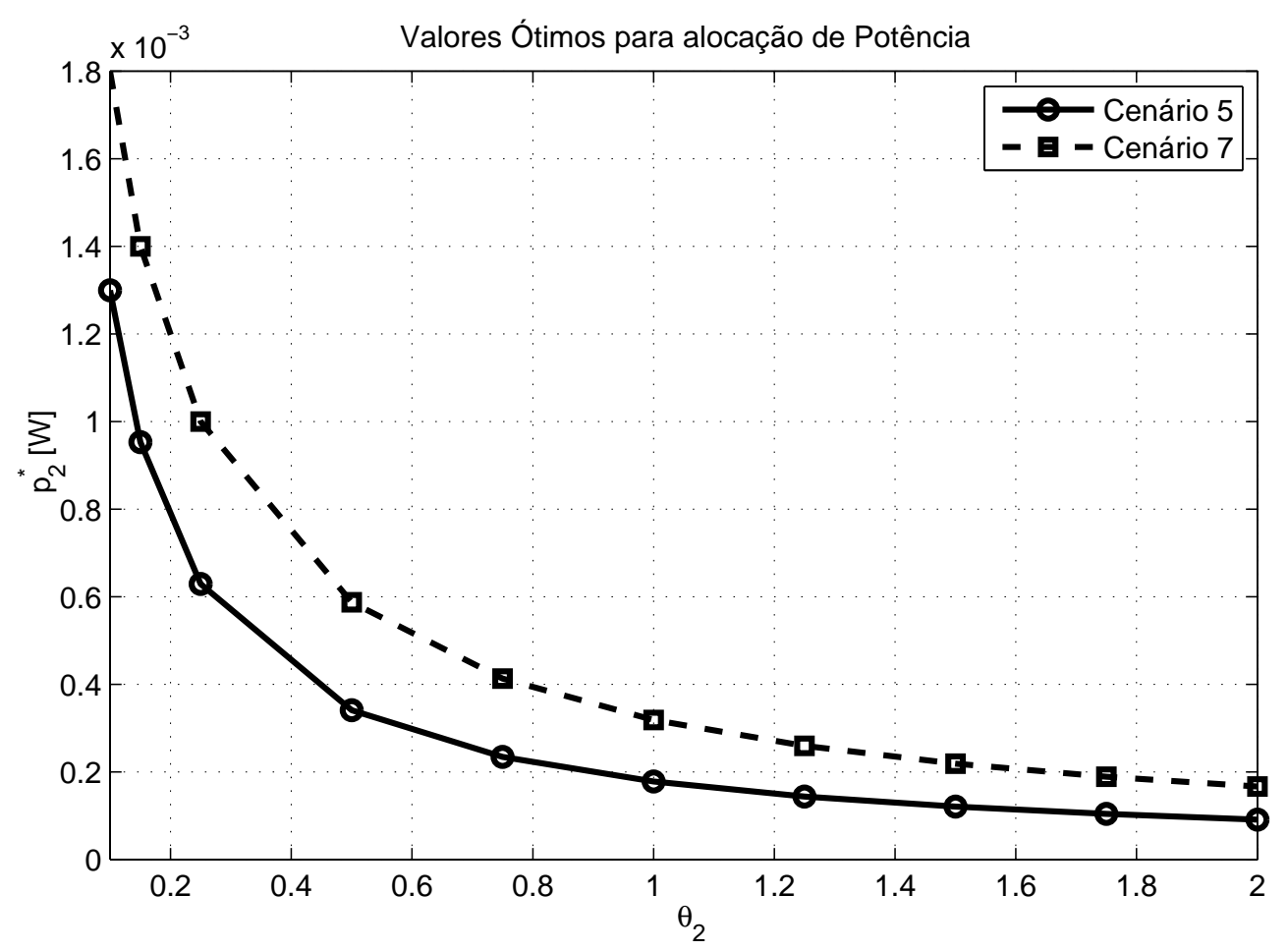

Figura 44: Potência de transmissão ótima em função dos valores de expoente de qualidade de serviço estatística $\theta$; para o usuário número 2 , nos cenário 5 e 7 , considerando que o mesmo transmite em apenas uma subportadora.

de forma expedita na figura 44, na qual a potência de transmissão do usuário 2, que garante a eficiência energética efetiva máxima, decai de forma exponencial com o crescimento do valor do expoente de qualidade de serviço estatística $\theta_{2}$. De forma semelhante à figura 44, a figura 45 apresenta os valores ótimos de potência para o usuário 2 que maximizam a eficiência energética efetiva do sistema em função da ineficiência do amplificador de potência.

Duas conclusões podem ser elaboradas a partir da figura 45. A primeira é que quanto maior é a ineficiência do amplificador, menor é a potência necessária para se atingir a máxima eficiência energética efetiva. A segunda conclusão é que esse decaimento é exponencial inicialmente (para valores de eficiência do amplificador maiores que 50\%), passando a apresentar comportamento assintótico do tipo linear quando a eficiência do amplificador vai a zero.

O último parâmetro a ser analisado é a potência consumida pelos circuitos 


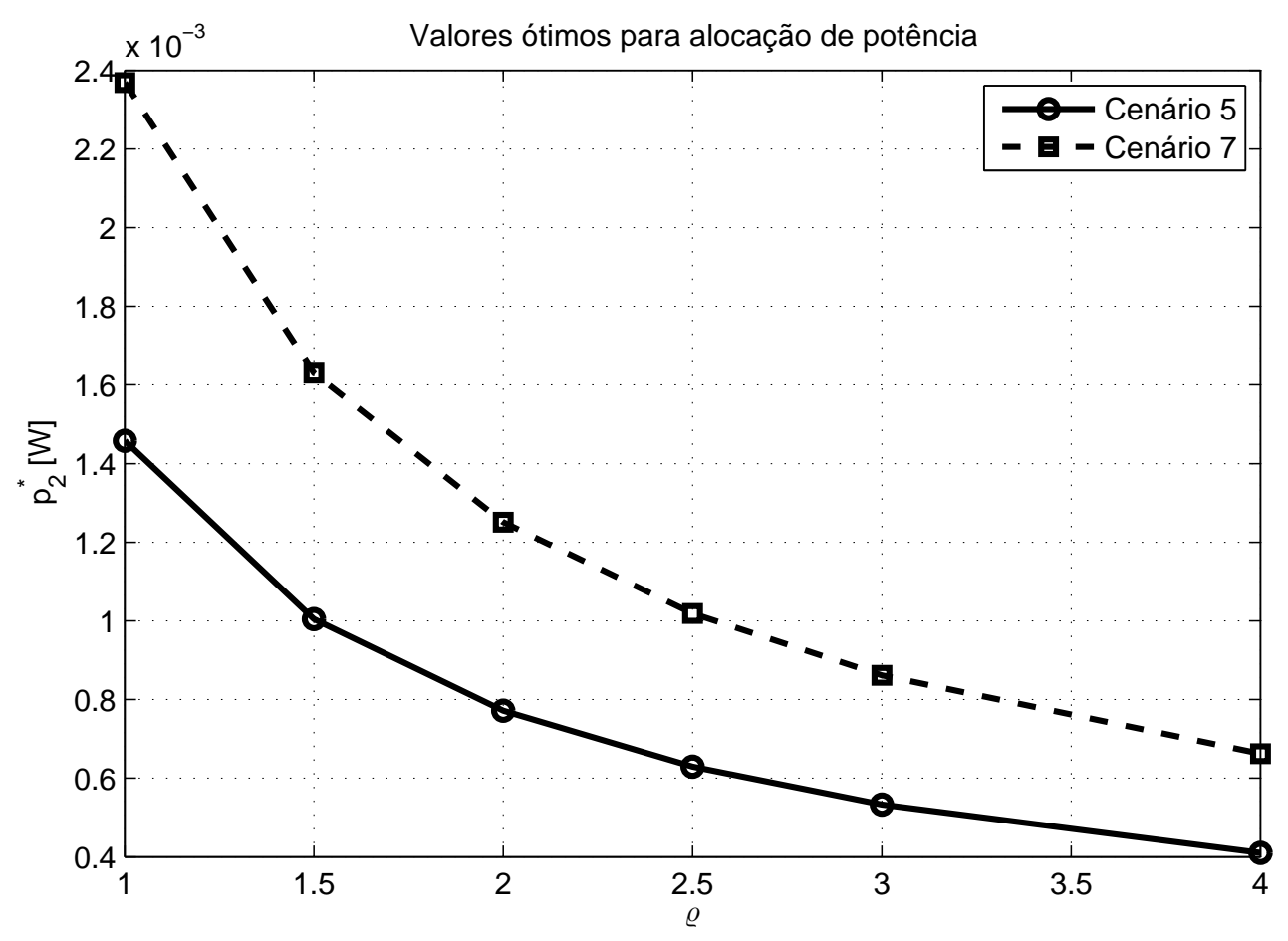

Figura 45: Potência de transmissão ótima em função da ineficiência do amplificador $\varrho$ para o usuário número 2 , nos cenários 5 e 7 , considerando que o mesmo transmite em apenas uma subportadora.

do transmissor $P_{\mathrm{C}}$. A figura 46 apresenta a potência ótima para o usuário 2 nos cenários 5 e 6 de forma semelhante aos resultados apresentados nas figuras anteriores, i.e. considerando todos os parâmetros das tabelas 16 e 17 fixos com exceção da potência consumida pelos circuitos. Adicionalmente, o usuário 2 transmite em apenas uma subportadora.

Observe que ao contrário dos demais parâmetros analisados $(\theta$ e $\varrho)$ o aumento da potência consumida nos circuitos implica no aumento da potência ótima de transmissão que maximiza eficiência energética efetiva. É possível ainda verificar que esse crescimento é linear em relação a $P_{\mathrm{C}}$ e que a taxa deste mesmo crescimento depende dos demais parâmetros do sistema (banda, ineficiência do amplificador e expoente de qualidade de serviço).

Essa característica é importante uma vez que a diferença de gastos de potência com os circuitos utilizados é muito diferente quando estação rádio base e 


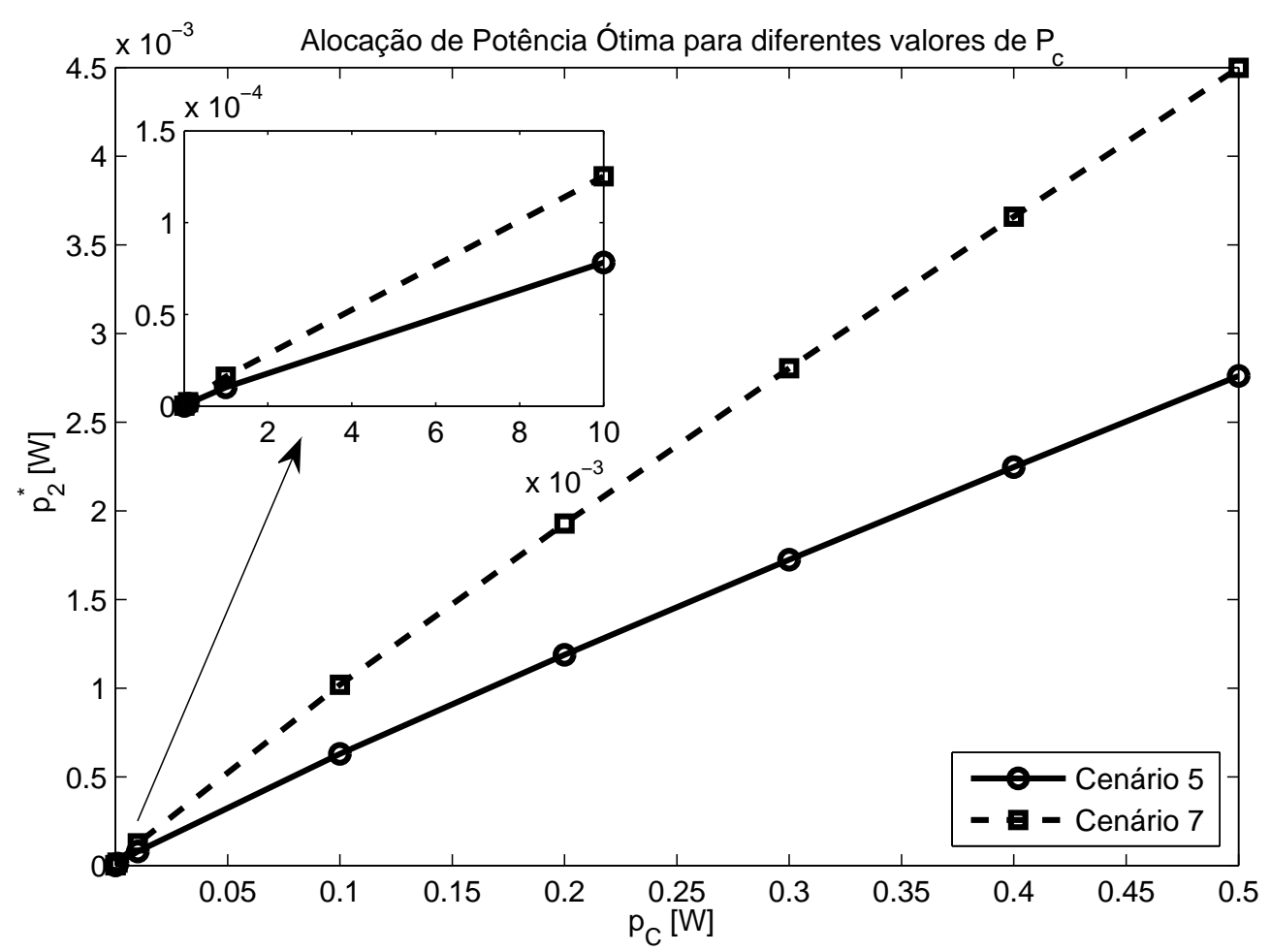

Figura 46: Potência de transmissão ótima em função da potência consumida pelos circuitos do transmissor $P_{\mathrm{C}}$ para o usuário número 2 , nos cenários 5 e 7 , considerando que o mesmo transmite em apenas uma subportadora.

unidade móvel são comparadas. Por exemplo, no trabalho de (LOODARICHEH; MALLICK; BHARGAVA, 2014), a potência consumida pelos circuitos na estação rádio base é mil vezes maior que a potência consumida no terminal móvel. Esta diferença implica em um desvio de potência ótima para transmissão significativo, que pode ainda ser agravado pelos demais parâmetros do sistema, i.e., dados os parâmetros do sistema, a taxa de crescimento da potência ótima de transmissão em relação a $P_{\mathrm{C}}$ pode ser grande o suficiente para que o ponto de máximo da função de eficiência energética efetiva do sistema esteja fora do domínio do problema.

Portanto, fica evidente que o projeto de redes de comunicação sem fio energeticamente eficientes vai além dos problemas de alocação de recursos. Construir amplificadores eficientes e reduzir o consumo de potência nos circuitos, principalmente da estação rádio-base, é de fundamental importância para o aumento 
global da eficiência energética da rede. 


\section{CONCLUSÕES E TRABALHOS FUTUROS}

Esta Tese tratou de problemas de alocação de recursos em redes de comunicação sem fio de múltiplo acesso em dois diferentes cenários e topologias: o primeiro abordou o controle de potência no enlace de subida de sistemas cooperativos MCDS/CDMA e o segundo da alocação de potência e espectro no enlace de descida de sistemas OFDMA. Foram propostas soluções para os problemas de otimização de alocação de potência e de subportadoras sujeitos, ou não, ao atendimento de qualidade de serviço, taxa de transmissão mínima e de atraso estatístico máximo tolerável.

Esta Tese de doutorado apresentou um total de sete soluções distintas para três diferentes problemas de alocação de recursos em redes sem fio de múltiplo acesso. Especificamente, soluções para os seguintes problemas de otimização foram propostas:

- Maximização da eficiência energética em sistema cooperativos com múltiplas subportadoras ortogonais com múltiplo acesso por divisão de código de sequência direta - MC-DS/CDMA;

- Maximização da capacidade efetiva em sistemas de múltiplo acesso por divisão de frequências ortogonais com garantias de qualidade de serviço estatística representada por atraso máximo tolerável e a probabilidade de violação do mesmo; 
- Maximização da eficiência energética efetiva de sistemas OFDMA;

Para o primeiro problema de otimização foram propostas cinco metodologias para solucioná-lo: três métodos distribuídos, baseados em teoria de jogos e dois métodos centralizados, baseados em métodos heurísticos. Entre os cinco, o método EE-MDPCA que considera a média de ganhos dos canais merece destaque, pois, o compromisso entre complexidade e desempenho que este apresenta é promissor. Com complexidade constante e atingindo $96 \%$ do valor da solução ótima com pouco mais da metade da potência de transmissão média dos demais métodos, esta abordagem apresenta todas as características desejadas em um algoritmo distribuído de alocação de recursos.

De forma geral, para todos os algoritmos distribuídos, o número de bits por pacote tem um impacto significativo no desempenho do sistema, i.e. quanto maior o número de bits por pacote maior é a potência necessária para garantir a máxima eficiência energética. Logo, aumentar este parâmetro induz o método de otimização a buscar a máxima eficiência espectral em detrimento da eficiência energética.

O segundo problema tratado, da maximização da capacidade efetiva no enlace direto de sistemas OFDMA, foi solucionado utilizando uma versão relaxada do problema original associado ao método de decomposição dual de Lagrange. Utilizando exemplos numéricos demonstrou-se o funcionamento do algoritmo proposto em situações com restrições leves e em regimes rigorosos de qualidade de serviço estatística. O algoritmo proposto mostrou-se capaz de resolver o problema de otimização de forma eficiente para ambos os casos.

Adicionalmente, com o intuito de compreender o significado prático da capacidade efetiva, simulações foram conduzidas a fim de verificar a frequência com que aconteciam violações da restrição da qualidade de serviço estatística. Para 
o cenário de simulação proposto, estas violações ocorrem, em média, uma vez a cada 400 segundos, o que do ponto de vista prático torna a metodologia proposta implementável nos padrões de tecnologia atuais e futuros (sistemas de quarta e quinta geração).

O terceiro problema investigado nesta Tese de doutorado refere-se à maximização da eficiência energética efetiva, i.e., a maior eficiência energética que pode ser garantida pelo transmissor de um sistema OFDMA dado um atraso máximo tolerável e uma probabilidade de violação de atraso na entrega de informação. Para resolver este problema fez-se uso do método de Dinkelbach para então solucionar o problema paramétrico através do método de otimização baseado na decomposição dual de Lagrange.

Um estudo sobre o impacto de parâmetros do sistema inerentes ao projeto e à construção de equipamentos de qualidade foi oferecido e desenvolvido. Foram analisados o impacto da eficiência do amplificador de potência, da tolerância e intolerância ao atraso e, finalmente, da potência consumida pelos circuitos da estação rádio base. Quanto ao método proposto para a solução do problema de otimização, foi possível observar que o mesmo converge rapidamente, mesmo em cenários complexos e realistas encontrados nos sistemas de quarta geração atuais (LTE e WiMAX).

A característica que pode ser considerada a mais importante da proposta de solução para os dois últimos problemas investigados é o fato da alocação de recursos ser conduzida sem a necessidade de conhecimento das condições de canal. Esta característica permite que o gerenciamento do sistema seja simplificado uma vez que a efetiva alocação de recursos não requer nenhum tipo de realimentação e/ou estimador. Adicionalmente, a ausência de troca de informações de controle do sistema entre a estação rádio-base e terminais móveis permite uma maior, mesmo que marginal, eficiência espectral quando comparado aos algoritmos de 
alocação de recursos mais tradicionais, os quais necessitam de realimentação e/ou troca de informação entre os ativos da rede, tendo em vista gerenciar os recursos disponíveis de forma eficiente.

Sendo assim, a contribuição desta Tese de doutorado pode ser sumarizada nos seguintes pontos:

1. Proposta e caracterização de um algoritmo distribuído para maximização da eficiência energética no enlance reverso de sistemas cooperativos MCDS/CDMA utilizando teoria de jogos e o algoritmo iterativo de water-filling;

2. Proposta e caracterização de um algoritmo distribuído para maximização da eficiência energética no enlance reverso de sistemas cooperativos MCDS/CDMA utilizando teoria de jogos e o algoritmo distribuído de controle de potência baseado no equilíbrio de Verhulst;

3. Proposta e caracterização de um algoritmo distribuído para maximização da eficiência energética no enlance reverso de sistemas cooperativos MCDS/CDMA considerando o sistema como um DS/CDMA convencional, e realizando alocação de potência uniforme em todas as subportadoras;

4. Proposta e caracterização de um algoritmo centralizado para maximização da eficiência energética no enlance reverso de sistemas cooperativos MCDS/CDMA utilizando o método heurístico baseado no comportamento de vaga-lumes;

5. Proposta e caracterização de um algoritmo centralizado para maximização da eficiência energética no enlance reverso de sistemas cooperativos MCDS/CDMA utilizando a otimização heurística por enxame de partículas;

6. Proposta e caracterização de um algoritmo centralizado para a maximização da capacidade efetiva do enlace direto de sistemas OFDMA sem a 
necessidade de conhecimento da condição instantânea do canal;

7. Proposta e caracterização de um algoritmo centralizado para a maximização da eficiência energética efetiva do enlace direto de sistemas OFDMA sem a necessidade de conhecimento da condição instantânea do canal;

Durante o desenvolvimento do trabalho foram identificados temas e problemas ainda em aberto, ou não resolvidos satisfatoriamente na literatura, que podem ser considerados em trabalhos futuros, tais como:

1. Análise da capacidade efetiva em canais de múltiplo acesso sujeitos à interferência utilizando como base o trabalho de (WU; NEGI, 2003);

2. Descrição e proposta de soluções promissoras do ponto de vista de implementação para os problemas relacionados à capacidade efetiva no domínio discreto utilizando técnicas mais sofisticadas, tais como modulação adaptativa, com base em trabalhos de alocação de recursos no domínio discreto em sistemas multiportadora como (CAMPELLO, 1998);

3. Incorporação dos efeitos da perda de percurso e do sombreamento ao modelo de capacidade efetiva proposto; solução dos problemas relacionados à maximização da capacidade efetiva e da eficiência energética efetiva considerando tais efeitos do canal empregando técnicas como método de Dinkelbach e decomposição dual de Lagrange;

4. Tratamento dos problemas de controle de potência e seleção do retransmissor de forma conjunta em redes cooperativas MC-DS/CDMA com base nos trabalhos de (KHAYATIAN; SAADAT; ABOUEI, 2013). 


\section{REFERÊNCIAS}

ABRAO, T. et al. Multiple access network optimization aspects via swarm search algorithms. In: MANSOUR, P. N. (Ed.). Search Algorithms and Applications. Rijeka, Croácia: InTech, 2011. cap. 13, p. 261-298.

ADANYIA, M. H. A. C. et al. Firefly algorithm in telecommunications. In: YANG, X.-S.; CHIEN, S. F.; TING, T. on (Ed.). Bio-Inspired Computation in Telecommunications. Primeira ed. Whaltam: Elsevier, 2015. cap. 3, p. 44-70.

AEIN, J. M. Power balancing in systems employing frequency reuse. COMSAT Technical Review, v. 3, n. 2, p. 277-300, 1973.

AGEEV, D. V. Bases of the theory of linear selection. code demultiplexing. Proceedings of the Leningrad Experimental Institute of Communication, p. 3-35, 1935.

AHN, S. et al. The effect of multiplexing users in qos provisioning scheduling. IEEE Transactions on Vehicular Technology, v. 59, p. 2575-2581, Junho 2010.

AKKARAJITSAKUL, K. et al. Game theoretic approaches for multiple access in wireless networks: A survey. Communications Surveys Tutorials, IEEE, v. 13, n. 3, p. 372-395, 2011. ISSN 1553-877X.

ALI, A. H. Design and analysis of mc-cdma transceivers model based fourier transform. Journal of Information Engineering and Applications, v. 4, n. 9, p. 109-118, 2014.

ANTONIOU, A.; LU, W.-S. Practical Optimization: Algorithms and Engineering Applications. New York: Springer, 2007.

ARNOLD, O. et al. Power consumption modeling of different base station types in heterogeneous cellular networks. In: Future Network and Mobile Summit, 2010. Florença, Itália: IEEE, 2010. p. 1-8.

AVRIEL, M. et al. Generalized Concavity. Philadelphia: Society for Industrial and Applied Mathematics, 2010. (Classics in Applied Mathematics, 63).

BELLHOUSE, D. The problem of waldegrave. Journal Eletronique d'Histoire des Probabilités et de la Statistique, v. 3, n. 2, p. 1-12, 2007.

Ben-Tal, A.; NEMIROVSKI, A. Lectures on Modern Convex Optimization. 2013. Disponível em <http://www2.isye.gatech.edu/ nemirovs/Lect_ModConvOpt. pdf $>$. Acesso em 12 de Fevereiro de 2015.

BERMAN, A.; Shaked-Monderer, N. Completely Positive Matrices. USA: World Scientifc, 2003. 
BETZ, S.; POOR, H. Energy efficiency in multi-hop cdma networks: a game theoretic analysis considering operational costs. In: Proceedins of the IEEE International Conference on Acoustics, Speech and Signal Processing. Las Vegas: IEEE, 2008.

BHATT, S. K. Equivalence of various linearization algorithms for linear fractional programming. Zeitschrift für Operations Research: Methods and Models of Operations Research, v. 33, p. 39-43, 1989. Short Note.

BOCK, F. An algorithm for solving traveling salesman and related net-work optimization problems. In: 14th ORSA meeting. St. Louis: Informs, 1958.

BOCK, F.; EBSTEIN, B. Assignment of transmitter power by linear programming. IEEE Transactions on Electromagnetic Compatibility, v. 6, n. 2, p. 36-44, Julho 1964.

BOHGE, M. et al. Dynamic resource allocation in ofdm systems: an overview of cross-layer optimization principles and techniques. Network, IEEE, v. 21, n. 1, p. 53-59, Janeiro 2007. ISSN 0890-8044.

BOREL, E. La theéorie du jeu et les Équations intégrales à noyau symétrique. Comptes Rendus de l'Acadaémie des Sciences, v. 173, p. 1304-1308, 1921.

BORWEIN, J. M.; LEWIS, A. S. Convex Analysis and Nonlinear Optimization, Theory and Examples. Segunda. Nova Iorque: Springer, 2006. (CMS Books in Mathematics).

BOYD, S.; VANDENBERGHE, L. Convex Optimization. Cambridge: Cambridge University Press, 2004.

BRADLEY, S.; HAX, A.; MAGNANTI, T. Applied Mathematical Programming. Boston: Addison Wesley, 1977.

BRANKE, J. et al. Multiobjective Optimization: Interactive and Evolutionary Approaches. Berlin, Alemanha: Springer, 2008.

CAMPELLO, J. Optimal discrete bit loading for multicarrier modulation systems. In: Information Theory, 1998. Proceedings. 1998 IEEE International Symposium on. Cambridge, MA: IEEE, 1998.

CAMPOS-DELGADO, D.; LUNA-RIVERA, M. Characterization of stability margins of the foschini-miljanic power allocation strategy under constant and time-varying delays. In: Electrical Engineering Computing Science and Automatic Control (CCE), 2011 8th International Conference on. México: IEEE, 2011. p. 1-6.

CEET, C. f. E.-E. T. CEET Annual Report 2013. Australia, 2013.

CHANG, C.-S. Stability, queue length, and delay of deterministic and stochastic queueing networks. IEEE Transactions on Automatic Control, v. 39, p. 913-931, Maio 1994. 
CHANG, C.-S.; THOMAS, J. A. Effective bandwidth in high-speed digital networks. IEEE Journal on Selected Areas in Communications, v. 13, n. 6, p. 1091-1100, Agosto 1995.

CHARALAMBOUS, T.; LESTAS, I.; VINNICOMBE, G. On the stability of the foschini-miljanic algorithm with time-delays. In: Decision and Control, 2008. CDC 2008. 4\%th IEEE Conference on. México: IEEE, 2008. p. 2991-2996. ISSN 0191-2216.

CHARNES, A.; COOPER, W. W. Programming with linear fractional functionals. Naval Research Logistics Quarterly, v. 9, p. 181-186, 1962.

CHONG, E. K. P.; ZAK, S. H. An Introduction to Optimization. 2. ed. New York: John Wiley \& Sons, Inc., 2001.

CISCO. Cisco Visual Networking Index: Global Mobile Data Traffic Forecast Update, 2013-2018. 2014. Disponível em: <http://www.cisco.com/c/en/ us/solutions/collateral/service-provider/visual-networking-index-vni/white paper_c11-520862.pdf $>$. Acesso em 20/01/2015.

COTTle, R. W.; DANTZIG, G. B. Complementary pivot theory of mathematical programming. Linear Algebra and its Applications, Elsevier, v. 1, n. 1, p. 103-125, Janeiro 1968.

COVER, T. M.; GAMAL, A. A. E. Behavior theorem for the relay channel. IEEE Transactions on Information Theory, v. 25, n. 5, p. 572-584, 1979.

CROES, G. A. A method for solving traveling salesman problems. Operations Research, n. 6, p. 791-812, 1958.

CROUZEIX, J. P.; FERLAND, J. A.; SCHAIBLE, S. An algorithm for generalized fractional programs. Journal of Optimization Theory and Applications, v. 47, n. 1, p. 35-49, 1985.

CUI, S.; GOLDSMITH, A. J.; BAHAI, A. Energy-constrained modulation optimization. Wireless Communications, IEEE Transactions on, v. 4, n. 5, p. 2349-2360, Setembro 2005.

DAHLMAN, E. et al. 3G Evolution: HSPA and LTE for Mobile Broadband. Oxford: Elsevier, 2007.

DARWIN, C. A Origem das Espécies. Sexta edição. Portugal: Planeta Vivo, 2009. Tradução por Ana Afonso.

DINKELBACH, W. On nonlinear fractional programming. Management Science, v. 13, n. 7, p. 492-498, 1967.

DU, K.-L.; SWAMY, M. N. S. Wireless Communication Systems: From RF Subsystems to $4 G$ Enabling Technologies. Cambridge: Cambridge University Press, 2010. 
EIA, U. S. E. I. A. How much electricity does and American home use? 2015. Disponível em: <http:/ $/$ www.eia.gov/tools/faqs/faq.cfm?id=97\&t=3>. Acesso em 08/03/2015.

EKSTRöM, H. et al. Technical solutions for the $3 \mathrm{~g}$ long-term evolution. IEEE Communications Magazine, v. 44, n. 3, p. 38-45, Março 2006.

ELKAMCHOUCHI, H.; ELRAGAL, H.; MAKAR, M. Power control in cdma system using particle swarm optimization. In: National Radio Science Conference, 200\%. (NRSC). Egito: IEEE, 2007. p. 1-8.

ELTEK. Energy Efficiency for Telecom Growth: An Eltek White Paper. 2012. Disponível em: <http://www.eltek.com/photoalbum/view2/ P3NpemU9b3JnJmlkPTQ4MzgzNw > . Acesso em 08/03/2015.

ERCEG, V. et al. An empirically based path loss model for wireless channels in suburban environments. IEEE Journal on Selected Areas in Communications, p. 1205-1211, Julho 1999.

EUSTAQUIO, R. G.; KARAS, E. W.; RIBEIRO, A. A. Constraints qualification for nonlinear programming. In: I Encuentro Regional Argentino Brasileño de Investigación Operativa (ERABIO), XXI Encuentro Nacional de Docentes en Investigación Operativa (ENDIO) y XIX Escuela de Perfeccionamiento en Investigación Operativa (EPIO). Posadas, Argentina: ALIO, 2008. p. 1-12.

FANG, L.; FIGUEIREDO, R. J. de. A game-theoretic approach to utility-based power control in multi-carrier ds/cdma systems. In: Consumer Communications and Networking Conference, 200\%. CCNC 200\%. 4th IEEE. Las Vegas: IEEE, 2007. p. $155-159$.

FISCHER, G. Future Challenges in RGD with Respect to mobile Communication basestations. USA, 2008.

FOSCHINI, G. J.; MILJANIC, Z. A simple distributed autonomous power control algorithm and its convergence. IEEE Transactions on Vehicular Technology, v. 42, n. 4, p. 641-646, 1993.

FUnDEnBERG, D.; TIROLE, J. Game Theory. Cambridge: The MIT Press, 1991.

GALLAGER, R. G. Information Theory and Reliable Communication. New York: John Wiley \& Sons, Inc., 1968.

GAREY, M. R.; JOHNSON, D. S. Computers and Intractability: A Guide to the Theory of NP-Completeness. San Francisco: Freeman, 1979.

GIBBENS, R. J.; HUNT, P. Effective bandwidths for the multi-type uas channel. Queueing Systems, v. 9, p. 17-28, 1991.

GIBBOnS, R. A Primer in Game Theory. Harvester-Wheatsheaf: Prentice Hall, 1992. 
GILLI, M. An Introduction to Optimization Heuristics. 2004. < http://www. unige.ch/ses/dsec/static/gilli/CyprusLecture2004.pdf>. Notas de Aula.

GILLI, M.; WINKER, P. Heuristic optimization methods in econometrics. Acesso em 20/02/2015. 2007. Disponível em: <http://www.unige.ch/ses/dsec/ static/gilli/Teaching/GilliWinkerHandbook.pdf $>$.

GLICKSBERG, I. L. A further generalization of the kakutani fixed point theorem, with application to nash equilibrium. Proceedings of the American Mathematical Society, v. 3, n. 1, p. 170-174, 1952.

GOLDSMITH, A. Wireless Communications. Cambridge: Cambridge University Press, 2005. ISBN 9780511841224.

GOLUB, G.; Van Loan, C. Matrix Computations. Baltimore: Johns Hopkins University Press, 2012. (Johns Hopkins Studies in the Mathematical Sciences). ISBN 9781421407944.

GOODMAN, D.; MANDAYAM, N. Power control for wireless data. Personal Communications, IEEE, v. 7, n. 2, p. 48-54, Abril 2000. ISSN 1070-9916.

GRANAS, A.; DUGUNDJI, J. Fixed Point Theory. New York: Springer, 2003. (Monographs in Mathematics). ISBN 9780387001739.

GRANDHI, S. A. et al. Centralized power control in cellular radio systems. IEEE Transactions on Vehicular Technology, v. 42, n. 4, p. 466-468, 1993.

GRANT, M.; BOYD, S. Graph implementations for nonsmooth convex programs. In: BLONDEL, V.; BOYD, S.; KIMURA, H. (Ed.). Recent Advances in Learning and Control. Alemanha: Springer-Verlag Limited, 2008, (Lecture Notes in Control and Information Sciences). p. 95-110. <http://stanford.edu/ rboyd/graph_dcp.html $>$.

GRANT, M.; BOYD, S. CVX: Matlab Software for Disciplined Convex Programming, version 2.1. 2014. <http://cvxr.com/cvx>. Acesso em $11 / 03 / 2015$.

GROSS, T. J.; ABRãO, T.; JESZENSKY, P. J. E. Distributed power control algorithm for multiple access systems based on verhulst model. AEUE International Journal of Electronics and Communications, v. 65, n. 4, p. 361-372, 2011.

GUéRIN, R.; AHMADI, H.; NAGHSHINEH, M. Equivalent capacity and its application to bandwidth allocation in high-speed networks. IEEE Journal in Selected Areas of Communications, v. 9, p. 968-981, 1991.

HALCK, O. M.; DAHL, F. A. On Classification of Games and Evaluation of Players - with Some Sweeping Generalizations About the Literature. 1999. Disponível em: <http://citeseerx.ist.psu.edu/viewdoc/summary?doi=10.1.1.43. 7439>. Acesso em 27/02/2015. 
Conclusive remarks. In: HAMMER, E. J. P.; KORTE, B. (Ed.). Discrete Optimization II Proceedings of the Advanced Research Institute on Discrete Optimization and Systems Applications of the Systems Science Panel of NATO and of the Discrete Optimization Symposium co-sponsored by IBM Canada and SIAM Banff, Aha. and Vancouver. Elsevier, 1979, (Annals of Discrete Mathematics, v. 5). p. 427 - 453. Disponível em: < http://www.sciencedirect. $\mathrm{com} /$ science/article/pii/S0167506008703662>.

HARPER, D. Online Etymology Dictionary. 2015. < http://www.etymonline. com/index.php?term $=$ heuristic\&allowed_in_frame $=0>$. Acesso em 20/02/2015.

HATA, M. Empirical fformu for propagation loss in land mobile radio services. IEEE Transactions on Vehicular Technology, v. 29, n. 3, p. 317-325, 1980.

HUANG, J. et al. A close examination of performance and power characteristics of $4 \mathrm{~g}$ lte networks. In: Proceedings of the 2012 MobiSys. Reino Unido: ACM, 2012. p. 1-14.

IEA, I. E. A. Energy Efficiency. 2015. Disponível em: < http://www.iea.org/ topics/energyefficiency/>. Acesso em: 08/03/2015.

IEEE COMPUTER SOCIETY. IEEE Standard 802.15.4a. New York, 2007.

JAGANNATHAN, R. On some properties of programming problems in parametric form pertaining to fractional programming. Management Science, v. 12, p. 609-615, 1966.

JANG, J.; LEE, K. B. Transmit power adaptation for multiuser ofdm systems. IEEE Journal on Selected Areas in Communications, v. 21, n. 2, p. 171-178, Janeiro 2003.

KARUSH, W. Minima of Functions of Several Variables with Inequalities as Side Constraints. Dissertação (Mestrado) - University of Chicago, Chicago, Illinois, 1939.

KELLY, F. P. Effective bbandwidth at multi-class queues. Queueing Systems, v. 9 , p. $5-16,1991$.

KENNEDY, J. The particle swarm: social adaptation of knowledge. In: Evolutionary Computation, 199\%., IEEE International Conference on. Indianapolis: IEEE, 1997. p. 303-308.

KENNEDY, J.; EBERHART, R. Particle swarm optimization. In: Proceedings of IEEE International Conference on Neural Networks. Australia: IEEE, 1995. v. 4 , p. $1942-1948$.

KHAYATIAN, H.; SAADAT, R.; ABOUEI, J. Coalition-based approaches for joint power control and relay selection in cooperative networks. Vehicular Technology, IEEE Transactions on, v. 62, n. 2, p. 835-842, Fev 2013.

KIRKPATRICK, S.; GELATT, C. D.; VECCHI, M. P. Optimization by simulated annealing. Science, v. 220, n. 4598, p. 671-680, 1983. 
KRAMER, G.; GASTPAR, M.; GUPTA, P. Cooperative strategies and capacity theorem for relay networks. IEEE Transactions on Information Theory, v. 51, n. 9, p. 3037-3063, 2005.

KROGSTAD, H. E. The Karush-Kuhn-Tucker Theorem. 2010. Disponível em $<$ http://www.math.ntnu.no/ hek/Optimering2010/KKTtheoremV2010.pdf $>$. Notas de Aula. Acesso em 12/02/2015.

KUHN, H. W.; TUCKER, A. W. Nonlinear programming. In: Proceedings of the 2nd Berkeley Symposium. Berkeley: University of California Press, 1951. p. 481-492.

KUPRIYANOVICH, L. Radio. Life and Sciences, n. 07, p. 49, 1957. Disponível em: <http://publ.lib.ru/ARCHIVES/N/\%27\%27Nauka_i_jizn\%27\%27\%27/ "Nauka_i_jizn",,1957,N07.[pdf].zip >. Acesso em 02/03/2015.

LAGRANGE, J. L. Mécanique Analytique. Paris: V Coucier, 1811.

LANEMAN, J. N. Cooperative Diversity in Wireless Networks: Algorithms and Architectures. Tese (Doutorado) — Massachusetts Institute of Technology, 2002.

LANEMAN, J. N.; TSE, D. N. C.; WORNELL, G. W. Cooperative diversity in wireless networks: Efficient protocols and outage behavior. IEEE Transactions on Information Theory, v. 50, n. 12, p. 3062-3080, 2004.

LEE, J.; LEYFFER, S. Mixed Integer Nonlinear Programming. New York: Springer, 2011. (The IMA Volumes in Mathematics and its Applications). ISBN 9781461419273.

LIU, H.; YIN, H. Receiver design in multicarrier direct-sequence cdma communications. IEEE Transactions on Communications, v. 49, n. 8, p. 1479-1487, Agosto 2001.

LOODARICHEH, R.; MALLICK, S.; BHARGAVA, V. Energy-efficient resource allocation for ofdma cellular networks with user cooperation and qos provisioning. Wireless Communications, IEEE Transactions on, v. 13, n. 11, p. 6132-6146, Novembro 2014. ISSN 1536-1276.

LU, J. et al. $m$-psk and $m$-qam ber computation using signal-space concepts. IEEE Transactions on Communications, v. 47, p. 181-184, Fevereiro 1999.

LUPAS, R.; VERDú, S. Linear multiuser detectors for synchronous code-division multiple access channels. IEEE Transactions on Information Theory, v. 35, n. 1, p. 123-136, 1989.

MACKENZIE, A.; WICKER, S. Game theory in communications: motivation, explanation, and application to power control. In: Global Telecommunications Conference, 2001. GLOBECOM '01. IEEE. Santo Antonio: IEEE, 2001. v. 2, p. 821-826.

MALCOLM, M. Unit 7.3: Sequential Games. 2011. Notas de Aula. Disponível em: < http://jasandford.com/401_f12/sequential.pdf>. Acesso em 27/02/2015. 
MESHKATI, F.; POOR, H.; SCHWARTZ, S. Energy-efficient resource allocation in wireless networks. Signal Processing Magazine, IEEE, v. 24, n. 3, p. 58-68, Maio 2007. ISSN 1053-5888.

MESHKATI, F.; SCHWARTZ, H. P. P.; MANDAYAM, N. An energy-efficient approach to power control an receiver design in wireless data networks. IEEE Transactions on Communications, v. 53, n. 11, p. 1885-1894, 2005.

MEULEN, E. C. V. D. Three-terminal communication channels. Advances in Applied Probability, v. 3, n. 1, p. pp. 120-154, 1971. ISSN 00018678.

MOLISCH, A.; ZHANG, J.; MIYAKE, M. Time hopping and frequency hopping in ultrawideband systems. In: Communications, Computers and signal Processing, 2003. PACRIM. 2003 IEEE Pacific Rim Conference on. Canada: IEEE, 2003. v. 2, p. 541-544.

MONTMORT, P. R. de. Essay D'Analyse Sur Les Jeux de Hazard. Paris: Jacque Quillau, 1713. Disponível na Bibliothèque Nationale de France em < http:// gallica.bnf.fr/ark:/12148/bpt6k110519q/f1.image>. Acesso em 27/02/2015.

MOSHAVI, S. Multi-user detection for ds-cdma communications. IEEE Communications Magazine, v. 34, n. 10, p. 124-136, Outubro 1996.

MOUSTAFA, M.; NAGHSHINEH, I. H. H. Genetic algorithm for mobiles equilibrium. In: Proceedings of the $21^{\circ}$ Century Military Communications Conference Proceedings (MILCOM). Los Angeles: IEEE, 2000. p. 70-74.

MUROTA, K. Discrete Convex Analysis. Philadelphia: Society for Industrial and Applied Mathematics, 2003. (Monographs on Discrete Mathematics and Applications). ISBN 9780898715408.

MURTY, K. G. Linear Complementarity, Linear and Nonlinear Programming. Berlin: Helderman-Verlag, 1988.

MYERSON, R. B. Game Theory: Analysis of Conflict. USA: Harvard University Press, 1997. ISBN 9780674341166.

NASH, J. F. The bargaining problem. Econometrica, v. 18, n. 2, p. 155-162, 1950 .

NASH, J. F. Equilibrium points in $n$-person games. Proc. of the National Academy of Sciences, v. 36, p. 48-49, 1950.

NASH, J. F. Non-cooperative Games. The Annals of Mathematics, v. 54, n. 2, p. 286-295, 1951.

NASH, J. F. Two-person cooperative games. Econometrica, v. 21, n. 1, p. 128-140, 1953.

NETO, F. C. D. Otimização Multidimensional Baseada em Heurísticas Aplicada aos Sistemas de Comunicação Sem Fio. Tese (Doutorado) - Escola Politécnica da Universidade de São Paulo, São Paulo, 2012. 
NETTLETON, R. W. Traffic theory and interference management for a spread spectrum cellular mobile radio system. In: Proceedings of the 1980 IEEE International Conference on Communications (ICC). Seattle: IEEE, 1980.

NETTlETON, R. W.; ALAVI, H. Downstream power control for spread spectrum cellular mobile radio system. In: Proceedings of the 1982 IEEE Globecom. Miami: IEEE, 1982. p. 84-88.

NETTLETON, R. W.; ALAVI, H. Power control for a spread spectrum celullar mobile radio system. In: Proceedings of the $33^{a}$ IEEE Vehicular Technology Conference. Canada: IEEE, 1983. p. 242-246.

NG, D.; LO, E.; SCHOBER, R. Energy-efficient resource allocation for secure ofdma systems. Vehicular Technology, IEEE Transactions on, v. 61, n. 6, p. 2572-2585, Julho 2012.

NOCEDAL, J.; WRIGHT, S. J. Numerical Optimization. Segunda. Nova Iorque: Springer-Verlag, 2006.

OLIVEIRA, R. M. de. Algoritmos de Busca Global para Problemas de Otimização Geométricos e Multiplicativos. Tese (Doutorado) - Universidade Estadual de Campinas - Faculdade de Engenharia Elétrica e de Computação, Campinas, 2005.

PALOMAR, D. P.; FONOLLOSA, J. R. Practical algorithms for a family of waterfilling solutions. IEEE Transactions on Signal Processing, v. 53, n. 2, p. 686-695, Fevereiro 2005.

PANG, J. S.; SCUTARI, G.; WANG, F. F. F. Distributed power allocation with rate constraints in gaussian parallel interference channels. IEEE Transactions on Information Theory, v. 54, n. 8, p. 3471-3489, Agosto 2008.

PAVEL, L. Game Theory for Control of Optical Networks. New York: Birkhäuser, 2012. (Static \& Dynamic Game Theory: Foundations \& Applications). ISBN 9780817683221 .

QIAO, D.; GURSOY, M.; VELIPASALAR, S. The impact of qos constraints on the energy efficiency of fixed-rate wireless transmissions. Wireless Communications, IEEE Transactions on, v. 8, n. 12, p. 5957-5969, Dezembro 2009 .

QUALCOMM. Qualcomm History. 2015. Disponível em: < https://www. qualcomm.com/company/about/history $>$. Acesso em 02/03/2015.

RARDIN, R.; UZSOY, R. Experimental evaluation of heuristic optimization algorithms: A tutorial. Journal of Heuristics, Kluwer Academic Publishers, v. 7, n. 3, p. 261-304, 2001. ISSN 1381-1231.

REKLAITIS, G. V.; RAVINDRAN, A. Engineering Optimization: Methods and Applications. New York: Wiley, 1983. 
RENY, P. J. Non-cooperative games (equilibrium existence). The New Palgrave Dictionary of Economics, p. 1-12, 2005.

ROCKAFELlaR, R. T. Convex Analysis. New Jersey: Princeton University Press, 1970.

ROCKAFELLAR, R. T. Lagrange multipliers and optimality. SIAM Review, Society for Industrial and Applied Mathematics, v. 35, n. 2, p. 183-238, Junho 1993.

RODRIGUEZ, V. An analytical foundation for resource management in wireless communication. In: Global Telecommunications Conference, 2003. GLOBECOM '03. IEEE. Miami: IEEE, 2003. v. 2, p. 898-902.

SAMPAIO, L. et al. Power allocation in multirate ds/cdma systems based on verhulst equilibrium. In: Communications (ICC), 2010 IEEE International Conference on. Africa do Sul: IEEE, 2010. p. 1-6. ISSN 1550-3607.

SAMPAIO, L. et al. Game theoretic energy efficiency design in mc-cdma cooperative networks. Sensors Journal, IEEE, v. 14, n. 9, p. 3065-3075, Setembro 2014.

SAMPAIO, L. D. H. et al. Ant colony optimization for resource allocation and anomaly detection in communication networks. In: ABRãO, T. (Ed.). Search Algorithms for Engineering Optimization. Croácia: InTech, 2013. cap. 5, p. 109-142.

SAMPAIO, L. D. H. et al. Energy efficiency design in mc-cdma cooperative networks. In: IEEE. Personal Indoor and Mobile Radio Communications (PIMRC), 2013 IEEE 24th International Symposium on. Londres, 2013. p. 207-212. ISSN 2166-9570.

SARAYDAR, C.; MANDAYAM, N. B.; GOODMAN, D. Efficient power control via pricing in wireless data networks. Communications, IEEE Transactions on, v. 50, n. 2, p. 291-303, Fevereiro 2002. ISSN 0090-6778.

SCHAIBLE, S. Bibliography in fractional programming. Zeitschrift für Operations Research, v. 26, p. 211-241, 1982.

SCHAIBLE, S. Fractional programming. Zeitschrift für Operations Research, v. 27 , p. $39-54,1983$.

SCHWALBE, U.; WALKER, P. Zermelo and the early history of game theory. Games and Economic Behavior, v. 34, n. 1, p. 123-137, 2001.

SCUTARI, G. et al. Convex optimization, game theory and variational inequality theory. IEEE Signal Processing Magazine, v. 27, n. 3, p. 35-49, 2010.

SHAH, V.; MANDAYAM, N.; GOODMAN, D. Power control for wireless data based on utility and pricing. In: Personal, Indoor and Mobile Radio Communications, 1998. The Ninth IEEE International Symposium on. Boston: IEEE, 1998. v. 3, p. 1427-1432. 
SHANNON, C. E. A mathematical theory of communication. The Bell System Technical Journal, v. 27, p. 379-423, 623-656, 1948.

SIMON, M. K.; ALOUINI, M.-S. Digital Communication Over Fading Channels. New York: John Wiley \& Sons, Inc., 2000.

SLATER, M. Lagrange Multipliers Revisited. Connecticut, 1950. Discussion Article: 403.

SMITH, A. E.; COIT, D. W. Penalty functions. In: BAECK, T.; FOGEL, D.; MICHALEWICZ, Z. (Ed.). The Handbook of Evolutionary Computation. Bristol, U.K.: Oxford University Press and Institute of Physics Publishing, 1997. cap. C5.2, p. 1-10.

SOUZA, 1. R. et al. Energy and spectral efficiencies trade-off with filter optimisation in multiple access interference-aware networks. Transactions on Emerging Telecommunications Technologies, p. 1-15, 2013. ISSN 2161-3915.

STANCZAK, S.; WICZANOWSKI, M.; BOCHE, H. Fundamentals of Resource Allocation in Wireless Networks: Theory and Algorithms. Berlin: Springer Berlin Heidelberg, 2009. (Foundations in Signal Processing, Communications and Networking). ISBN 9783540793861.

TSE, D.; VISWANATH, P. Fundamentals of Wireless Communication. Cambridge: Cambridge University Press, 2005. (Wiley series in telecommunications). ISBN 9780521845274.

TSP, T. S. P. Breakdown of Electricity Generation by Energy Source. 2015. Disponível em: < http://www.tsp-data-portal.org/ Breakdown-of-Electricity-Generation-by-Energy-Source\#tspQvChart> . Acesso em 08/03/2015.

University of Wisconsin - Madison. NEOS Project. 2013. < http://neos-guide. org/>. Acesso em 22 de Janeiro de 2015.

VANDERBEI, R. J. Linear Programming: Foundations and Extensions. $2^{\mathrm{a}}$. ed. New York: Springer, 2000. (International Series in Operations Research \& Management Science). ISBN 9781461476306.

VARADHAN, S. R. S. Asymptotic probability and differential equations. Communications on Pure and Applied Mathematics, v. 19, p. 261-286, 1966.

VERDú, S. Optimum sequence detection of asynchronous multiple-access communications. In: IEEE International Symposium in Information Theory. Canada: IEEE, 1983.

VERDú, S. Adaptive multiuser detection. In: GLISIC, S. G.; LEPPANEN, P. A. (Ed.). Code Division Multiple Access Communications. Nowell, MA: Kluwer Academic, 1995. p. 97-116. 
VERHULST, P. F. Notice sur la loi que la population poursuit dans son accroissement. Correspondance Mathématique et Physique, v. 10, p. 113-121, 1838 .

VITERBI, A. CDMA: Principles of Spread Spectrum Communication. Reading, MA: Addison-Wesley Publishing Company, 1995. (Addison-Wesley wireless communications series). ISBN 9780201633740.

VON NEUMANN, J. Zur theorie der gesellschaftsspiele. Mathermatische Annalen, v. 100, p. 295-320, 1928. Tradução para o Inglês em: R. D. Luce e A. W. Tucker, Contributions to the Theory of Games IV, p. 13-42, Princeton University Press, 1959.

VON NEUMANN, J. Über ein Ökonomisches gleichungssystem und eine verallgemeinerung des brouwerschen fixpunktsatzes. Ergebnisse eines Mathematischen Kolloquiums, v. 8, p. 73-83, 1937. Traduzido para o inglês por G. Morgenstern e publicado em The Review of Economic Studies, Vol. 13, No. 1, (1945-1946) publicado pela Oxiford University Press.

VON NEUMANN, J.; MORGENSTERN, O. Theory of Games and Economic Behavior. New Jersey: Princeton University Press, 1944. ISBN 0691119937.

VOORNEVELD, M. Best - response potential games. Economic Letters, v. 66, p. 289-295, 2000.

WONG, C. Y. et al. Multiuser ofdm with adaptive subcarrier, bit, and power allocation. Selected Areas in Communications, IEEE Journal on, v. 17, n. 10, p. 1747-1758, Outubro 1999. ISSN 0733-8716.

WONG, I.; EVANS, B. Optimal resource allocation in the ofdma downlink with imperfect channel knowledge. Communications, IEEE Transactions on, v. 57, n. 1, p. 232-241, Janeiro 2009. ISSN 0090-6778.

WU, D.; NEGI, R. Effective capacity: a wireless link model for support of quality of service. IEEE Transactions on Wireless Communications, v. 2, n. 4, p. 630-643, Julho 2003.

XIONG, C. et al. Energy-efficient design for downlink ofdma with delay-sensitive traffic. Wireless Communications, IEEE Transactions on, v. 12, n. 6, p. 3085-3095, Junho 2013. ISSN 1536-1276.

YANG, X. Nature-inspired Metaheuristic Algorithms. Frome: Luniver Press, 2008. ISBN 9781905986286.

YANG, X.-S. Firefly algorithms for multimodal optimization. In: WATANABE, O.; ZEUGMANN, T. (Ed.). Stochastic Algorithms: Foundations and Applications. Berlin Heidelberg: Springer, 2009, (Lecture Notes in Computer Science, v. 5792). p. 169-178. ISBN 978-3-642-04943-9. 
YEE, N.; LINNARTZ, J.-P.; FETTWEIS, G. Multi-carrier cdma in indorr wireless radio networks. In: Proceedings of the Fourth International Symposium on Personal, Indoor and Mobile Radio Communications (PIMRC). Japão: IEEE, 1993. p. 109-113.

YU, W.; LUI, R. Dual methods for nonconvex spectrum optimization of multicarrier systems. IEEE Transactions on Communications, v. 54, p. 1310-1322, Julho 2006.

ZAPPONE, A.; BUZZI, S.; JORSWIECK, E. Energy-efficient power control and receiver design in relay-assisted ds/cdma wireless networks via game theory. IEEE Communications Letters, v. 15, n. 7, p. 701-703, Julho 2011.

ZENG, C.; HOO, L. M. C.; CIOFFI, J. M. Optimal water-filling algorithms for gaussian multiaccess channel with intersymbol interference. In: Proceedings of the IEEE International Communications Conference (ICC). Helsinki, Finlândia: IEEE, 2001. p. 2421-2427.

ZENNECK, J. Wireless Telegraphy. Primeira edição. New York: McGraw-Hill Book Company, 1908. Traduzido do alemão por A. E. Seelig, 1915.

ZERMELO, E. Über eine anwendung der mengenlehre auf die theorie des schachspiels. In: Proceedings of the Fifth Congress of Mathematicians. Cambridge: Cambridge University Press, 1913. p. 501-504. 


\section{APÊNDICE A - FUNDAMENTOS DE ANÁLISE CONVEXA}

Nesta seção são apresentados os conceitos e definições básicas relacionadas à análise convexa: funções e conjuntos convexos, operações com conjuntos e funções que preservam a convexidade, condições de primeira e segunda ordem para convexidade de funções e funções quase convexas.

\section{A.1 Conjuntos Convexos}

Definição 22 (Conjunto Convexo). Um conjunto $C \subseteq \mathbb{R}^{n}$ é convexo se o segmento de reta entre quaisquer dois pontos de C está contido em C. Ou seja, para quaisquer $\mathbf{x}, \mathbf{y} \in C$ e qualquer $\lambda \in[0,1]$ tem-se que:

$$
\lambda \mathbf{x}+(1-\lambda) \mathbf{y} \in C
$$

São exemplos simples de conjuntos convexos (BOYD; VANDENBERGHE, 2004):

- O conjunto vazio, $\emptyset$;

- Conjuntos unitários, $\{\mathbf{x}\} \in \mathbb{R}^{n}$;

- O conjunto dos números reais, $\mathbb{R}$;

- Qualquer reta; 
- Qualquer segmento de reta;

- Um intervalo fechado em $\mathbb{R}$;

A fim de ilustrar a diferença entre conjuntos convexos e não convexos a figura 47 é apresentada. O conjunto (a) na figura é um exemplo de conjunto convexo, uma vez que para quaisquer pontos $\mathbf{x}$ e $\mathbf{y}$ o segmento de reta entre eles pertence ao conjunto. Já o conjunto (b) é não convexo uma vez que o ponto c que pertence ao segmento de reta entre $\mathbf{x}$ e $\mathbf{y}$ não pertence ao conjunto.

\section{(a)}

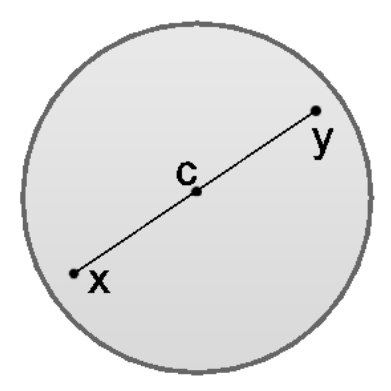

(b)

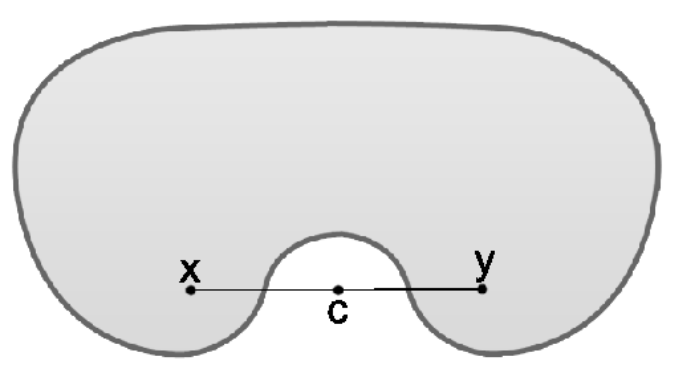

Figura 47: Exemplo de Conjunto convexo e não convexo: o conjunto (a) é convexo pois quaisquer que sejam os pontos $\mathbf{x}$ e $\mathbf{y}$, todo o segmento de reta entre eles pertence ao conjunto. O conjunto (b) não é convexo, conforme demonstra o ponto c que não pertence ao conjunto. Fonte: adaptado de (BOYD; VANDENBERGHE, 2004).

Existem operações com conjuntos que preservam a convexidade; sendo assim, considere $C_{1}$ e $C_{2}$ conjuntos convexos no $\mathbb{R}^{n}$. Os seguintes conjuntos também são convexos (BOYD; VANDENBERGHE, 2004, Seção 2.3 - Páginas 35-42):

1. $C_{1} \cap C_{2}$ (intersecção);

2. $C_{1}+C_{2}=\left\{\mathbf{x}+\mathbf{y} \mid \mathbf{x} \in C_{1}, \mathbf{y} \in C_{2}\right\}$ (união); 
3. $\alpha C_{1}=\left\{\alpha \mathbf{x} \mid \mathbf{x} \in C_{1}\right\}$, com $\alpha \in \mathbb{R}$ (escalonamento);

4. $f\left(C_{1}\right)=\left\{f(\mathbf{x}) \mid \mathbf{x} \in C_{1}\right\}$ se, e somente se, $f: \mathbb{R}^{n} \rightarrow \mathbb{R}^{m}$ for uma função afim, i.e. se $f(\mathbf{x})=\mathbf{A} \mathbf{x}+\mathbf{b}$, com $b \in \mathbb{R}^{m}$ e $\mathbf{A} \in \mathbb{R}^{m \times n}$ (combinação das propriedades 2 e 3$)$;

Além das quatro operações enumeradas anteriormente outras duas funções preservam a convexidade de conjuntos. A primeira função é a função perspectiva definida como $P: \mathbb{R}^{n+1} \rightarrow \mathbb{R}^{n}$ cujo domínio é $\operatorname{dom} P=\mathbb{R}^{n} \times \mathbb{R}_{++}\left(\operatorname{com} \mathbb{R}_{++}=\right.$ $\left.\left\{x \in \mathbb{R}_{++} \mid x>0\right\}\right)$ e $P(\mathbf{z}, t)=\mathbf{z} / t$. O objetivo da função perspectiva é normalizar um vetor de tal forma que a última dimensão torne-se um e seja removida do vetor (BOYD; VANDENBERGHE, 2004). Para ilustrar o funcionamento da função perspectiva apresenta-se o seguinte exemplo:

Exemplo 3. A função perspectiva pode ser interpetrada como a ação do orifício em uma câmera escura: este tipo primitivo de câmera fotográfica gera a partir da luz presente no ambiente $\left(\mathbb{R}^{3}\right)$ uma imagem bidimensional $\left(\mathbb{R}^{2}\right)$. Considerando que a câmera tenha apenas um orifício na origem e que dentro da câmera existe uma plano para a formação da imagem em $z_{3}=-1$, um objeto no ponto $\mathbf{z}$ acima da câmera $\left(z_{3}>0\right)$ forma uma imagem no ponto $-\left(z_{1} / z_{3} ; z_{2} / z_{3} ; 1\right)$ do plano de imagem. Portanto, retirando-se a última coordenada do vetor uma vez que a mesma sempre será -1 para qualquer imagem formada a partir de um objeto acima da câmera, é possível afirmar que qualquer objeto em um ponto $\digamma$ aparece em $y=-\left(z_{1} / z_{3} ; z_{2} / z_{3}\right)=-P\left(\mathbf{z}, z_{3}\right)$ no plano de imagens (BOYD; VANDENBERGHE, 2004, Observação 2.1 na página 39). Um interpretação geométrica para a função perspectiva é apresentada na figura 48 .

Desta forma, considere um conjuto arbitrário $C$. Se $C \subseteq \operatorname{dom} P$ é convexo, então a imagem $P(C)=\left\{P\left(\mathbf{z}, z_{n+1}\right) \mid \mathbf{z} \in C\right\}$ também é convexa (BOYD; VANDENBERGHE, 2004). 


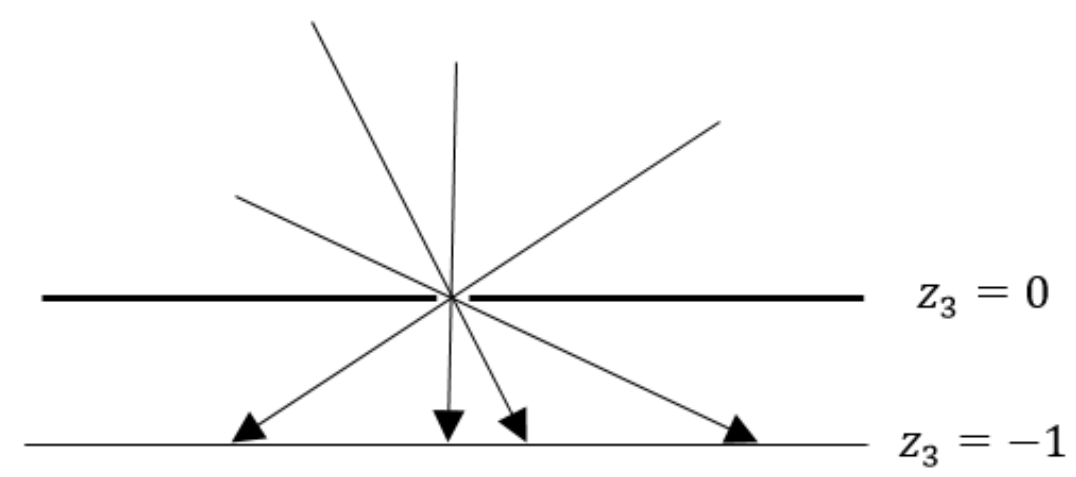

Figura 48: Interpretação da função perspectiva utilizando o conceito de câmera escura. A linha em $z_{3}=0$ é opaca com exceção do orifício na origem. Os raios de luz emitidos ou refletidos por objetos fora da câmera, representados pelas flexas, atingem o plano $z_{3}=-1$ formando uma imagem bidimensional. O mapeamento da posição do objeto para sua posição na imagem está relacionada a função perspectiva. Fonte: adaptado de (BOYD; VANDENBERGHE, 2004).

Outra função que preserva a convexidade de um conjunto são as funções lineares fracionais construídas pela operação de composição da função de perspectiva com uma função afim. Sem perda da generalidade, considere $g: \mathbb{R}^{n} \rightarrow \mathbb{R}^{m+1}$ uma função afim definida como:

$$
g(\mathbf{x})=\left[\begin{array}{c}
\mathbf{A} \\
\mathbf{c}^{T}
\end{array}\right] \mathbf{x}+\left[\begin{array}{l}
\mathbf{b} \\
d
\end{array}\right]
$$

onde $\mathbf{A} \in \mathbb{R}^{m \times n}, \mathbf{b} \in \mathbb{R}^{m}, \mathbf{c} \in \mathbb{R}^{n}$ e $d \in \mathbb{R}$. A função $f: \mathbb{R}^{n} \rightarrow \mathbb{R}^{m}$ definida por $f=P \circ g$ ou seja $f(\mathbf{x})=(\mathbf{A} \mathbf{x}+\mathbf{b}) /\left(\mathbf{c}^{T} \mathbf{x}+\mathbf{d}\right) \operatorname{com} \operatorname{dom} f=\left\{\mathbf{x} \mid \mathbf{c}^{T} \mathbf{x}+\mathbf{d}>0\right\}$ é chamada de função linear fracional.

Desta forma, seja $C \in \mathbb{R}^{n}$ um conjunto arbitrário. Se $C \in \operatorname{dom} f$, i.e. $\forall \mathbf{x} \in C, \mathbf{c}^{T} \mathbf{x}+\mathbf{d}>0$, então $f(C)=\{f(\mathbf{x}) \mid \mathbf{x} \in C\}$ é um conjunto convexo (BOYD; VANDENBERGHE, 2004, Página 42).

Outro conceito importante em análise convexa é o de envoltória convexa; segundo (ROCKAFELLAR, 1970; BOYD; VANDENBERGHE, 2004): 
Definição 23 (Envoltória Convexa). A envoltória convexa de um conjunto arbitrário é o menor conjunto convexo que contém tal conjunto, i.e. a envoltória convexa de um conjunto $C \in \mathbb{R}^{n}$ é o conjunto de todas as combinações convexas de elementos do conjunto $C$, i.e. para $\lambda_{1}+\ldots+\lambda_{k}=1$, com $\lambda_{i} \geq 0, i=1, \ldots, k$, a envoltória convexa de $C$, denominada $\operatorname{conv} C$ é definida como:

$$
\operatorname{conv} C=\left\{\lambda_{1} \mathbf{x}_{1}+\ldots+\lambda_{k} \mathbf{x}_{k} \mid \mathbf{x}_{i} \in C, i=1, \ldots, k ; \lambda_{1}+\ldots+\lambda_{k}=1\right\}
$$

A envoltória convexa pode ser interpretada, também, como a intersecção de todos os conjuntos convexos que contém $C$, i.e. conv $C=\cap_{i=1}^{k} S_{i}$, onde $C \subseteq S_{i}, i=$ $1, \ldots, k$ e $S_{i}$ é convexo para $i=1, \ldots, k$.

Para ilustrar a o conceito de envoltória convexa a figura 49 é apresentada a seguir.

a)

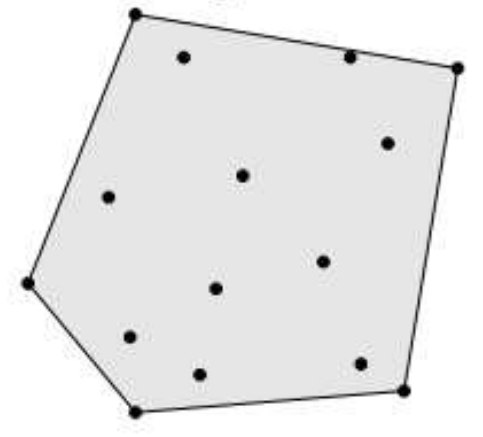

b)

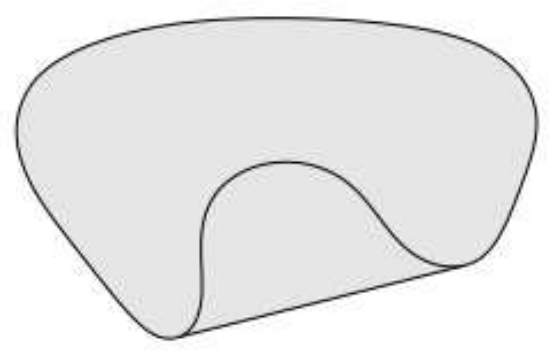

Figura 49: Exemplos de envoltórias convexas no $\mathbb{R}^{2}$ : em a) a envoltória convexa do conjunto composto pelos pontos em preto é o pentágono sombreado. Já em b) o conjunto delimitado pela linha contínua que lembra o formato de um rim tem sua envoltória convexa delimitada pela área sombreada. Fonte: (BOYD; VANDENBERGHE, 2004, Figura 2.3 na Página 24) 


\section{A.2 Funções Convexas}

De acordo com (ROCKAFELLAR, 1970) e (BOYD; VANDENBERGHE, 2004), funções convexas são definidas como:

Definição 24 (Função Convexa). Uma função $f: \mathbb{R}^{n} \rightarrow \mathbb{R}$ é convexa se o domínio de $\operatorname{dom} f$ é um conjunto convexo e se para todo $\mathbf{x}, \mathbf{y} \in \operatorname{dom} f, e \lambda \in$ $[0,1]$, tem-se:

$$
f(\lambda \mathbf{x}+(1-\lambda) \mathbf{y}) \leq \lambda f(\mathbf{x})+(1-\lambda) f(\mathbf{y})
$$

Uma possivel interpretação geométrica do conceito de função convexa é que dado dois pontos quaisquer do dominio da função, o segmento de reta entre estes pontos jaz acima dos valores da função convexa. A figura 50 apresenta um exemplo de função convexa e ilustra a interpretação geométrica aqui descrita.

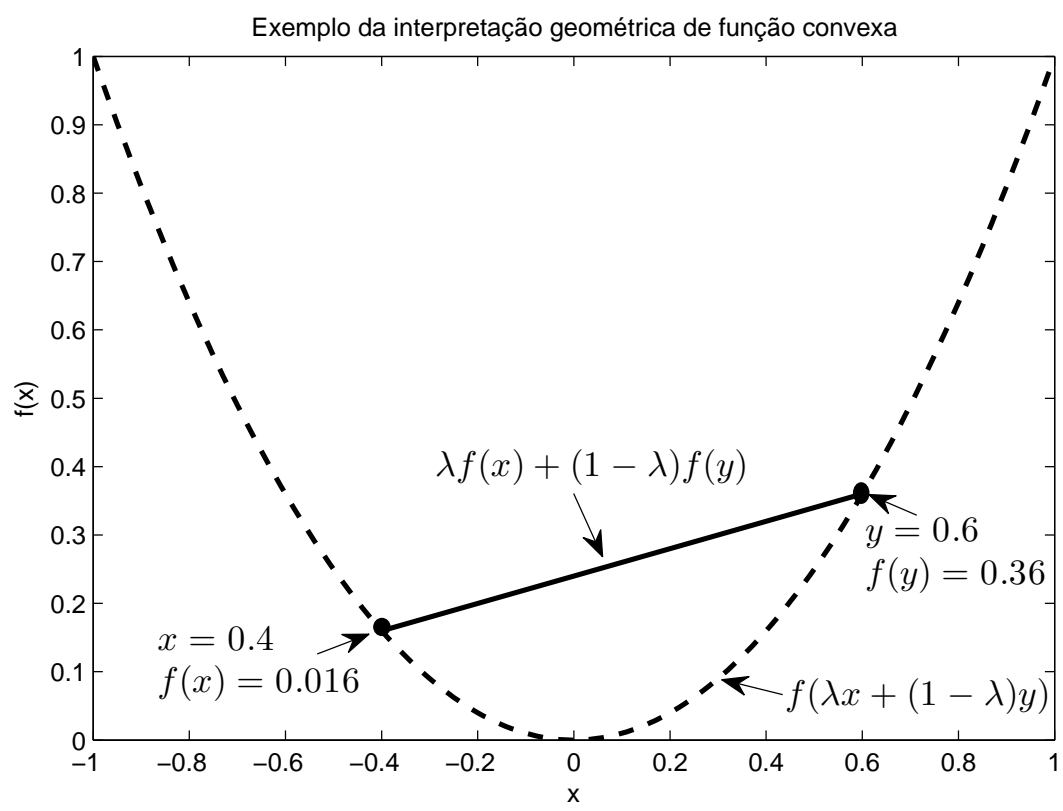

Figura 50: A função $f$ definida como $f: \mathbb{R} \rightarrow \mathbb{R}, f(x)=x^{2}$ é um exemplo de função convexa. Os pontos $(-0,4,0 ; 016)$ e $(0,6 ; 0,36)$ são destacados e o segmento de reta entre tais pontos (descrito pela equação $\lambda f(x)+(1-\lambda) f(y)$ $\operatorname{com} \lambda \in[0,1])$ está acima da curva da função $f$ entre $x$ e $y$, indicada na figura pela equação $f(\lambda x+(1-\lambda) y) \operatorname{com} \lambda \in[0,1]$. 
Para facilitar a compreensão do conceito de função convexa apresenta-se a definição do epigrafo de uma função (ROCKAFELLAR, 1970, Seção 4 na Página 23).

Definição 25 (Epigrafo). Seja $f: \mathbb{R}^{n} \rightarrow \mathbb{R}$ uma função arbitrária. O epigrafo de $f$, denominado epi $f$ é um subconjunto de $\mathbb{R}^{n+1}$ definido como:

$$
\text { epi } f=\{(\mathbf{x}, y) \mid \mathbf{x} \in \operatorname{dom} f, y \in \mathbb{R}, y \geq f(\mathbf{x})\}
$$

Geometricamente, o epigrafo é o conjunto de todos os pontos acima do gráfico da função. Para ilustrar essa interpretação é apresentada a figura 51.

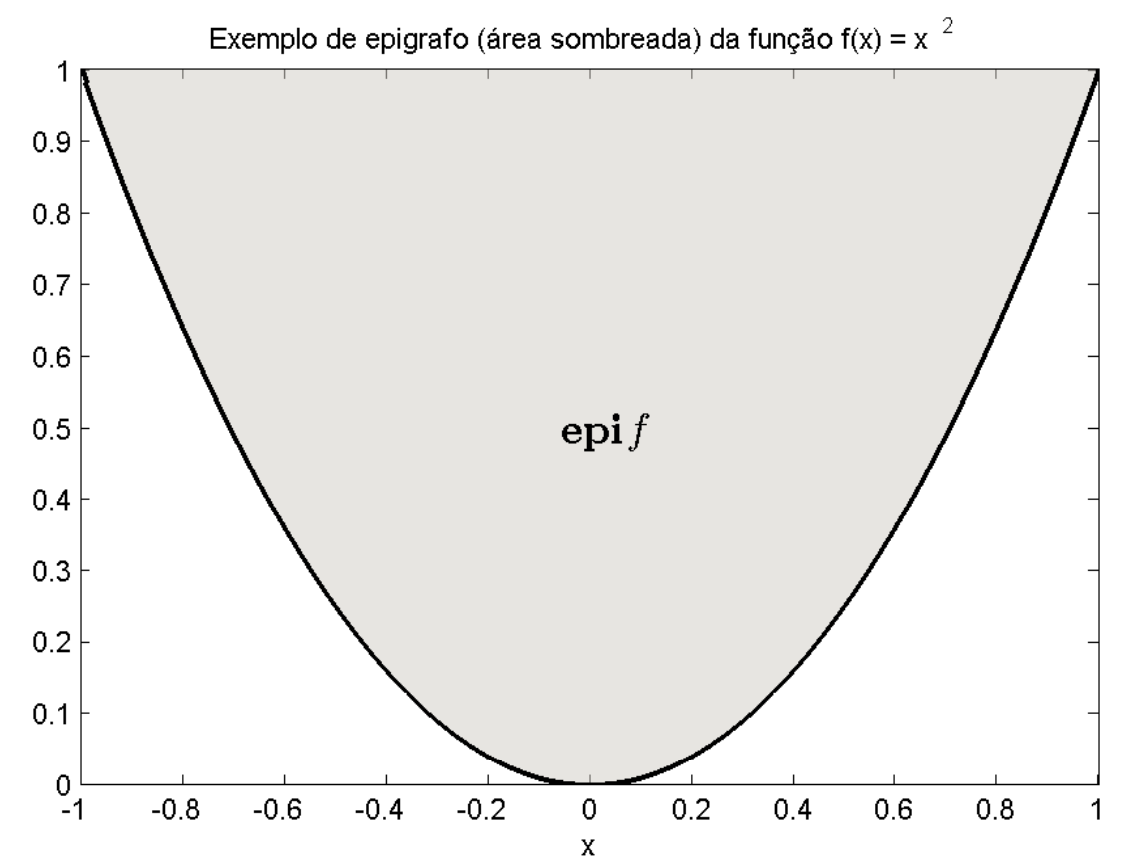

Figura 51: A área sombreada é um exemplo de epigrafo da função $f:[-1,1] \rightarrow$ $[0,1], f(x)=x^{2}$.

Observação 6. Seja $f: \mathbb{R}^{n} \rightarrow \mathbb{R}$ uma função arbitrária. Então $f$ é convexa em $\mathbb{R}^{n}$ se epi $f$ é um subconjunto de $\mathbb{R}^{n+1}$ e epi $f$ é um conjunto convexo (ROCKAFELLAR, 1970).

Um conceito de fundamental importância para esta Tese é o conceito de concavidade de funções. Uma função côncava é uma função cujo negativo é 
convexo, i.e. $f$ é côncava se $-f$ é convexa (ROCKAFELLAR, 1970). Uma interpretação geométrica para as diferenças entre funções côncavas e convexas é apresentada na figura 52 .
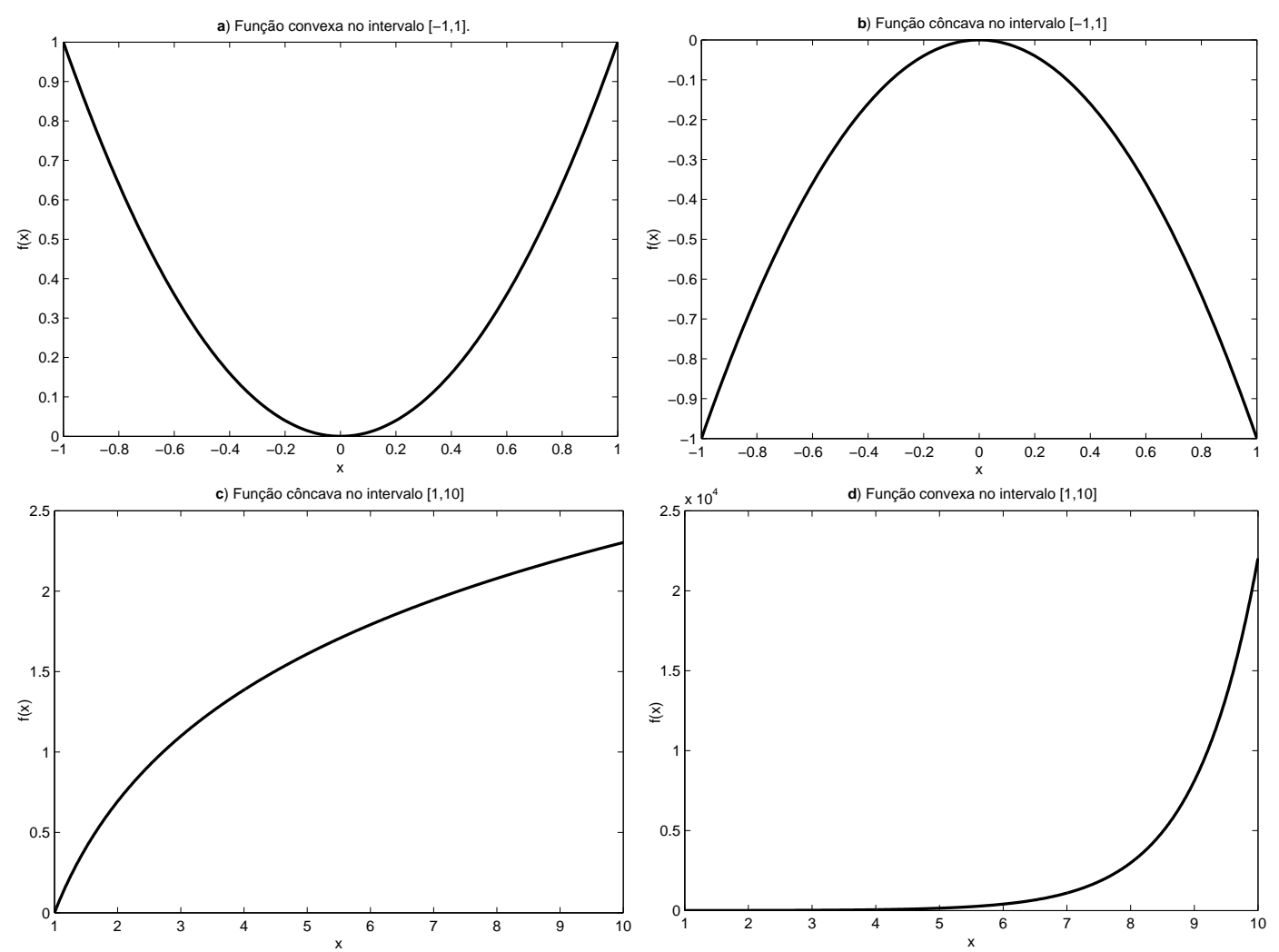

Figura 52: Interpretação geométrica da diferença entre funções convexas (a) e (d) e côncavas (b) e (c).

Uma inequação importante para o estudo de análise convexa é a Desigualdade de Jensen, que é obtida a partir da generalização da desigualdade na equação (A.4) para combinações convexas (ROCKAFELLAR, 1970, Teorema 4.3, Página 25):

Teorema 12 (Desigualdade de Jensen). Seja $f$ uma função arbitrária tal que $f: \mathbb{R}^{n} \rightarrow \mathbb{R}$. Logo, $f$ é convexa se, e somente se

$$
f\left(\lambda_{1} \mathbf{x}_{1}+\ldots+\lambda_{m} \mathbf{x}_{m}\right) \leq \lambda_{1} f\left(\mathbf{x}_{1}\right)+\ldots+\lambda_{m} f\left(\mathbf{x}_{m}\right)
$$

para qualquer $\lambda_{1} \geq 0, \ldots, \lambda_{m} \geq 0$ e $\lambda_{1}+\ldots+\lambda_{m}=1$. 
Embora todas as definições, observações e teoremas acerca de funções convexas apresentados até aqui sejam suficientes para definir se uma função é convexa, existem, no caso de funções diferenciáveis condições de primeira e segunda ordem que permitem a averiguação da convexidade de forma mais imediata. Os teoremas 13 e 14 abaixo foram extraídos de (BOYD; VANDENBERGHE, 2004, 3.1.3 e 3.1.4 nas Páginas 69-71) e (ROCKAFELLAR, 1970, Teorema 4.4 na Página 26).

Teorema 13 (Condição de Primeira Ordem). Suponha que $f: \mathbb{R}^{n} \rightarrow \mathbb{R}$ seja uma função diferenciável, i.e. o gradiente $\nabla f$ existe em cada ponto em $\operatorname{dom} f$. Então, $f$ será convexa se, e somente se, $\operatorname{dom} f$ for convexo e

$$
f(\mathbf{y}) \geq f(\mathbf{x})+\nabla f(\mathbf{x})^{T}(\mathbf{y}-\mathbf{x})
$$

for válido para todo $\mathbf{x}, \mathbf{y} \in \operatorname{dom} f$.

Demonstração. Considere inicialmente o caso em que $n=1$. Demonstra-se então que uma função diferenciável $f: \mathbb{R} \rightarrow \mathbb{R}$ é convexa se, e somente se

$$
f(y) \geq f(x)+f^{\prime}(x)(y-x)
$$

para todo $x$ e $y$ no domínio de $f$. Assuma que a função $f$ é convexa e que $x, y \in \operatorname{dom} f$. Uma vez que o domínio da função é convexo, pode-se concluir que para todo $\lambda \in(0,1], \lambda y+(1-\lambda) x \in \operatorname{dom} f$ e da convexidade de $f$ sabe-se que

$$
f(\lambda y+(1-\lambda) x) \leq \lambda f(y)+(1-\lambda) f(x)
$$


rearranjando os termos da equação acima

$$
\begin{aligned}
f(\lambda y+(1-\lambda) x) & \leq \lambda f(y)+(1-\lambda) f(x) \\
f(x+\lambda(y-x)) & \leq f(x)+\lambda(f(y)-f(x)) \\
f(x+\lambda(y-x))-f(x) & \leq \lambda(f(y)-f(x)) \\
\frac{f(x+\lambda(y-x))-f(x)}{\lambda} & \leq(f(y)-f(x)) \\
f(y) & \geq f(x)+\frac{f(x+\lambda(y-x))-f(x)}{\lambda}
\end{aligned}
$$

Considere a função $g(\lambda)=f(x+\lambda(y-x))$. É possível reescrever a última inequação em (A.10) de acordo com a função $g$ :

$$
f(y) \geq f(x)+\frac{g(\lambda)-g(0)}{\lambda}
$$

tomando o limite de quando $\lambda \rightarrow 0$ em ambos lados:

$$
\begin{aligned}
& f(y) \geq f(x)+\lim _{\lambda \rightarrow 0} \frac{g(\lambda)-g(0)}{\lambda} \\
& f(y) \geq f(x)+g^{\prime}(0)
\end{aligned}
$$

Uma vez que $g^{\prime}(\lambda)=f^{\prime}(x+\lambda(y-x))(y-x)$, substituindo $g^{\prime}(0)$ na equação acima obtêm-se:

$$
f(y) \geq f(x)+f^{\prime}(x)(y-x)
$$

justamente a inequação que se desejava demonstrar. Seguindo este mesmo raciocínio é possível estender esta prova ao caso genérico onde $f: \mathbb{R}^{n} \rightarrow \mathbb{R}$. Neste caso, considere $\mathbf{x}, \mathbf{y} \in \operatorname{dom} f$ e que $f$ é convexa. Da definição de convexidade e rearranjando a inequação como em (A.10):

$$
f(\mathbf{y}) \geq f(\mathbf{x})+g^{\prime}(0)
$$

Diferente do caso $n=1$, a derivada de $g$ é definida como $g^{\prime}(\lambda)=\nabla_{\mathbf{x}} f(\mathbf{x}+\lambda(\mathbf{y}-$ 
$\mathbf{x}))(\mathbf{y}-\mathbf{x})$. Substituindo $g^{\prime}(0)$ na equação acima:

$$
f(\mathbf{y}) \geq f(\mathbf{x})+\nabla_{\mathbf{x}} f(\mathbf{x})^{T}(\mathbf{y}-\mathbf{x})
$$

exatamente o que queria ser demonstrado. Isto conclui a parte da necessidade da condição ser satisfeita para que a função seja convexa. É necessário ainda provar a suficiência desta condição. Considere $f: \mathbb{R}^{n} \rightarrow \mathbb{R}$ que satisfaz a condição em (A.7). Sejam $\mathbf{x}, \mathbf{y} \in \operatorname{dom} f$ e $\lambda \in[0,1]$ de tal forma que $\mathbf{z}=\lambda \mathbf{x}+(1-\lambda) \mathbf{y}$. Note que como o domínio de $f$ é convexo então $z \in \operatorname{dom} f$. Adicionalmente, como assumiu-se que $f$ satisfaz (A.7), então as seguintes desigualdades são verdadeiras:

$$
f(\mathbf{x}) \geq f(\mathbf{z})+\nabla_{\mathbf{z}} f(\mathbf{z})^{T}(\mathbf{x}-\mathbf{z}) \quad f(\mathbf{y}) \geq f(\mathbf{z})+\nabla_{\mathbf{z}} f(\mathbf{z})^{T}(\mathbf{y}-\mathbf{z})
$$

Agora, multiplicando as inequações acima por $\lambda$ e $(1-\lambda)$, respectivamente, e somando-se os resultados obtêm-se:

$$
\begin{aligned}
& \lambda f(\mathbf{x})+(1-\lambda) f(\mathbf{y}) \geq f(\mathbf{z})+\nabla_{\mathbf{z}} f(\mathbf{z})^{T}(\lambda \mathbf{x}+(1-\lambda) \mathbf{y}-\mathbf{z}) \\
& \lambda f(\mathbf{x})+(1-\lambda) f(\mathbf{y}) \geq f(\lambda \mathbf{x}+(1-\lambda) \mathbf{y})
\end{aligned}
$$

Note que esta é a condição que $f$ deve satisfazer para ser considerada uma função convexa. Portanto, se $f$ satisfaz a condição em (A.7) é suficiente concluir que $f$ é uma função convexa.

Teorema 14 (Condição de Segunda Ordem). Seja $f: \mathbb{R}^{n} \rightarrow \mathbb{R}$ uma função duplamente diferenciável, i.e. que a matriz Hessiana ou segunda derivada ${ }^{1} \nabla^{2} f$ existe em cada ponto do dominio de $f$. Então $f$ é convexa se, e somente se a matriz Hessiana de $f$ é positiva semidefinida, ou seja, $\forall \mathbf{x} \in \operatorname{dom} f$,

$$
\nabla^{2} f(\mathbf{x}) \succeq 0
$$

Demonstração. A demonstração a seguir foi retirada da página 35 do livro de soluções da obra (BOYD; VANDENBERGHE, 2004). Assuma que $n=1$. Suponha

\footnotetext{
${ }^{1}$ Para o caso $n=1$.
} 
que $f$ é convexa. Sendo assim, $\operatorname{sejam} x, y \in \operatorname{dom} f \operatorname{com} y>x$. Do teorema 13 segue:

$$
f^{\prime}(x)(y-x) \leq f(y)-f(x) \leq f^{\prime}(y)(y-x)
$$

o que implica que:

$$
\begin{aligned}
f^{\prime}(x)(y-x) & \leq f^{\prime}(y)(y-x) \\
f^{\prime}(x)(y-x)-f^{\prime}(y)(y-x) & \leq 0 \\
f^{\prime}(y)(y-x)-f^{\prime}(x)(y-x) & \geq 0 \\
\frac{f^{\prime}(y)-f^{\prime}(x)}{(y-x)} & \geq 0
\end{aligned}
$$

tomando o limite da desigualdade acima quando $y \rightarrow x$ resulta em $f^{\prime \prime}(x) \geq 0$. Logo, provou-se que se uma função é convexa então a segunda derivada é positiva em qualquer ponto do domínio. Considere agora que $f^{\prime \prime}(z) \geq 0$ para todo $z \in$ $\operatorname{dom} f$. Sejam dois pontos arbitrários $x, y \in \operatorname{dom} f \operatorname{com} x<y$, a seguinte desigualdade é verdadeira:

$$
0 \leq \int_{x}^{y} f^{\prime \prime}(z)(y-z) d z
$$

desenvolvendo o termo a direita da inequação tem-se:

$$
\begin{aligned}
0 & \leq\left.\left(f^{\prime}(z)(y-z)\right)\right|_{z=x} ^{z=y}+\int_{x}^{y} f^{\prime}(z) d z \\
0 & \leq-f^{\prime}(x)(y-x)+f(y)-f(x) \\
f(y) & \geq f(x)+f^{\prime}(x)(y-x)
\end{aligned}
$$

o que mostra que a função $f$ é convexa. A generalização para $n>1$ é possível observando-se que uma função é convexa se, e somente se ela é convexa em todas as linhas, i.e. a função $g(t)=f\left(\mathbf{x}_{0}+t \mathbf{v}\right)$ é convexa em $t$ para todo $\mathbf{x}_{0} \in \operatorname{dom} f$ e todo v. Desta forma, $f$ é convexa se, e somente se

$$
g^{\prime \prime}(t)=\mathbf{v}^{T} \nabla^{2} f\left(\mathbf{x}_{0}+t \mathbf{v}\right) \mathbf{v} \geq 0
$$


para todo $\mathbf{x}_{0} \in \operatorname{dom} f, \mathbf{v} \in \mathbb{R}^{n}$ e $t$ que satisfaça $\mathbf{x}_{0}+t \mathbf{v} \in \operatorname{dom} f$. Ou seja, é necessário e suficiente que $\nabla^{2} f(\mathbf{x}) \succeq 0$ para todo $\mathbf{x} \in \operatorname{dom} f$.

Corolário 2. Seja $f: \mathbb{R}^{n} \rightarrow \mathbb{R}$ uma função duplamente diferenciável. A função f é côncava se, e somente se:

$$
\nabla^{2} f(\mathbf{x}) \preceq 0
$$

para todo $\mathbf{x} \in \operatorname{dom} f$.

Demonstração. A prova segue a idéia da prova do teorema 14.

Assim como conjuntos, existem operações com funções que preservam a convexidade da função. Abaixo estão listadas exemplos de operações que preservam a convexidade (BOYD; VANDENBERGHE, 2004, Seção 3.2 nas Páginas 79-90):

1. Soma ponderada não negativa de funções convexas. Sejam $f_{i}, i=$ $1, \ldots, m$ funções convexas e $\alpha_{i} \geq 0, i=1, \ldots, m$, então $\sum_{i=1}^{m} \alpha_{i} f_{i}$ é uma função convexa.

2. Composição com função afim. Suponha $f: \mathbb{R}^{n} \rightarrow \mathbb{R}, \mathbf{A} \in \mathbb{R}^{n \times m} \mathrm{e}$ $\mathbf{b} \in \mathbb{R}^{n}$. Seja $g: \mathbb{R}^{m} \rightarrow \mathbb{R}$ tal que $g(\mathbf{x})=f(\mathbf{A x}+\mathbf{b}) \operatorname{com} \operatorname{dom} g=$ $\{\mathbf{x} \mid \mathbf{A} \mathbf{x}+\mathbf{b} \in \operatorname{dom} f\}$. Então $g$ é convexa se, e somente se $f$ é uma função convexa.

3. Máximo elemento-a-elemento. Sejam $f_{1}$ e $f_{2}$ funções convexas. Então a função $f$ definida como $f(\mathbf{x})=\max \left\{f_{1}(\mathbf{x}), f_{2}(\mathbf{x})\right\} \operatorname{com} \operatorname{dom} f=\operatorname{dom} f_{1} \cap$ $\operatorname{dom} f_{2}$ também é uma função convexa.

4. Composição com outra função. Sejam $f_{1}: \mathbb{R}^{m} \rightarrow \mathbb{R}, f_{2}: \mathbb{R}^{n} \rightarrow \mathbb{R}^{m}$ e $f=f_{1} \circ f_{2}: \mathbb{R}^{n} \rightarrow \mathbb{R}$ tal que $f(\mathbf{x})=f_{1}\left(f_{2}(\mathbf{x})\right)$ e $\operatorname{dom} f=\{\mathbf{x} \in$ $\left.\operatorname{dom} f_{2} \mid f_{2}(\mathbf{x}) \in \operatorname{dom} f_{1}\right\}$. As seguintes regras de composição são verdadeiras: 
- $f$ é convexa se $f_{1}$ é convexa, $f_{1}$ é não decrescente em cada argumento da função e $f_{2}$ é convexa;

- $f$ é convexa se $f_{1}$ é convexa, $f_{1}$ é não crescente em cada argumento da função e $f_{2}$ é côncava;

- $f$ é côncava se $f_{1}$ é côncava, $f_{1}$ é não decrescente em cada argumento da função e $f_{2}$ é côncava;

- $f$ é côncava se $f_{1}$ é côncava, $f_{1}$ é não crescente em cada argumento da função e $f_{2}$ é convexa;

5. A função perspectiva. Seja $f: \mathbb{R}^{n} \rightarrow \mathbb{R}$. A função perspectiva de $f$ é definida como $g: \mathbb{R}^{n+1} \rightarrow \mathbb{R}$ tal que $g(\mathbf{x}, t)=t f(\mathbf{x} / t)$ e $\operatorname{dom} g=$ $\{(\mathbf{x}, t) \mid \mathbf{x} / t \in \operatorname{dom} f, t>0\}$. Desta forma, se $f$ é uma função convexa, $g$ também é uma função convexa.

Uma importante propriedade de funções convexas está relacionada a mínimos locais e globais. Antes de proceder com o teorema sobre a otimalidade global de funções convexas, apresentar-se-á as definições matemáticas de mínimo local e mínimo global (OLIVEIRA, 2005).

Definição 26 (Mínimo Local). Seja $f: C \subseteq \mathbb{R}^{n} \rightarrow \mathbb{R}$. Um ponto $\mathbf{x} \in C$ é denominado mínimo local de $f$ em $C$ se existe uma esfera $\mathcal{S}(\mathbf{x}, \epsilon)=\{\mathbf{y} \in$ $\left.\mathbb{R}^{n} \mid\|\mathbf{y}-\mathbf{x}\|<\epsilon\right\}$, tal que

$$
f(\mathbf{x}) \leq f(\mathbf{y}), \quad \forall \mathbf{y} \in C \cap \mathcal{S}(\mathbf{x}, \epsilon)
$$

Definição 27 (Mínimo Global). Seja $f: C \subseteq \mathbb{R}^{n} \rightarrow \mathbb{R}$. Um ponto $\mathbf{x} \in C$ é denominado minimo global de $f$ em $C$ se para todo $\mathbf{y} \in C$ e $\mathbf{y} \neq \mathbf{x}$ :

$$
f(\mathbf{x}) \leq f(\mathbf{y})
$$

Outra forma de definir um minimo global é através da definição de minimo local: 
seja $\mathbf{x}$ é um mínimo local, $\mathbf{x}$ é um minimo global se $C \cap S(\mathbf{x}, \epsilon)=C$.

Mínimos locais de funções convexas são mínimos globais conforme demonstrado pelo teorema a seguir (MUROTA, 2003, Teorema 1.1 na Página 10).

Teorema 15 (Otimalidade Global). Seja $f: \mathbb{R}^{n} \rightarrow \mathbb{R}$ uma função convexa. Se $\mathbf{x}$ é um minimo local de $f$ em $\operatorname{dom} f$, então $\mathbf{x}$ é também um minimo global de $f$ no $\operatorname{dom} f$, i.e.

$$
f(\mathbf{x}) \leq f(\mathbf{y}), \quad \forall \mathbf{y} \in \operatorname{dom} f
$$

Demonstração. Seja x um ótimo local da função convexa $f$ anteriormente enunciada. Então $f(\mathbf{z}) \geq f(\mathbf{x})$ para qualquer $\mathbf{z}$ na vizinhança de $\mathbf{x}$. Para qualquer $\mathbf{y}$, $\mathbf{z}=\lambda \mathbf{x}+(1-\lambda) \mathbf{y}$ está na vizinhança de $\mathbf{x}$ para $\lambda \in(0,1)$ e $\lambda$ suficientemente próximo de 1. Da definição de função convexa segue:

$$
\begin{aligned}
& \lambda f(\mathbf{x})+(1-\lambda) f(\mathbf{y}) \geq f(\lambda \mathbf{x}+(1-\lambda) \mathbf{y}) \geq f(\mathbf{x}) \\
& \lambda f(\mathbf{x})+(1-\lambda) f(\mathbf{y}) \geq f(\mathbf{z}) \geq f(\mathbf{x})
\end{aligned}
$$

O que implica que $f(\mathbf{y}) \geq f(\mathbf{x}) \forall \mathbf{y} \in \operatorname{dom} f$.

\section{A.3 Funções Quase Convexas}

A quase convexidade é considerada uma forma generalizada de convexidade. A definição de função quase convexa é apresentada a seguir (BOYD; VANDENBERGHE, 2004, Seção 3.4.1 na Página 95).

Definição 28 (Função Quase Convexa). Uma função $f: \mathbb{R}^{n} \rightarrow \mathbb{R}$ é denominada quase convexa se seu dominio e todos os conjuntos de nivel inferior

$$
S_{\alpha}=\{\mathbf{x} \in \operatorname{dom} f \mid f(\mathbf{x}) \leq \alpha\}
$$

para $\alpha \in \mathbb{R}$, forem convexos. 
Assim como para funções convexas, se $f$ é uma função quase convexa então - $f$ é quase côncava, i.e. seu domínio e todos os conjuntos de nível superior $S_{\alpha}=\{\mathbf{x} \in \operatorname{dom} f \mid f(\mathbf{x}) \geq \alpha\}$ são convexos.

Uma forma mais prática de verificar a quase convexidade é através da desigualdade de Jensen para funções quase convexas. Desta forma, uma função $f: \mathbb{R}^{n} \rightarrow \mathbb{R}$ é convexa se, e somente se o domínio de $f$ é convexo e para todo $\mathbf{x}, \mathbf{y} \in \operatorname{dom} f$ e $\lambda \in[0,1]$ (BOYD; VANDENBERGHE, 2004, Equação 3.19, Página 98) resulta:

$$
f(\lambda \mathbf{x}(1-\lambda) \mathbf{y}) \leq \max \{f(\mathbf{x}), f(\mathbf{y})\}
$$

Em outras palavras, uma função é quase convexa quando para qualquer intervalo do domínio os valores da função em tal intervalo não excedem o máximo valor dos extremos do intervalo. A figura 53 ilustra a desigualdade em (A.30) para uma função cujo domínio é $\mathbb{R}$. 


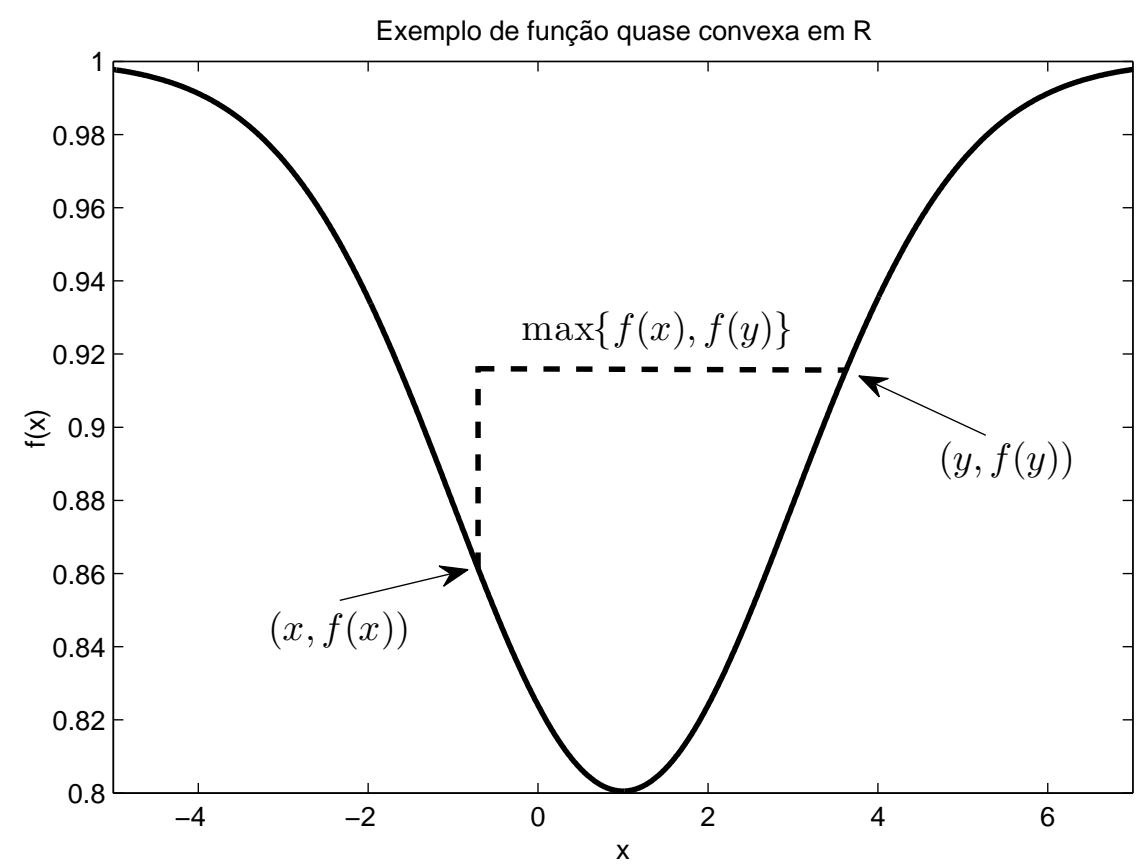

Figura 53: Interpretação geométrica da desigualdade de Jensen para funções quase convexas.

Adicionalmente, funções quase convexas no $\mathbb{R}$ podem ser caracterizadas através de outras propriedades. Seja $f: \mathbb{R} \rightarrow \mathbb{R}$ uma função contínua; A função $f$ é quase convexa se, e somente se uma das seguintes condições é satisfeita (BOYD; VANDENBERGHE, 2004, Página 99):

- $f$ é não decrescente;

- $f$ é não crescente;

- Existe um ponto $x \in \operatorname{dom} f$ de tal forma que $\forall y \leq x$ e $y \in \operatorname{dom} f$, a função é não crescente e $\forall z \geq x$ e $z \in \operatorname{dom} f$ a função é não decrescente.

O ponto $x \in \operatorname{dom} f$ supracitado é denominado mínimo global da função $f$. Observando-se a figura 53 é possível notar tal ponto em $x=1$ uma vez que para $x \leq 1$ a função é não crescente e para $x \geq 1$ é não decrescente. 
Note que toda função convexa tem todos os subconjuntos de nível inferior convexos portanto toda função convexa é quase convexa, todavia o contrário não se aplica. A título de exemplo a figura 54 apresenta em (a) uma função quase convexa que não é convexa e em (b) uma função quase convexa que é convexa.
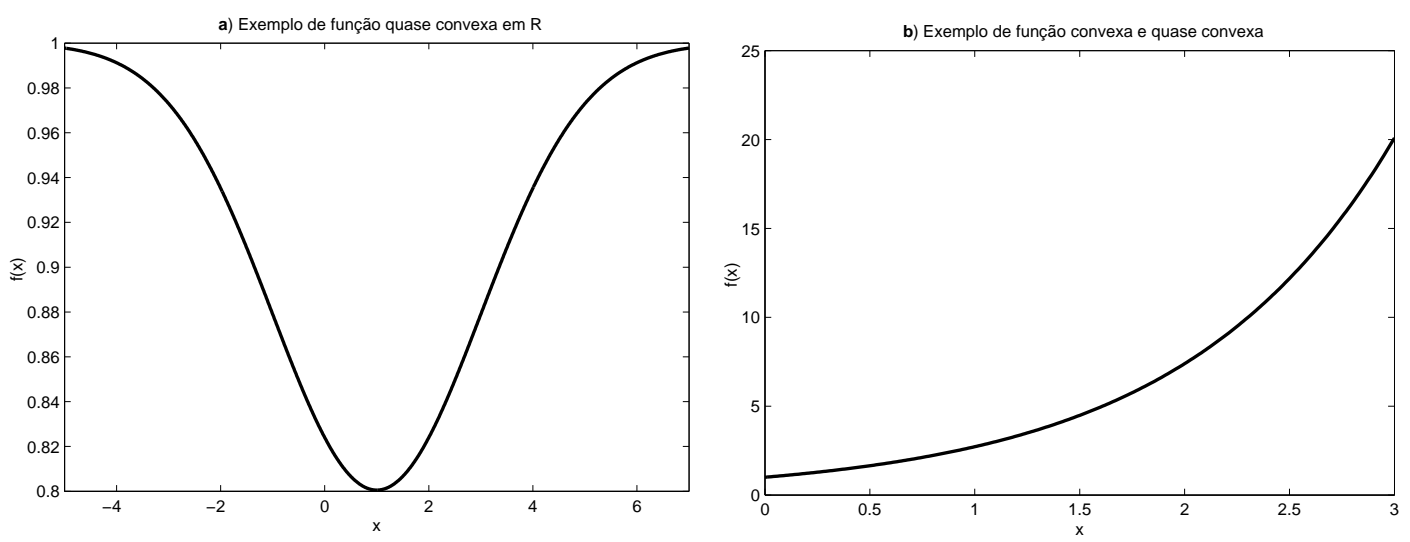

Figura 54: Exemplo de função quase convexa que não é convexa (a) e função quase convexa que é convexa (b). 